\title{
Investigations on Catalyzed Steam Gasification of Biomass
}

\author{
L. K. Mudge \\ S. L. Weber \\ D. H. Mitchell \\ L. J. Sealock, Jr. \\ R. J. Robertus
}

January1981

Prepared for the US. Department of Energy under Contract DE-AC06-76RLO 1830

Pacific Northwest Laboratory Operated for the US. Department of Energy by Battelle Memorial Institute 


\section{NOT I C E}

This report was preparedas an account of work sponsored by the United States Government. Neither-theUnited States nor the Department of Energy, nor any of their employees, nor any of their contractors, subcontractors, or their employees, makes any warranty, express or implied, or assumes any legal liability or responsibility for the accuracy, completeness or usefulness of any- information, apparatus, product or process disclosed, or represents that its use would not infringe privately owned rights.

The views, opinions and conclusions contained in this report are those of the contractor and do not necessarily represent those of the United States Government or the United States Department of Energy.

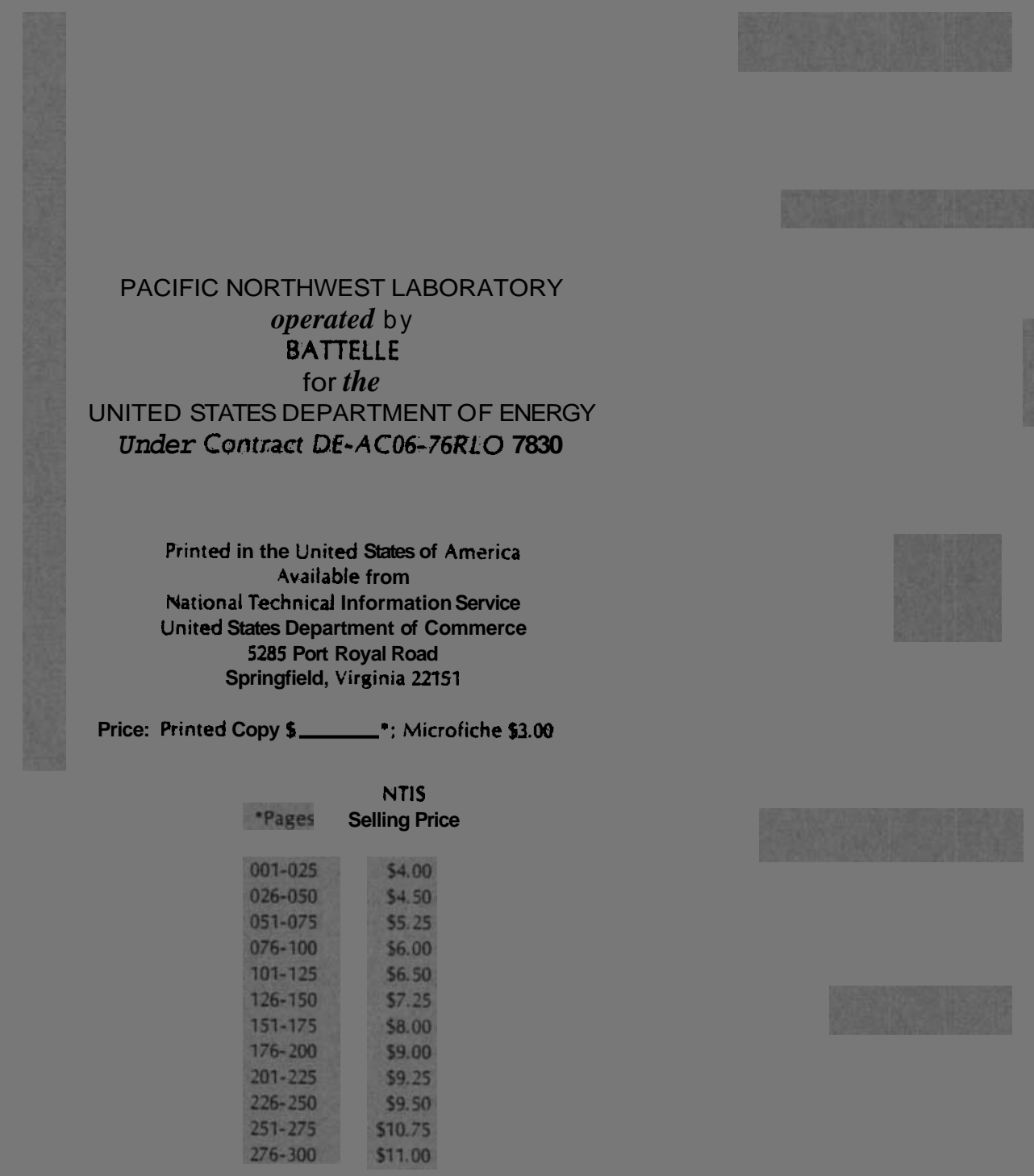


PNL -3695

UC -11

\section{6}

INVESTIGATIONS ON CATALYZED STEAM GASIFICATION OF BIOMASS
L. K. Mudge
S. L. Weber
D. H. Mitchell
L. J. Sea lock, Jr.
R. J. Robertus

January 1981

Prepared for the U.S. Department of Energy under Contract DE-AC06-76RLO-1830

Pacific Northwest Laboratory Richland, Washington 99352 


\section{SUMARY}

The Pacific Northwest Laboratory (PNL) is conducting an ongoing study, sponsored by the Biomass Energy Systems Division of the U.S. Department of Energy, on the gasification of biomass in the presence of catalysts. The purpose of the study is to evaluate the technical and economic feasibility of producing specific gas products via the catalytic gasificaton of biomass. This report presents the results of research conducted from December 1977 to October 1980.

The study was comprised of laboratory studies, process development, and economic analyses. The laboratory studies were conducted to develop operating conditions and catalyst systems for generating methane-rich gas, synthesis gases, hydrogen, and carbon monoxide; these studies also developed techniques for catalyst recovery, regeneration, and recycling. A process development unit (PDU) was designed and constructed to evaluate laboratory systems at conditions approximating commercial operations. The economic analyses, performed by Davy Mckee, Inc. for PNL, evaluated the feasibility of adapting the wood-to-methane and wood-to-methanol processes to full-scale commercial operations. Plants were designed in the economic analyses to produce fuel-grade methanol from wood and substitute natural gas (SNG) from wood via catalytic gasification with steam.

Conditions developed in the laboratory for generation of a methane-rich gas and a synthesis gas for methanol production were confirmed in the fluidbed, PDU operations. No particular problems with scale-up were experienced.

Catalytic steam gasification of biomass has several advantages over conventional gasification.

- No oxygen is required for generation of a methane-rich gas or a methanol synthesis gas, therefore, no oxygen plant is needed.

- Little or no tar is produced requiring only simple gas cleaning and waste-water treatment equipment.

- No shift reactor is required for methanol synthesis. 
- Methanation requirements are low resulting in high conversion efficiency.

- Yields and efficiencies are greater.

The commercial gasification plants were designed to process 2000 tons $(1800 \mathrm{t})$ of dry wood per day and $10 \%$ of that capacity. For the large-scale methanol plant, production is 997 tons $(900 \mathrm{t})$ of methanol per day with a higher heating value (HHV) of 9784 Btu per pound. For the large-scale SNG plant, production is 21.6 million scfd $\left(610,000 \mathrm{~m}^{3} /\right.$ day $)$ of SNG with a $\mathrm{HN}$ of 956 Btu per scf $\left(35,600 \mathrm{~kJ} / \mathrm{nm}^{3}\right)$. All yields from the small-scale plants are $10 \%$ of the large-scale plants. The plant design included all process and support facilities necessary to convert wood. The plant location is the Pacific Northwest.

The capital costs for the large-scale wood-to-methanol and wood-to-methane plants are, on a September 1980 basis, $\$ 120,830,000$ and $\$ 95,115,000$, respectively. Production costs that allow for return on capital were calculated at various wood costs for both utility and private investor financing. At a wood cost to the large-scale plant of $\$ 20$ per dry ton $(\$ 22 / t$ dry), the methanol cost was $\$ 0.55 / \mathrm{gal}(\$ 0.15 / \mathrm{L})$ and $\$ 0.69 / \mathrm{gal}(\$ 0.18 / \mathrm{L})$ for utility and private investor financing, respectively; similarly, methane costs were $\$ 6.50 / \mathrm{mi} 11$ ion Btu and $\$ 8.10 / \mathrm{million}$ Btu, respectively. Similar costs for the small-scale plants were $2-1 / 2$ to 3 times greater than for the large-scale plants. The cost calculated by the utility financing method includes a return on equity of $15 \%$ and an interest rate of $10 \%$ on debt. The private investor financing method, which is $100 \%$ equity financing, incorporated a discounted cash flow return on equity of $12 \%$. Economics are presented as a function of wood cost and plant size.

The thermal efficiency of the wood-to-methanol plant is 53\%. The thermal efficiency of the wood-to-methane plant, without taking credit for byproduct char, is $58 \%$.

Continued research in catalytic gasification of biomass will include laboratory studies to examine more catalysts, PDU studies to test results of the catalyst development, and economic analyses to develop a computer code that will determine the effects of changes in process yields and requirements on overall plant economics. 
CONTENTS

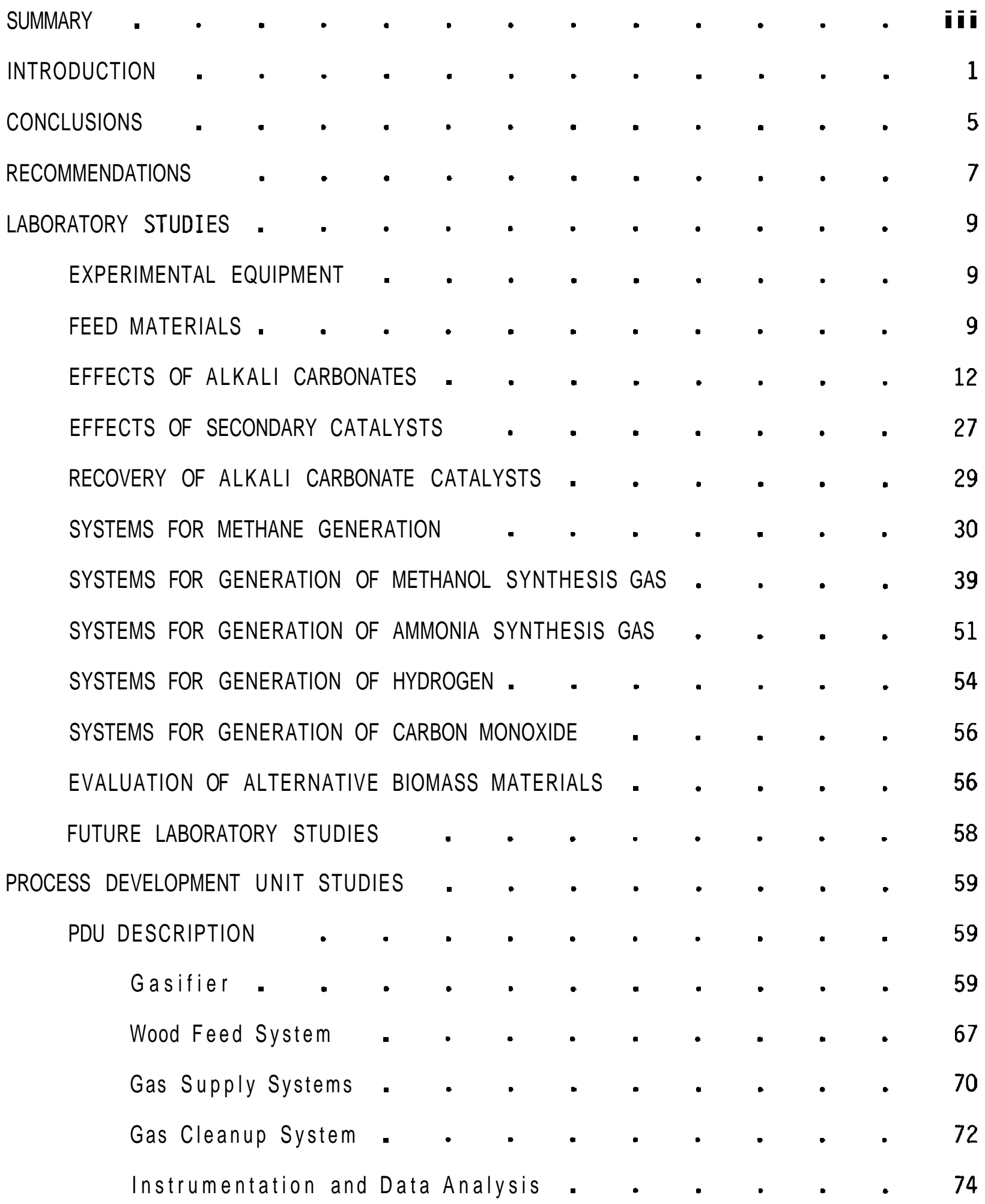


PDU OPERATION •

Test Procedures and Safety Considerations • . • . 78

Feedstock for the PDU $\quad$.

PDU Results with the Agitated-Bed Gasifier • • • • 79

PDU Results With the Fluid-Bed Gasifier . • • • 87

Calculation of Equilibrium Gas Compositions • • • 992

FEASIBILITY STUDIES • • • • • • • • • • • • • • 105

ECONOMICS OF CATALYTIC GASIFICATION . • • • • • 105

Wood-to-Methane Plant . . . . . . . . 105

Wood-to-Methanol Plant . • • • . • • 120

COMPUTER MODELLING STUDIES $\quad \cdot \quad \cdot \quad \cdot \quad \cdot \quad \cdot \quad \cdot \quad \cdot \quad \cdot \quad 137$

FUTURE MODELLING EFFORTS . • • • • • • • • • • 144

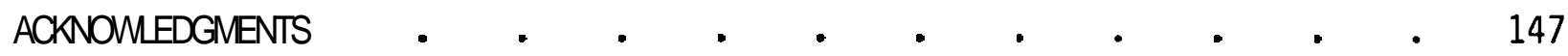

REFERENCES • • • • • • • • • • • • • 


\section{FIGURES}

1 Surmary of Study Activities . . . . . . . . 3

2 Batch-Feed Reactor . . . . . . . . . . 10

3 Continuous Wood-Feed Reactor . • • • • • • . 11

4 Volume of Gas Production for Catalyzed and Noncatalyzed Steam Gasification of Wood at $550^{\circ} \mathrm{C}$. . . . . . . . 14

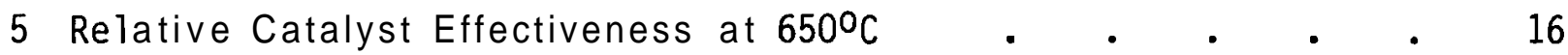

6 Effect of Temperature on Gas Production With and Without Potassium Carbonate Catalyst . • • . • • . . 17

7 Effect of Sodium Carbonate Concentration on Gas Yield at $650^{\circ} \mathrm{C} \quad 18$

8 Catalyzed Test Results on Remaining Carbon Versus Time . 21

9 Uncatalyzed Test Results on Remaining Carbon Versus Time . 22

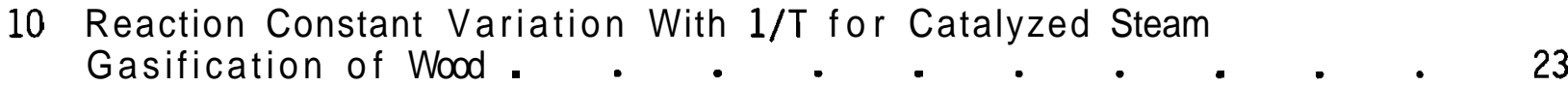

11 Postulated Effectiveness Factor • • • • • • 26

12 Hydrogen Chemisorption Apparatus . . . . . . . 34

13 Pore Distribution in Fresh and Coked Catalyst . . . . . . 35

14 Coked Ni-3266 Catalyst, 3340X . . . . . • • . . 36

15 Unused Ni-3266 Catalysts, 10,021X . . . . • . . 37

16 Relative Concentrations of Elements on Fresh and Exposed Catalyst Surfaces Employed for Methanantion . 38

17 Pore Distribution in Catalyst Used for Synthesis Gas Generation . 42

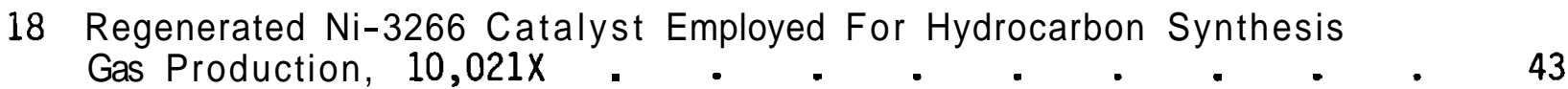

19 S\$M Micrograph of Fresh Ni-3266, 3960X - 44

20 S\$M Micrograph of Ni-3266 After 28.6 h of Operation, 13,200X . • 45

$21 \mathrm{~S} \$ \mathrm{M}$ Micrograph of Ni-3266 After $61 \mathrm{~h}$ of Operation, 13,200X . $\quad 45$ 
SEM Micrograph of Carbon Layers on Ni-3266 After $72 \mathrm{~h}$

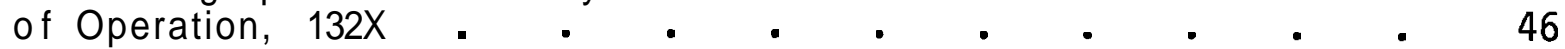

23 S $9 M$ Micrograph of Coked $\mathrm{Ni}-3266$ After $88 \mathrm{~h}$ of Operation, 132X 46

24 S 9 M Micrograph of Coked Ni-3266 After $117 \mathrm{~h}$ of Operation, 132X 47

25 Relative Concentrations of Exposed Elements on Ni-3266

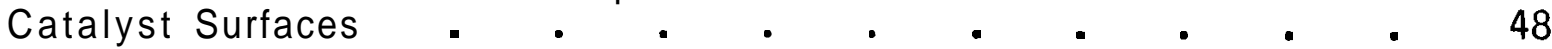

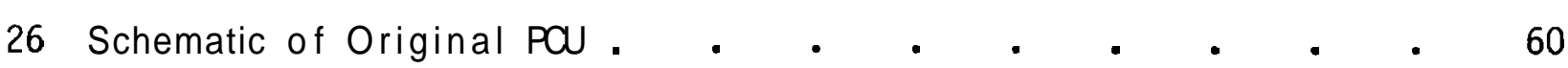

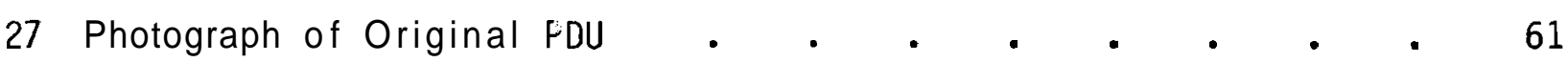

28 Schematic of the Stirred-Bed Gasifier . • • • • . 62

29 Bottom Head of Stirred-Bed Gasifier . • . . • . . 64

30 View of Gasifier Cross Section . . . . . . . . 65

Schematic of Fluidized-Bed Gasifier . • . . . • . 68

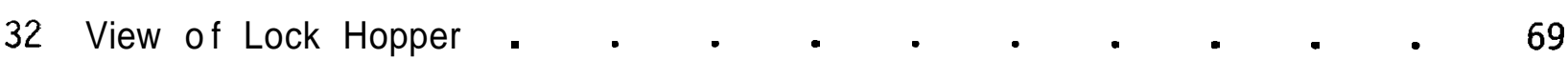

33 Gas Heater and Controls . . • . . . . . . . 71

34 Gas Recycle System . . . . . . . . . . 73

Electrostatic Precipitator . . . . . . . . . 75

36 PDU Schematic As of October 1980 . $\quad$ • . . . . . . 76

37 Methane Yields from the Agitated-Bed Gasifier as a Function

of Temperature and Catalyst . . . . . . . . 81

38 Carbon Conversions for Methane Production in the

Agitated-Bed Gasifier . . . . . . . . . 82

Synthesis Gas Yields as a Function of Temperature

in the Agitated-Bed Gasifier . . . . . . . . 84

40 Carbon Conversions for Synthesis Gas Production in the

Agitated-Bed Gasifier

Effect of Steam-to-Wood Ratio on Gas Composition from the

Fluid-Bed Gasifier . . . . . . . . . . . 88

42 Temperature Profiles in Fluid-Bed Gasifier . • • • • 91 
Comparisons of Catalyzed Versus Uncatalyzed Results for Methane Production

44 Comparisons of Catalyzed versus Uncatalyzed Results for Synthesis Gas Production . . . . . . .

45 Effects of Temperature on the Dry Gas Equilibrium Composition at Atmospheric Pressure for Steam-to-Wood Ratio of 0.33 .

46 Effects of Temperature on the Dry Gas Equilibrium Composition at Atmospheric Pressure for Steam-to-Wood Ratio of 1 . . 98

47 Potential Methane and Methanol Yields at Atmospheric Pressure . 99

48 Effect of Temperature on Equilibrium Standard Heats of Reaction . 100

49 Effect of Pressure on Equilibrium Standard Heats of Reaction . . 101

50 Effect of Pressure on Production of a Methane-Rich Gas . 102

51 Effect of Pressure on Production of a Methanol Synthesis Gas . 103

52 Wood-To-Methane Process Areas . . . . . . . . 108

53 Effect of Wood Prices on Gas Cost for 2000 ton/day Dry Wood . 116

54 Wood-To-Methanol Process Area . . . . . . . . 125

55 Effect of Wood Prices on Methanol Cost for 2000 ton/day Dry Wood . 132 


\section{$\underline{\text { TABLES }}$}

1 Comparative Analysis of Wood and Bark . • • • • 13

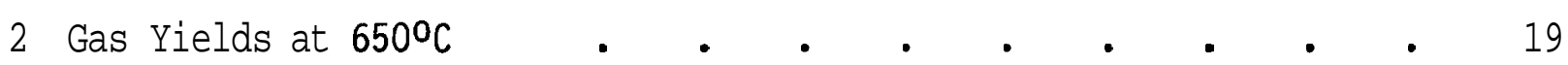

3 Elemental Yields at $650^{\circ} \mathrm{C}$. . . . . . . . . 19

4 Gas Yield from Different Wood and Bark Materials at $650^{\circ} \mathrm{C}$. 20

5 Reaction Rate Constants for Wood Char-Steam Reaction in the Presence of Catalysts . • • • • • • • 24

6 Activation Energies for the Wood-Char/Steam Reaction . 25

7 Yields from Batch Experiments of Wood-Steam Gasification in the Presence of Catalysts . . . . . • . . 28

8 Carbon Conversions and Energy Efficiencies in Batch Experiments - 28

9 Catalysts Tested for Methane Production . • • • • 31

10 Results of a Catalyst Lifetime Test for Methane Production · 32

11 Catalyst Performance Following Catalyst Regeneration . 33

12 Catalyst Characterization Tests Performed on a Ni-3266 Catalyst Used For Methane Production

13 Lifetime and Regenerability of Catalysts Tested for Methane Generation . . . • . . . . 39

14 Catalysts Screened for Methanol Synthesis Gas Production 40

15 Results of a Catalyst Lifetime Test for Hydrocarbon Synthesis Gas Production. • • • • • • • • • • 41

16 Characteristics of a Ni-3266 Catalyst Employed for Synthesis

17 Use of a $\mathrm{Ni}-\mathrm{Cu}-\mathrm{Mo} / \mathrm{Al}_{2} \mathrm{O}_{3}$ Catalyst for Synthesis Gas Generation . • • . . • . • • • •

18 Lifetime and Regenerability of Catalysts Tested for Hydrocarbon Synthesis Gas Production at $750^{\circ} \mathrm{C}$

19 Catalyst Systems Tested for Ammonia Synthesis Gas Production . 
Experimental Results of Lodgepole Wood Impregnated with $17 \% \mathrm{~K}_{2} \mathrm{CO}_{3}$ in the Presence of Air, Steam, Girdler G-3

and Si-A1 Catalysts. . . . . . . . . . . 52

Experimental Results of Lodgepole Wood Impregnated with $17 \% \mathrm{~K}_{2} \mathrm{CO}_{3}$ in the Presence of Air, Steam, and Commercial

Girdler 6-93 Co Shift Catalyst.

Catalysts Tested for Hydrogen Production Studies . 54

Typical Results for Lodgepole Wood Impregnated with

$17 \mathrm{wt} \% \mathrm{~K}_{2} \mathrm{CO}_{3}$ in the Presence of Steam and Catalysts 55

24 Experimental Results for CO Production from Lodgepole Wood . 56

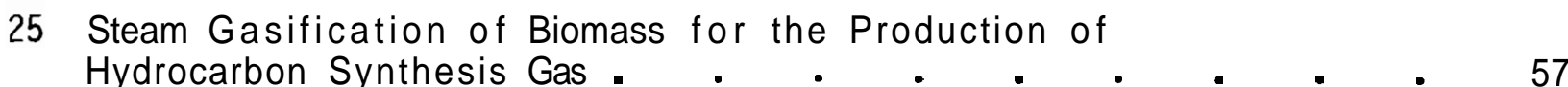

26 Compositions of Feedstocks Used in PDU Operations . 79

27 Ammonia Synthesis Gas Results from the Agitated-Bed Gasifier . 86

28 Results of PDU Tests Witn Nickel Extrudate Catalyst 89

29 Results of PDU Tests with Nonporous Alumina Spheres 90

30 Results of Fluid-Bed PDU Tests with Nickel Catalyst 93

31 Wood-to-Methane Plant Design Basis--2000 ton/day Dry Wood . 107

32 Ultimate Analysis of Feedstock. 109

33 Wood-To-Methane Capital Cost Summary--2000 ton/day Dry Wood . 112

Direct Cost Summary for Wood-to-Methane Plant--2000 ton/day
Dry Wood . . . . . . 113

35 Total Capital Cost Requirement For Wood-to-Methane Plant--

36 Annual Direct Operating Costs For Wood-to-Methane Plants--
2000 ton/day Dry Wood

37 Methane Cost-Utility Financing Method--2000 ton/day Dry Wood . 118

38 Methane Cost - Equity Financing Method--2000 ton/day Dry Wood 119

39 Total Capital Requiremerit for 200-ton/day Wood-to-Methane Plant . 120 
40 Annual Direct Operating Costs for 200-ton/day Wood-to-Methane Plant . • • • • • • • • • • • . 121

41 Gas Cost - Utility Financing Method--200 ton/day Dry Wood • 122

42 Gas Cost - Equity Financing Method--200 ton/day Dry Wood 123

43 Wood-to-Methanol Plant Design Bisis--2000 ton/day Dry Wood . 124

44 Wood-to-Methanol Capital Cost Summary--2000 ton/day Dry Wood . 128

45 Direct Cost Summary For Wood-to-Methanol Plant--2000 ton/day Dry Wood . • • • . • • • • • . 129

46 Total Capital Required For Wood-to-Methanol Plant--2000 ton/day Dry Wood . . • • . . . • • . . . 130

47 Annual Direct Operating Costs For Wood-to-Methanol Plant-2000 ton dry wood/day . . . . . . . . . 131

48 Methanol Cost-Utility Financing Method--2000 ton/day Dry Wood . 133

49 Methanol Cost-Equity Financing Method--2000 ton/day Dry Wood . 134

50 Total Capital Requirement for 210-ton Dry Wood/Day Methanol Plant . 135

51 Annual Direct Operating Costs f Jr 200-ton Dry Wood/Day Methanol Plant • • • • • • • • • . 136

52 Methanol Cost - Utility Financing Method--200 ton Dry Wood/Day • 138

53 Methanol Cost - Equity Financing Method--200 ton Dry Wood/Day . 139 


\section{GLOSSARY OF TERMS}

acfm = cubic feet of volume per minute at actual conditions

atm, $\quad$ ATM = atmosphere or atmospheric pressure

$B C=$ booster compressor

$\mathrm{BD}=$ blow down

田W = boiler feed water

Btu = British thermal unit equal to 1055 Joules

$C S=$ carbon steel

$D C=\operatorname{direct}$ cost

$\mathrm{D} / \mathrm{H}=$ direct hire

DCF = discounted cash flow

$\mathrm{DEA}=$ diethanolamine

$E, M, L=$ equipment, materials, and labor

$F=$ degrees Fahrenheit

$\mathrm{ft}=$ feet

$\mathrm{ft}^{2}=$ area in square feet

$\mathrm{ft}^{3}=$ volume in cubic feet

gpm $=$ gallons per minute

$\mapsto O=$ home office

$\mathrm{HHV}=$ higher heating value

$\mathrm{hp}=$ horsepower

$\mathrm{IP}=$ high pressure

$\mathrm{HT}=$ high temperature

$|C|=$ Imperial Chemicals, Incorporated

$I D=$ inside diameter

in. = inches

$\mathrm{k}-\mathrm{0}, \mathrm{KO}=$ knock out

$\mathrm{kW}=$ kilowatt

$1 \mathrm{~b}=$ pounds mass

$L G=$ length

$\mathrm{LP}=$ low pressure

$M=$ thousand

MHR, MH = manhour 


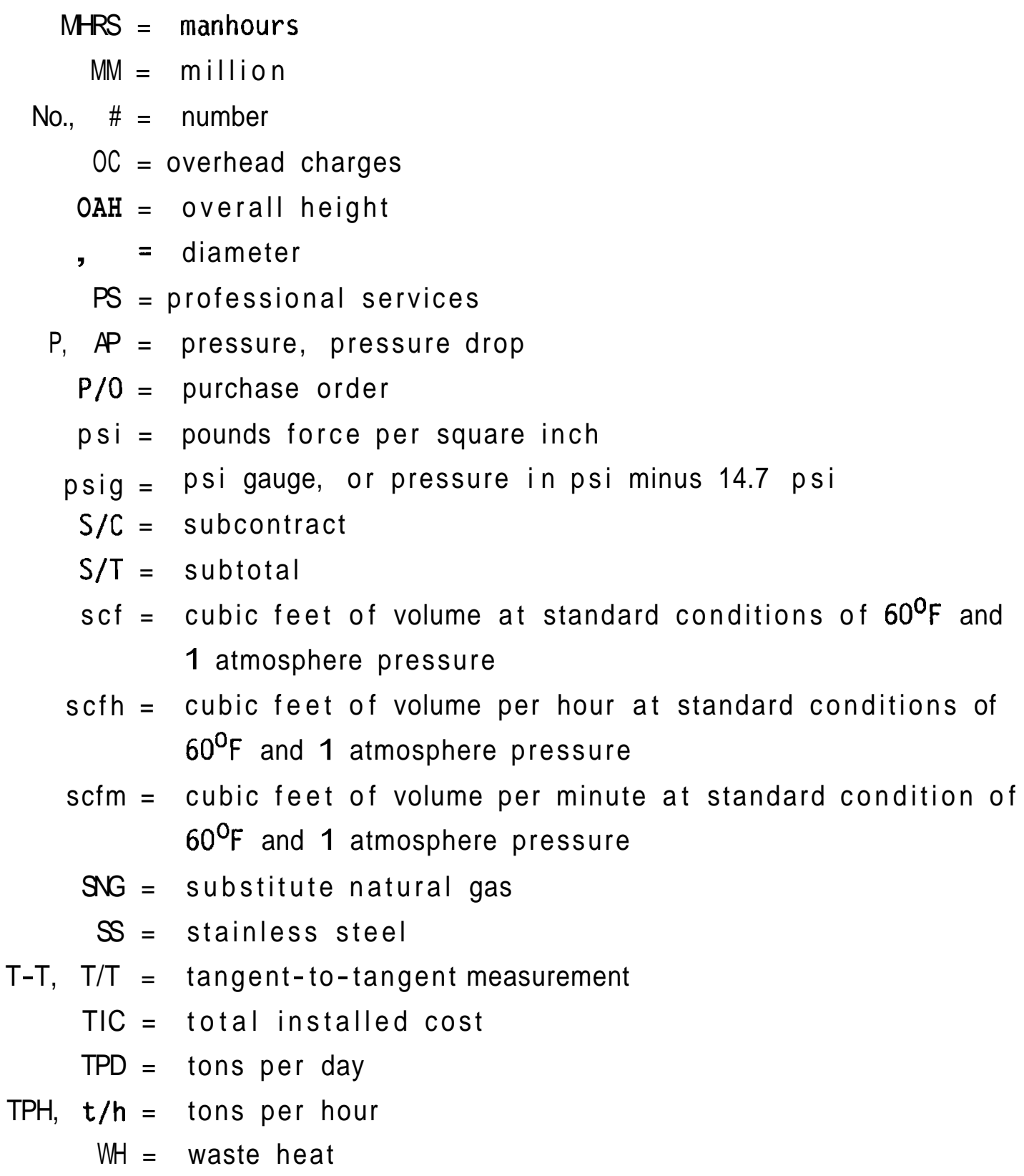




\section{INTRODUCTION}

The Pacific Northwest Laboratory (PNL) is conducting studies on steam gasification of biomass in the presence of catalysts. These, studies are sponsored by the Biomass Energy Systems Division of the U.S. Department of Energy (DOE).

Gasification processes are commonly used to convert carbonaceous matter, including biomass, into gases and some condensible liquids (tars). Although there are exceptions with some refractory carbonaceous materials, the residues from such processes comprise principally the inert mineral constituents of the feed material. These residues are essentially devoid of significant quantities of carbon or char. In contrast, the residues from many so-called pyrolysis processes are classified as chars because they contain a substantial fraction of the carbon from the original carbonaceous feed material.

Both gasification and pyrolysis of carbonaceous materials produce a mixture of gaseous products as a result of the complex parallel, competitive, and sequential chemical reactions. The preferred reactions, those that produce the most desirable products, are limited and slow at conventional processing temperatures. However, the rates can be enhanced by inclusion of certain catalysts. Furthermore, a variety of catalysts are used industrially to promote certain reactions to emphasize formation of desired products from other gas mixtures. For example, methanation catalysts promote the formation of methane from hydrogen and carbon morioxide, shift catalysts promote the formation of hydrogen from water, and carbon monoxide and gasification catalysts promote the breakdown of carbonaceous matter to gases.

The state-of-the-art procedure for conversion of a carbonaceous material to a synthesis gas involves several steps:

1) gasification by partial combustion with pure oxygen and steam to form a mixture of gases $\left(\mathrm{CO}, \mathrm{H}_{2}, \mathrm{CO}_{2}, \mathrm{CH}_{4}, \mathrm{H}_{2} \mathrm{~S}\right)$,

2) shift conversion to yield a $2: 1 \mathrm{H}_{2}: \mathrm{CO}$ ratio in the gas mixture,

3) acid gas removal, 
4) reforming of hydrocarbons,

5) moisture removal, and

6) further gas cleanup to remove traces of sulfur compounds that would otherwise poison catalysts.

Partial combustion of the carbonaceous material with pure oxygen to provide heat for the endothermic gasification reactions is currently practiced for gasification to produce synthesis gas mixtures. An expensive, energy-consuming oxygen plant is required for these gasification processes to avoid dilution of the product gases with nitrogen. Conversion of wood to hydrocarbon synthesis gas is simplified somewhat because of the negligible sulfur content of wood, but the conversion still involves the steps of gasification, shift conversion, reforming, $\mathrm{CO}_{2}$ removal, and moisture removal.

The overall objective of the PNL studies is to evaluate the technical and economic feasibility of producing specific gas products via the catalytic gasification of biomass. Specific products that are being studied include (a) methane, (b) synthesis gases for production of ammonia, methanol, and hydrocarbons, (c) hydrogen, and (d) carbon monoxide. In the studies, yields of high-value, gaseous products from a single-reaction stage are enhanced by the proper choice of reactants, operating conditions, and catalyst combinations. Gaseous products, successfully produced by the various steam gasification systems employed to date, include synthesis gases for hydrocarbon, methanol, and ammonia generation and a methane-rich gas.

This report details progress of the laboratory studies, process development unit (PDU) studies, and economic analyses conducted at PN from December 1977 to October 1980. Activities of the project are summarized in Figure 1. Appendices A through D present the economic analysis of wood-to-methane and wood-to-methanol plants completed by Davy McKee, Inc., of Cleveland, Ohio. These conceptual plants use the catalytic gasification processes developed at PNL. 
1979

DATE

ACTIVITY

LABORATORY STUDIES

PRIMARY CATALYST STUDIES

WOOD COMPOSITION

KINETIC STUDIES

CATALYST COMBINATIONS

FOR SPECIFIC PRODUCTS

PRIMARY CATALYST RECOVERY

AND RECYCLE

SECONDARY CATALYST RECOVERY,

REGENERATION AND RECYCLE

DTA, DSC AND TMA STUDIES

EVALUATION OF ALTERNATIVE

BIOMASS FEEDSTOCKS

CATALYST LIFETIME STUDIES

CATALYST DEVELOPMENT

PDU OPERATIONS SUPPORT

PDU STUDIES

DESIGN, PROCUREMENT AND INSTALLATION PREPARE SAFE OPERATING PROCEDURES PRELIMINARY TESTING

TEST CATALYST COMBINATIONS

IN STIRRED BED SYSTEM

FLUID BED MODIFICATIONS

TEST CATALYST COMBINATIONS

IN FLUID BED SYSTEM

DESIGN AND MODIFY FOR PRESSURE

OPERATION

TEST CATALYST COMBINATIONS

AT ELEVATED PRESSURE

CATALYST ATRITION TESTING

FEASIBILITY STUDIES

ECONOMICS FOR SNG PRODUCTION

ECONOMICS FOR METHANOL PRODUCTION

ASPEN CODE DEVELOPMENT

ECONOMICS FOR PRODUCTION OF OTHER PRODUCTS

JFMAM J J A S OND JFMAM J J A SOND J FMAM J J ASOND J F MAM J JASOND

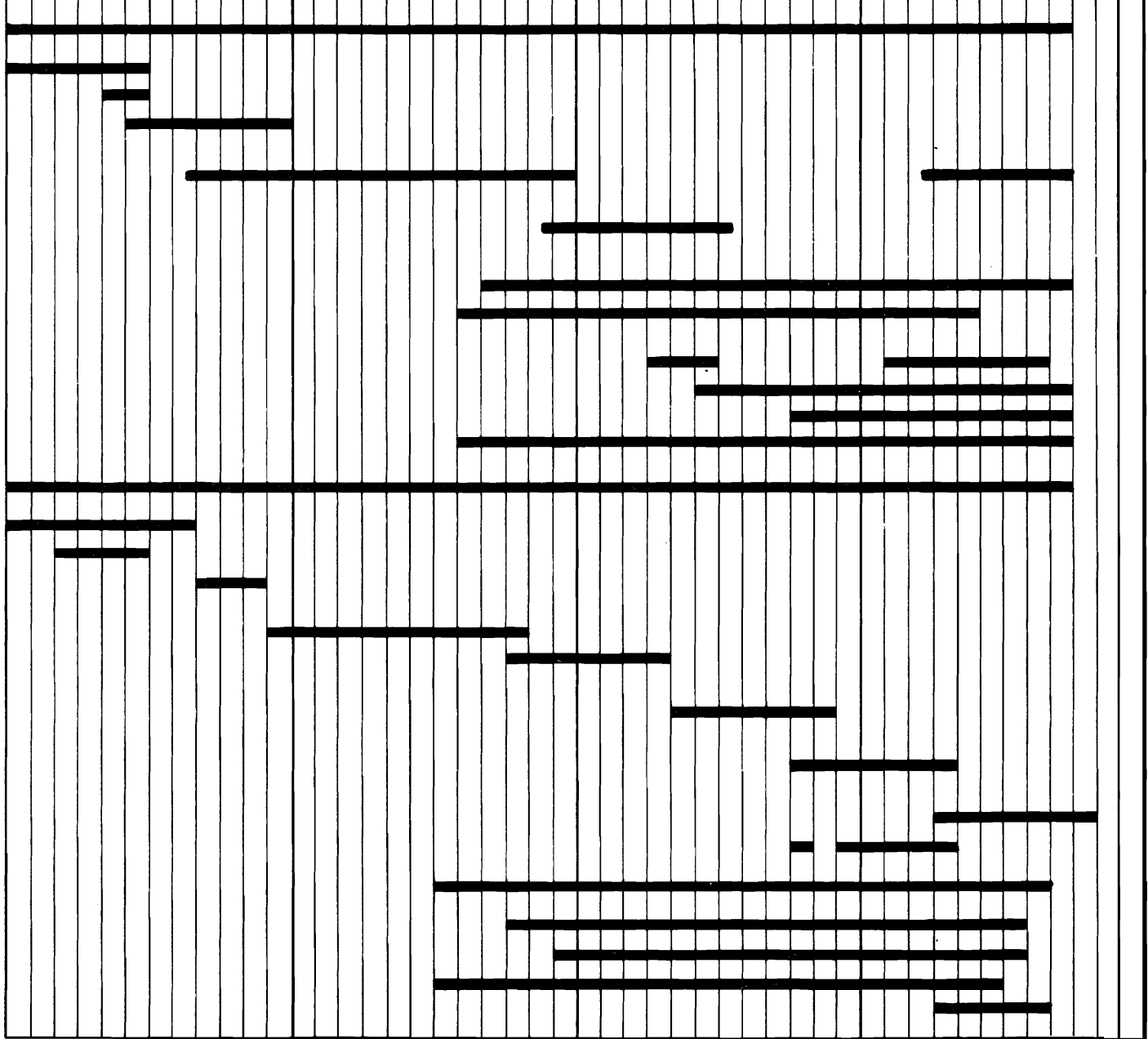

FIGURE 1 Summary of Study Activities 


\section{CONCLUSIONS}

The following conclusions are based on current results from PNL studies on catalyzed steam gasification of wood:

a Steam gasficiation of wood in the presence of catalysts to produce a methane-rich gas and a methanol synthesis gas is technically feasible.

a A nickel-on-silica-alumina catalyst was effective both for generation of a methane-rich gas and for generation of a methanol synthesis gas at respective temperatures of $550^{\circ}$ and $750^{\circ} \mathrm{C}$.

a Catalyst systems need not include an alkali carbonate primary catalyst.

a Presence of an active nickel catalyst essentially eliminates production of condensable liquids during the gasification processes.

a Potential yields of methane and methanol are significantly greater from the catalytic processes than from conventional processes that employ oxygen-steam gasification of wood in a fixed bed.

a Cost of methane from wood by catalytic gasification in a 2000-ton $(1800-t)$ dry wood per day plant is competitive with projected future costs of substitute natural gas (SNG) .

- Cost of methanol from wood by catalytic gasification in a 2000-ton $(1800-t)$ dry wood per day plant is competitive with the current price of methanol.

a Major operating costs are for wood, labor, gasifier catalyst, and taxes and insurance.

a Investment costs and high labor costs make production of methanol and SNG in a 200-ton (180-t) dry wood per day plant economically unattractive.

Further conclusions based on task studies are presented in the discussion. 


\section{RECOMMENDATIONS}

Results from the studies on catalyzed steam gasification of wood show considerable promise for commercial production of valuable chemical products. Realization of this promise depends on successful development of long-1ife catalyst systems and on availability of commercial quantities of feedstock. We, therefore, recommend continuation of studies on the development of design parameters for a commercial facility. Such studies may logically include pilot-plant operations for production of one or more products at a site with a wood residue source of 10 to 50 wet tons (9 to 45 t) per day.

Near-term studies are required before pilot-plant operations can be definitively considered. Laboratory-scale studies on evaluation of specially prepared catalyst compositions should continue. These studies will evaluate yields from the new catalysts as well as catalyst lifetime and regenerability. Thermal requirements for the processes should also be determined. Systems for generation of an ammonia synthesis gas should be evaluated further.

We recommend PDU studies to evaluate yields at pressures up to $7 \mathrm{~atm}$ from the catalyst systems developed in the laboratory. Information on catalyst durability in fluid-bed operations should be developed.

Feasibility studies have indicated that processes for generation of SNG and methanol via catalytic gasification of wood are economic at large scale. Yields and process inputs have been improved since completion of these studies. We, therefore, recommend the continued development of the computer code system to evaluate the effects of these process changes on the overall economics. 


\section{LABORATORY STUDIES}

The laboratory studies are designed to develop a fundamental understanding of the catalytic gasification of biomass, to provide a sound basis for design and operation of the PDU, and to provide support services for PDU operation. Results of these studies, presented in the following sections, are intended to define feasible reactant-catalyst combinations and operating conditions.

\section{EXPERIMENTAL EQUIPMENT}

Two types of experimental systems were employed in the laboratory phase of the project: 1) a batch-feed reactor shown in Figure 2, and 2) a continuous wood-feed reactor, shown in Figure 3. The batch-feed reactor was used to complete preliminary catalyst screening studies, to obtain kinetic data on the steam reaction with wood char, and to determine alkali carbonate recovery tests. The system was designed for atmospheric pressure operation and is quite flexible with respect to control of experimental variables including (1) sample sizes up to $15 \mathrm{~g}$, (2) steam flow rates, (3) temperatures up to $850^{\circ} \mathrm{C}$, (4) auxiliary gas addition, and (5) recovery and quantification of gases, oil/tars, and char produced during gasification.

The continuous wood-feed reactor was employed to obtain data regarding the generation of specific products from wood, to screen catalyst systems, and to investigate catalyst lifetime and regeneration. The reactor system is constructed primarily of quartz, designed for atmospheric pressure operation, and is flexible with respect to control of experimental variables including:

1) wood feed rates, 2) steam flow rates, 3) temperatures up to $850^{\circ} \mathrm{C}$, and 4) auxiliary gas addition.

\section{FEED MATERIALS}

The wood samples used in the laboratory gasification studies include separate wood and bark samples of western larch (tamarack), lodgepole pine, douglas fir, and cottonwood. The samples were hand picked from a small private chipping operation in Usk, Washington. These samples were dried and milled to the desired particle size. Chemical and physical characterization of these wood 


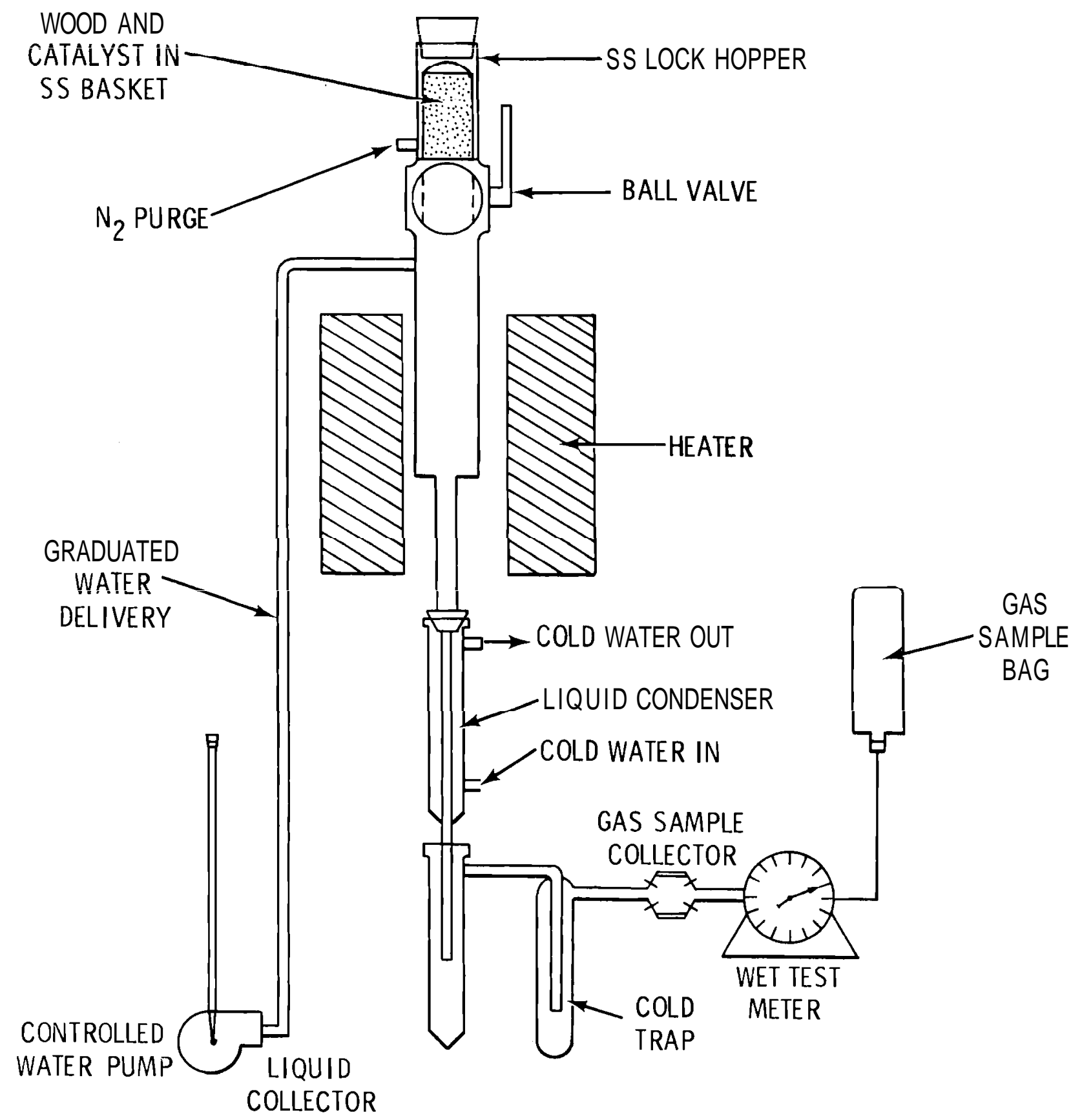

FIGURE 2. Batch-Feed Reactor 


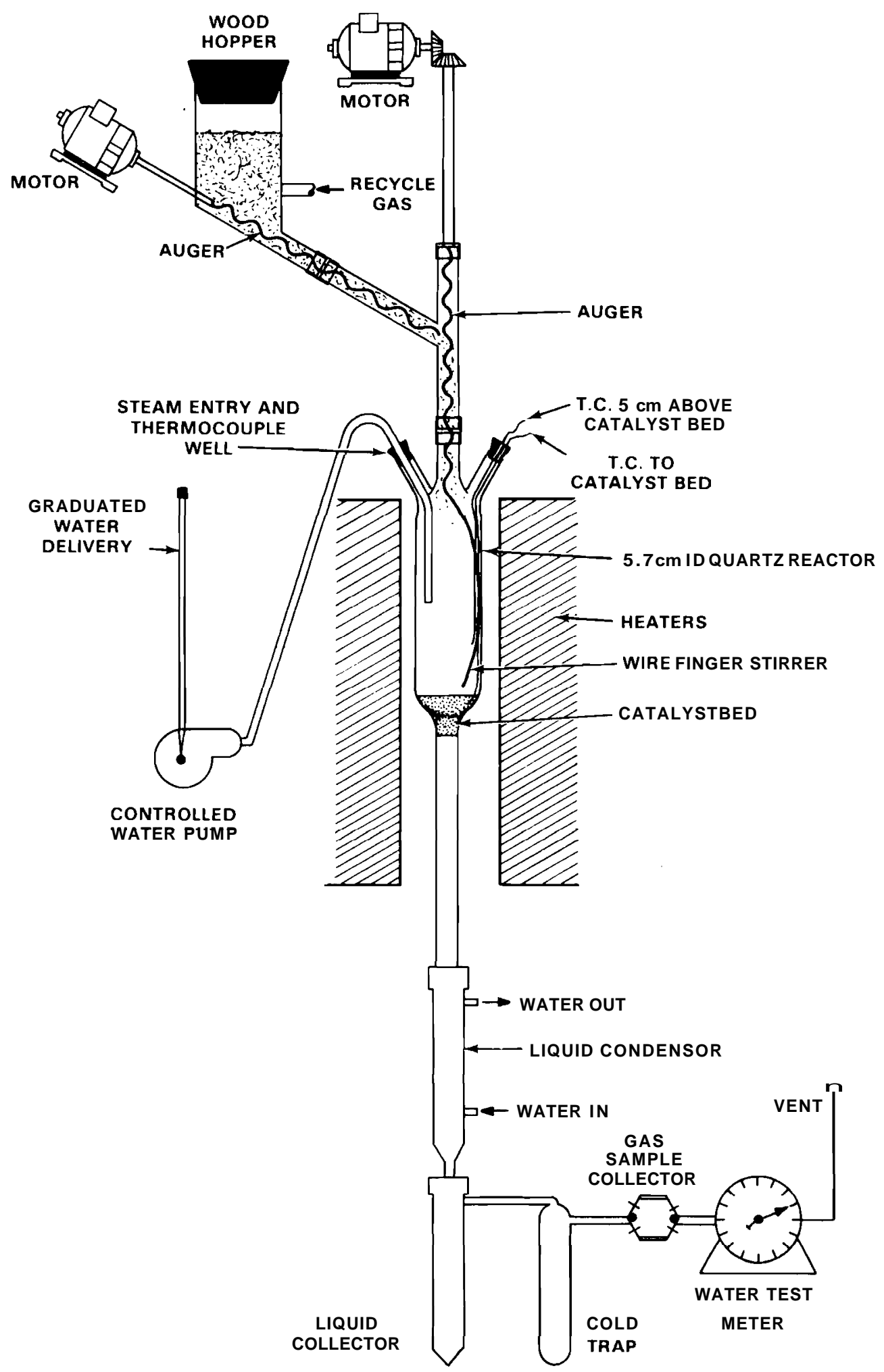

FIGURE 3. Continuous Wood-Feed Reactor 
samples are presented in Table 1. Analysis of a field corn sample used as an alternative feedstock is also given in Table 1. Lodgepole pine and douglas fir were the primary feedstocks used in the laboratory studies.

The potassium carbonate, sodium carbonate, and borax gasification catalysts used in the laboratory studies were Baker analyzed reagents. Trona was supplied by Stauffer Chemical Company of Wyoming, Green River, Wyoming.

\section{EFFECTS $\sigma$ ALKALI CARBONATES}

The catalytic effects of different alkali carbonates on the reaction of steam with wood and wood char were determined in the laboratory. Results of these determinations are presented in the following discussion.

In view of the heterogeneous nature of the wood-catalyst-steam interactions, we investigated two methods of catalyst mixing with wood--dry mixing and solution impregnation. Sodium carbonate and lodgepole pine were selected as the reference materials.

The above catalyst/wood mixtures and wood were gasified with steam at $550^{\circ} \mathrm{C}$ and $650^{\circ} \mathrm{C}$. Results obtained at $550^{\circ} \mathrm{C}$ with a catalyst concentration of $3 \times 10^{-3} \mathrm{~g} \cdot \mathrm{mole}$ sodium $/ \mathrm{g}$ wood are shown in Figure 4 . Also shown for comparison is the gas yield for simple pyrolysis of wood under the same conditions. These data show that impregnating the wood particles with sodium carbonate catalyst is a better contacting method than dry mixing the equivalent amount of catalyst with the wood. Impregnation produces about $10 \%$ more gas than dry mixing with a slight increase in rate of gas production. Both contacting methods significantly increase total gas production (75\% to $90 \%$ increase) and rate of gasification. However, using a boiling solution instead of an ambient solution of catalyst for impregnation had no additional effect.

The effectiveness of four different catalysts (potassium carbonate, sodium carbonate, trona and borax) in concentrations of $3 \times 10^{-3}$ and $3 \times 10^{-4} \mathrm{~g} \cdot \mathrm{mole}$ alkali/g wood at $550^{\circ} \mathrm{C}, 650^{\circ} \mathrm{C}$, and $750^{\circ} \mathrm{C}$ was also evaluated. These catalysts were chosen from the large number of possible candidates because: 1) experimental investigations with other materials have shown these to be the most active gasification catalysts, and 2) of the large number of possible 
TABLE 1. Comparative Analysis of Wood and Bark

\begin{tabular}{|c|c|c|c|c|c|c|c|c|c|}
\hline $\begin{array}{c}\text { Analyses } \\
\text { \% by wt. (dry basis) }\end{array}$ & Lodgepole & $T$ & $\frac{\text { od }}{\bar{C} \theta} \theta$ wee & $\overline{\text { Douglas Fir }}$ & Lodgepole & Tamarack & $\begin{array}{l}\text { Bark } \\
\text { Cottonwood }\end{array}$ & Douglas Fir & $\begin{array}{l}\text { Field } \\
\text { Corn }\end{array}$ \\
\hline \multicolumn{10}{|l|}{ Proximate } \\
\hline Volatile Matter & 82.0 & 83.1 & 83.1 & 85.7 & 75.5 & 71.3 & 76.1 & 72.1 & 64.9 \\
\hline Fixed Carbon & 17.7 & 16.6 & 15.3 & 14.2 & 21.8 & 26.1 & 18.9 & 24.7 & 11.4 \\
\hline Ash & 0.3 & 0.3 & 1.4 & 0.1 & 2.7 & 2.5 & 5.0 & 3.2 & 1.9 \\
\hline \multicolumn{10}{|l|}{ Ult imat ${ }^{(a)}$} \\
\hline Sulfur & $49 \mathrm{ppm}$ & $145.5 \mathrm{ppm}$ & $72 \mathrm{ppm}$ & $47.5 \mathrm{ppm}$ & $329.5 \mathrm{ppm}$ & $236 \mathrm{ppm}$ & $235 \mathrm{ppm}$ & 204 ppm & 0.2 \\
\hline Nitrog $\leqslant n$ & $622 \mathrm{ppm}$ & 387 ppm & 708 ppm & $552 \mathrm{ppm}$ & 0.29 & 0.26 & 0.30 & 0.31 & 0.7 \\
\hline Oxygen & 42.3 & 42.7 & 40.7 & 40.7 & 38.8 & 39.8 & 40.5 & 36.7 & 47.2 \\
\hline Ash & 0.3 & 0.4 & 1.8 & 0.8 & 2.7 & 2.5 & 3.5 & 2.7 & 1.9 \\
\hline \multicolumn{10}{|l|}{ Heating Value } \\
\hline \multicolumn{10}{|l|}{ Additional Information } \\
\hline $\begin{array}{l}\text { Mesh Size of Sample } \\
\text { Moisture Content at }\end{array}$ & $-8+20$ & $-8+20$ & $-8+20$ & $-8+20$ & $-8+20$ & $-8+20$ & $-8+20$ & $-8+20$ & $-14+20$ \\
\hline PNL (\%) Dried at $135^{\circ} \mathrm{C}$ & 2.0 & 4.0 & 3.6 & 4.3 & 3.8 & 2.5 & 5.0 & 3.2 & \\
\hline
\end{tabular}




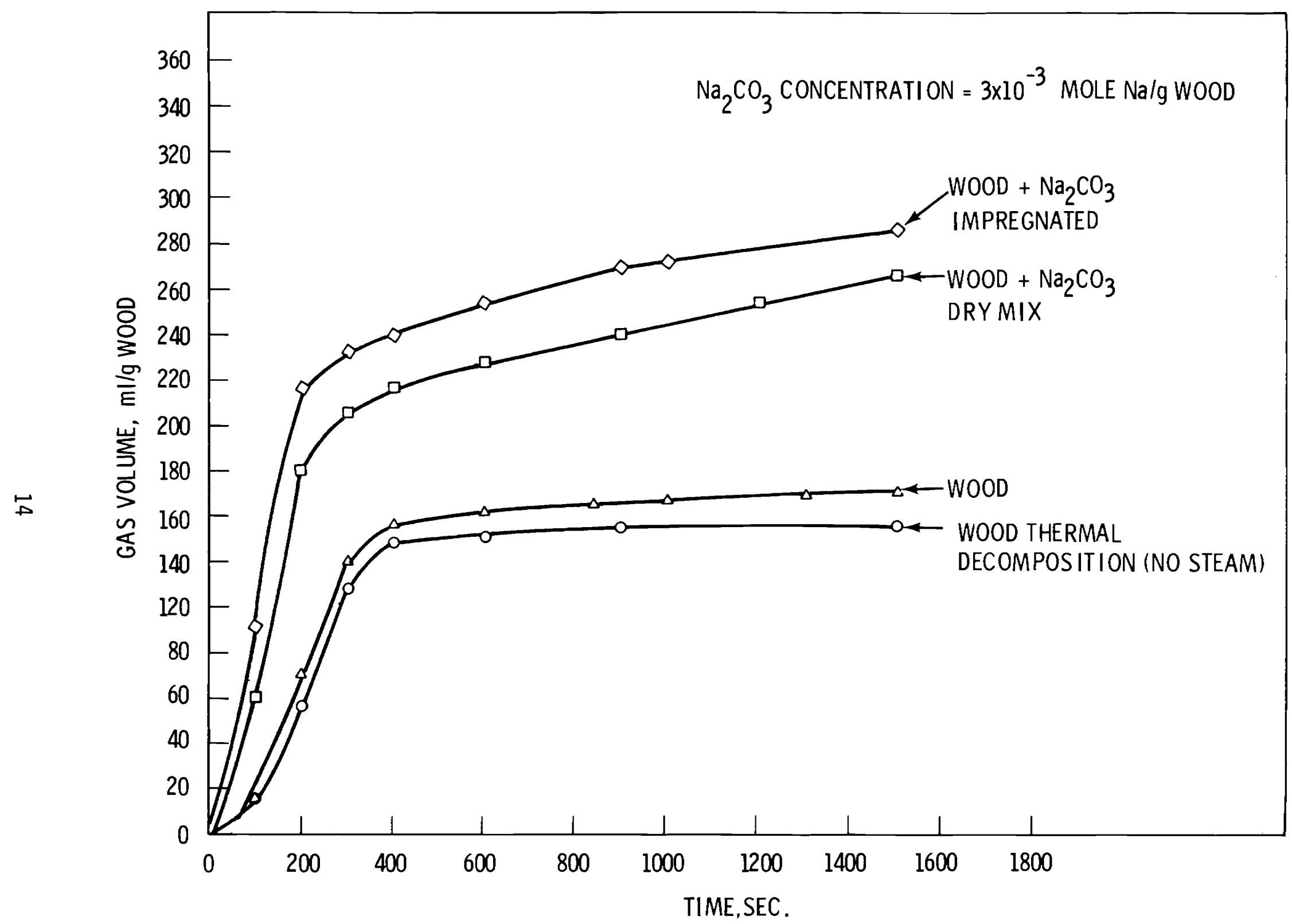

FIGURE 4. Volume of Gas Production for Catalyzed and Noncatalyzed Steam Gasification of Wood at $550^{\circ} \mathrm{C}$ 
gasification catalysts, these are relatively inexpensive. Typical results obtained at $650^{\circ} \mathrm{C}$ for a catalyst concentration of $3 \times 10^{-3} \mathrm{~g} \cdot \mathrm{mole}$ alkali/g wood and steam flow of $1.2 \mathrm{~g} / \mathrm{min}$ are shown in Figure 5 . These data show a diminishing order of effectiveness for potassium carbonate, sodium carbonate, trona and borax. The same relative order of effectiveness was observed at other temperatures and catalyst concentrations. The effect of temperature with and without potassium carbonate catalyst on gas yields is shown in Figure 6; the effect of sodium carbonate concentration is shown in Figure 7.

The steam gasification reactions produce a char residue and a gas mixture containing some condensable volatiles. The yields of these products (condensable volatiles not included) are shown in Tables 2 and 3 . These products are apparently formed from pyrolysis of wood to yield a mixture of gas, condensable liquids, and char. Further gasification then takes place by interaction of char and steam as shown in Equation (1) and by interaction of carbon monoxide and steam in the water-gas shift reaction shown in Equation (2):

$$
\begin{gathered}
\mathrm{C}(\text { char })+\mathrm{H}_{2} \mathrm{O} \rightarrow \mathrm{CO}+\mathrm{H}_{2} \\
\mathrm{CO}+\mathrm{H}_{2} \mathrm{O}+\mathrm{CO}_{2}+\mathrm{H}_{2}
\end{gathered}
$$

A close examination of the data in Tables 2 and 3 shows that the increased yield of hydrogen and carbon dioxide that results from the use of catalysts cannot entirely be attributed to Equations (1) and (2). Although the alkali carbonates are effective catalysts for these reactions, the increased yield of carbon dioxide and hydrogen is attributed to the effect that these alkali carbonates have on the yields from pyrolysis.

It has been shown that alkaline catalysts increase the yield of char from pyrolysis of cellulosic materials at the expense of condensable volatiles (Mudge, Sealock and Weber 1979; Sealock, Weber and Mudge 1980; Mudge et al. 1980). The increased char yield illustrates the fact that the catalysts could increase the amount of hydrogen and carbon dioxide without a proportionate reduction in the final yield of carbon monoxide and char as expected from 


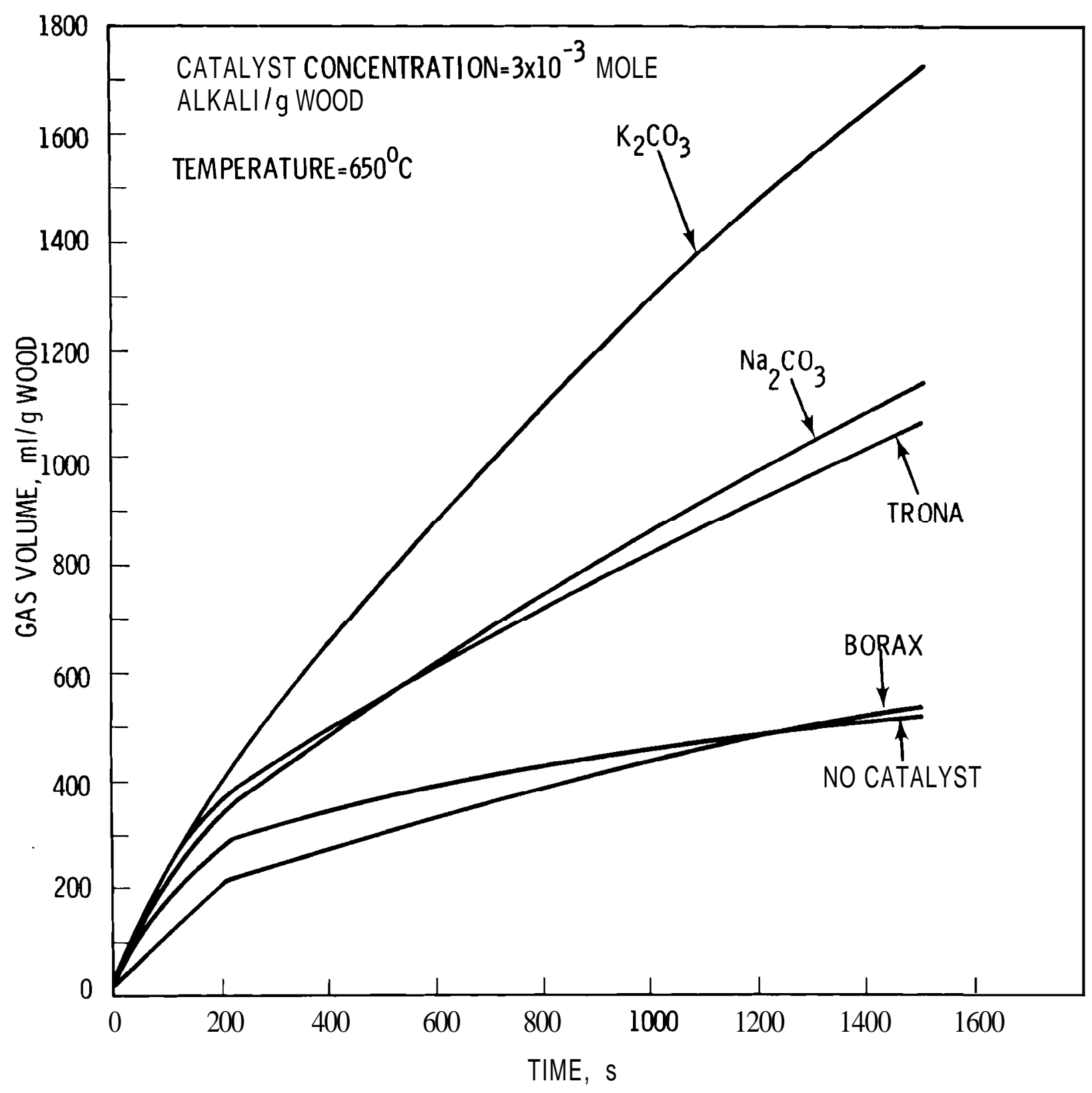

FIGURE 5. Relative Catalyst Effectiveness at $650^{\circ} \mathrm{C}$

Equations (1) and (2). The increased gas yield is attributed to cracking of tars and other liquid organics produced during pyrolysis.

Gas yields from wood and bark of four different species and from cellulose with and without impregnated potassium carbonate catalyst are given in Table 4 for steam gasification at $650^{\circ} \mathrm{C}$. Concentration of hydrogen in the product gas 


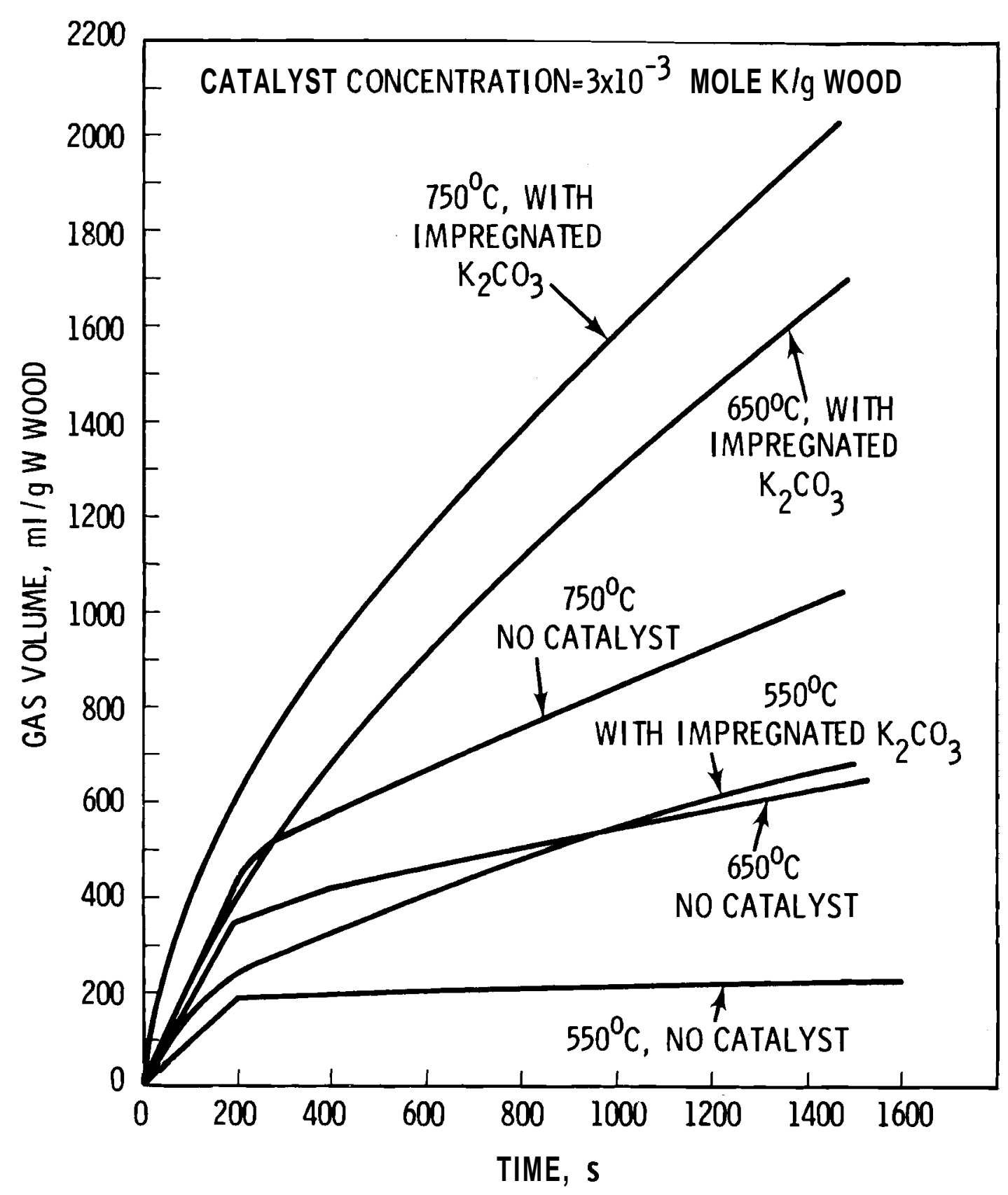

FIGURE 6. Effect of Temperature on Gas Production With and Without Potassium Carbonate Catalyst

was about 60 vol\% for catalyzed and about 15 vol\% for uncatalyzed tests. All woods gave a slightly higher hydrogen concentration and, in most cases, a slightly lower carbon monoxide and methane concentration in the product gas than their respective barks. Differences with wood variety were considered insignificant. 


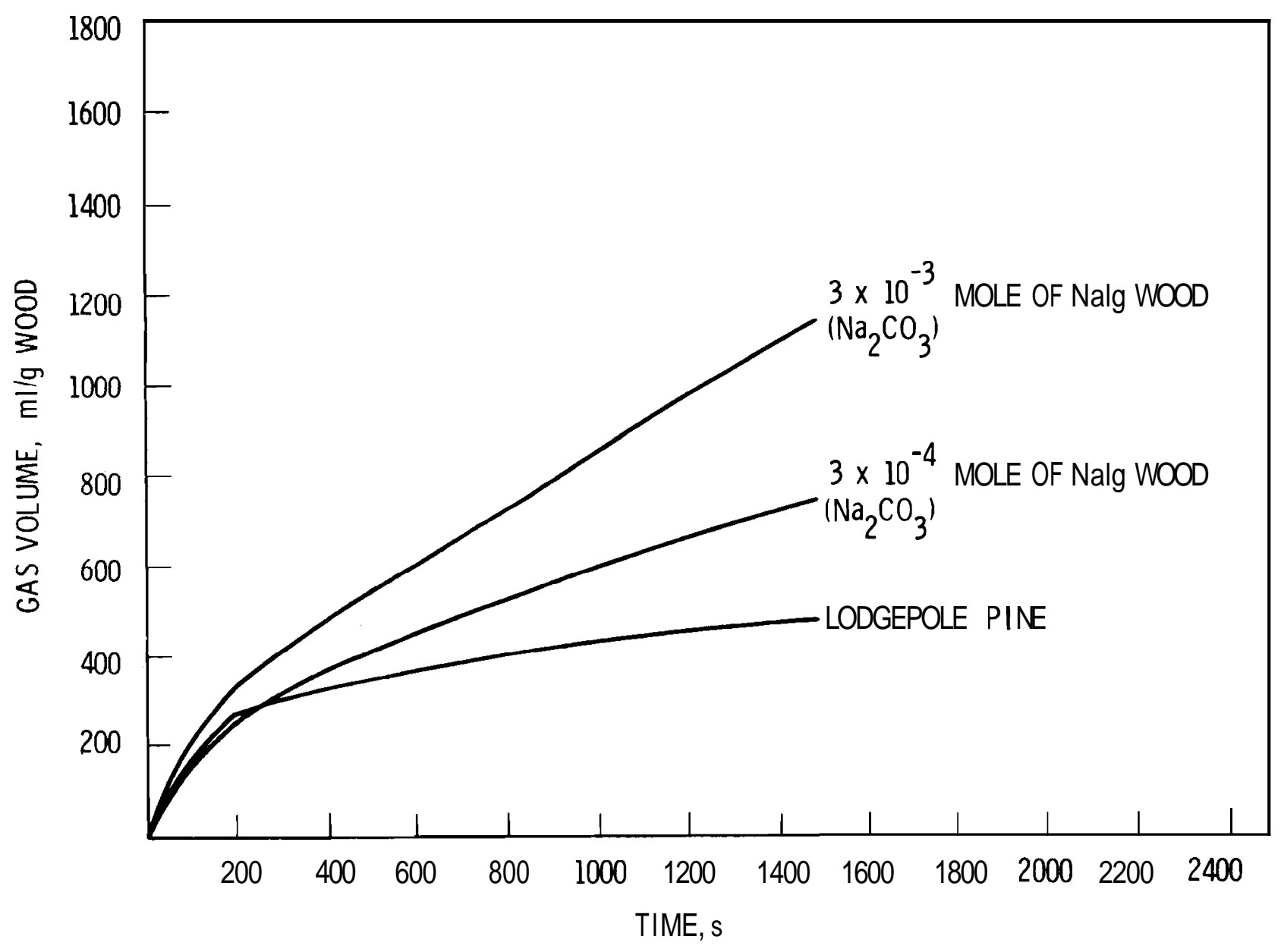

FGURE 7. Effect of Sodium Carbonate Concentration on Gas Yield at $650^{\circ} \mathrm{C}$

Experiments were conducted to examine the kinetics of catalyzed biomass gasification. Initially, the rate correlations were expected to be patterned after those reported by Gardner, Sarnuels and Wilks (1979) and Johnson (1974). This could not be accomplished, as our data based on gasification products were not comparable to the thermogravimetric data based on the total weight loss used in these references. However, the data could be used to generate rate correlations in a manner similar to that reported by Lefrancois, Barclay and Skaperdas (1967) for their bench-scale studies on coal and coal char gasification. 
TABLE 2. Gas Yields at $650^{\circ} \mathrm{C}$

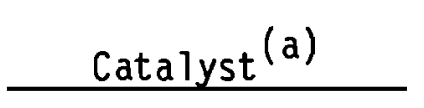

Potassium Carbonate

Sodium Carbonate

Trona

None

\begin{tabular}{|c|c|c|c|c|c|c|}
\hline & \multicolumn{2}{|c|}{ Volume 0} & \multirow{2}{*}{\multicolumn{3}{|c|}{ Gas, $\mathrm{ml} / \mathrm{g}$ wood $(\mathrm{b}$}} & \\
\hline b- & 2 & $\underline{\mathrm{C}}_{2}$ & & & & Tota \\
\hline 895 & 578 & 3 & 7 & 57 & 145 & 1685 \\
\hline 581 & 407 & 4 & 8 & 59 & 116 & 1175 \\
\hline 424 & 350 & 5 & 10 & 73 & 111 & 973 \\
\hline 94 & 94 & 6 & 4 & 47 & 235 & 480 \\
\hline
\end{tabular}

(a) Catalyst concentration $=3 \times 10^{-3} \mathrm{~g} \cdot \mathrm{mole}$ alkali $/ \mathrm{g}$ wood.

(b) Steam flow = $1.2 \mathrm{~g} / \mathrm{min}, 25 \mathrm{~min}$ for reaction with $10 \mathrm{~g}$ wood.

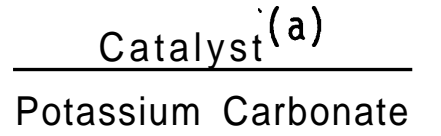

Sodium Carbonate

Trona

None

\section{TABLE 3. Elemental Yields at $650^{\circ} \mathrm{C}$}

\begin{tabular}{|c|c|c|c|}
\hline$\left(\frac{W+i}{4}\right.$ & $\begin{array}{l}n \text { Gas Produ } \\
\text { Wt in Wood }\end{array}$ & 100 & $\left(\frac{W+C \text { in Residue }}{}\right) 100$ \\
\hline $\mathrm{H}$ & 0 & c & \\
\hline 130 & 188 & 75 & 22 \\
\hline 97 & 138 & 58 & 29 \\
\hline 79 & 132 & 56 & 35 \\
\hline 32 & 69 & 38 & 31 \\
\hline
\end{tabular}

(a) Catalyst concentration $=3 \times 10^{-3} \mathrm{~g} \cdot \mathrm{mole}$ alkali $/ \mathrm{g}$ wood.

(b) Steam flow - $1.2 \mathrm{~g} / \mathrm{min}, 25$ min for reaction with $10 \mathrm{~g}$ wood.

When wood is contacted with steam at elevated temperatures, a series of complex physical changes and chemical reactions are initiated. These phenomena include 1) rapid volatilization (pyrolysis) to yield gases, condensable liquids, and a char residue and 2) steam reaction with the pyrolysis products. Steam reaction with the char residue occurs at a slow rate relative to pyrolysis.

The model used to analyze laboratory data assumes that, as discussed above, the overall changes occur in two consecutive stages: 1) pyrolysis of the wood and 2) steam gasification of the char residue. For this analysis the reactions in these stages are assumed to occur consecutively and to be independent. 
TABLE 4. Gas Yield from Different Wood and Bark Materials at $650^{\circ} \mathrm{C}$

\begin{tabular}{|c|c|c|c|}
\hline \multirow[b]{2}{*}{ Material } & \multicolumn{3}{|c|}{ Volume gas, ${ }^{(a)} \mathrm{L} / \mathrm{g}$ biomass } \\
\hline & $3 \times 10^{-3}$ & $\mathrm{~g} \cdot \mathrm{mole}_{2} \mathrm{CO}_{3} / \mathrm{g}$ biomass & No catalyst \\
\hline Douglas fir bark & & 2.2 & 0.7 \\
\hline Lodgepole bark & & 2.1 & 0.7 \\
\hline Tamarack bark & & 2.0 & 0.6 \\
\hline Cottonwood bark & & 2.0 & 1.0 \\
\hline Lodgepole wood & & 2.0 & 0.6 \\
\hline Tamarack wood & & 2.0 & 0.5 \\
\hline Douglas $\mathrm{f}$ ir wood & & 1.9 & 0.5 \\
\hline Cottonwood wood & & 1.7 & 0.7 \\
\hline Cellulose & & 1.5 & 0.6 \\
\hline
\end{tabular}

(a) Steam flow $=1.2 \mathrm{~g} / \mathrm{min}$, experiment $25 \mathrm{~min}$ in duration.

Kinetic data were obtained at five concentrations of impregnated potassium carbonate: $0,4,8,12$, and $17 \mathrm{wt} \%$. Temperatures studies included $550^{\circ} \mathrm{C}$, $650^{\circ} \mathrm{C}, 750^{\circ} \mathrm{C}$, and $850^{\circ} \mathrm{C}$. The total carbon gasified at each sampling was assumed to be the carbon appearing in the product gas and was determined from gas volume and gas composition data. The percent carbon was determined by difference and plotted versus time on semi-log paper. Examples are shown in Figures 8 and 9 for catalyzed and uncatalyzed tests, respectively. The results in Figures 8 and 9 can be interpreted by the two reaction stages previously def i ned.

During the first $160 \mathrm{~s}$, the losses correspond to pyrolysis of the wood. The base carbon remaining in the residue then reacts with the steam in the gasification stage.

It appears from the results in Figure 8 that more base carbon remains in the residue after the pyrolysis stage at $650^{\circ} \mathrm{C}$ than after the pyrolysis stage at $550^{\circ} \mathrm{C}$, and it appears from the results in Figure 9 that more base carbon 


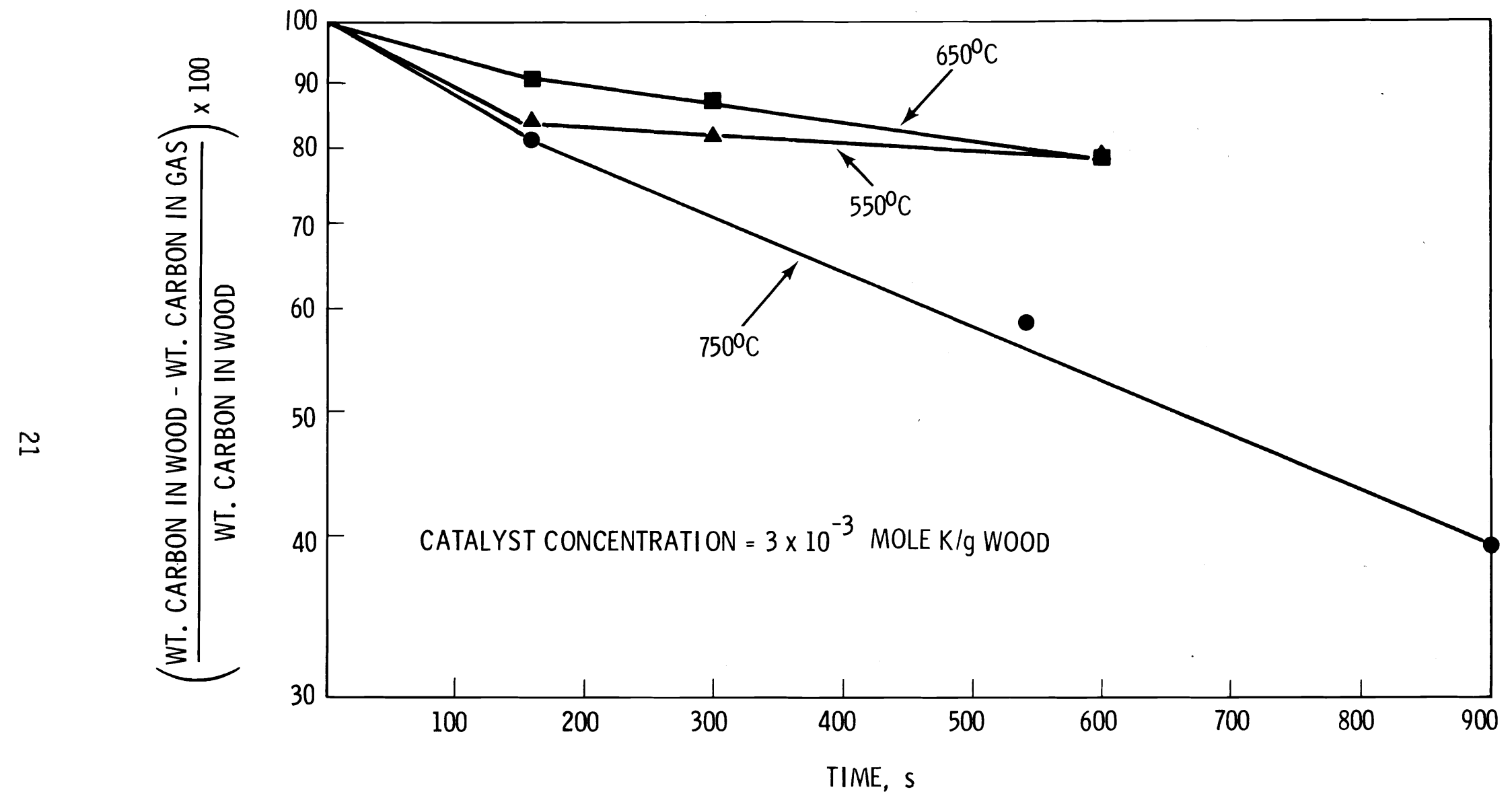

FIGURE 8. Catalyzed Test Results on Remaining Carbon Versus Time 


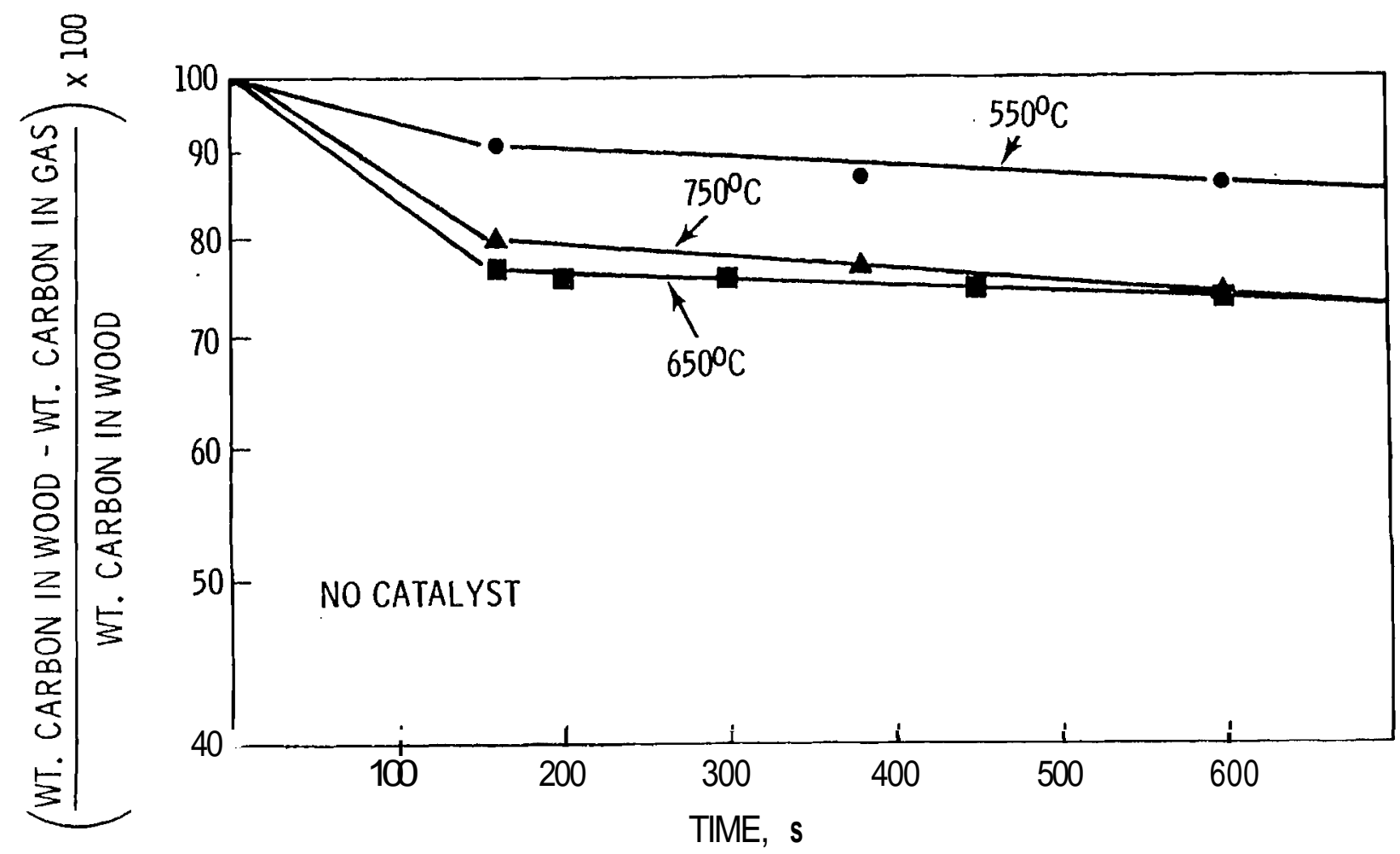

FIGURE 9. Uncatalyzed Test Results on Remaining Carbon Versus Time

remains after the pyrolysis stage at $750^{\circ} \mathrm{C}$ than at $650^{\circ} \mathrm{C}$. Since condensable volatiles were not included in the determination of remaining base carbon, this may or may not be the actual case.

The data plotted in Figures 8 and 9 depict reasonably linear relationships for the gasification stage. Assuming pseudo-first-order kinetics, the following expression for the gasification stage reaction rate constant is obtained:

$$
k=\frac{1}{\left(t_{2}-t_{1}\right)} \ln \left(\frac{c_{1}}{c_{2}}\right)
$$

where $c_{1}$ is the carbon remaining at the time $t_{1}$ and $c_{2}$ is the amount of carbon remaining at the time $t_{2}$. 
The activation energy $E_{a}$ is obtained from a plot of in $k$ vs $1000 / T$ (see Figure 10) as indicated by the Arrhenius equation:

$$
\ln \left(\frac{k_{2}}{k_{1}^{2}}\right)=\frac{E}{R} a\left(\frac{T_{2}-T_{1}}{T_{1} T_{2}}\right)
$$

Gas production rates, rate constants, and activation energies were determined from these studies using the techniques discussed. Carbon-steam reaction rate constants for the various alkali carbonate catalyst concentrations are given in Table 5. Steam flow rates of $0.4 \mathrm{~g} / \mathrm{min}$ and $1.2 \mathrm{~g} / \mathrm{min}$ were employed in these experiments. An increase in steam flow rate significantly increased the value of the carbon-steam reaction rate constant. This is an indication that the

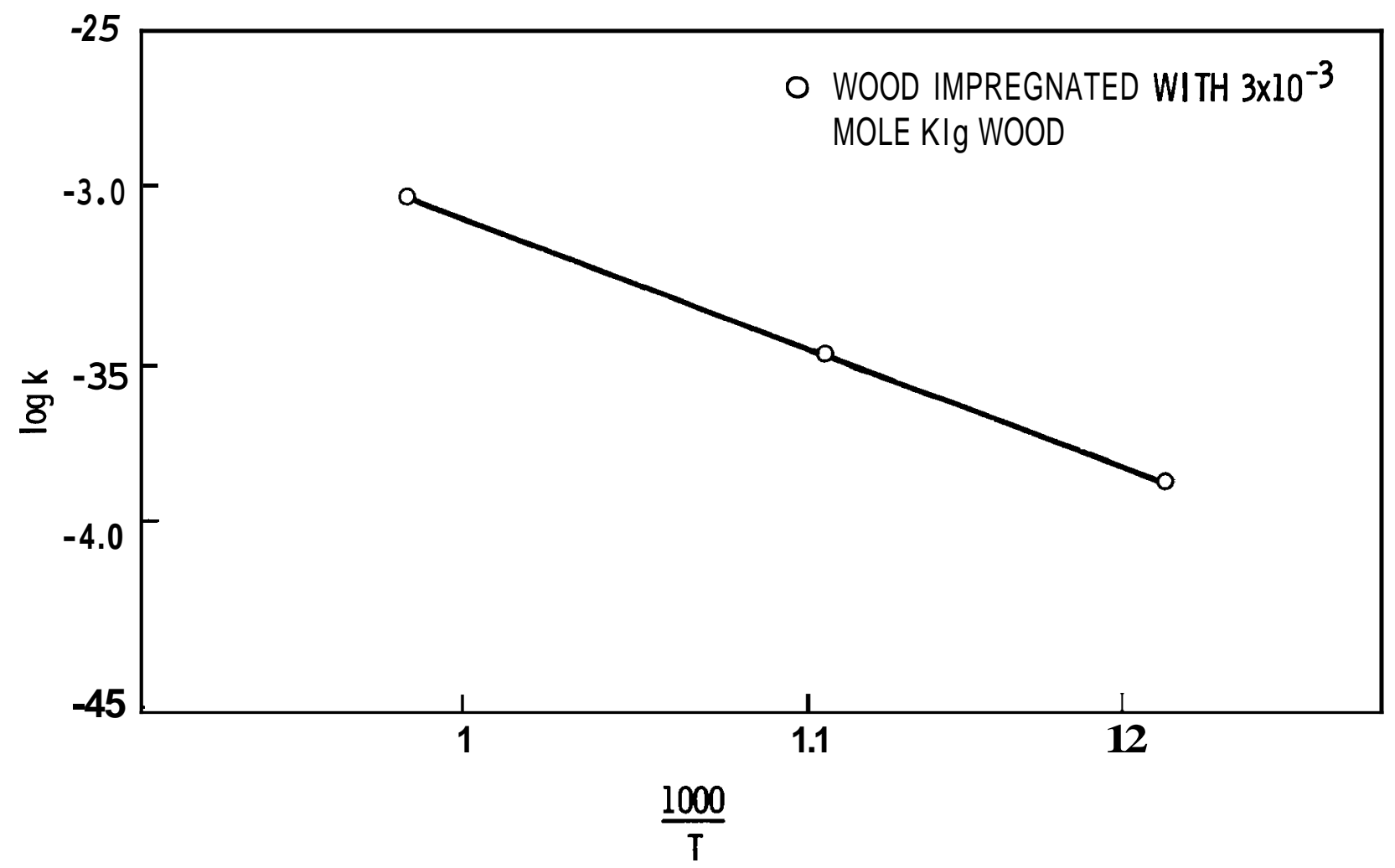

FIGURE 10. Reaction Constant Variation With $1 / T$ for Catalyzed Steam Gasif ication of Wood 
TABLE 5. Reaction Rate Constants for Wood Char-Steam Reaction in the Presence of Catalysts

Reaction

Temperature, Steam Rate,

$\frac{{ }^{\circ} \mathrm{C}}{550}$

$\mathrm{g} / \mathrm{min}$

550

0.4

0.4

550

0.4

550

0.4

550

0.4

550

1.2

550

1.2

550

1.2

650

650

0.4

0.4

650

0.4

650

0.4

650

0.4

650

1.2

650

1.2

650

750

1.2

0.4

750

0.4

750

0.4

750

0.4

750

0.4

750

1.2

750

1.2

850

0.4

850

0.4

850

0.4

850

0.4

850

0.4

\begin{tabular}{cc}
${\mathrm{Wt} \% \mathrm{~K}_{2} \mathrm{CO}_{3}}_{3}$ & Rate Constant \\
\cline { 2 - 3 } 17 & $2.6 \times 10^{-5}$ \\
12 & $2.5 \times 10^{-5}$ \\
8 & $2.5 \times 10^{-5}$ \\
4 & $2.2 \times 10^{-5}$ \\
0 & $2.6 \times 10^{-5}$ \\
17 & $1.4 \times 10^{-4}$ \\
0 & $1.1 \times 10^{-4}$ \\
0 & $1.0 \times 10^{-4}$ \\
17 & $1.3 \times 10^{-4}$ \\
12 & $1.2 \times 10^{-4}$ \\
8 & $8.6 \times 10^{-5}$ \\
4 & $8.0 \times 10^{-5}$ \\
0 & $4.0 \times 10^{-5}$ \\
17 & $3.4 \times 10^{-4}$ \\
0 & $9.3 \times 10^{-5}$ \\
0 & $9.9 \times 10^{-5}$ \\
17 & $3.1 \times 10^{-4}$ \\
12 & $3.1 \times 10^{-4}$ \\
8 & $3.1 \times 10^{-4}$ \\
4 & $2.5 \times 10^{-4}$ \\
0 & $8.2 \times 10^{-5}$ \\
17 & $9.9 \times 10^{-4}$ \\
0 & $2.0 \times 10^{-4}$ \\
17 & $1.1 \times 10^{-3}$ \\
12 & $6.9 \times 10^{-4}$ \\
8 & $4.2 \times 10^{-4}$ \\
4 & $4.3 \times 10^{-4}$ \\
0 & $3.1 \times 10^{-4}$ \\
& \\
\hline 17 &
\end{tabular}


reaction rate is influenced by the mass transfer or diffusional properties in the char. The activation energies calculated at the lower steam rate are presented in Table 6. A discussion of the postulated mechanism follows.

Experiments completed early in the program with a continuous wood-feed reactor allowed visual observation of the reaction process. The presence of the potassium carbonate catalyst was observed to induce swelling of the wood particle when exposed to reaction temperatures. Diffusion is the controlling mechanism for alkali carbonate catalyzed steam gasification of wood char as indicated by 1) the fact that the reaction kinetics are dependent upon the steam flow rate and 2) the fact that particle swelling is induced by the alkali carbonate.

It is postulated that the swelling of the wood particle increases the pore diameters thus making the char surface more accessible. In contrasting a small pore without the alkali carbonate to a large pore with the alkali carbonate, the reaction rate in the smaller pore will be more diffusion limited at the higher temperatures. First order reaction rate equations that include diffusional limitations conclude that the calculated reaction rate constant, $k$, is proportional to the square root of the true reaction rate constant $k_{t}$, or

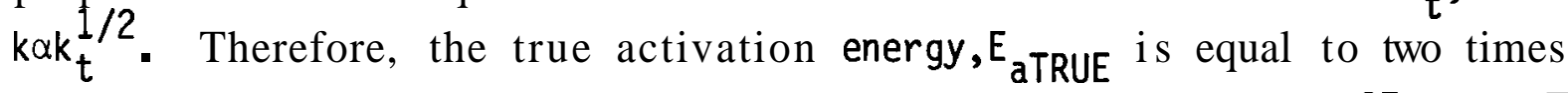
the observed or calculated activation energy, $E_{a O B S}$, or $E_{a T R U E}=2 E_{a O B S}$. The effectiveness factors associated with diffusion limitations is represented graphically in Figure 11 and discussed below.

TABLE 6. Activation Energies for the Wood-Char/Steam Reaction(a)

$\begin{array}{cc}\frac{\mathrm{Fk}_{2} \mathrm{CO}_{3}}{0} & \frac{\mathrm{E}_{\mathrm{a}}(\mathrm{kcal} / \mathrm{mole})}{30} \\ 4 & 18 \\ 8 & 17 \\ 12 & 21 \\ 17 & 23\end{array}$

(a) Steam flow rate is $0.4 \mathrm{~g} / \mathrm{min}$. 


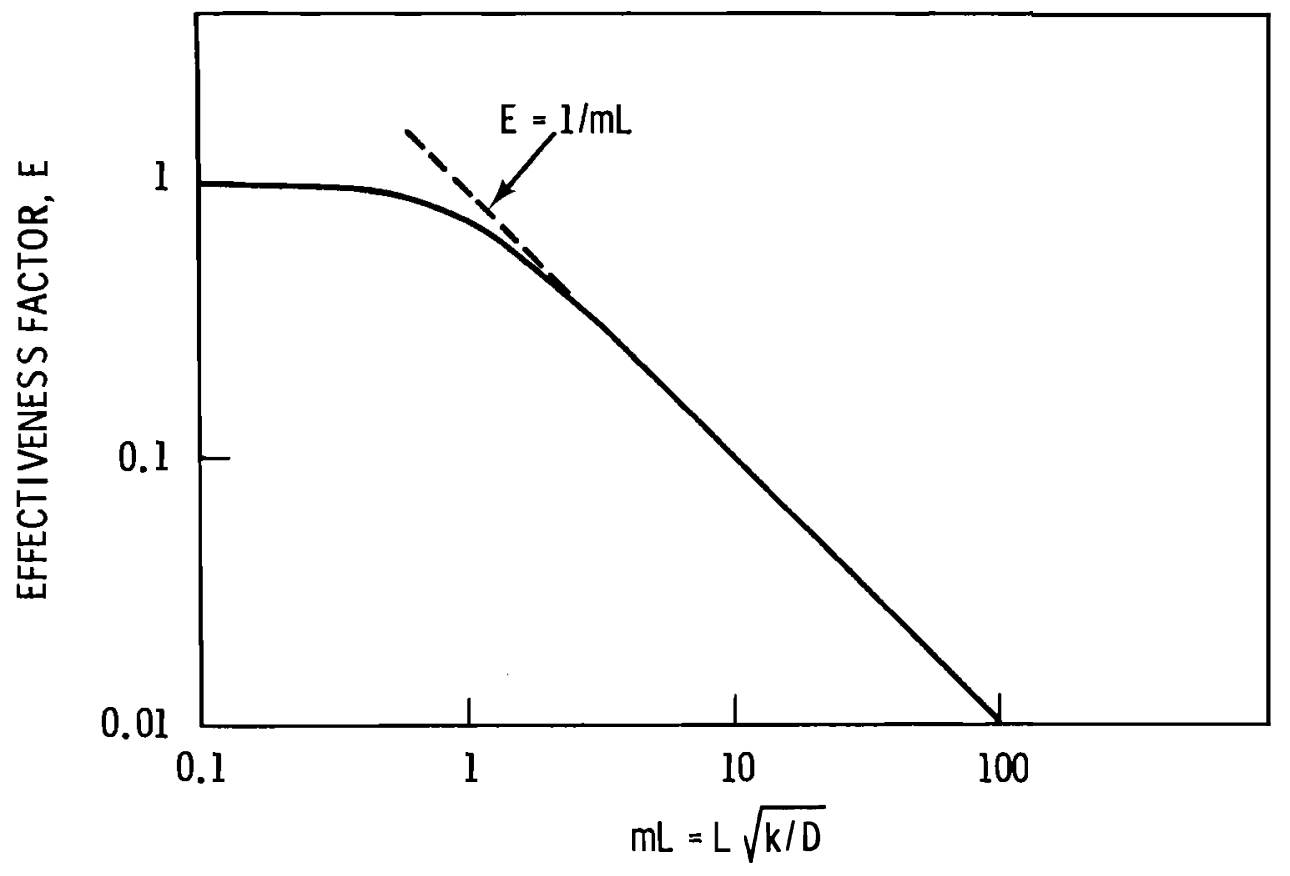

FIGURE 11. Postulated Effectiveness Factor

Since the reaction rate is directly proportional to the reactant concentration in a first order reaction, the average concentration near the particle surface, $\bar{A}$, compared to the bulk stream concentration, $A$, is a measure of how much the reaction rate is affected by diffusion. The ratio $\bar{A} / A$ is defined as the effectiveness factor $E$ shown in Figure 11. Therefore, the observed reaction rate constant $k$ is equal to the true reaction rate constant, $k_{t}$, multiplied by the effectiveness factor, E. Figure 11 illustrates how $E$ varies within the pore with a plot of $E$ vs $\mathrm{mL}$, or $E$ vs $L \sqrt{k / D}$ where:

$$
\begin{aligned}
& m=\sqrt{k / D} \\
& k=\text { observed reaction rate constant } \\
& D=\text { diffusivity coefficient } \\
& L=\text { length of pore }
\end{aligned}
$$

Ideally E would equal $\mathrm{mL}$, which equals 1 . This would indicate that the limitation by pore diffusion is essentially absent. 
Major conclusions obtained from the kinetic studies are as follows:

- The effect of alkali carbonate on the char-steam reaction rate is negligible at temperatures below $550^{\circ} \mathrm{C}$.

- Char-steam reaction rate constants increase with increased alkali carbonate concentration at temperatures from $650^{\circ} \mathrm{C}$ to $850^{\circ} \mathrm{C}$.

- The catalyst appears to enhance the char-steam reaction rate by increasing carbon surface area available for reaction.

- The carbon-steam reaction rate appears to become more diffusional limited as alkali carbonate concentration is decreased.

\section{EFFECTS OF SECONDARY CATALYSTS}

Data obtained in studies with alkali carbonates show that at $550^{\circ} \mathrm{C}$ potassium carbonate had little effect on the carbon-steam reaction but had an effect on the initial wood pyrolysis reaction and yields of pyrolysis products. Experiments were designed that considered the fact that less carbon, a greater quantity of liquids, and a smaller quantity of gases are produced during gasification in the absence of the alkali carbonate at $550^{\circ} \mathrm{C}$. Theoretically an increase in gas yield could be accomplished if liquids produced could be hydrocracked to the desired gases in the presence of steam and catalysts. Data obtained from studies completed in the batch reactor demonstrated that at temperatures ranging from $550^{\circ} \mathrm{C}$ to $750^{\circ} \mathrm{C}$ a $1: 1$ silica-alumina ( $\mathrm{Si}-\mathrm{Al}$ ) to $\mathrm{NiO}$ or $\mathrm{Ni}$ catalyst combination significantly increased the gas volume, energy efficiency, and carbon conversion to the gaseous phase over the yields with the alkali carbonate. Table 7 presents yields comparing batch experiments with potassium carbonate and those with the $\mathrm{Ni} / \mathrm{Si}-\mathrm{Al}$ catalyst mixture. Carbon conversions and energy efficiencies are shown in Table 8.

The $\mathrm{Ni}$ and NiO catalysts utilized in these studies are proven and well known throughout industry for their hydrogenation capabilities. The strength of the silica-alumina catalyst lies in its acidic cracking function. This catalyst includes a high concentration of Bronsted and Lewis acid centers. Lewis acid sites promote cracking by removal of hydride ions from the molecules of the reactants, thus giving a carbonium ion intermediate. Bronsted acid 

TABLE 7. Yields from Batch Experiments of Wood-Steam Gasification
in the Presence of Catalysts $(a)$

\begin{tabular}{|c|c|c|c|c|}
\hline \multirow[b]{2}{*}{ Experiments } & \multicolumn{4}{|c|}{ Yields, wt\% } \\
\hline & Gases & Liquids & $\underline{\text { Char }}$ & Water \\
\hline \multicolumn{5}{|l|}{ At $550^{\circ} \mathrm{C}$} \\
\hline $17 \% \mathrm{~K}_{2} \mathrm{CO}_{3}$ & 38.9 & 8.4 & 28.1 & 25.0 \\
\hline Ni $1404: S i-A 1 \quad(1: 1)$ & 74.8 & 0.0 & 22.9 & 0.0 \\
\hline \multicolumn{5}{|l|}{ At $650^{\circ} \mathrm{C}$} \\
\hline $17 \% \mathrm{~K}_{2} \mathrm{CO}_{3}$ & 62.1 & 7.2 & 23.2 & 6.0 \\
\hline Ni $1404: S i-A 1 \quad(1: 1)$ & 88.3 & 2.3 & 18.9 & -16.0 \\
\hline \multicolumn{5}{|l|}{ At $750^{\circ} \mathrm{C}$} \\
\hline $17 \% \mathrm{~K}_{2} \mathrm{CO}_{3}$ & 95.2 & 4.9 & 13.1 & -25.0 \\
\hline Ni $1404: S i-A 1 \quad(1: 1)$ & 107.3 & 1.1 & 14.3 & -18.0 \\
\hline
\end{tabular}

(a) All tests utilized a 10-g charge of lodgepole wood with a stream rate of $0.4 \mathrm{~g} / \mathrm{min}$.

TABLE 8. Carbon Conversions and Energy Efficiencies in Batch Experiments(a)

$\%$ Carbon

Experiments Converted to a Gas Btu Gas/Btu Wood x 100

At $550^{\circ} \mathrm{C}$
$17 \% \mathrm{~K}_{2} \mathrm{CO}_{3}$
Ni 1404:Si-A1 $\quad(1: 1)$
25
16
48
46

At $650^{\circ} \mathrm{C}$

$17 \% \mathrm{~K}_{2} \mathrm{CO}_{3}$

Ni 1404:Si-A1 (1:1)

38

36

55

57

At $750^{\circ} \mathrm{C}$

$17 \% \mathrm{~K}_{2} \mathrm{CO}_{3}$

59

65

Ni $1404: S i-A 1(1: 1)$

68

84

(a) All tests utilized a 10-g charge of lodgepole wood with a stream rate of $0.4 \mathrm{~g} / \mathrm{min}$. 
sites yield a proton to the reactant molecules, i.e., olefins and aromatics, resulting in an intemediate carbonium ion formation (Andrew, Martin and Noher 1971). With the large quantity of liquids produced from the wood during pyrolysis and the knowledge that an aromatic ring must first be hydrogenated before it can be cracked, a hydrocracking reaction should be ideal for this process. Combining these two catalysts into a single system gives both required catalytic functions, hydrogenation and cracking, or hydrocracking. The presence of steam gives additional reforming of the organics. The data and results presented here are reproducible and support the fact that at the $550^{\circ} \mathrm{C}$-to $-750^{\circ} \mathrm{C}$ temperature range, a $\mathrm{Ni}$ or $\mathrm{Ni0}: \mathrm{Si}-\mathrm{Al}$ catalyst system is a more effective catalyst system for gasification of wood than $17 \mathrm{wt} \%$ impregnated potassium carbonate.

\section{REOOVERY OF ALKALI CARBONATE CATALYSTS}

Recovery and recycling of alkali carbonate is required for those processes that use a primary gasification catalyst. As presented in later sections, the alkali-carbonate primary catalyst is needed for generation of an ammonia synthesis gas and a hydrogen-rich gas. The objective of the alkali carbonate recovery tests was to determine primary catalyst loss per unit of biomass processed. Residues from gasification experiments were used to conduct the tests. The residues were selected from batch experiments conducted with a potassium carbonate catalyst at $750^{\circ} \mathrm{C}$ with a steam rate of $0.4 \mathrm{~g} / \mathrm{min}$ which gave an average of $92 \%$ carbon conversion to gas.

The recovery experiment consisted of washing the residue with water or a water-solvent mixture. The wash was filtered and the filtrate and residue were retained for potassium analysis. The potassium in the residue and filtrate was analyzed with an induction couple plasma ICP spectrometer instrument. The parameters of the studies included:

- Leaching Solutions:

(a) water,

(b) water/methanol $(1: 1)$,

(c) acidic (pH 3),

(d) water/acetone (1:1) 
a Solution/Residue Weight Ratio: 10 and 100

- Leaching Solution Temperature: $95^{\circ} \mathrm{C}$ (water only) and $25^{\circ} \mathrm{C}$

- Leaching Time: $2 \mathrm{~h}$ (water only) and $1 \mathrm{~h}$.

Results of these tests can be summarized as follows:

- $98 \%$ potassium recovery is achieved with a solution/residue weight ratio of 100 for 1) a water wash, 2) an acid wash, or 3) a water/ methanol wash at $25^{\circ} \mathrm{C}$.

- $95 \%$ potassium recovery is obtained with a $10 / 1$ water wash at $25^{\circ} \mathrm{C}$.

- A leaching time of $1 \mathrm{~h}$ yields the same results as a 2 -h leaching time.

a $25^{\circ} \mathrm{C}$ is a better leaching temperature than $95^{\circ} \mathrm{C}$.

$X$-ray diffraction studies were performed to identify the type of alkali compound remaining in the char residue. Results indicate that $\mathrm{K}_{2} \mathrm{CO}_{3} \cdot \mathrm{H}_{2} \mathrm{O}$ and $\mathrm{K}_{2} \mathrm{CO}_{3}$ are the only alkali compounds in the residue.

With $95 \%$ recovery, the cost of potassium carbonate and sodium carbonate catalysts at September 1980 prices would be $\$ 2.60 /$ dry ton of wood and $\$ 0.40 /$ dry ton of wood, respectively. No loss in effectiveness of the recovered catalyst was observed.

\section{SYSTEMS FOR METHANE GENERATION}

The objective of these studies was to find catalyst combinations and operating conditions for generation of a methane-rich gas. Favored systems developed in the laboratory did not include the use of a primary alkali carbonate catalyst.

Numerous secondary catalyst systems for generation of a methane-rich gas at $550^{\circ} \mathrm{C}$ were tested with the equipment shown in Figure 3. Favorable activity for methane production was observed with some catalysts tested in these studies (see Table 9). Catalysts that are effective for generation of a methane-rich gas were determined to have the following properties: a nickel concentration of $25 \mathrm{wt} \%$ or greater, an acidic support, a BET surface area of greater than $100 \mathrm{~m}^{2} / \mathrm{g}$, and a nickel surface area of $30 \mathrm{~m}^{2} / \mathrm{g}$ or greater. 
TABLE 9. Catalysts Tested for Methane Production

Harshaw Ni-0101

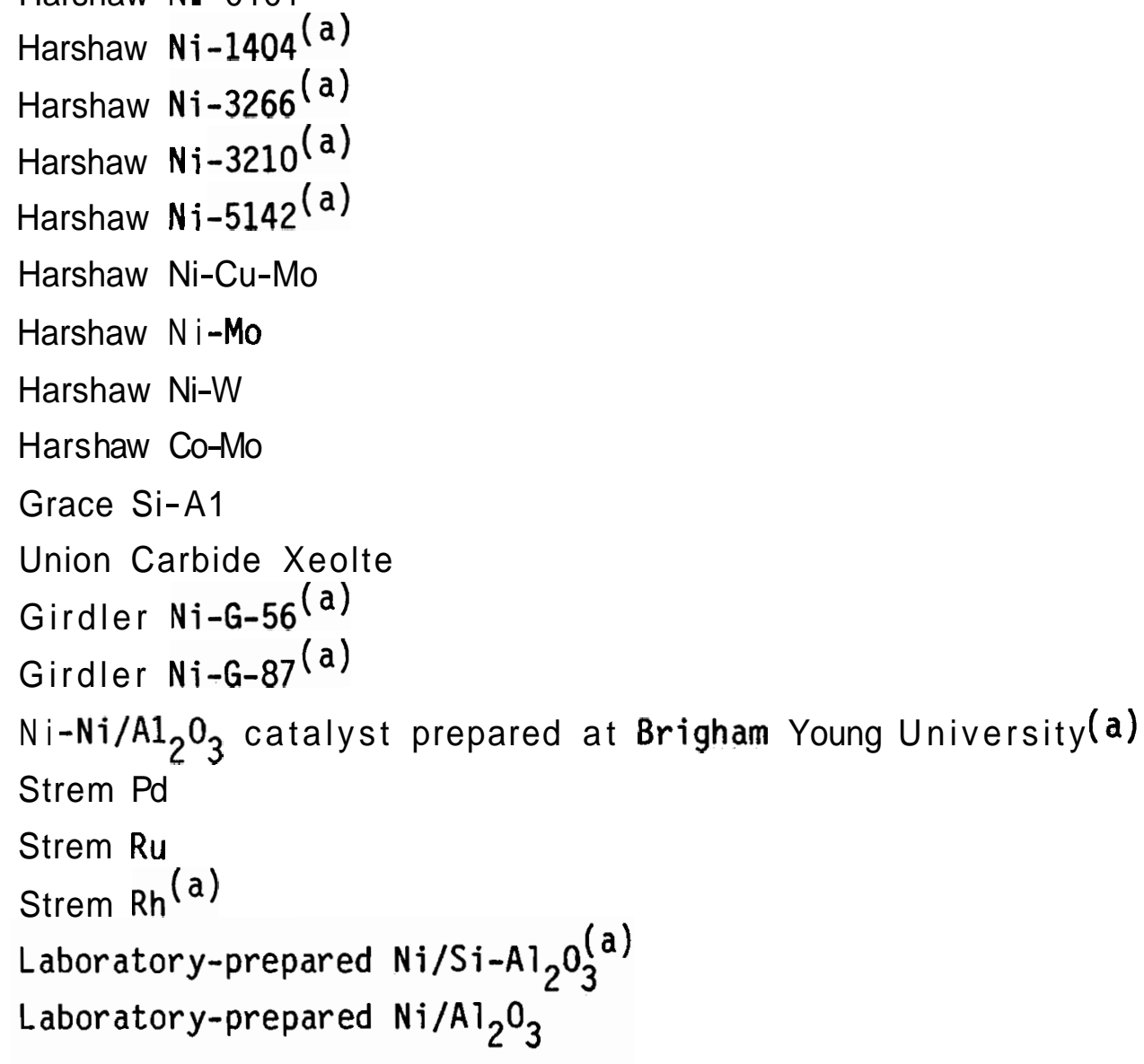

(a) Active for methane generation.

After selection of suitable catalyst systems, attention was focused on catalyst lifetime and regeneration. These studies coincide with the development of a suitable catalyst for operation in the PDU.

Lifetime of a Harshaw Ni-3266 catalyst was determined for generation of a methane-rich gas. Table 10 presents test results and conditions prior to catalyst deactivation. A wood-feed to catalyst weight ratio of 10 was obtained before noticeable loss of catalyst activity. Loss of activity appears to be caused by carbon deposition on the catalyst. The deactivated catalyst was regenerated with steam at $650^{\circ} \mathrm{C}$ to remove carbon from the catalyst surface; 
TABLE 10. Results of a Catalyst Lifetime Test for Methane Production

\begin{tabular}{ll} 
Catalyst & $\mathrm{Ni}-3266$ \\
Reactor Temperature & $560^{\circ} \mathrm{C}-585^{\circ} \mathrm{C}$ \\
Catalyst Bed Temperature & $550^{\circ} \mathrm{C}-560^{\circ} \mathrm{C}$ \\
Wood Feed Rate & $0.29 \mathrm{~g} / \mathrm{min}$ \\
Steam Rate & $0.10 \mathrm{~g} / \mathrm{min}$ \\
Carbon Conversion to a Gas & $68 \%$ \\
Wood-Feed/Catalyst Weight Ratio & 10 \\
(BTU Gas/BTU Wood) x 100 & 66 \\
scf $\mathrm{CH}_{4} /$ ton Dry Wood $\left(\mathrm{nm}^{3} / \mathrm{t}\right)(\mathrm{a})$ & $10,200(320)$ \\
Gas Composition & \\
\multicolumn{1}{l}{$\mathrm{H}_{2}$} & 29.5 vol\% \\
$\mathrm{CO}_{2}$ & 34.3 vol\% \\
$\mathrm{C}_{2} \mathrm{H}_{6}$ & Trace vol\% \\
$\mathrm{CH}_{4}$ & 25.4 vol\% \\
$\mathrm{CO}$ & 10.8 vo $1 \%$
\end{tabular}

(a) Includes methanation of $\mathrm{H}_{2}$ and $\mathrm{CO}$.

this was followed by reduction with hydrogen at a space velocity of $95 \mathrm{~h}^{-1}$ and a temperature of $450^{\circ} \mathrm{C}$. The regenerated catalyst was then subjected to the test conditions employed before deactivation. The regenerated catalyst showed more renewed activity and longer life than the fresh catalyst. A woodfeed to catalyst ratio of 52 was obtained before a second deactivation occurred. Results following regeneration are presented in Table 11. The major difference between gasification results shown in Tables 10 and 11 is a decrease in carbon conversion with the regenerated catalyst, a possible result of some loss in catalyst activity. No further regeneration of the catalyst was attempted.

Catalyst characterization studies were completed on catalysts exposed to gasification conditions for extended periods and on regenerated catalysts. Catalyst characterization equipment items included a hydrogen chemisorption 
TABLE 11. Catalyst Performance Following Catalyst Regeneration

\begin{tabular}{ll} 
Catalyst & $\mathrm{Ni}-3266$ \\
Reactor Temperature & $580^{\circ} \mathrm{C}-600^{\circ} \mathrm{C}$ \\
Catalyst Bed Temperature & $545^{\circ} \mathrm{C}$ to $555^{\circ} \mathrm{C}$ \\
Wood Feed Rate & $0.31 \mathrm{~g} / \mathrm{min}$ \\
Steam Rate & $0.10 \mathrm{~g} / \mathrm{min}$ \\
Carbon Conversion to Gas & $59 \%$ \\
Wood-Feed/Catalyst Weight Ratio & 52 \\
(BTU Gas/BTU Wood) x 100 & 58 \\
scf CH$/$ ton Dry Wood $\left(\mathrm{nm}^{3} / \mathrm{t}\right)^{(\mathrm{a})}$ & $9,300(290)$ \\
Gas Composition & \\
$\mathrm{H}_{2}$ & $33.6 \mathrm{vol} \%$ \\
$\mathrm{CO}_{2}$ & $33.6 \mathrm{vol} \%$ \\
$\mathrm{CH}_{4}$ & $22.5 \mathrm{vol \%}$ \\
$\mathrm{CO}$ & $10.31 \mathrm{vol} \%$ \\
$\mathrm{C}_{2} \mathrm{H}_{6}$ & Trace \\
\hline
\end{tabular}

(a) Includes methanation of $\mathrm{H}_{2}$ and $\mathrm{CO}$.

apparatus, a BET surface area analyzer, a porosimeter, and a scanning electron microscope (SEM) working in conjunction with an electron microprobe (EM). A schematic of the hydrogen chemisorption apparatus is shown in Figure 12. Relative activities of the nickel catalysts are determined by measuring chemisorption of hydrogen on nickel which occurs as follows: $\mathrm{H}_{2}+2 \mathrm{Ni}(\mathrm{s}) \rightarrow 2 \mathrm{NiH}$. Table 12 presents results of surface area studies on a Harshaw Ni-3266 catalyst employed for methane production. A significant decrease in the BET and nickel surface areas occurs upon deactivation (coking).

The pore distribution in a fresh and coked (deactivated) Harshaw Ni-3266 catalyst is shown in Figure 13. The catalyst was coked in operations to generate a methane-rich gas. Coking of the catalyst reduces the concentration of smaller diameter micropores, which explains the drastic loss of BET and nickel surface areas as noted in Table 12. 


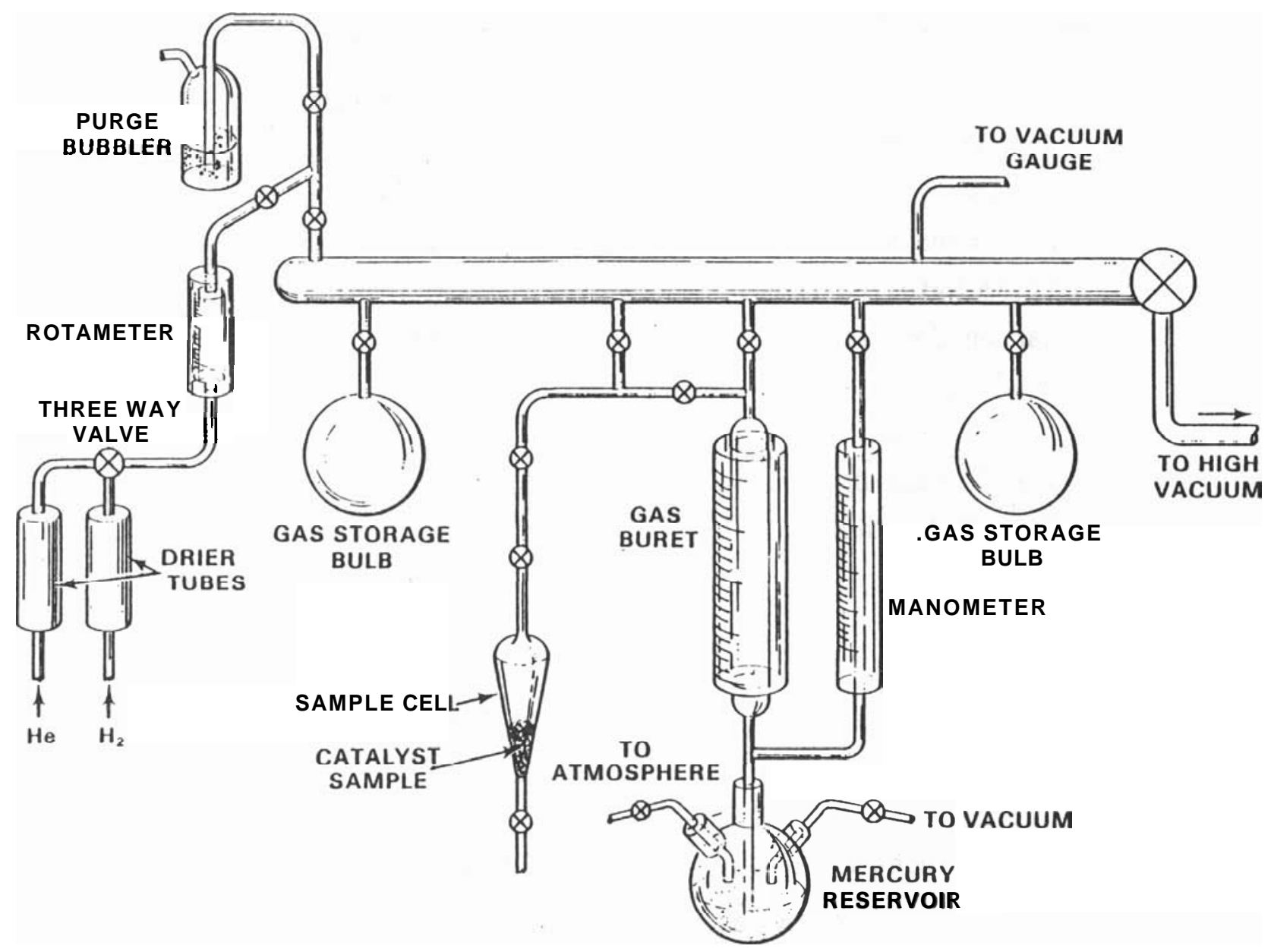

FIGURE 12. Hydrogen Chemisorption Apparatus

TABLE 12. Catalyst Characterization Tests Performed on a Ni-3266 Catalyst Used For Methane Production

BET Surface Area, $\mathrm{m}^{2} / \mathrm{g}$

Nickel Surface Area, $\mathrm{m}^{2} / \mathrm{g}$
Unused $\mathrm{Ni}-3266$ 145

56
Coked $\mathrm{Ni}-3266$

$$
\text { 47-45 }
$$

The SEM was used in conjunction with the EM to study coke deposition on a $\mathrm{NI}-3266$ catalyst. Figure 14 presents a micrograph of a coked Ni-3266 catalyst employed for generation of a methane-rich gas. 


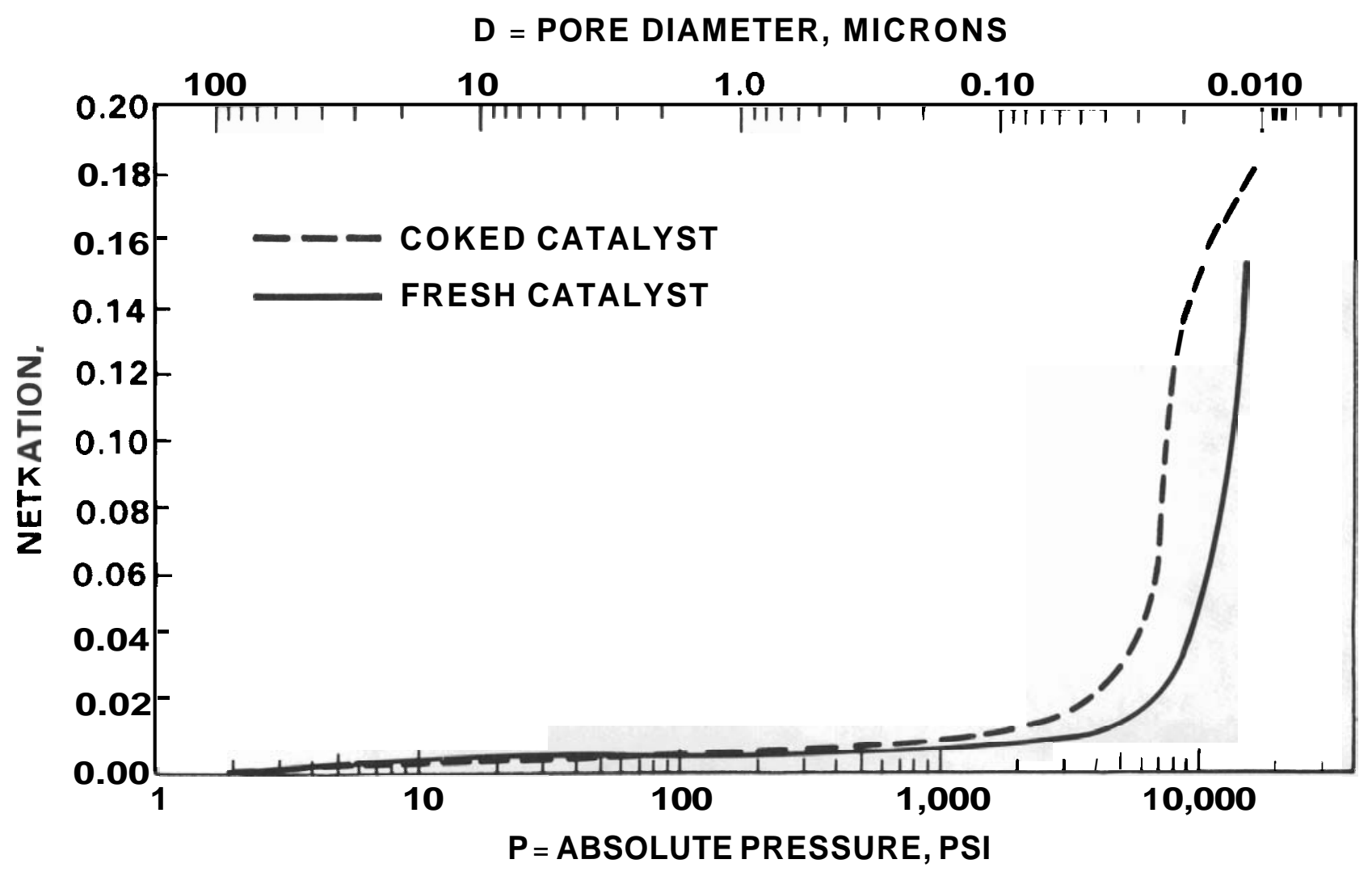

FIGURE 13. Pore Distribution in Fresh and Coked Catalyst

The micrograph shows that the majority of the catalyst surface is covered with carbon. This can be contrasted to a micrograph of a fresh Ni-3266 catalyst shown in Figure 15. The contrast in surface morphology explains why the coked catalyst was inactive. The EM supplies information regarding the relative concentration of surface nickel sites available for reaction. Figure 16 illustrates a comparison of surface nickel concentrations of coked and fresh catalyst. This figure indicates that the catalyst surface is being covered with carbon prohibiting contact of reactants with the active sites on the catalyst. A carbon-hydrogen-nitrogen (CHN) analysis indicated that the carbon content of the coked catalyst was 15 wt\%.

Studies on catalyst lifetime and regeneration are in progress to determine catalyst requirements. Catalyst systems that show favorable activity for generation of a methane-rich gas are also being studied. The weight'ratio of wood 


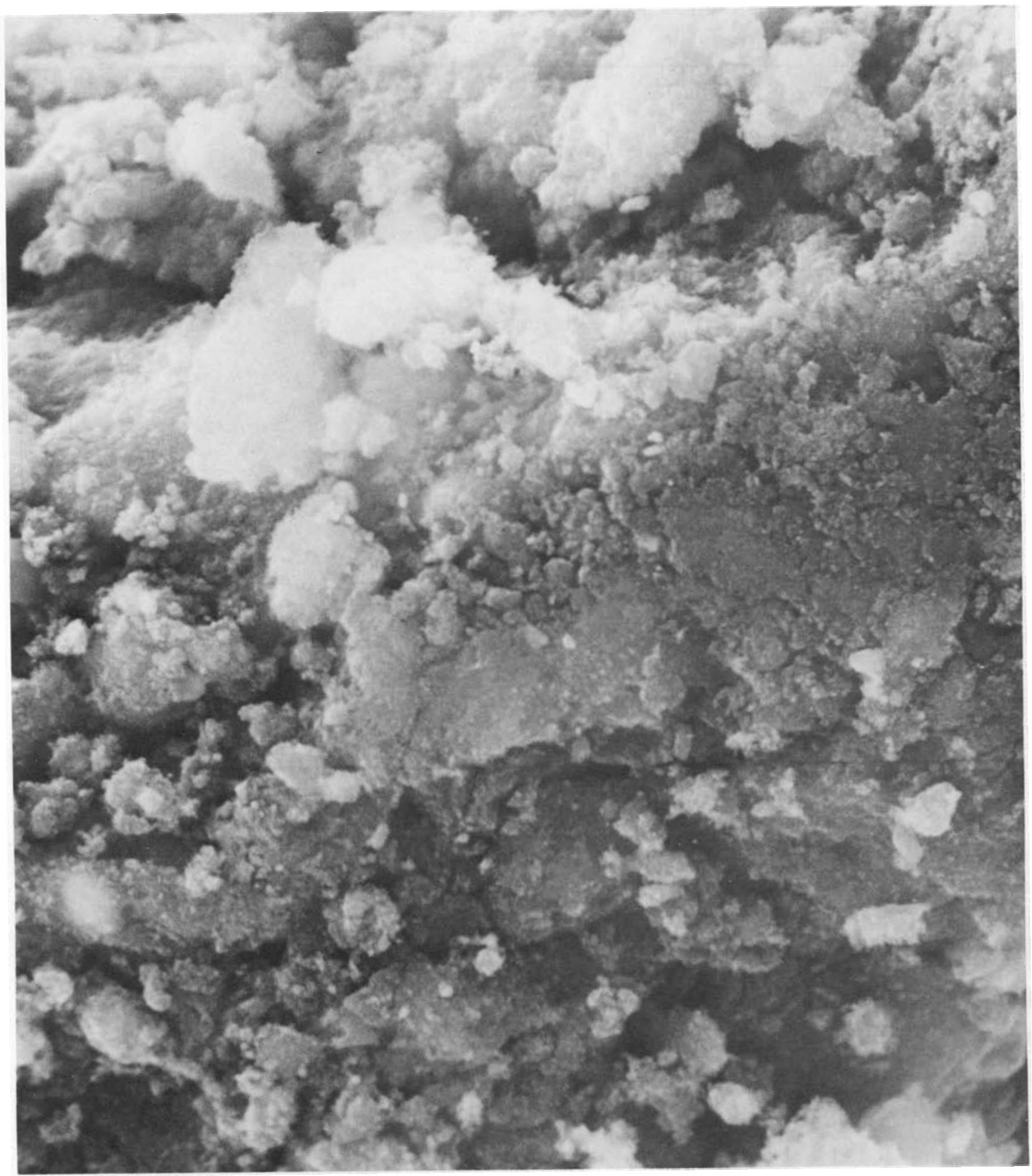

FIGURE 14. Coked Ni-3266 Catalyst, 3340X 


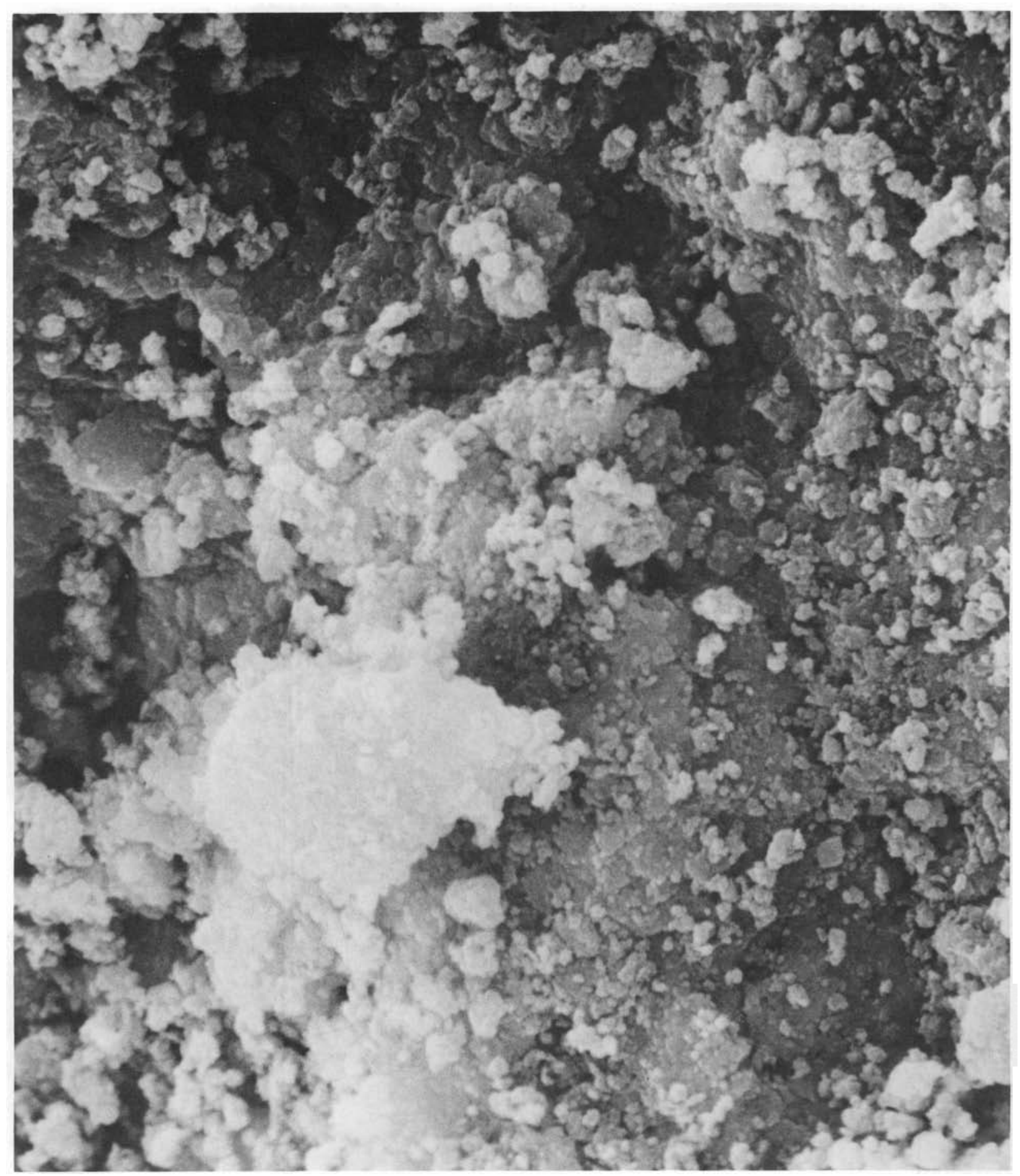

FIGURE 15. Unused $\mathrm{Ni}-3266$ Catalysts, 10,021X 


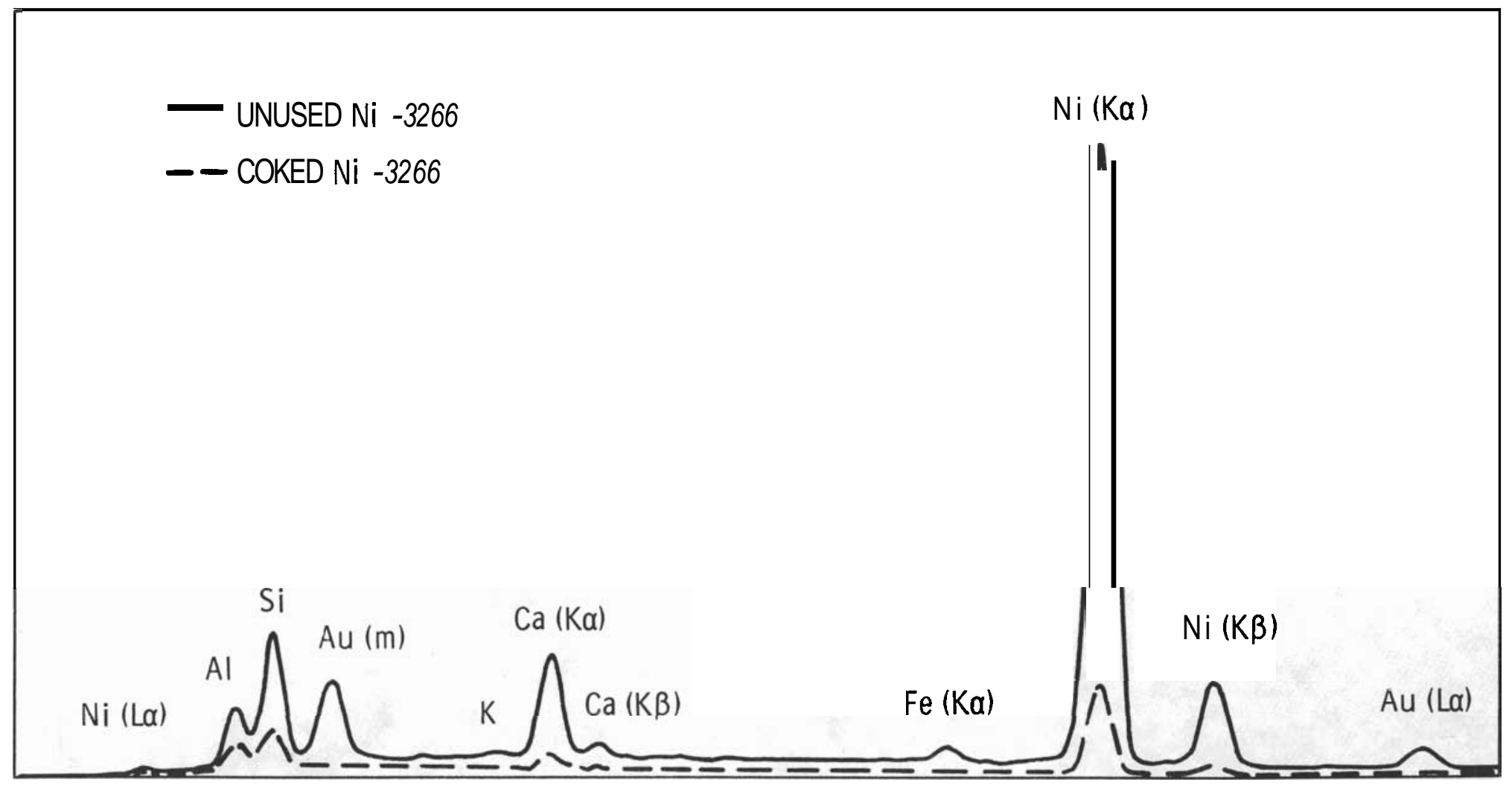

FIGURE 16. Relative Concentrations of Elements on Fresh and Exposed Catalyst Surfaces Employed for Methanantion 
processed to catalyst charge before deactivation is given in Table 13 for the fresh and regenerated catalysts tested to date. A catalyst with an inhibitor for coke deposition should give extended life. Such catalyst systems are being developed.

\section{SYSTEMS FOR GENERATION OF METHANOL SYNTHESIS GAS}

The objective of these studies was to develop catalyst systems and operating conditions for the direct generation of a hydrogen and carbon monoxide gas mixture that could be used for methanol or hydrocarbon synthesis. Treatment of the gas mixture for carbon dioxide removal was intended to be the only necessary operation to make the mixture suitable for methanol synthesis.

A list of catalysts tested for production of a methanol, or hydrocarbon, synthesis gas is presented in Table 14. Favorable activity for synthesis gas generation was observed in some catalysts as noted. Tests of combinations of these catalysts with a primary (alkali carbonate) gasification catalyst showed that gas yields were similar with or without the primary catalyst. Therefore, the primary gasification catalyst was eliminated from further study.

Preliminary tests performed with the Ni-3266 for synthesis gas production looked promising. Typical results are presented in Table 15. At $750^{\circ} \mathrm{C}$ a woodfeed to catalyst charge ratio of 74 was obtained prior to catalyst deactivation. Potential methanol yield is shown as a weight fraction of dry wood.

TABLE 13. Lifetime and Regenerability of Catalysts Tested for Methane Generation

\begin{tabular}{|c|c|c|}
\hline Catalyst & $\begin{array}{l}\text { Wood-Feed to } \\
\text { Fresh Catalyst } \\
\text { Charge Ratio } \\
\end{array}$ & $\begin{array}{l}\text { Wood-Feed To } \\
\text { Catalyst Charge Ratio } \\
\text { Following Regeneration } \\
\end{array}$ \\
\hline Harshaw Ni-3266 & 10 & 52 \\
\hline Laboratory-Prepared $\mathrm{Ni} / \mathrm{Si}-\mathrm{Al}$ & 13 & 6 \\
\hline Laboratory-Prepared $\mathrm{Ni} / \mathrm{Al}_{2} \mathrm{O}_{3}$ & 5 & Not Determined \\
\hline Harshaw Ni-3266 & 28 & Not Determined \\
\hline Ni-3266:Si-A1 (3:1) & 15 & 30 \\
\hline
\end{tabular}


TABLE 14. Catalysts Screened for Methanol Synthesis Gas Production

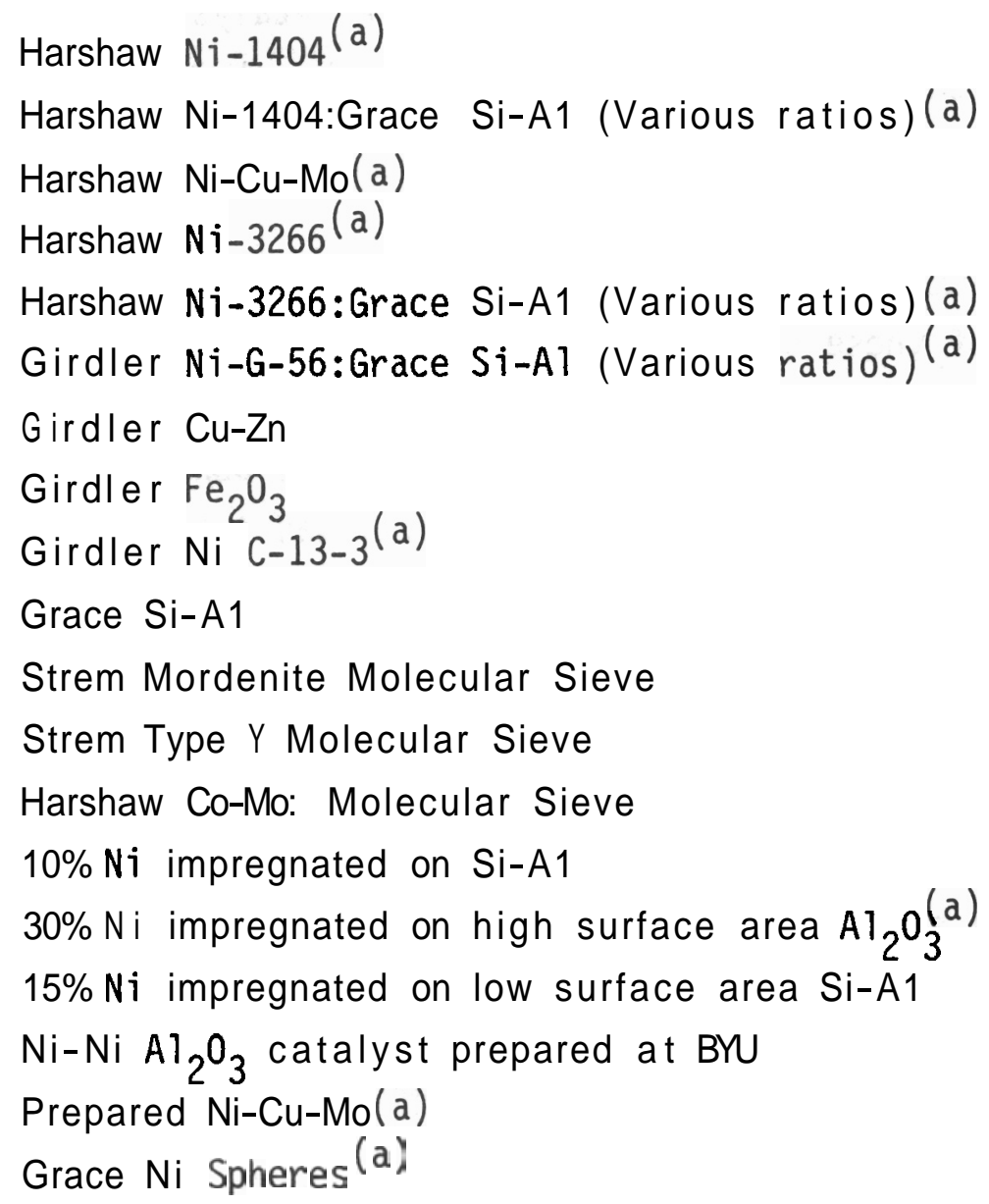

(a) Favorable activity shown

Attempts to regenerate the catalyst with steam gasification of the deposited carbon and subsequent hydrogen reduction were unsuccessful. Catalyst characterization studies were subsequently performed. Table 16 presents BET and hydrogen chemisorption results for the Ni-3266 catalyst before and after testing for synthesis gas production.

The pore distribution determined for fresh and regenerated Ni-3266 catalyst used for synthesis gas generation is shown in Figure 17. The concentration of small diameter micropores is obviously drastically decreased in the regenerated catalyst. This decrease results in loss of overall and active surface area as shown in Table 16. 
TABLE 15. Results of a Catalyst Lifetime Test for Hydrocarbon Synthesis Gas Production

Catalyst

Reactor Temperature

Catalyst Bed Temperature

Wood Feed Rate

Steam Feed Rate

Carbon Conversion to a gas

Wood-Feed/Catalyst Weight Ratio

$\mathrm{H}_{2} / \mathrm{CO}$ Mole Ratio

(BTU Gas/BTU Wood) x 100

Potential Weight Fraction Wood as Methanol
$\mathrm{Ni}-3266$

$770^{\circ} \mathrm{C}$ to $825^{\circ} \mathrm{C}$

$745^{\circ} \mathrm{C}$ to $760^{\circ} \mathrm{C}$

$0.23 \mathrm{~g} / \mathrm{min}$

$0.20 \mathrm{~g} / \mathrm{min}$

$90 \%$

74

1.96

99

0.66

Gas Composition

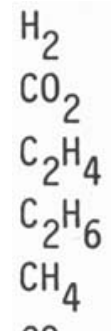

$\mathrm{CO}$
53.0 vol\%

16.9 vo1\%

Trace vol\%

Trace vol\%

3.1 vol\%

27.0 vol\%

TABLE 16. Characteristics of a Ni-3266 Catalyst Employed for Synthesis Gas Production

BET Surface Area, $\mathrm{m}^{2} / \mathrm{g}$

Nickel Surface Area, $\mathrm{m}^{2} / \mathrm{g}$ $\underline{\text { Unused }} \quad \underline{\text { Regenerated }}$

$145 \quad 1.4$

$56 \quad 0.4$

The inability to restore catalyst activity was undoubtedly the result of this permanent loss of active surface sites. SEM studies show similar results. Figure 18 shows a micrograph of a regenerated Ni-3266 catalyst. Contrasting this with the micrograph of an unused catalyst presented earlier in Figure 15 reveals a decrease in surface concentration of active sites on regenerated 


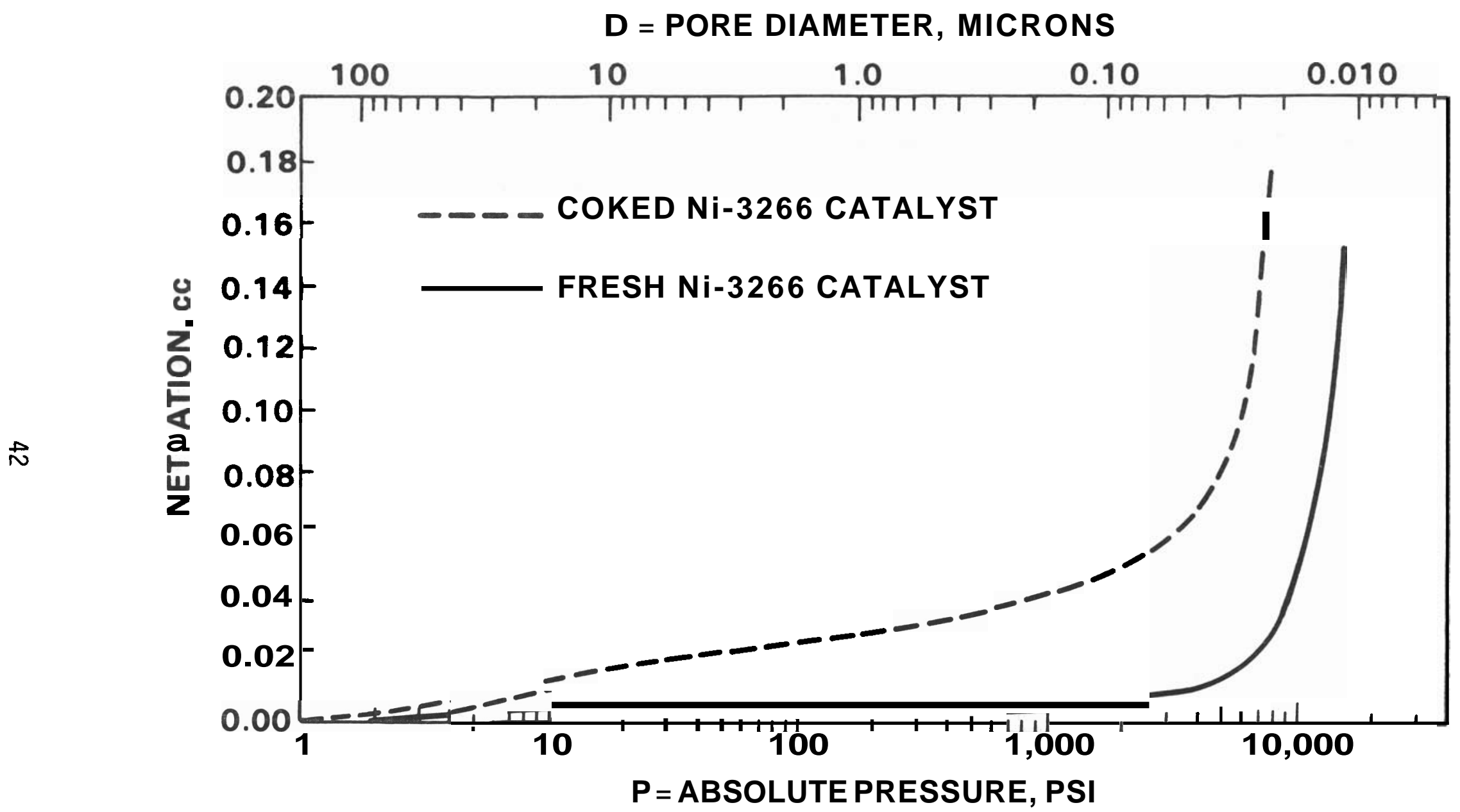

FIGURE 17. Pore Distribution in Catalyst Used for Synthesis Gas Generation 


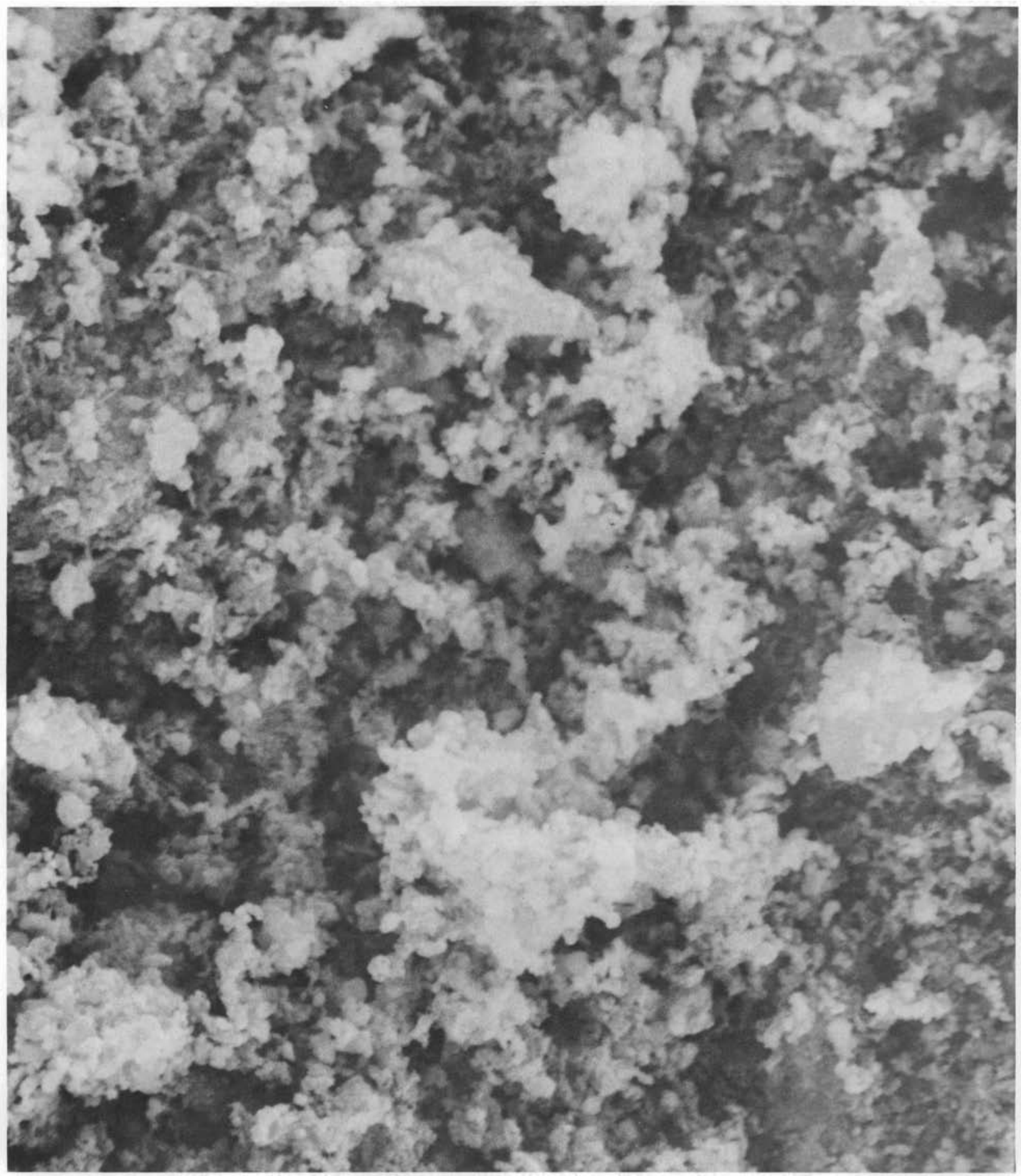

FIGURE 18. Regenerated $\mathrm{Ni}-3266$ Catalyst Employed For Hydrocarbon Synthesis Gas Production, 10,021X 
catalyst. This indicates that the regenerated catalyst has been sintered and supports the data presented in Table 16 and the pore distribution determinations.

A SEM was used in conjunction with an EM to examine the surface changes of a Ni-3266 catalyst with exposure to conditions for synthesis gas generation. Catalyst samples were removed from the reactor at various exposure times in a test for generation of synthesis gas. The micrographs presented in Figures 19 through 24 show the gradual buildup of char (carbon) on the nickel catalyst with increased exposure time. The pore spaces are filled initially, see Figure 21, which decreases the surface area available for reaction. Carbon continues to deposit on the catalyst until layers coat the surface, see Figure 22. Figures 23 and 24 show that the surface is completely coated with layers of carbon after exposure times of 88 and $117 \mathrm{~h}$, respectively.

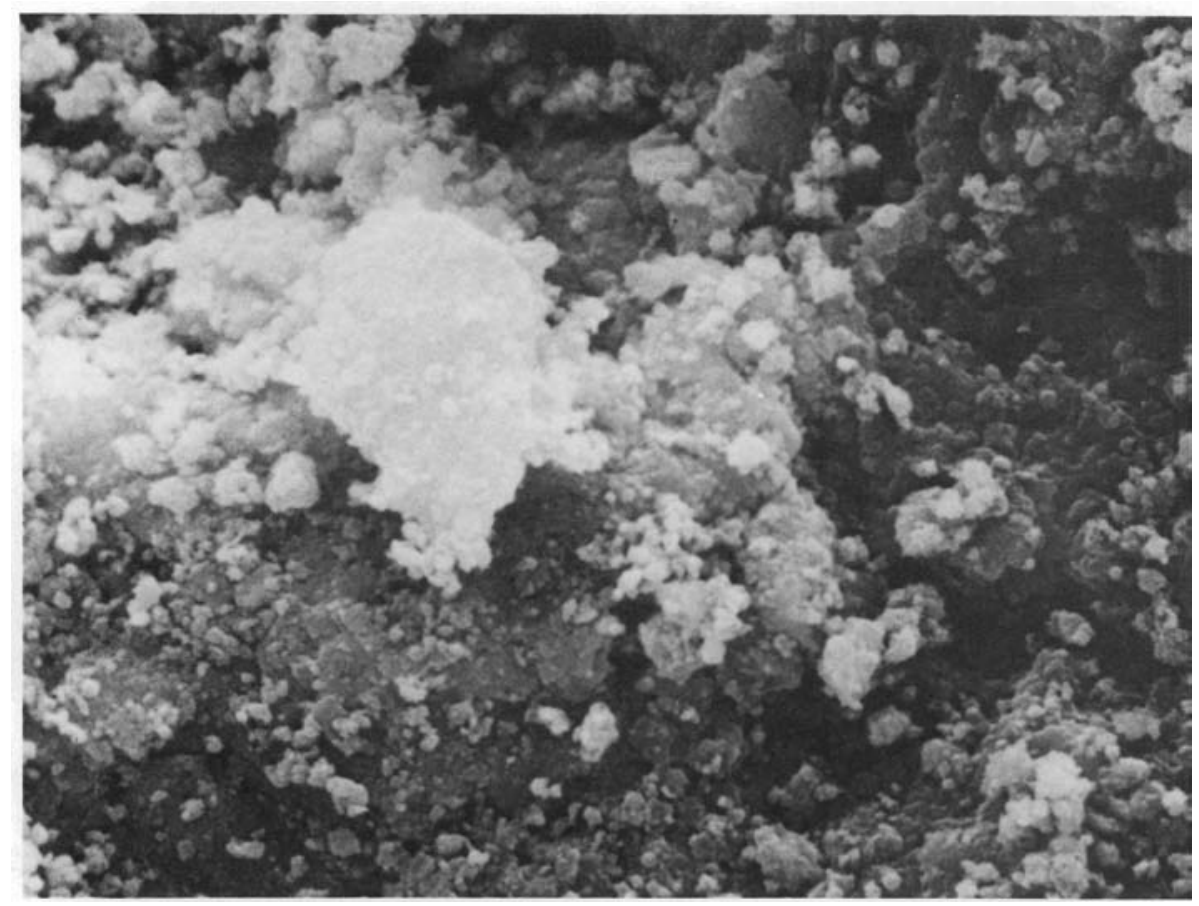

FIGURE 19. SEM Micrograph of Fresh Ni-3266, 3960X 


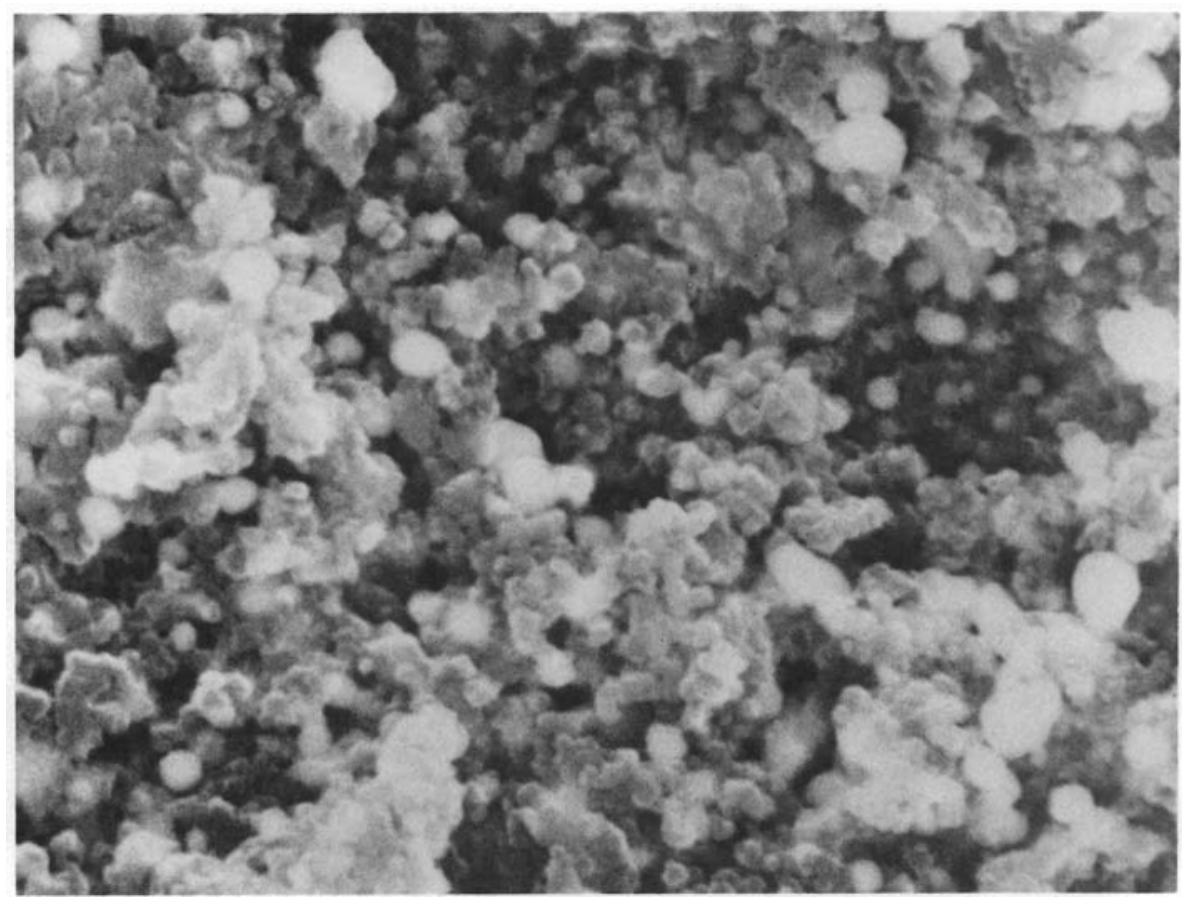

FIGURE 20. $\$ 9 M$ Micrograph of Ni-3266 After $28.6 \mathrm{~h}$ of Operation, 13,200x

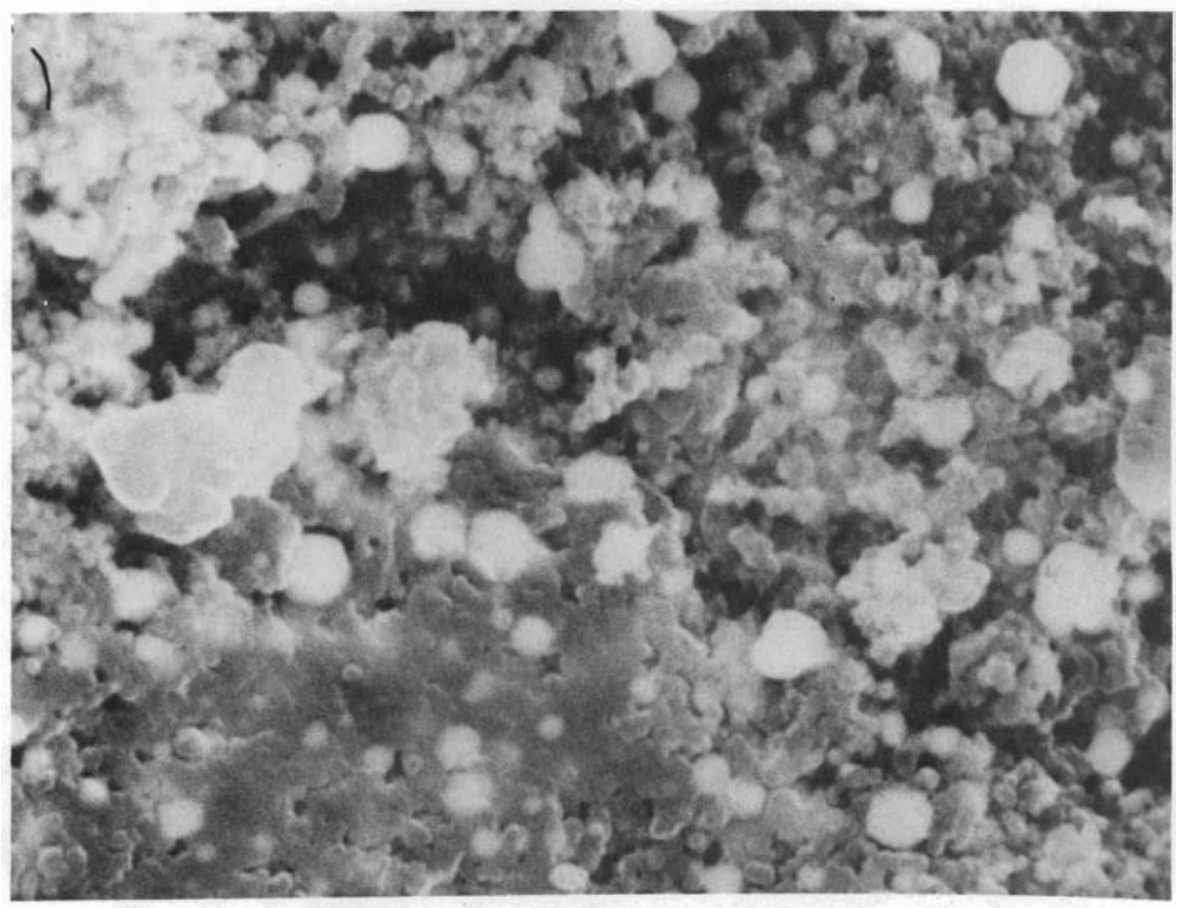

FIGURE 21. SEM Micrograph of Ni-3266 After $61 \mathrm{~h}$ of Operation, 13,200X 


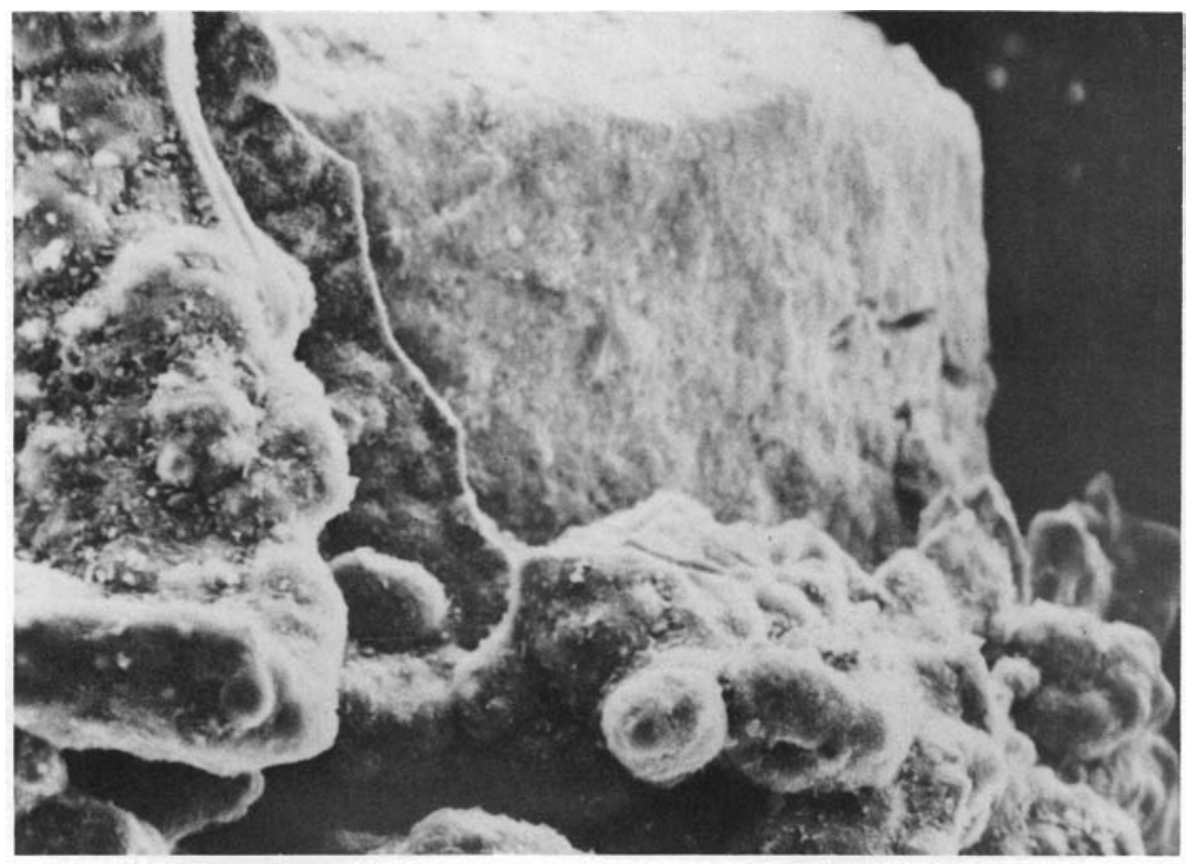

FIGURE 22. SEM Micrograph of Carbon Layers on Ni-3266 After $72 \mathrm{~h}$ of Operation, 132X

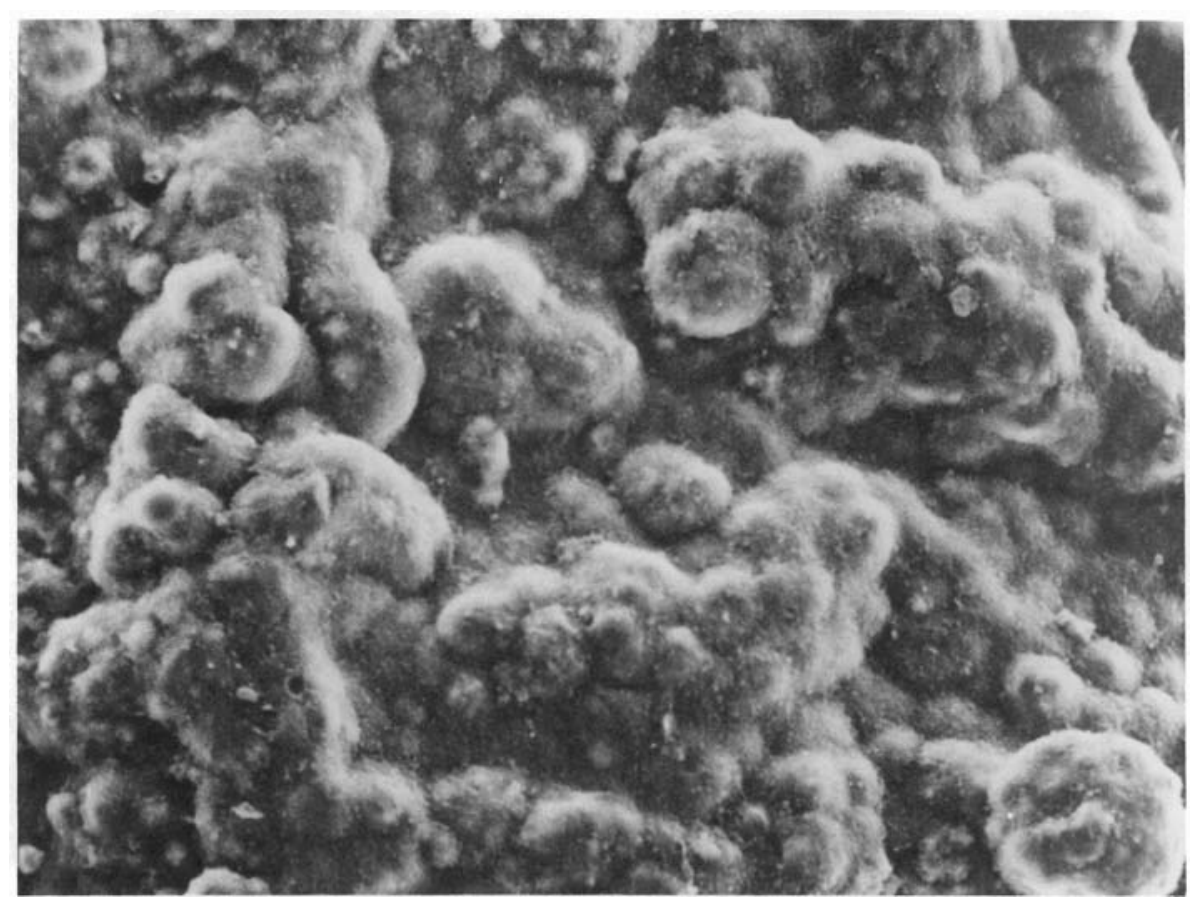

FIGURE 23. SEM Micrograph of Coked Ni-3266 After $88 \mathrm{~h}$ of Operation, $132 \mathrm{X}$ 


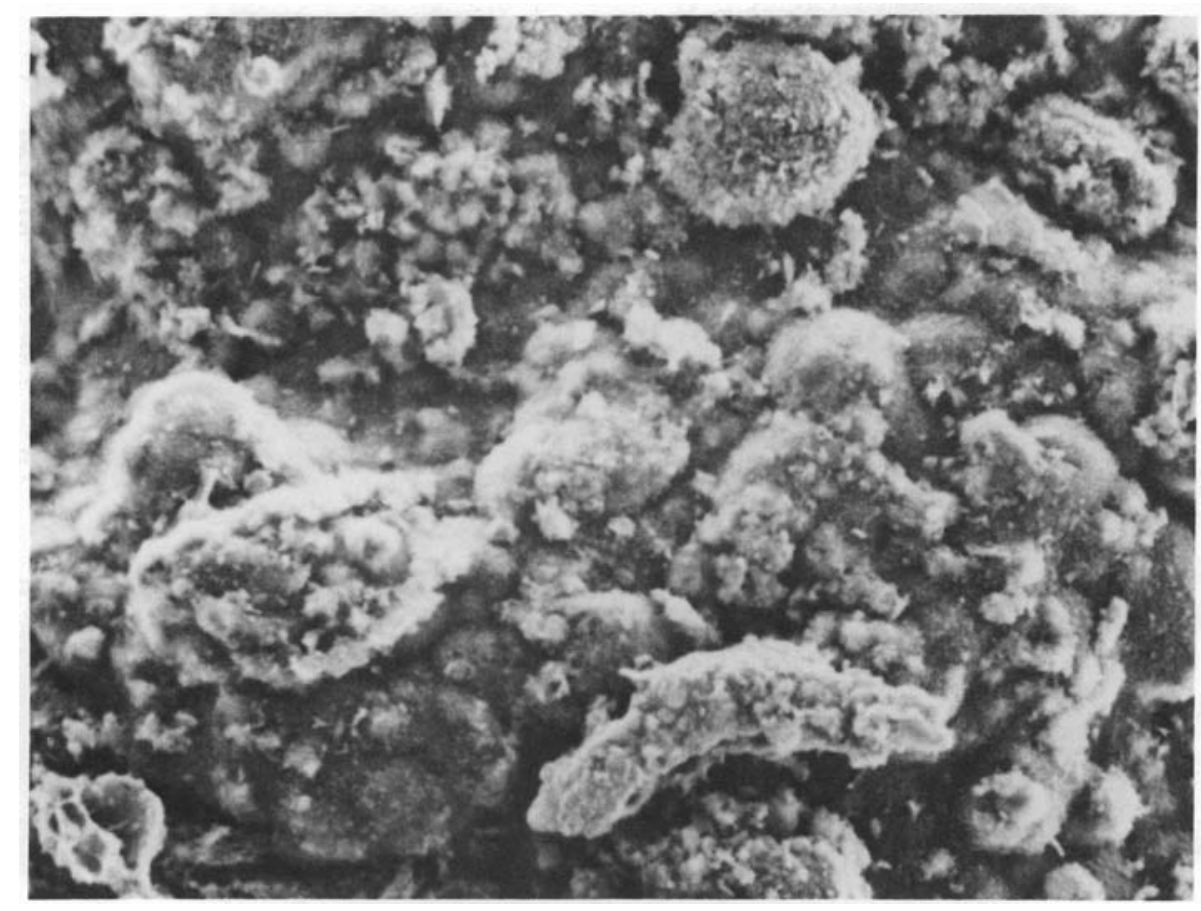

FIGURE 24. SEM Micrograph of Coked Ni-3266 After $117 \mathrm{~h}$ of Operation, 132X

Electron microprobe scans of the exposed catalyst surfaces are shown in Figure 25. The relative concentrations of nickel, silicon and aluminum decrease with catalyst exposure time. The gradual decrease in the nickel peak, with exposure time, further indicates that the catalyst surface is being coated with carbon.

As a result of the inability to regenerate the Ni-3266 catalyst, attention was shifted to evaluation of a Ni-Cu-Mo alloy catalyst on an alumina support for synthesis gas generation. Preliminary studies with this alloy catalyst for synthesis gas generation has indicated excellent resistance to carbon deposition. Work on methanation reactions with a Ni-Cu alloy catalyst by Araki and Ponec (1976) demonstrated that the presence of copper dilutes the number of nickel sites, thus inhibiting carbon formation. Therefore, an alloy catalyst for synthesis gas production may have the lifetime needed for economic feasibility. 


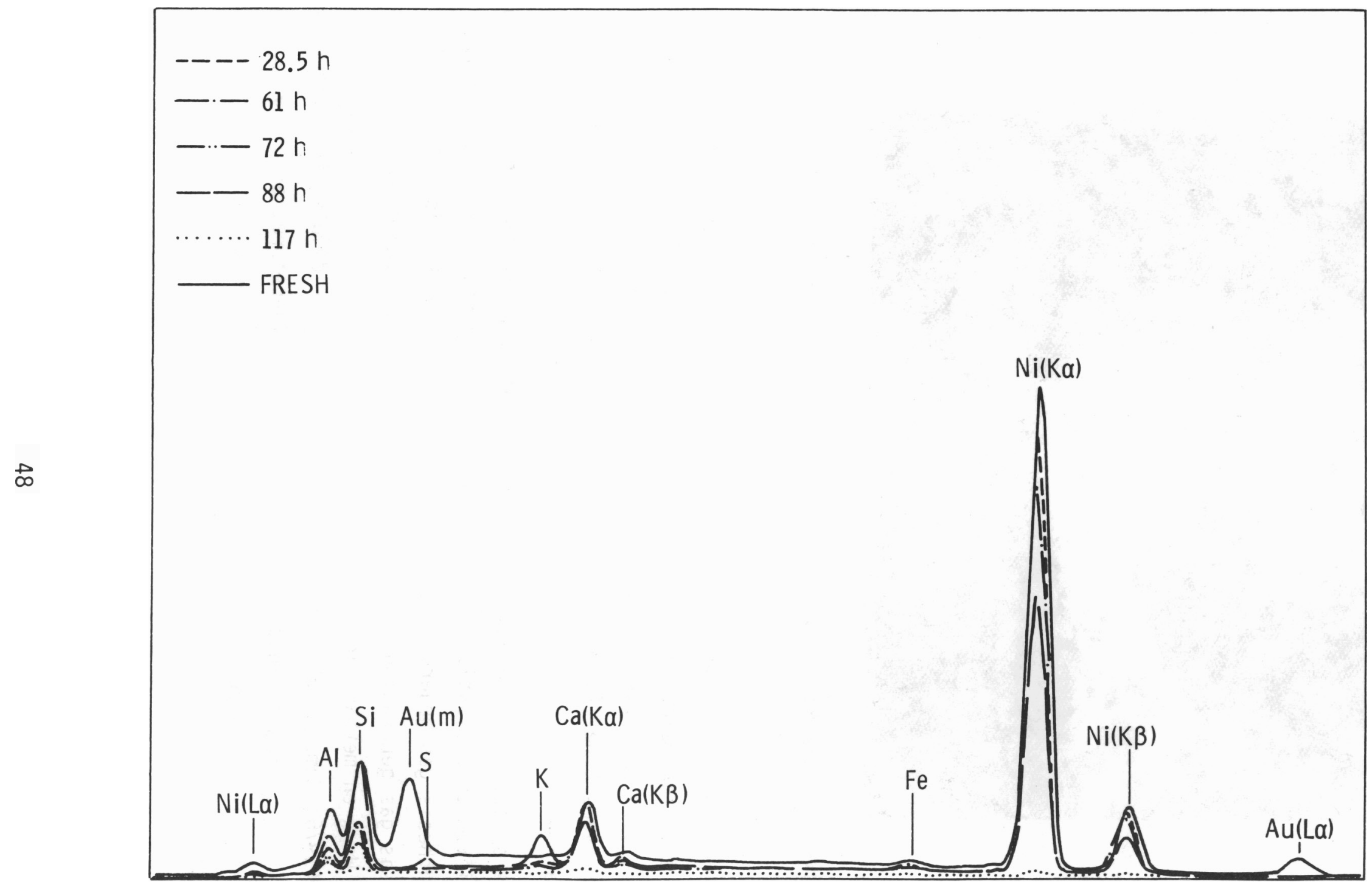

FIGURE 25. Relative Concentrations of Exposed Elements on Ni-3266 Catalyst Surfaces 
Experiments to evaluate a Harshaw Ni-Cu-Mo alloy catalyst on alumina showed a significant increase in catalyst lifetime. Data in Table 17 present average results obtained with the alloy catalyst. Early in the experiment, catalyst activity decreased slightly. No further change in activity occurred for the next $175 \mathrm{~h}$. Although still active, the catalyst was then subjected to regeneration with steam at $800^{\circ} \mathrm{C}$ followed by hydrogen reduction at $450^{\circ} \mathrm{C}$. Catalyst activity was restored to that of the original catalyst by this procedure. The experiment was continued for an additional $210 \mathrm{~h}$ with only the initial slight deactivation. Regeneration again restored the slight activity lost after which the experiment was continued another $24 \mathrm{~h}$ before the catalyst was removed for characterization studies.

TABLE 17. Use of a $\mathrm{Ni}-\mathrm{Cu}-\mathrm{Mo} / \mathrm{Al}_{2} \mathrm{O}_{3}$ Catalyst for Synthesis Gas Generation

$\begin{array}{ll}\text { Reactor Temperature } & 740^{\circ} \mathrm{C} \text { to } 805^{\circ} \mathrm{C} \\ \text { Catalyst Temperature } & 745^{\circ} \mathrm{C} \text { to } 765^{\circ} \mathrm{C} \\ \text { Wood Feed Rate } & 0.23 \mathrm{~g} / \mathrm{min} \\ \text { Steam Rate } & 0.20 \mathrm{~g} / \mathrm{min} \\ \text { Wood Feed/Catalyst Weight Ratio } & 188.0 \\ \text { Carbon Conversion to a Gas } & 85.0 \% \\ \text { (BTU Gas/BTU Wood) x } 100 & 94.6 \\ \mathrm{H}_{2} / \mathrm{CO} \text { Ratio } & 2.03 \\ \text { Gas Composition } & \\ \mathrm{H}_{2} & 51.4 \mathrm{vo} 1 \% \\ \mathrm{CO} & 25.3 \mathrm{vo} 1 \% \\ \mathrm{CO}_{2} & 17.8 \mathrm{vo} 1 \% \\ \mathrm{CH}_{4} & 5.2 \mathrm{vo} 1 \% \\ \mathrm{C}_{2} \mathrm{H}_{6} & 0.2 \mathrm{vo} 1 \%\end{array}$

Lifetime and regenerability of catalysts tested to date are presented in Table 18. Conclusions derived from the catalyst systems studied for hydrocarbon synthesis gas production are given below: 
- Properties of the most effective catalyst tested for the production of a methane-rich gas include a nickel content of 30 wt $\%$ or greater, an acidic support, a BET surface area of $100 \mathrm{~m}^{2} / \mathrm{g}$ or greater, and a nickel surface area of $30 \mathrm{~m}^{2} / \mathrm{g}$ or greater.

- The nickel catalyst lifetime employed for methane production is short. However, the catalyst is regenerable with steam and subsequent hydrogen reduction. Further tests need to be completed to determine the nickel catalyst activity after repeated regenerations.

- A Ni-Cu-Mo alloy catalyst looks promising for hydrocarbon synthesis gas production, exhibiting good catalyst lifetime as well as regenerability.

TABLE 18. Lifetime and Regenerability of Catalysts Tested for Hydrocarbon Synthesis Gas Production at $750^{\circ} \mathrm{C}$

\begin{tabular}{|c|c|c|}
\hline Catalyst & $\begin{array}{l}\text { Wood-Feed } \\
\text { to Catalyst } \\
\text { Charge Ratio } \\
\end{array}$ & $\begin{array}{c}\text { Wood-Feed to Catalyst } \\
\text { Charge Ratio } \\
\text { Fol lowing Regeneration }\end{array}$ \\
\hline Harshaw Ni-Cu-Mo & 188 & (a) \\
\hline Harshaw Ni-3266 & 74 & 4.4 \\
\hline Grace Si-A1 & $100^{(b)}$ & \\
\hline Harshaw Ni-1404 & 52 & 5 \\
\hline Girdler C-13-3 & 17 & Not Determined \\
\hline $\begin{array}{l}\text { Prepared Ni-Cu-Mo } \\
15 \% \mathrm{Ni} \text { On Low Surface }\end{array}$ & 30 & 1st:23 2nd:10 \\
\hline $\begin{array}{l}\text { Area Support } \\
30 \% \mathrm{Ni} \text { On High Surface }\end{array}$ & 17 & 18 \\
\hline Area Support & 50 & $1 s t: 16$ \\
\hline Grace Ni Spheres & 70 & Not Determined \\
\hline
\end{tabular}

(a) ' No deactivation - was subjected to regeneration scheme twice. (b) No deactivation at $850^{\circ} \mathrm{C}$. 
SYSTEMS FOR GENERATION OF AMMONIA SYNTHESIS GAS

The objective of these studies was to generate a gas mixture with the proper hydrogen-to-nitrogen ratio for ammonia synthesis. The gas mixture is produced by reacting air, steam and wood in the presence of catalysts. A summary of catalyst systems tested is given in Table 19.

\author{
TABLE 19. Catalyst Systems Tested for Ammonia \\ Synthesis Gas Production \\ Girdler G-3 Fe-Cr: Strem Si-A1 (3:1) \\ Girdler 6-93 Co-Mo \\ Girdler G-3 $\mathrm{Fe}-\mathrm{Cr}$ \\ Girdler G-9 Cu-Mn \\ Harshaw HT-100 Ni-Mo \\ Girdler G-101 $\mathrm{V}_{2} \mathrm{O}_{5}$ : Strem Si-Al (3:1) \\ Girdler 6-66 A Cu-Zn \\ Harshaw $0301 \mathrm{Fe}_{2} \mathrm{O}_{3}$
}

Effective catalyst systems for ammonia synthesis gas production were found to be combinations of primary and secondary catalysts. The primary catalyst was potassium carbonte (17 wt\%) impregnated in the wood, and the secondary catalyst was a Girdler 6-93 cobalt molybdate: silica-alumina (Si-A1) system at a weight ratio of $3: 1$ respectively, or a Girdler G-3 chromium promoted iron oxide and silica-alumina at a weight ratio of $3: 1$. Typical results using the Girdler G-3 catalyst with the silica-alumina are given in Table 20.

Various operating parameters, temperature, steam space velocity, and wood-feed rate, were studied for production of ammonia synthesis gas. Results obtained using the 6-93 Co-Mo CO shift catalyst are presented in Table 21. Examination of the $\mathrm{CO}$ concentrations presented in Table 21 shows that increasing the steam rate decreases the $\mathrm{CO}$ concentration via the water gas shift reaction ( $\mathrm{CO}+\mathrm{H}_{2} \mathrm{O}-\mathrm{CO}_{2}+\mathrm{H}_{2}$ ) and that a gas consisting almost entirely of $\mathrm{H}_{2}, \mathrm{~N}_{2}$ and $\mathrm{CO}_{2}$ is produced. Carbon monoxide yields as low as 2\% were 
TABLE 20. Experimental Results of Lodgepole Wood Impregnated with 17\%

$\mathrm{K}_{2} \mathrm{CO}_{3}$ in the Presence of Air, Steam, Girdler $\mathbf{G - 3}$ and Si-Al Catalysts

$\begin{array}{lc}\text { Secondary Catalyst } & \mathrm{Fe}-\mathrm{Cr} / \mathrm{Si}-\mathrm{Al}(3: 1) \\ \text { Reactor Temperature } & 655^{\circ} \mathrm{C} \\ \text { Catalytic Bed Temperature } & 625{ }^{\circ} \mathrm{C} \text { to } 680^{\circ} \mathrm{C} \\ \text { Air Rate } & 0.2 \mathrm{~L} / \mathrm{min} \\ \text { Wood Feed Rate } & 0.4 \mathrm{~g} / \mathrm{min} \\ \text { Carbon Conversion to a Gas } & 67 \% \\ \mathrm{H}_{2} / \mathrm{N}_{2} \text { Ratio } & 3.1 \\ \text { Cold Gas Efficiency } & 74 \% \\ \text { Gas Composition } & \\ \mathrm{H}_{2} & 53.4 \mathrm{vol} \% \\ \mathrm{~N}_{2} & 17.0 \mathrm{vol} \% \\ \mathrm{CO}^{2} & 3.3 \text { vol\% } \\ \mathrm{CO}_{2} & 22.9 \text { vol\% } \\ \mathrm{CH}_{4} & 2.4 \text { vol\% } \\ \mathrm{C}_{2} \mathrm{H}_{4} & 0.1 \mathrm{vol} \% \\ \mathrm{C}_{2} \mathrm{H}_{6} & 0.1 \text { vol\% }\end{array}$

obtained by increasing steam rates. The increased steam rate magnifies the water gas shift reaction thus producing more $\mathrm{H}_{2}$ and $\mathrm{CO}_{2}$, and less $\mathrm{CO}$. Typical results obtained by increasing steam rates while at the same time maintaining the $\mathrm{H}_{2}: \mathrm{N}_{2}$ ratio at $3: 1$ are included in Table 21 .

Major conclusions of the completed ammonia synthesis gas studies are summarized below:

- Girdler G-3 chromium-promoted iron oxide or a Girdler 6-93 cobaltmolybdate $\mathrm{CO}$ shift catalyst produced an optimum $\mathrm{H}_{2}: \mathrm{N}_{2}$ ratio of $3: 1$. Of the catalysts tested, these catalysts produced the highest overall conversions (65\%) to the gaseous phase while maintaining the desired product yields. 
TABLE 21. Experimental Results of Lodgepole Wood Impregnated with $17 \% \mathrm{~K}_{2} \mathrm{CO}_{3}$ in the Presence of Air, Steam, and Commercial Girdler 6-93 c0 Shift Catalyst

\begin{tabular}{|c|c|c|c|c|}
\hline & \multicolumn{4}{|c|}{ Steam Rate } \\
\hline & $0.64 \mathrm{~g} / \mathrm{min}$ & $1.0 \mathrm{~g} / \mathrm{min}$ & $1.2 \mathrm{~g} / \mathrm{min}$ & $1.6 \mathrm{~g} / \mathrm{min}$ \\
\hline Run number & $6-5$ & $6-5$ & $6-13$ & $6-13$ \\
\hline Secondary Catalyst & Co-Mo & Co-Mo & Co-Mo & Co-Mo \\
\hline Reactor Temperature, ${ }^{\circ} \mathrm{C}$ & 650 & 650 & 650 & 650 \\
\hline $\begin{array}{l}\text { Catalyst Bed Temperature, } \\
{ }^{\circ} \mathrm{C}\end{array}$ & 675 & $645-675$ & $640-670$ & $645-670$ \\
\hline A ir Rate L/min & 0.2 & 0.2 & 0.2 & 0.2 \\
\hline Wood Feed Rate, g/min & 0.4 & 0.4 & 0.5 & 0.4 \\
\hline $\mathrm{H}_{2} / \mathrm{N}_{2}$ Ratio & 3.0 & 2.9 & 2.6 & 3.1 \\
\hline Cold Gas Efficiency, \% & 86 & 72 & 58 & 48 \\
\hline Gas Composition, vol\% & & & & \\
\hline $\mathrm{H}_{2}$ & 50.7 & 53.1 & 50.6 & 52.8 \\
\hline $\mathrm{N}_{2}$ & 17.1 & 18.1 & 19.3 & 16.8 \\
\hline $\mathrm{CO}$ & 7.3 & 4.1 & 4.6 & 2.9 \\
\hline $\mathrm{CO}_{2}$ & 21.2 & 23.1 & 23.3 & 25.0 \\
\hline $\mathrm{CH}_{4}$ & 2.7 & 0.8 & 0.8 & 1.6 \\
\hline $\mathrm{C}_{2} \mathrm{H}_{4}$ & 0.1 & 0 & 0.1 & 0.1 \\
\hline $\mathrm{C}_{2} \mathrm{H}_{6}$ & 0.2 & 0 & 0.1 & 0.1 \\
\hline
\end{tabular}

- A maximum steam rate of 4 times the wood feed rate produced $\mathrm{CO}$ yields as low as $2 \%$ by volume for both catalyst systems described above.

- An air inlet rate of approximately $40 \%$ by weight of the wood feed rate produced the desired $\mathrm{H}_{2}: \mathrm{N}_{2}$ ratio for both catalyst systems.

- Steam gasification rates at $550^{\circ} \mathrm{C}$ are too low to maintain a desired $\mathrm{H}_{2}: \mathrm{N}_{2}$ ratio of $3: 1$ at a significant gas production rate. Constant wood feed rates are critical in maintaining a $3: 1 \mathrm{H}_{2}: \mathrm{N}_{2}$ product ratio.

- An increase in temperature enhances the overall conversion to gaseous products. 
SYSTEMS FOR GENERATION OF HYDROGEN

The objective of these studies was to select catalysts and operating conditions for the direct production of hydrogen. A total of 22 experimental runs were completed. The catalysts tested are presented in Table 22. Various operating parameters and catalyst systems were investigated. Twelve specific catalyst systems were evaluated, and three temperature ranges $\left(550^{\circ} \mathrm{C}, 650^{\circ} \mathrm{C}\right.$, and $750^{\circ} \mathrm{C}$ ) were studied.

Two catalyst systems were found to be effective for hydrogen production: 1) Girdler Fe-Cr $\mathrm{CO}$ shift catalyst and a Harshaw Ni-1404 catalyst in a weight ratio of 3:1, respectively, and 2) Girdler 6-93 Co-Mo CO shift catalyst and Ni-1404 with the same 3:1 ratio. In all cases the wood feed was impregnated with 17 wto potassium carbonate. Table 23 presents typical results employing preferred catalysts at each temperature range. Data presented in Table 23 show that 64 vo $1 \%$ hydrogen is obtained with a carbon conversion to gas of $78 \%$

TABLE 22. Catalysts Tested for Hydrogen Production Studies

Girdler G-3 $\mathrm{Fe}-\mathrm{Cr}$

Girdler 6-93 Co-Mo

Girdler 6-64 $\mathrm{Fe}_{2} \mathrm{O}_{3}$

Girdler 6-64 $\mathrm{Fe}_{2} \mathrm{O}_{3}$ : Girdler 6-72 D Zno (1:1)

Strem Si-A1

Girdler G-3 Fe-Cr:Grace Si-A1 (1:1), (2:1), (3:1)

Girdler 6-66 $\mathrm{Cu}-\mathrm{Zn}$

Girdler G-3 Fe-Cr:Harshaw Ni-1404 (3:1)

Girdler 6-93 Co-Mo:Grace Si-A1 (2:1)

Girdler G-3 Fe-Cr:Grace Si-Al:Harshaw Ni1404 (4:2:1)

Girdler 6-93 Co-Mo:Harshaw Ni-1404 (1:1) 
TABLE 23. Typical Results for Lodgepole Wood Impregnated with $17 \mathrm{wt} \% \mathrm{~K}_{2} \mathrm{CO}_{3}$ in the Presence of Steam and Catalysts

Catalyst

Steam Rate, $\mathrm{g} / \mathrm{min}$

Wood Feed Rate, g/min

Cold Gas Efficiency, \%

Carbon Conversion

$$
\text { to Gases, \% }
$$

Gas Composition, vo $1 \%$

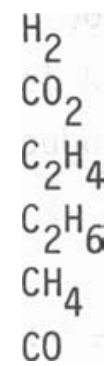

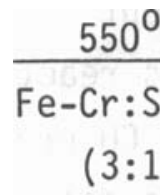

0.4

0.5

11

34

38.2

49.8

0.7

1.2

8.5

1.4

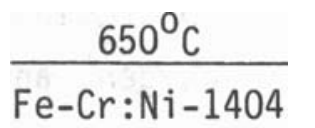

(3:1)

1.7

0.4

79

$\frac{750^{\circ} \mathrm{C}}{\mathrm{Fe}-\mathrm{Cr}: \mathrm{Ni}-1404}$

(3:1)

1.7

0.3

88

78

67

65.4

64.1

30.9

29.9

-- --

--

0.4

$--$

0.2

3.3

5.8

Conclusions from experimental results for the hydrogen production case are:

a $750^{\circ} \mathrm{C}$ is the preferred operating temperature of the three temperatures investigated.

- Hydrogen production is poor at $550^{\circ} \mathrm{C}$.

- Approximately $80 \%$ of the carbon in the wood was converted to gas in tests at $750^{\circ} \mathrm{C}$.

- The two catalyst systems previously described are suitable for hydrogen production.

a High steam-to-wood feed rates (order of $4: 1$ ) are required to obtain the desired $\mathrm{CO}$ shift reaction needed for hydrogen production. 
SYSTEMS FOR GENERATION OF CARBON MONOXIDE

The objective of the CO studies is to optimize the selective production of $\mathrm{CO}$ by employing steam, oxygen, and $\mathrm{CO}_{2}$ as reactants to gasify wood in the presence of catalysts. Maximum results for $\mathrm{CO}$ production obtained up to this point are presented in Table 24. Results to date appear unfavorable. Therefore, the direct production of $\mathrm{CO}$ from biomass is not recommended.

EVALUATION OF ALTERNATIVE BIOMASS MATERIALS

Laboratory studies to investigate the production of hydrocarbon synthesis gas (syngas) from alternative biomass materials were initiated this year. A corn feedstock was examined to determine the applicability of this type of feedstock. A proximate and ultimate analysis of the corn is presented in Table 1. Hydrocarbon synthesis gas studies at $750^{\circ} \mathrm{C}$ indicate that product

TABLE 24. Experimental Results for CO production from Lodgepole Wood

$\begin{array}{ll}\text { Primary Catalyst } & 17 \% \mathrm{~K}_{2} \mathrm{CO}_{3} \\ \text { Secondary Catalyst } & \text { Grace } \mathrm{Si}: \mathrm{Al} \\ \text { Reactor Temperature } & 850^{\circ} \mathrm{C} \\ \text { Catalyst Bed Temperature } & 725^{\circ} \mathrm{C} \text { to } 770^{\circ} \mathrm{C} \\ \text { Wood Feed Rate } & 0.6 \mathrm{~g} / \mathrm{min} \\ \text { Steam Rate } & 0.1 \mathrm{~g} / \mathrm{min} \\ \mathrm{O}_{2} \text { Rate } & 0.08 \mathrm{~g} / \mathrm{min} \\ \mathrm{CO}_{2} \text { Rate } & 1.5 \mathrm{~g} / \mathrm{min} \\ \text { Cold Gas Efficiency } & 127 \% \\ \text { Carbon Conversion to Gas } & 93 \% \\ \text { Gas Composition } & \\ \mathrm{H}_{2} & 15.7 \mathrm{vol} \% \\ \mathrm{CO}_{2} & 43.8 \mathrm{vo} 1 \% \\ \mathrm{C}_{2} \mathrm{H}_{4} & 0.6 \mathrm{vol} \% \\ \mathrm{C}_{2} \mathrm{H}_{6} & 0.1 \mathrm{vol} \% \\ \mathrm{CH}_{4} & 3.1 \mathrm{vol} \% \\ \mathrm{CO} & 36.7 \mathrm{vol} \%\end{array}$


yields and conversion efficiencies for corn and wood are similar. A comparison of steam gasification of corn and wood is depicted in Table 25. A catalyst system consisting of $\mathrm{Ni}-1404 / \mathrm{Si}-\mathrm{Al}$ at a $1: 1$ weight ratio was found to be suitable for steam gasification of corn. A NiO/Si-Al catalyst system or a $1: 3$ weight ratio of the $\mathrm{Ni}-1404 / \mathrm{Si}-\mathrm{Al}$ catalyst system proved to be unsatisfactory for corn feedstock. These catalyst systems had worked equally well with wood as the feedstock. The potential methanol yield indicates that about $5 \mathrm{gal}$ of methanol can be derived from one bushel of corn. Further studies on alternative feedstocks are planned.

TABLE 25. Steam Gasification of Biomass for the Production of Hydrocarbon Synthesis Gas

Feed

Catalyst System

Reactor and Catalyst Bed Temperature, ${ }^{\circ} \mathrm{C}$

Feed Rate, g/min

Steam Rate, g/min

Carbon Conversion to a Gas, \%

Cold Gas Efficiency, \%

Potential Weight Fraction Yield of Methanol

Gas Composition, vo 1\%

$\mathrm{H}_{2}$

co

$\mathrm{CO}_{2}$

$\mathrm{CH}_{4}$
Corn

$\mathrm{Ni}-1404: \mathrm{Si}-\mathrm{A} 1$

(1:1)

750

0.4

0.2

0.83

94

0.63

0.69

750

0.4

0.2

0.82

98
Ni-1404: Si-A1

$(1: 3)$

55.7

57.8

30.3

27.7

12.7

12.7

1.4 


\section{FUTURE LABORATORY STUDIES}

Catalyst development, lifetime, regenerability, and characterization studies will continue for both methane and hydrocarbon synthesis gas production. Nickel alloys on various substrates will be obtained in the near future from The Davison Chemical Division of W.R. Grace \& Co. These will be tested for both methane and hydrocarbon synthesis gas production. As a result of these tests, catalysts may be prepared in the laboratory for testing.

Investigations to produce an ammonia synthesis gas will resume this year. Operating conditions at $750^{\circ} \mathrm{C}$ wi 11 be optimized. Catalyst lifetime and regenerability will be studied for the favored catalyst system.

Alternative feedstocks, such as corn, alfalfa, and wheat straw, will be investigated regarding the feasibility of producing specific gases.

Thermal studies to determine the heat requirements (or release) in biomass (wood, lignin, cellulose) pyrolysis were initiated in FY-1980. These studies will continue and will include alkali carbonate catalyzed biomass. Methods that will be used to study pyrolysis and gasification of biomass include differential scanning calorimetry (DSC), thermal gravimetric analysis (TGA), and thermal mechanical analysis (TMA). Support studies for the PDU will also continue. 


\section{PROCESS DEVELOPMENT UNIT STUDIES}

The main objective of the PDU studies was to evaluate catalysts and operating conditions developed in the laboratory on a scale approximating commercial operations to identify heat and mass transfer problems associated with scale-up. Operations were structured to allow determination of material and energy distribution in the system.

Design and procurement of equipment began in January 1978. The initial design included a stirred-bed gasifier. By March 1980 the PDU was modified by converting the stirred bed to a fluidized bed. The PDU designs and operations are presented in the following discussion.

\section{PDU DESCRIPTION}

Design of the PDU with the stirred-bed gasifier was initiated before design criteria were fully established in the laboratory. Therefore, the PDU was designed for general purpose operation to develop the following information:

- process yields, conversion efficiency, thermal efficiency, throughput

- required or desirable process features (catalyst recycle, feed material preparation, product gas treatment)

- equipment requirements (materials handling, instrumentation, construction materials, unit operations)

- utility requirements

- emission control requirements.

A flow schematic of the original PDU with the stirred-bed gasifier is shown in Figure 26. A photograph of the completed PDU is shown in Figure 27.

\section{Gasifier}

The stirred-bed gasifier is illustrated in Figure 28. The gasifier is a 250-psig pressure vessel. The shell is $2 \mathrm{ft}(60 \mathrm{~cm})$ sch 80 carbon steel pipe $10 \mathrm{ft}(3 \mathrm{~m})$ long. The bottom head of the gasifier contains the gas inlet 


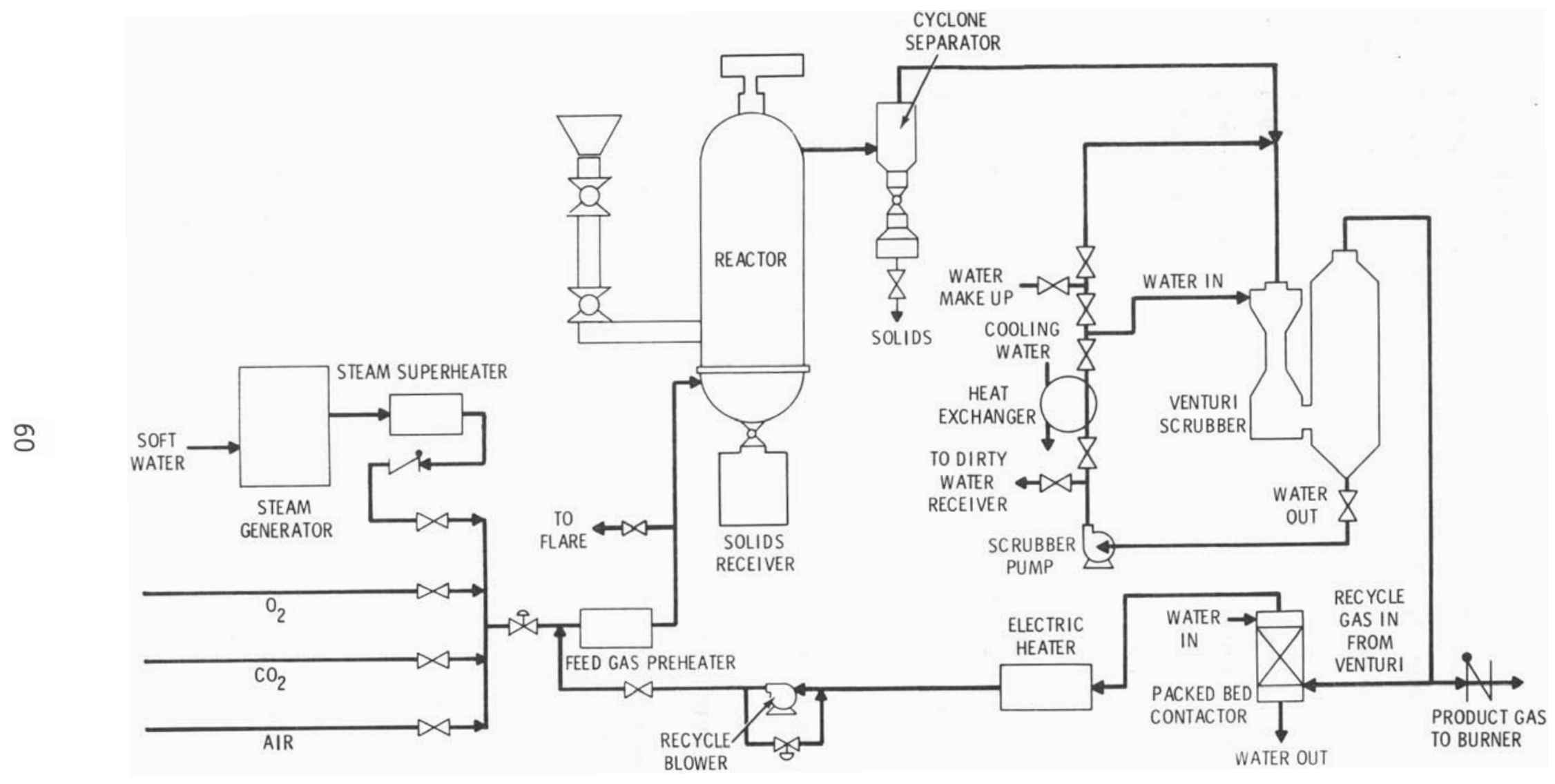

FIGURE 26. Schematic of Original PDU 


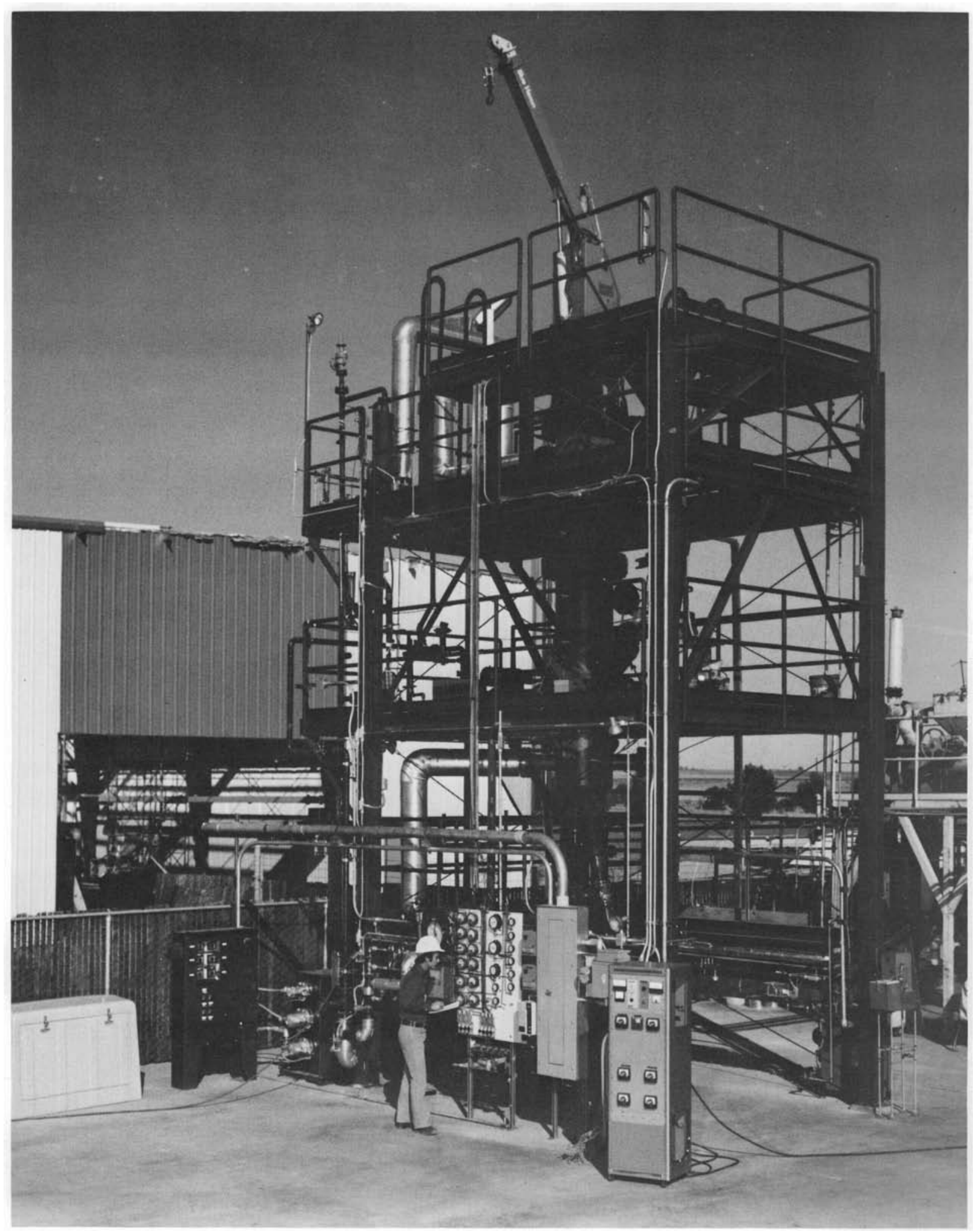

FIGURE 27. Photograph of Original PDU 


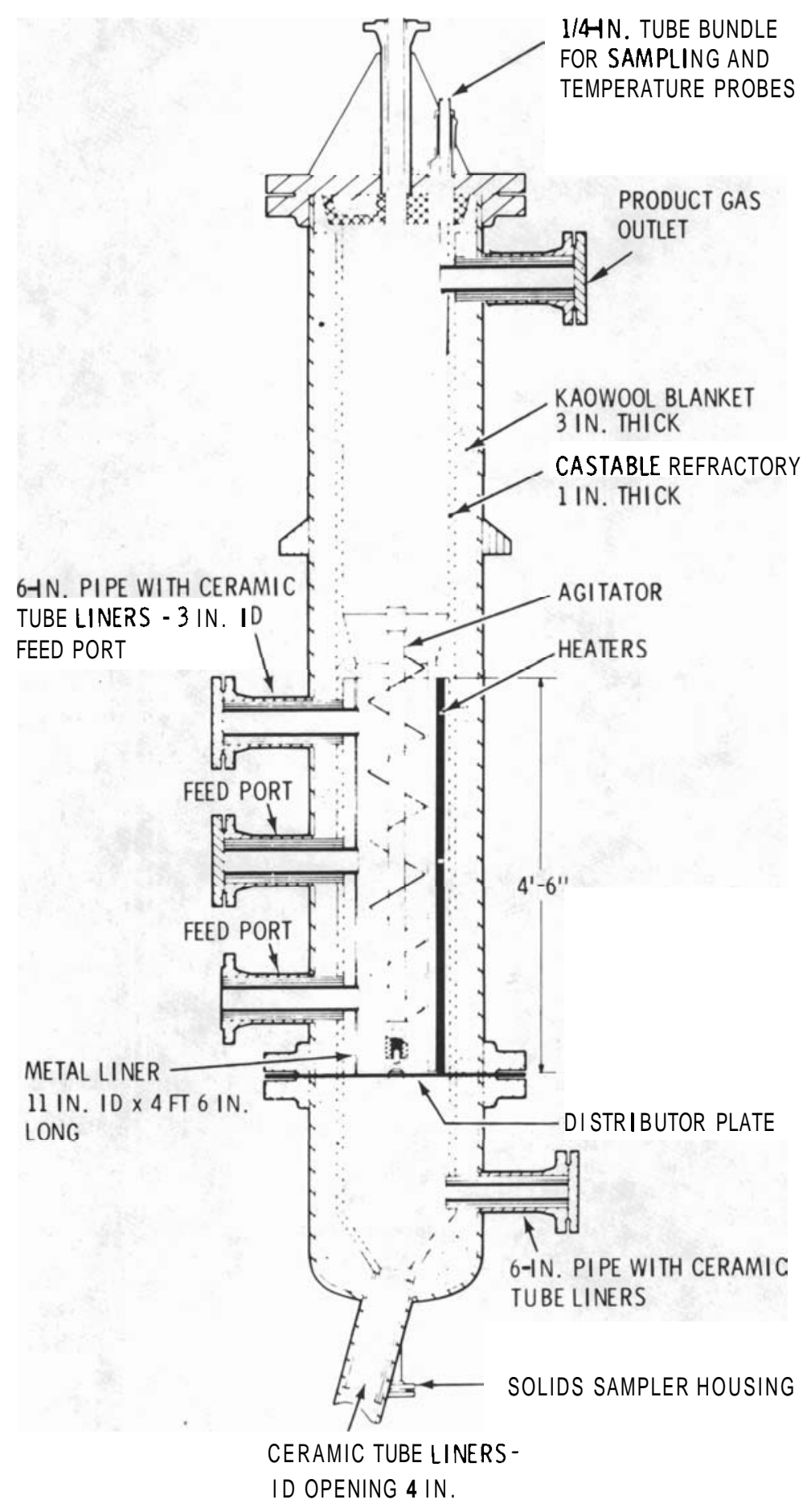

FIGURE 28. Schematic of the Stirred-Bed Gasifier 
nozzle and gas distributor plate. A drain line in the bottom head allows an operator to remove materials that fall through the distributor plate. Three small lines permit sampling of solids from three different levels in the gasifier. Figure 29 is a photograph of the bottom head section with the solid sampling and removal lines.

Three nozzles above the distributor plate on the gasifier allow addition of biomass at different levels in the four foot bed. We have, however, only used the lowest feed port. An internal auger about 8 in. $(20 \mathrm{~cm})$ in diameter was used to stir the 4 -ft-deep bed of catalyst and char.

Energy was supplied to the gasifier by heaters surrounding an 11-in. (28-cm) diameter, 310 stainless steel liner. Heater leads leave the gasifier through glands in three flanged ports. In the early experiments two types of heaters were tested. The original heaters were nichrome resistance heaters embedded in ceramic. Several different configurations were tried, however, these heaters could not withstand the reducing environment. They were replaced with incoloy-sheathed heaters wrapped around the stainless steel liner. These heaters lasted wel1 in the gasifier, however, their heat transfer characteristics did not allow operation at bed temperatures above $550^{\circ} \mathrm{C}$.

The reactor has an internal refractory lining 14 in. $(36 \mathrm{~cm})$ I.D. by 16 in. $(41 \mathrm{~cm})$ O.D. The remainder of the shell insulation is provided by Kaowoo ${ }^{\circledR}$. Figure 30 shows the refractory and Kaowoo $1^{\circledR}$ in the reactor as well as the three electrical ports at $120^{\circ}$ spacing and three biomass feed ports.

The stirred-bed gasifier was equipped with three instrument bundles. A bundle consisted of seven stainless steel tubes welded in a close-packed configuration. Each tube extended to different levels in the gasifier. One bundle was used to measure pressures at seven points in the bed. Bundle two had seven thermocouples at different levels. The third bundle was used for sampling the gas composition at different levels.

The exterior of the reactor was painted with temperature sensitive paint which changes colors as the temperature exceeds certain values. This is useful

8 Registered Trademark of Babcock and Wilcox. 


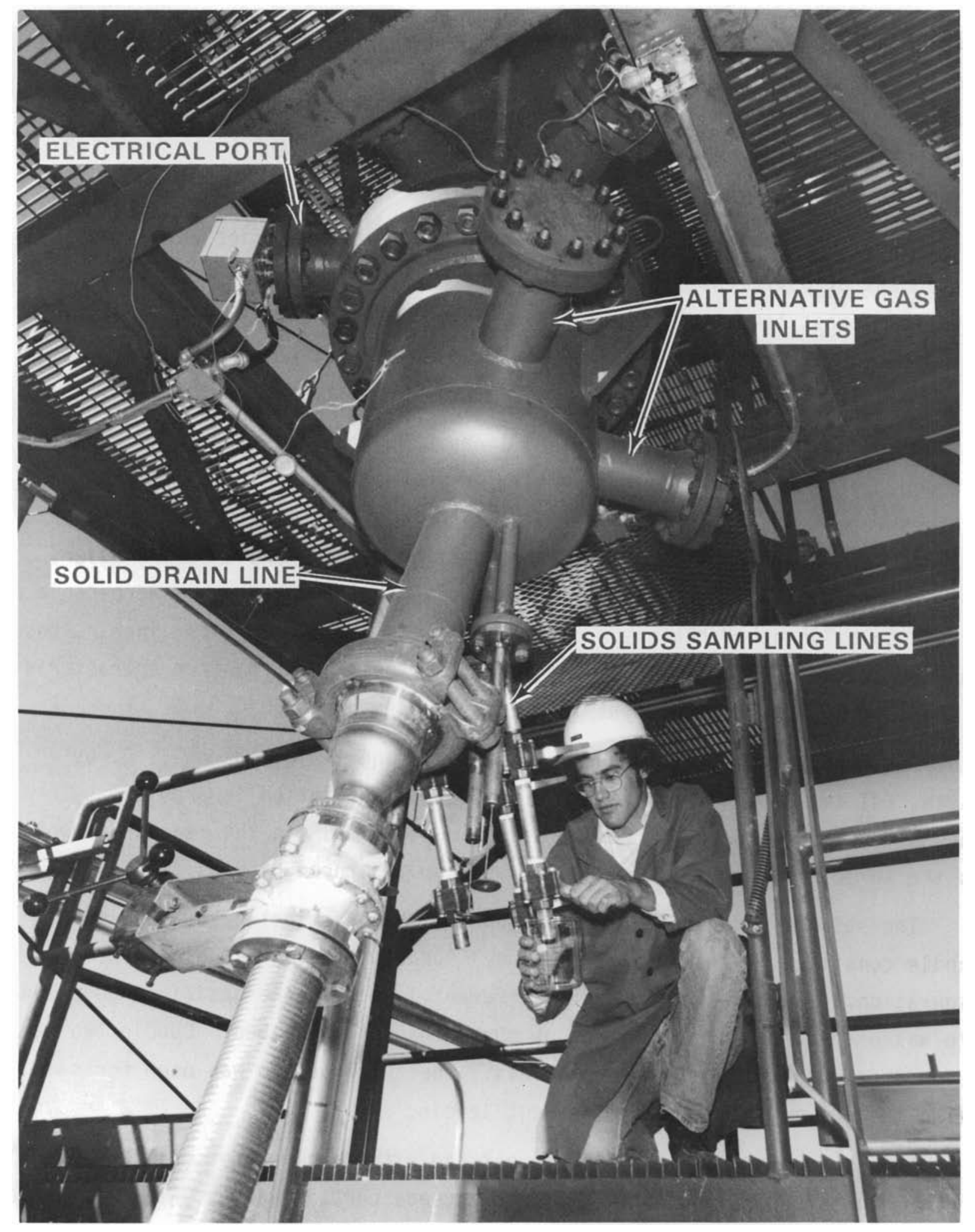

FIGURE 29. Bottom Head of Stirred-Bed Gasifier 


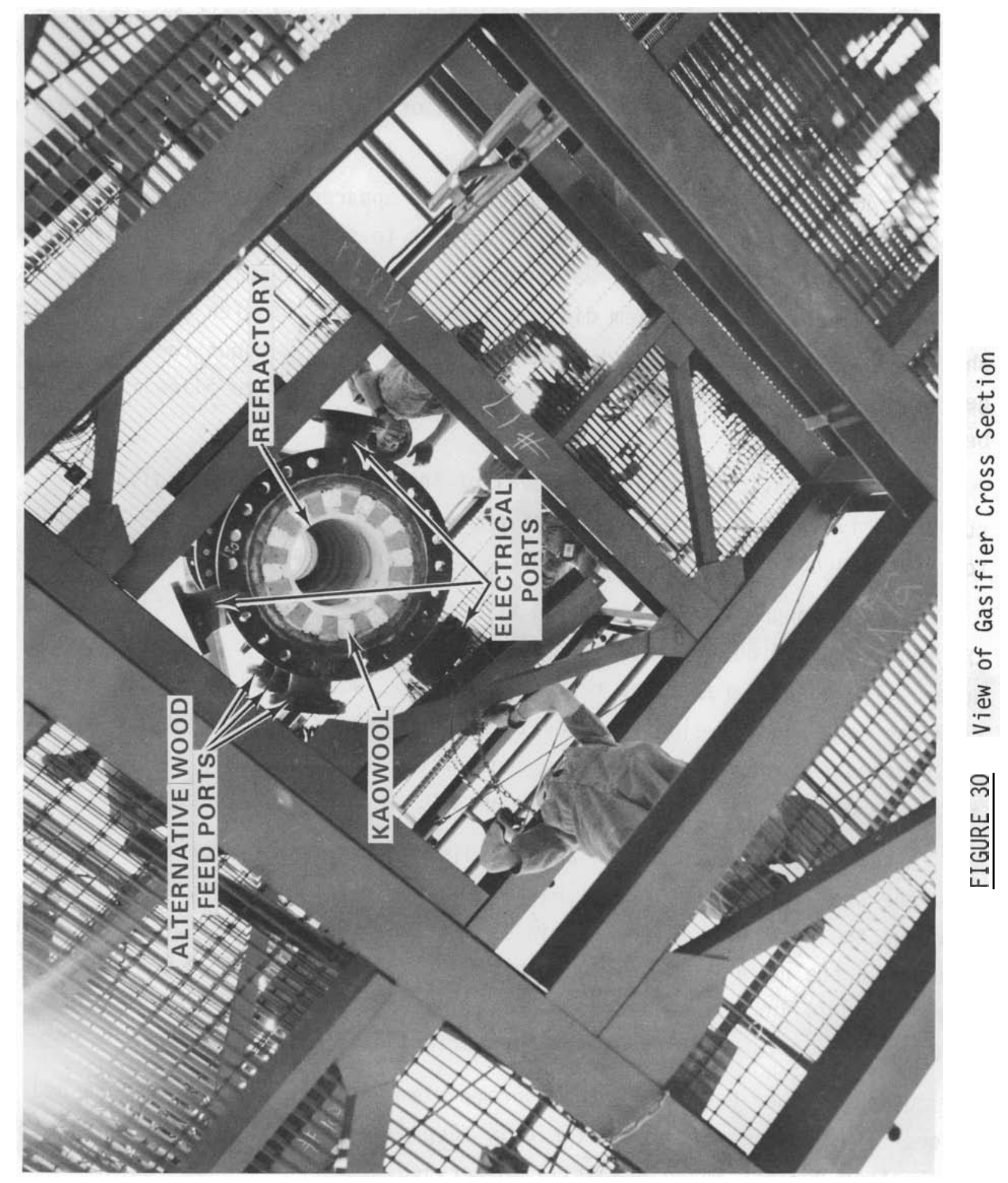


in identifying hot gas circulation between the shell and refractory. Seven thermocouples were glued to the shell exterior to monitor shell temperatures.

From October 1979 to March 1980 the PDU was modified extensively. The most significant change was the modification of the gasifier vessel to operate in a fluid-bed mode.

During the agitated-bed testing it became apparent that the agitated system was difficult to model, and very difficult to scale up. Also, and perhaps most importantly, the agitator was presumed to be the cause of severe catalyst attrition. Finally the system did not have good heat transfer characteristics which prohibited operation at temperatures above $600^{\circ} \mathrm{C}$ without the use of oxygen. For these reasons it was decided to convert the PDU to allow fluidizedbed operation.

The modifications involved removal of the agitator and the agitator support-drive system, installation of a new gas inlet section, a new distributor plate, a new stainless steel liner and gasifier heaters.

With the auger removed from the bed, the effective cross-sectional area of the reactor was $0.66 \mathrm{ft}^{2}\left(610 \mathrm{~cm}^{2}\right)$ instead of $0.35 \mathrm{ft}^{2}\left(330 \mathrm{~cm}^{2}\right)$ with the auger. The larger area meant that the gas flows would need to double to maintain the same linear velocity. For this reason a new liner for the bed was constructed for an inside effective area of $0.31 \mathrm{ft}^{2}\left(290 \mathrm{~cm}^{2}\right)$. The new liner, also made of 310 stainless steel, had an I.D. of 7.75 in. $(20 \mathrm{~cm})$.

A new gasifier bottom head and gas distributor were procured to accommodate the smaller diameter bed. This assembly was intentionally designed to decrease the heat loss in the gas inlet section. Only one bed-draining device is used in the new bottom head assembly. The distributor plate was repositioned from 14 in. $(36 \mathrm{~cm})$ to 2 in. $(5 \mathrm{~cm})$ below the wood-feed port. This allows the feed to be reacted with the hottest gas in the system.

Ceramic fiber heaters, with nichrome elements were clad to the new bed liner. These heaters failed after only several days use. They were replaced by sheathed heaters which are still in service. 
A problem remained in getting enough heat into the gasifier bed. This was solved by installing six cartridge heaters directly into the bed of char and catalyst. These heaters have a total capacity of $30 \mathrm{~kW}$ and have performed very well to date.

The top head of the gasifier had to be replaced for the installation of the cartridge heaters. The modified head does not utilize the instrument bundles described earlier. Instead, individual tubes for thermocouples and pressure sensors extend into different levels of the gasifier from the top head.

Figure 31 shows a schematic of the fluidized-bed gasifier as it now exists.

Wood Feed System

Wood is introduced to the gasifier using a lockhopper and an auger feeder. The lockhopper is a $4-\mathrm{ft}^{3}\left(0.11-\mathrm{m}^{3}\right)$ chamber with pneumatically operated ball valves on the top and bottom. Figure 32 shows the lower portion of the lockhopper. A level indicator in the lockhopper signals when wood loading is required. Operators raise weighed batches of wood to the hopper via a hydraulic-electric crane. The hopper valves are closed and the hopper is purged with $\mathrm{CO}_{2}$. After purging, the top hopper valve is opened, and the wood is added to the hopper. The top valve is closed. Air is purged from the hopper, and the bottom hopper valve is then opened. The wood drops to the auger feeder. Interlock mechanisms prevent operators from opening both hopper valves at the same time. Upon loss of power or supply air, the bottom valve fails to the closed position, and the top valve fails open to ensure safety.

The screw feeder consists of two metering screws approximately 2 in. $(5 \mathrm{~cm})$ in diameter. These operate with a variable-speed hydraulic drive at about 20 to $40 \mathrm{rpm}$. They push the wood onto a third screw oriented $90^{\circ}$ from the metering screws. The third screw (injector screw) is also about 2 in. $(5 \mathrm{~cm})$ in diameter. It operates at about 150 to $200 \mathrm{rpm}$ with a variable speed hydraulic motor. At this speed, wood is rapidly moved into the gasifier. The injector screw also is connected to a hydraulic ram that gives the screw 6 in. $(15 \mathrm{~cm})$ of travel. This feature is helpful in breaking jams in the injection 


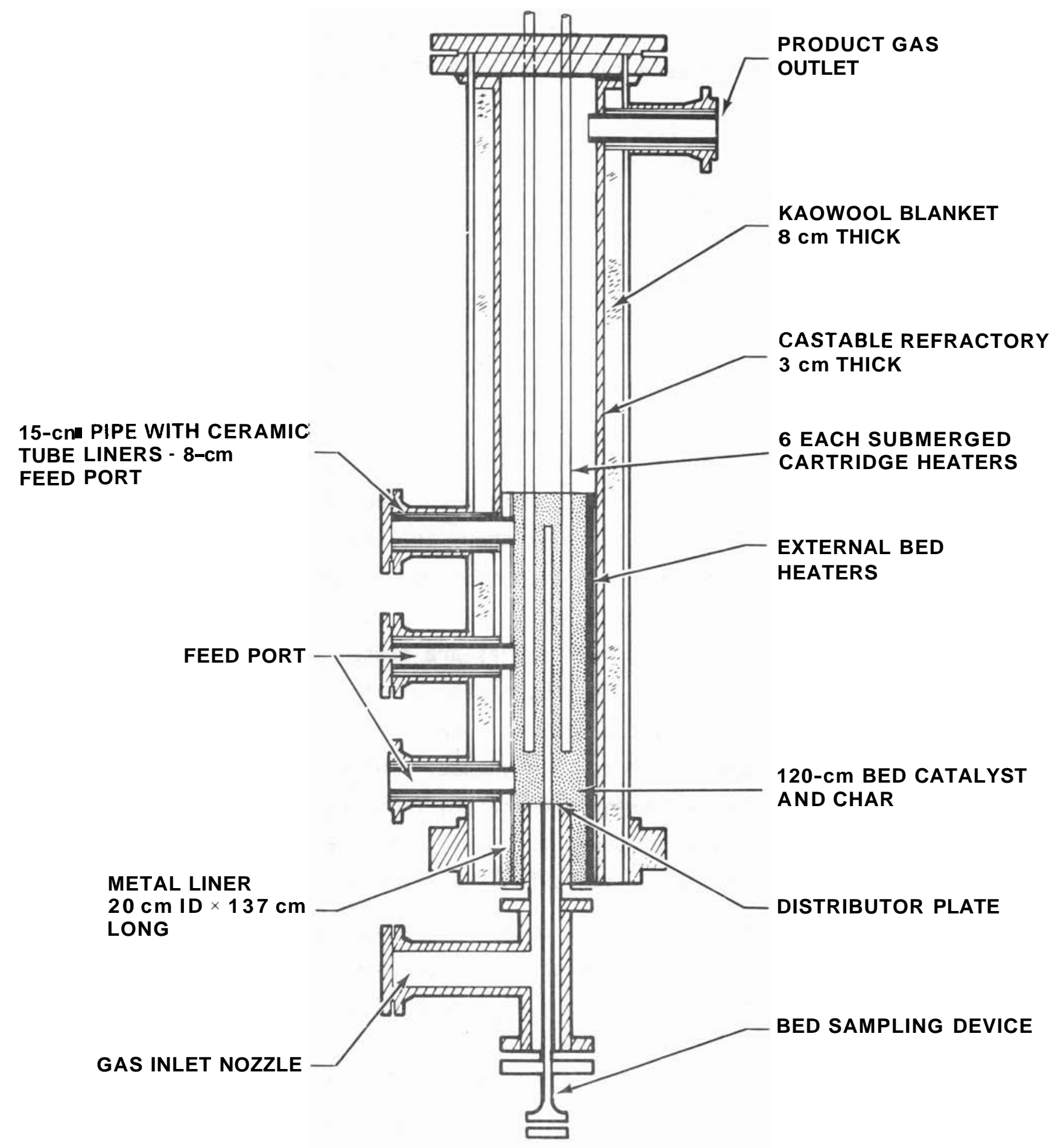

FIGURE 31. Schematic of Fluidized-Bed Gasifier 


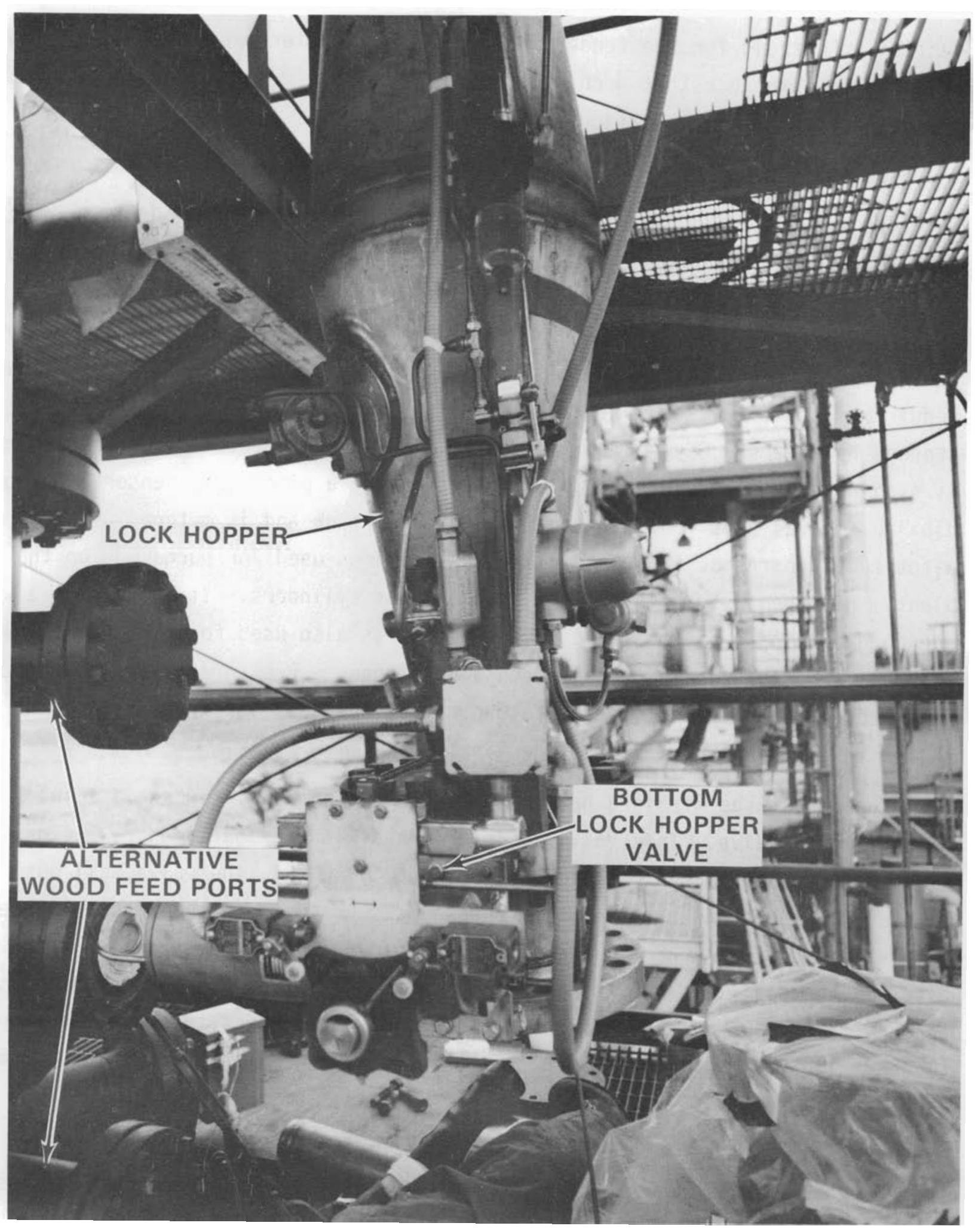

FIGURE 32. View of Lock Hopper 
section. Controls for the feeder include two tachometers, control valves, and an electric interlock that prohibits operation of the metering screws without the injector screw in operation.

\section{Gas Supply Systems}

Reactant gases include steam, oxygen, air, and carbon dioxide. Steam is supplied with a $150-1 \mathrm{~b} / \mathrm{h}(68-\mathrm{kg} / \mathrm{h}) 100-\mathrm{psi}(690-\mathrm{kPa})$ generator. The saturated steam is heated to $110^{\circ} \mathrm{C}$ with trace heaters prior to the steam control valve and orifice meter. A pneumatic integral orifice meter and controller are used for steam control. Oxygen can be fed to the gasifier if desired. Since oxygen requirements are low, the oxygen is supplied with 380 lb (170 kg) liquid oxygen storage cylinders. Oxygen flow is measured by a rotameter. Low pressure air is available as a feed gas. Air is metered using a pitot tube sensor. Carbon dioxide is available from a 6-ton (5-t) storage tank and is metered using a pitot tube apparatus. Carbon dioxide is sometimes used for purge gas on the plant. Nitrogen is available from standard gas cylinders. It is used as a quench gas in case of automatic shutdown. It is also used for purge gas. All feed gas temperatures are recorded on a datalogger. Pressures and flow rates are recorded in data books by operators. All feed gas lines contain check valves to eliminate backflow in the lines.

The feed gases mix in a header system and then travel through a 1-in. $(2.5-\mathrm{cm})$ ball valve. This valve is interlocked with the datalogger. If gasifier temperatures exceed a preset point (usually $800^{\circ} \mathrm{C}$ ), the valve will automatically close, thereby preventing runaway temperatures in the reactor. When the valve closes, another valve on the nitrogen quench system opens, and the gases in the gasifier are flushed out of the system. The feed gases then pass through the gas preheater. This unit uses electric heaters to bring the gases to about $700^{\circ} \mathrm{C}$. The controls for this heater and a portion of the heater are shown in Figure 33.

Provisions were made for recycling a portion of the product gas through the gas heater to the gasifier. This would be useful for boosting velocities in the gasifier. The blower used for recycle gas was a rotory lobe-type with a variable speed drive. A packed-bed contactor was placed upstream of the 


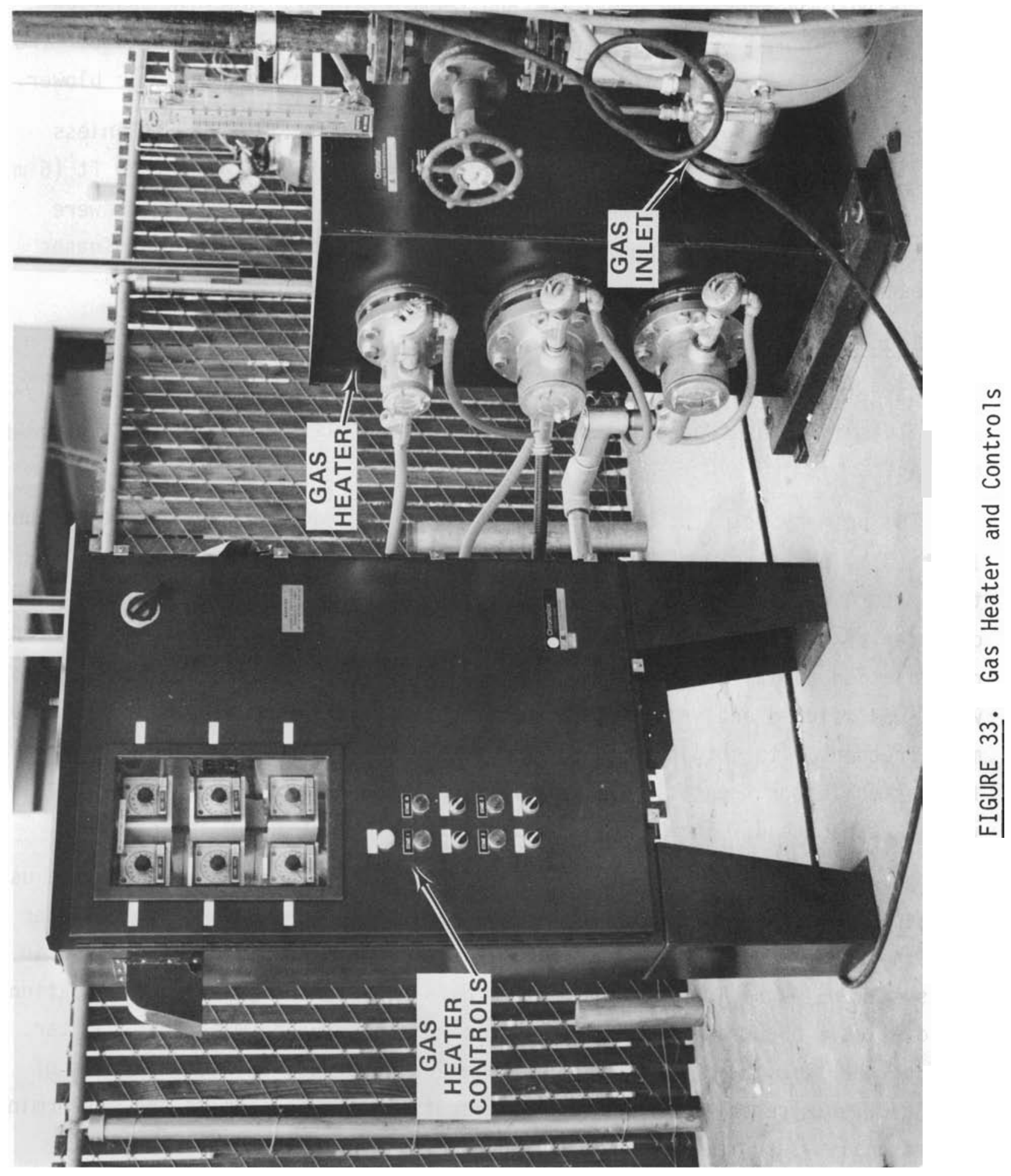


recycle blower to cool the recycle gas by direct contact with water if necessary. Figure 34 shows the contactor and recycle blower. Recycle gas flow rates were measured by differential pressure produced with a pitot tube. The automatic shutdown system described previously also stops the recycle blower.

Hot feed gases exit the gas heater through a $3-i n .(7.5-\mathrm{cm})$ stainless steel line leading to the gasifier inlet nozzle. This line (about $20 \mathrm{ft}(6 \mathrm{~m})$ long) was well insulated, however, heat loss was still high. Heaters were added to portions of the feed line to counteract the heat loss. Feed gases now reach the gasifier at temperatures between $750^{\circ} \mathrm{C}$ and $800^{\circ} \mathrm{C}$.

\section{Gas Cleanup System}

Gas cleaning is required to separate and recover the products for analysis. This involves separating the solids and liquids from the gas and cooling the gas.

The primary means of solids separation is by a dry cyclone operating about $10 \mathrm{ft}(3 \mathrm{~m})$ downstream of the gasifier. The cyclone usually operates in the temperature range of $300^{\circ} \mathrm{C}$ to $500^{\circ} \mathrm{C}$ depending on gasifier conditions. Inside diameter of the cyclone is $6 \mathrm{in}$. $(15 \mathrm{~cm})$. The cyclone is insulated to prevent condensation on its walls. Solids were drained from the cyclone into a drum which was weighed and sampled after a day's test. It was desirable to sample more frequently to obtain collection rates at steady state. A lock hopper system was built for the cyclone. It consisted of a 2 -in. $(5-\mathrm{cm})$ pipe with ball valves at each end. This cyclone hopper is drained at $1 / 2-h$ intervals.

Downstream of the cyclone (see Figure 26), a wet venturi scrubber was used for gas cooling and final particulate removal. The scrubber contacted water with the hot gas in a variable throat venturi. Water could be circulated in the system or passed through the system on a once-through basis. Circulation was difficult because flow meters and water lines plugged with char and tar. Most of the time the water to the scrubber was not recirculated. Yields of char and tar were determined by collecting timed liquid samples and performing solids analysis and measuring total organic carbon in the liquid phase.

The clean gas was then measured with a pitot tube and subsequently with an orifice meter. The pitot tube was unreliable with its opening tending to 


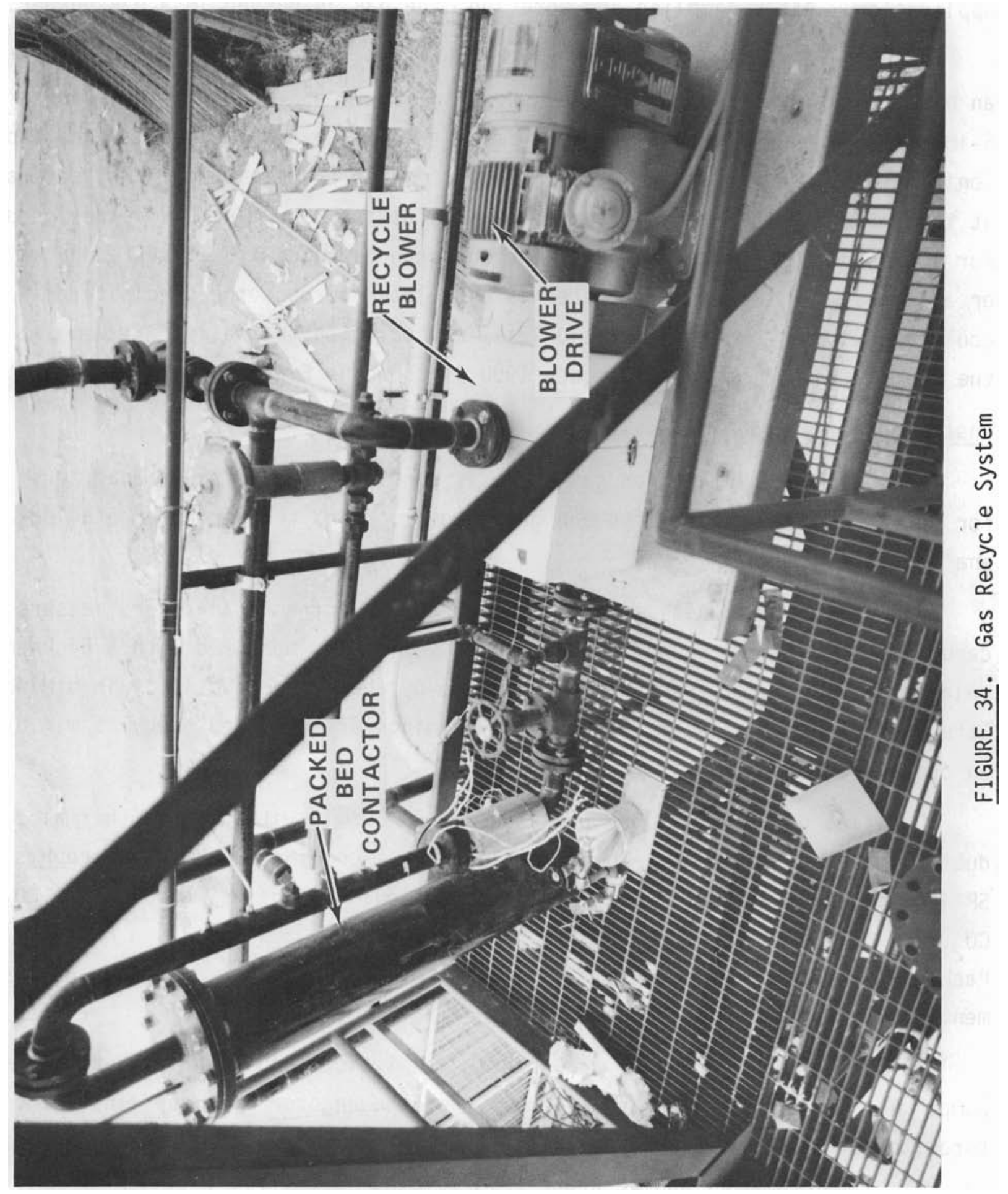


plug. The orifice meter has been a reliable gas metering device for this application. After sampling and metering, the gas is burned in a gas burner.

Poor performance of the venturi scrubber resulted in its replacement with an electrostatic precipitator (ESP) shown in Figure 35. The precipitator is a 5 -in. $(13-\mathrm{cm})$ pipe with a $1-\mathrm{in} .(2.5-\mathrm{cm})$ electrode down the center of the pipe. lonizing disks are located on the lower portion of the electrode. Gas enters at the bottom of the precipitator and exists at the top. The ESP is designed for 100 psig $(690 \mathrm{kPa})$ operation. The unit can operate with either a dry wall or a wetted wall. Currently, water is circulated through the precipitator to cool the gas and remove the particulates collected on the wall. A schematic of the PDU configuration as of October 1980 is shown in Figure 36.

Instrumentation and Data Analysis

Analytical equipment for gas analysis consists of continuous analyzers for instantaneous compositions and gas chromatographs for periodic detailed analysis.

Four continuous units are used. Two Beckman infrared analyzers measure carbon monoxide and carbon dioxide levels. Oxygen is measured with a Beckman polarographic sensor. Hydrogen is measured by thermal conductivity in a Mine Safety Appliances analyzer. Continuous readings are recorded every $15 \mathrm{~min}$ by an operator.

Detailed gas analyses are processed every 20 min with a Carle thermal conductivity gas chromograph. The chromatograph is combined with a Spectrophysics $\$ 4000$ microprocessor for automatic integration. The gases measured are $\mathrm{CO}$, $\mathrm{CO}_{2}, \mathrm{H}_{2}, \mathrm{~N}_{2}, \mathrm{O}_{2}$ and $\mathrm{C}_{1}$ to $\mathrm{C}_{4}$ paraffins and olefins. Occasionally a Hewlett Packard flame photometric chromatograph is used for hydrogen sulfide measurement in the parts per million range.

Samples from the PDU are drawn to the analytical equipment with a vacuum pump. The continuous samples are drawn from the reactor exit gas line. The chromatograph samples are normally taken after the gas is cleaned and cooled, however, these samples can be drawn from 10 other locations in the plant using a 12-position valve on the sample lines. 


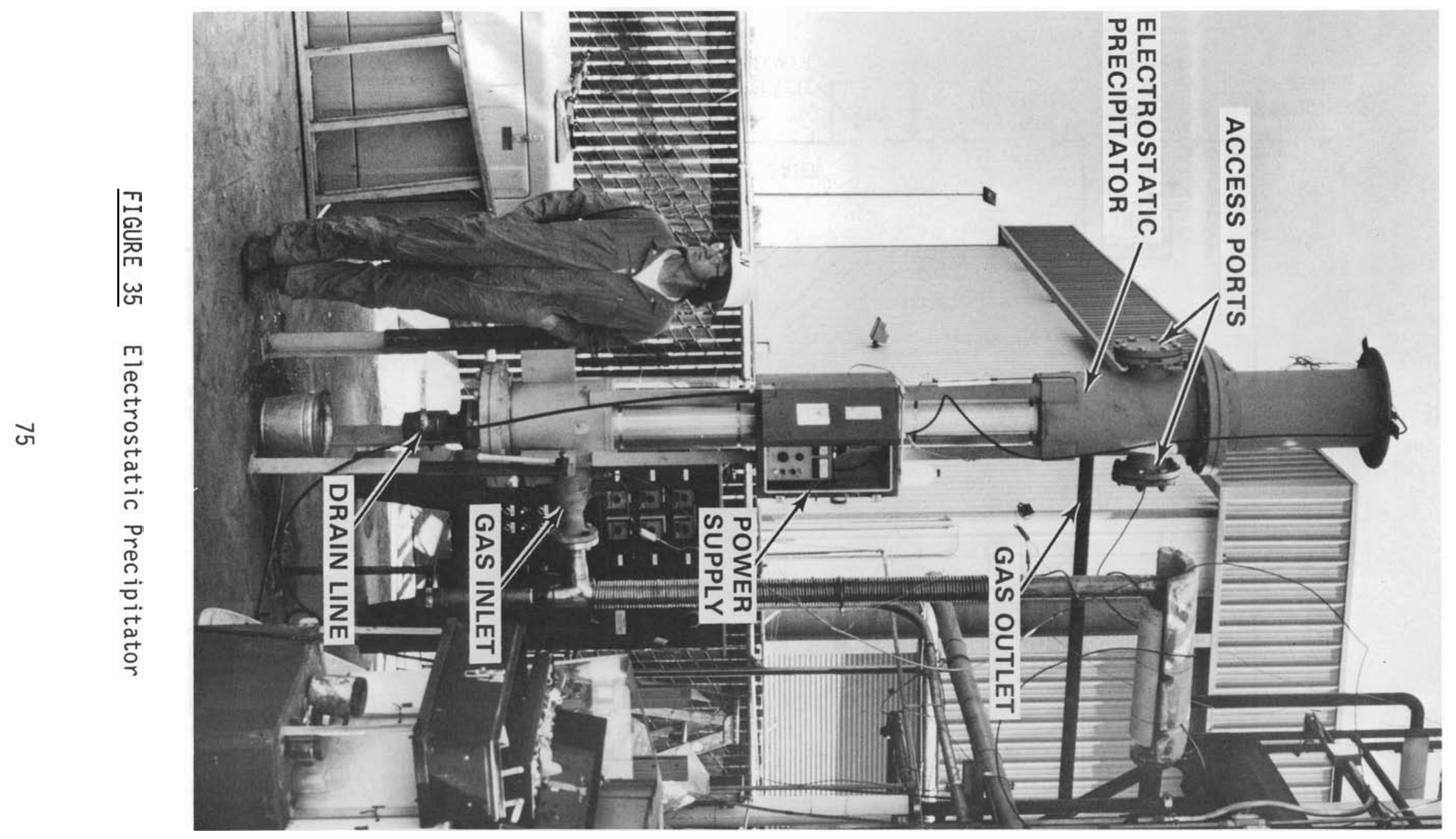




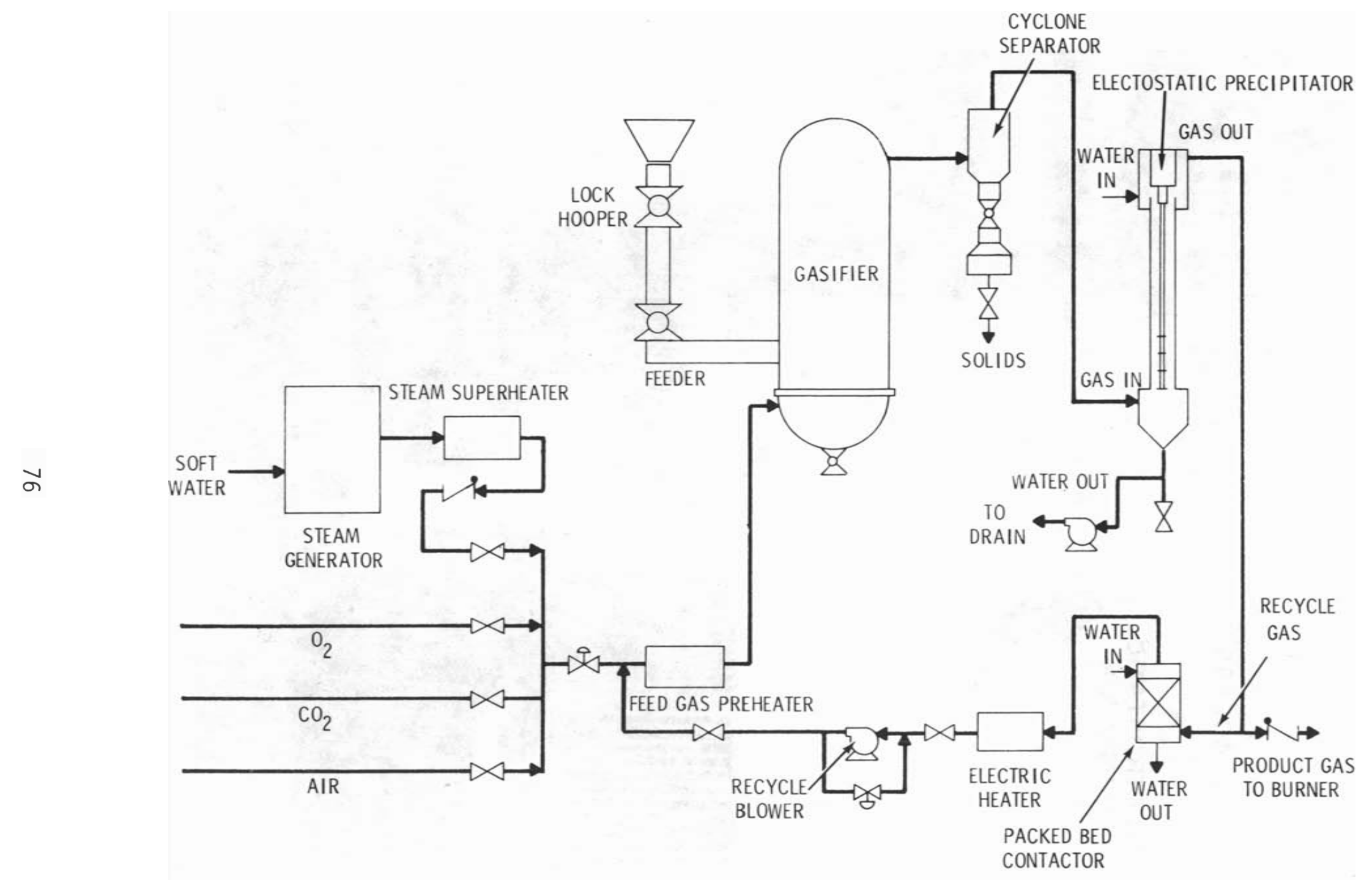

FIGURE 36. PDU Schematic As of October 1980 
Water content of the gas from the gasifier is an important factor in the mass balances. The water content was originally measured with a dewpoint hygrometer. However, this unit was unreliable, and poor service from the factory resulted in its discontinued use. Water content is now determined several times during a test by drawing a gas sample, condensing the water, and measuring the water collected and the dry gas volume.

Temperatures are scanned continuously and recorded at 20-min intervals on a 60-channel, printing datalogger. The datalogger can also automatically shutdown gas feed to the PDU should a temperature excursion occur. The temperatures monitored on the datalogger include each feed gas, the heated gas, 7 points in the gasifier, 7 reactor surface temperatures, off gas temperatures and cooling water temperatures. Alarms on the datalogger allow operators to see where problems may be developing and to take appropriate actions. Temperatures from the datalogger tapes are keypunched, and temperature plots are generated by a computer.

Pressures, differential pressures, controller settings, and meter readings are recorded at 1/2-h intervals in a data book by an operator. This data book also contains records of wood addition and cyclone collection rates. After a test, these data along with gas compositions and recorded temperatures are processed on a minicomputer to gain a preliminary estimate of the test results. The results of analyses subsequently performed on the liquids and solids are later entered into the computer for a final test analysis. Data are stored on magnetic disks. Original raw data are also kept for future reference.

\section{PDU OPERATION}

The purpose of the PDU operations was to test catalyst systems developed in the laboratory and to evaluate their practicality for large-scale operation. PDU operations were completed with the stirred-bed gasifier and the fluid-bed gasifier; results are presented in the following discussion.

Successful operation of the fluid-bed gasifier illustrated the technical feasibility of the catalytic processes. Results with the stirred-bed gasifier 
were of little value since operations without oxygen were limited to temperatures under $600^{\circ} \mathrm{C}$ and since scale-up of the gasifier appears to be impractical. $\underline{\text { Test Procedures and Safety Considerations }}$

Documents were prepared to assure safety of the PDU operation before startup was permitted. The first document, "Operational Safety Analysis Review for Catalytic Biomass Gasification PDU," contained an analysis of potential problems and hazards of each piece of equipment in the PDU and described the safety features to be incorporated into the original plant design. The second document, "Safe Operating Procedures," listed the steps for plant startup, shutdown, normal operation, and emergency conditions.

Normal test procedures begin with heating the plant to the desired temperature, which takes 3 to $4 \mathrm{~h}$. When at the desired temperature, wood is introduced, and the plant is operated at steady conditions for 3 to $5 \mathrm{~h}$. Wood feed is then stopped, and the plant is either partially or totally shutdown depending on whether or not it will be operated the following day.

\section{Feedstock for the PDU}

Wood feedstock for the PDU was limited in size by the screw feeder, which could deliver chips with a maximum dimension of about $1 / 2 \mathrm{in.}(13 \mathrm{~mm})$. Originally, wood was purchased that had been specially processed in a hammer mill. Later we found a supply of headrig sawdust (maple and alder) that was suitable for use in the PDU.

Another material that was used for several tests was forest residue. This was collected from the forest in the same manner wood residues are collected commercially. The wood has a different composition, containing much more ash from the soils than the normal plant feedstock. The compositions of the two feeds are given in Table 26.

Wood moisture content markedly influences PDU performance. Wet wood tends to bridge in the lock hopper and greatly increases the heat load that must be supplied to the gasifier. For these reasons, the wood feedstock was usually dried to 1 to 5 wt\% moisture before use in the PDU. 
TABLE 26. Compositions of Feedstocks Used in PDU Operations

\begin{tabular}{lccc}
\multicolumn{1}{c}{ Feedstock } & Headrig Sawdust & Forest Residue \\
\cline { 1 - 1 } Weight \% dry basis: & & \\
Carbon & 6 & 46 & 6 \\
Hydrogen & 48 & 39 \\
Oxygen & 0.1 & 9 \\
ash & & \\
Heat of combustion, dry basis, & $8300(19,300)$ & $8700(20,200)$ \\
Btu/lb $(\mathrm{kJ} / \mathrm{kg})$ & &
\end{tabular}

PDU Results with the Agitated-Bed Gasifier

The initial operation of the PDU with the agitated-bed gasifier began in the fall of 1978 and continued until the fall of 1979. Modifications to improve PDU operability were initiated at the end of this test period. Operation of the PDU with the agitated-bed gasifier was successful in obtaining data on generation of several specific gas products--a methane-rich gas, a methanol synthesis gas, and an ammonia synthesis gas. Results are presented in the following discussion.

Problems were encountered in operation of the agitated-bed gasifier including failure of the electrical heaters, unreliable wood feeding, and plugging of the venturi scrubber. The primary problem was installation and operation of the internal electrical heaters. Several designs were tried, but none proved to be completely successful. The maximum temperature obtained was $600^{\circ} \mathrm{C}$, which is $150^{\circ} \mathrm{C}$ below the desired upper temperature for operation.

The wood feeding problems were eliminated by replacement of the initial single-screw design. The original feeder used a single screw for metering and slowly injecting wood to the gasifier. We speculated that tars deposited in the screw channel, causing severe binding of the screw. The system currently in use separates the metering and injection functions. Two screws meter wood from the lock hopper onto a third screw which rapidly injects wood into the 
bed of catalyst. The injection screw is connected to a hydraulic ram capable of a 6 -in. $(15-\mathrm{cm})$ traverse for removal of any plug that might form.

The venturi scrubber gave problems with tarry solids plugging the water circulation lines. This problem was reduced by once-through scrubbing with water instead of water recycling.

Figures 37 and 38 summarize the effects of temperature and catalyst combinations on production of a methane-rich gas in the agitated-bed gasifier. Initially we hoped the primary gasification catalyst, potassium carbonate, would promote the steam-char reaction thereby increasing yields of $\mathrm{CO}$ and $\mathrm{H}_{2}$ and producing a high methane gas in the presence of a secondary methanation catalyst. This did not happen, however. At low temperatures, the gasification catalyst retarded both methane production and carbon conversion relative to yields with secondary catalysts only. For purposes of comparing other processes, Figure 37 gives the methane yields in totals possible--assuming all $\mathrm{CO}$ and $\mathrm{H}_{2}$ was converted. In the $525^{\circ} \mathrm{C}$ to $575^{\circ} \mathrm{C}$ temperature range, residual $\mathrm{H}_{2}$ and $\mathrm{CO}$ were both $10 \%$ to $15 \%$ in the PDU product gas. Another methanation step would be needed to convert these residuals to methane.

The shaded areas in Figures 37 and 38 represent maximum scatter of the data. The solid lines show trends for the operations where few problems occurred. The total possible methane production was definitely lowered by potassium carbonate at low temperatures but points were too scattered to see a real difference between concentrations of $5 \%$ and $10 \%$ by weight potassium carbonate.

We speculate that one effect of the primary catalyst was to attack the nickel methanation catalyst and deactivate it. At the same time, the potassium carbonate lost some of its effectiveness. Several observations support this hypothesis but are not necessarily conclusive. First, the catalyst pellets were discolored after these these tests but not when the potassium carbonate was absent. Hydrocarbon synthesis gas tests without the nickel catalyst (potassium carbonate + SiAl only) show a beneficial effect of the potassium carbonate was absent. Hydrocarbon synthesis gas tests without the nickel catalyst (potassium carbonate + SiAl only) showed a beneficial effect of the 


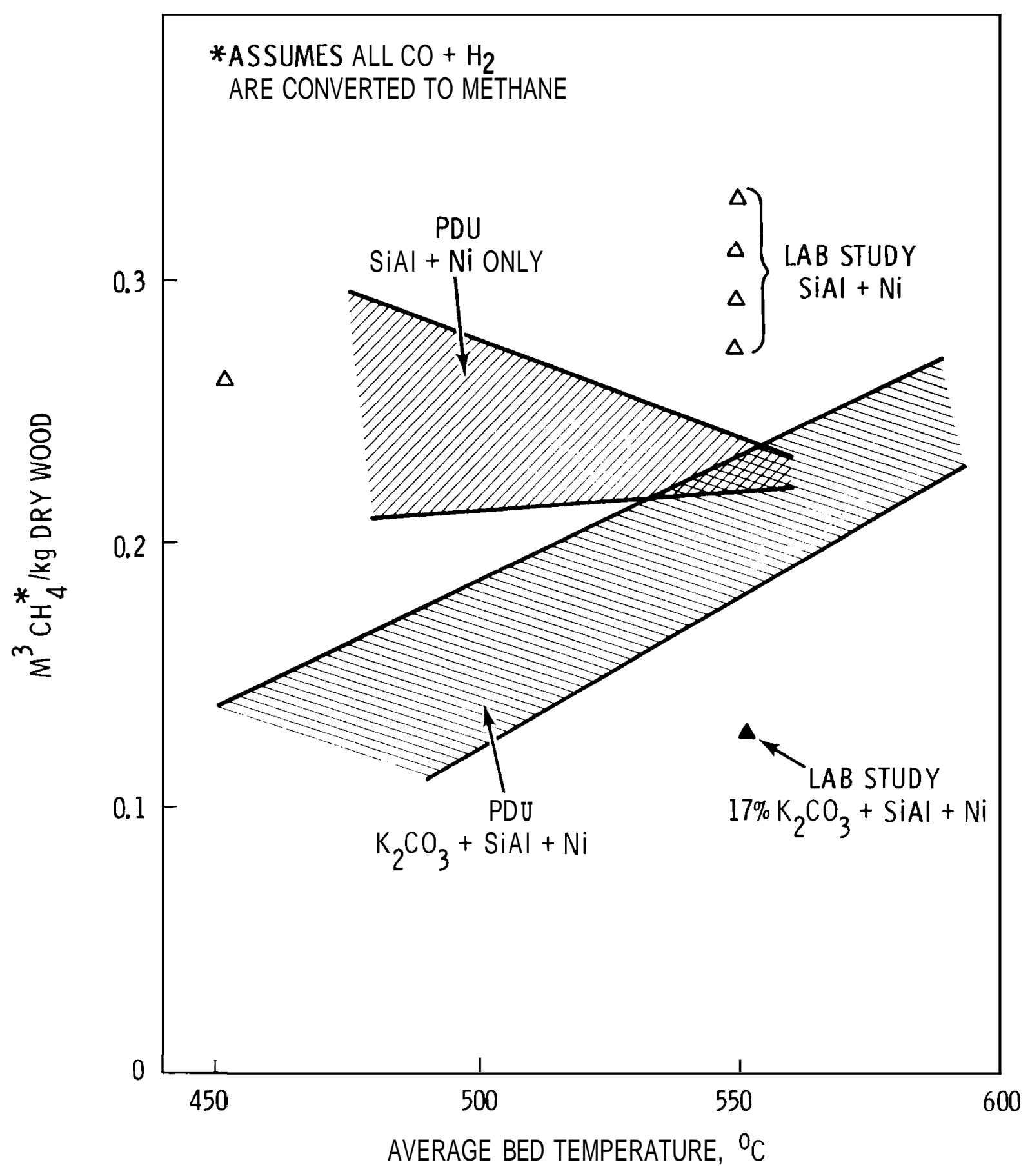

FIGURE 37. Methane Yields from the Agitated-Bed Gasifier as a Function of Temperature and Catalyst 


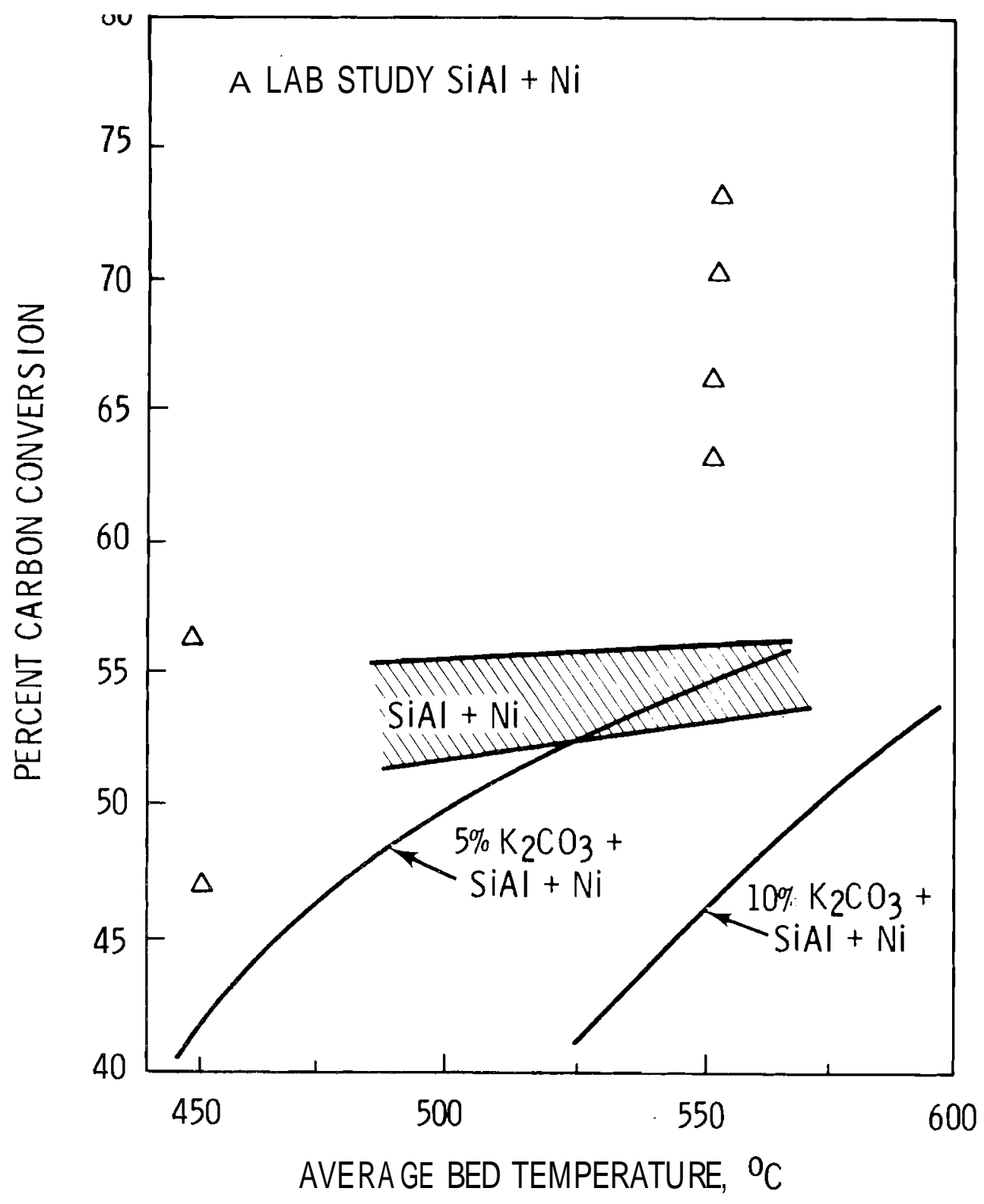

FIGURE 38. Carbon Conversions for Methane Production in the Agitated-Bed Gasifier

potassium carbonate in terms of increasing gas yields. Our ammonia synthesis gas tests clearly showed the effectiveness of the alkali in promoting the water-gas-shift reaction $\left(\mathrm{H}_{2} \mathrm{O}+\mathrm{CO} \rightarrow \mathrm{H}_{2}+\mathrm{CO}_{2}\right)$.

Laboratory studies showed that the alkali carbonate primary catalyst increases the yield of char, increases gas yield, and reduces condensable 
liquid yield at temperatures below $650^{\circ} \mathrm{C}$ with no secondary catalyst. The secondary silica alumina and nickel catalysts also effectively crack and reform liquids from pyrolysis of wood thereby increasing gas yields over those obtained with the primary catalyst. Figure 38 shows the same effects of these catalysts. The constant carbon conversion with temperature in the presence of secondary catalyst indicates that only pyrolysis of the wood is affected and is as complete at $450^{\circ} \mathrm{C}$ as at $600^{\circ} \mathrm{C}$. The water-gas reaction $\left(\mathrm{C}+\mathrm{H}_{2} \mathrm{O} \rightarrow \mathrm{CO}+\mathrm{H}_{2}\right)$ becomes significant at about $650^{\circ} \mathrm{C}$.

Tests on methanol, or hydrocarbon, synthesis gas production in the agitated-bed gasifier concentrated on generation of a $2: 1 \mathrm{H}_{2}$ : $\mathrm{CO}$ molar ratio in the gas stream. Figures 39 and 40 summarize findings for these tests. We found that the gasification catalyst was effective both in increasing gas yields and carbon conversions. The benefits of using the alkali were most apparent at higher $\left(\sim 700^{\circ} \mathrm{C}\right)$ temperatures. The primary catalyst (alkali carbonate) effectively promoted the water-gas reaction $\left(\mathrm{C}+\mathrm{H}_{2} \mathrm{O}+\mathrm{CO}+\mathrm{H}_{2}\right)$ at temperatures above $650^{\circ} \mathrm{C}$.

The preferred temperature for generation of a $2 \mathrm{H}_{2}: 1 \mathrm{CO}$ mole ratio gas is $850^{\circ} \mathrm{C}$. The heaters were inadequate for maintaining temperatures above $600^{\circ} \mathrm{C}$ in the PDU, and pure oxygen was needed to obtain even $700^{\circ} \mathrm{C}$. Yields are markedly improved at the higher temperatures and without addition of pure oxygen. A reactor configuration for steam gasification of the wood at $850^{\circ} \mathrm{C}$ was needed. Conceptually, tube bundles in a fluidized bed of catalyst could be used to provide the required endothermic heat of reaction.

From an operational standpoint, the gasification catalyst caused problems. When local hot spots developed, the carbonate melted fusing together the secondary catalyst and any char in the bed. This problem occurred several times and prompted a search for other catalyst (non melting) combinations that would also enhance gas yields and carbon conversion. The nickel and silica-alumina combination looked very promising in the laboratory. The low gas yields in the PDU were a little puzzling. We noticed after these tests that large amounts of the secondary catalysts were entrained from the gasifier. (It is not easy to detect this during a test.) We now speculate there was insufficient catalyst in the bed to promote gasification of the wood and char. Also, 


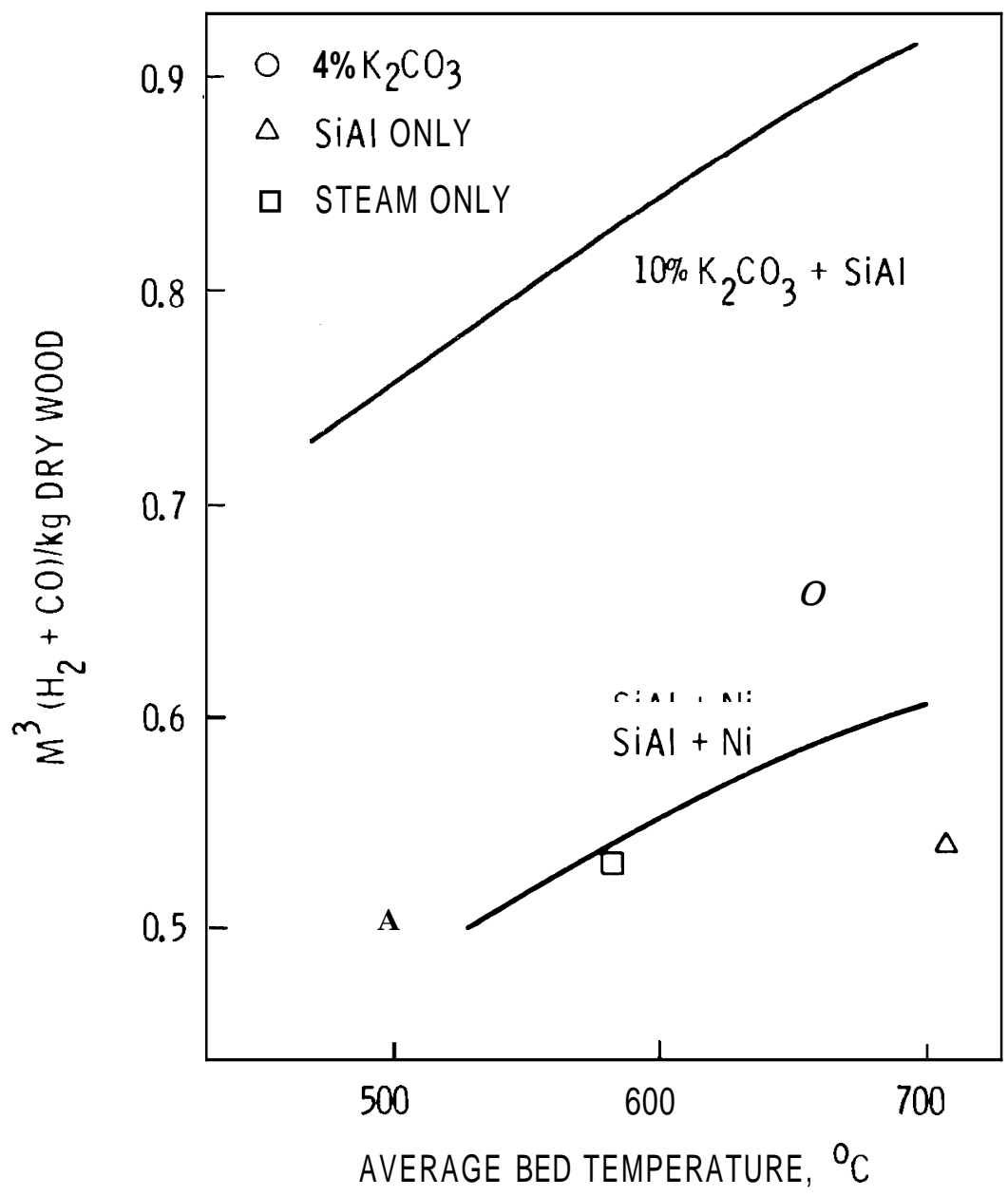

FIGURE 39. Synthesis Gas Yields as a Function of Temperature in the Agitated-Bed Gasifier

we have since determined that the presence of oxygen destroys the nickel catalyst. Later tests with the fluid-bed gasifier (presented in a later section) showed excellent results with a nickel-on-alumina secondary catalyst.

Comparing the carbon conversion plot for synthesis gas production with the similar plot for methane production shows an apparent contradiction. We see high carbon conversions at low temperatures for alkali-catalyzed tests in Figure 40 and low conversions in Figure 38. However, no methane test ever used air or oxygen to maintain bed temperatures, whereas synthesis gas tests used some oxygen. At times, the reactor heaters were not working so even for low 


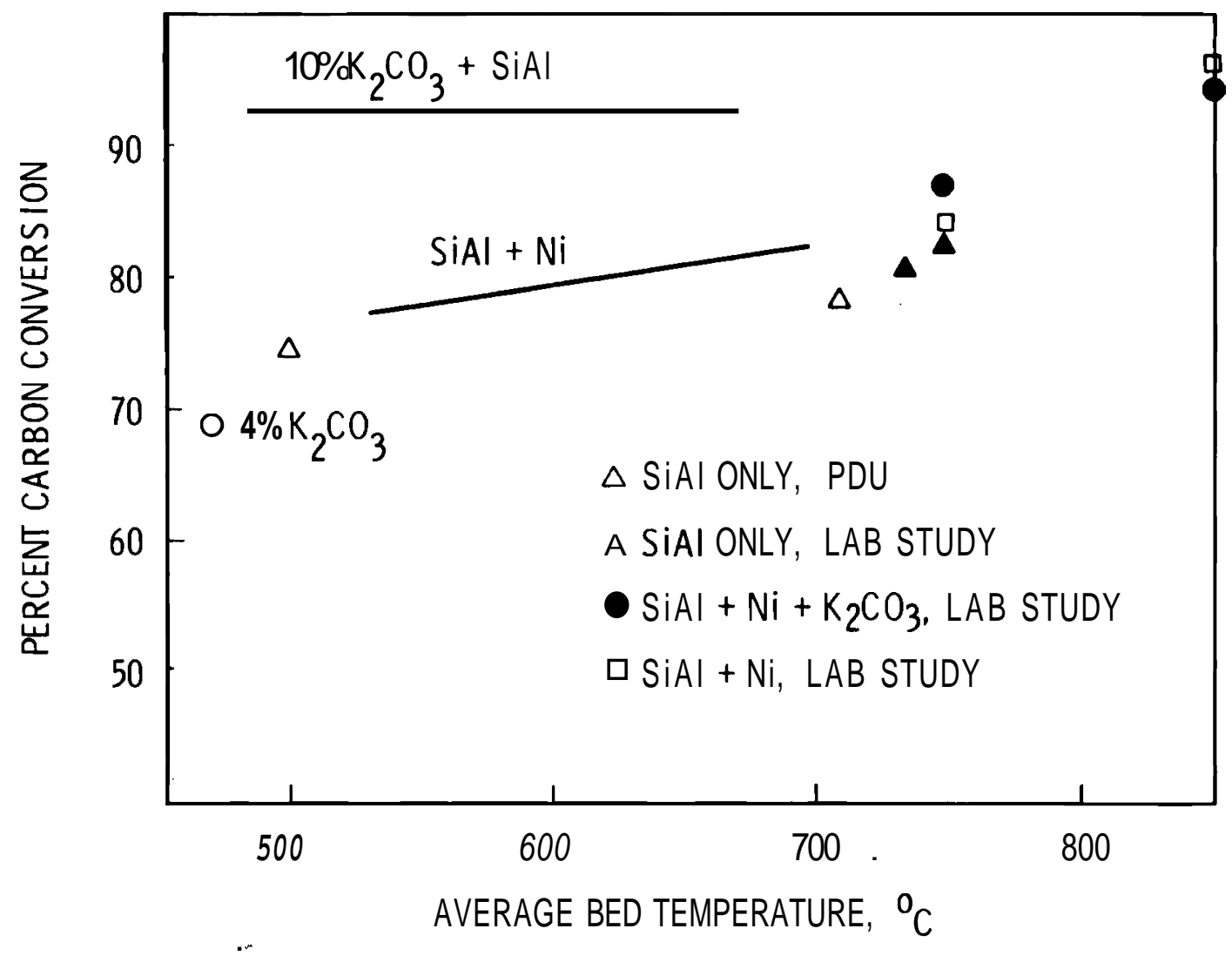

FIGURE 40. Carbon Conversions for Synthes is Gas Production in the Agitated-Bed Gasifier

temperature cases oxygen was added. For a particular synthesis gas test showing $80 \%$ carbon conversion (with $\mathrm{O}_{2}$ addition) the figure drops to $65 \%$ when the carbon burned is deducted.

A second order dilution effect was also possible in the methane production runs. Because product gases were recycled, only $75 \%$ (or less) of the feed gas to the gasifier was a reactant. By contrast, $100 \%$ of the feed gas to the gasifier during synthesis gas production was a reactant.

The amnonia synthesis gas studies were conducted to determine the effects of temperature and gasification catalyst on product gas flows and compositions, as well as wood conversions. All tests used a silica-alumina cracking catalyst plus an iron-chromium shift catalyst. Prior laboratory studies recommended a 4 to 1 steam/wood weight ratio to minimize $C O$ in the product gases. The PDU 
studies used ratios close to this. Wecognize that the high steam flows represent a significant energy penalty for any commercial operation.

In order to maintain desired bed temperatures, pure oxygen was added to the air stream to burn a portion of the wood feed. From an operational standpoint our procedure was 1 ) establish the desired operating temperature using precalculated oxygen/air ratios, 2) note hydrogen concentrations and product flows at steady state, and 3 ) readjust oxygen and air flows to give the desired $3: 1 \mathrm{H}_{2} / \mathrm{N}_{2}$ mole ratio.

A detail is important here when examining the gas compositions shown in Table 27. Nitrogen compositions depend solely on the air flow rates. With addition of pure $\mathrm{O}_{2}$ and air, the two sources of oxygen can be traded to get whatever nitrogen concentration is desired. Only operator inexperience and

TABLE 27. Ammonia Synthesis Gas Results from the Agitated-Bed Gasifier

$\begin{array}{lcccc}\text { Bed Temperature, }{ }^{\circ} \mathrm{C} & 627 & 654 & 732 & 735 \\ \mathrm{Wt \%} \mathrm{K}_{2} \mathrm{CO}_{3}(\mathrm{a}) & 0 & 10 & 0 & 10 \\ \mathrm{~kg} \mathrm{steam} / \mathrm{kg} \text { dry wood } & 5.2 & 4.0 & 4.7 & 3.8 \\ \mathrm{~kg} \text { air/kg dry wood } & .32 & .19 & .29 & .25 \\ \mathrm{~kg} \mathrm{O} \mathrm{O}_{2} / \mathrm{kg} \text { dry wood } & .19 & .15 & .23 & .17 \\ & & & & \\ \text { Dry Gas Composition, vol\% } & & & & \\ \mathrm{N}_{2} & 5 & 10 & 12 & 15 \\ \mathrm{CH}_{4} & 5 & 3 & 6 & 4 \\ \mathrm{H}_{2} & 26 & 39 & 23 & 32 \\ \mathrm{CO}_{2} & 51 & 40 & 39 & 40 \\ \mathrm{CO}^{2} & 11 & 7 & 18 & 7 \\ \text { Carbon Conversion to a Gas, \% } & 94 & 95 & 91 & 93 \\ \mathrm{~m}^{3} \text { dry gas/kg dry wood } & 1.37 & 1.81 & 1.37 & 1.75 \\ \text { Cold Gas Efficiency, \% } & 46 & 63 & 53 & 57\end{array}$

(a) Dry mixed with wood 
imprecise flow control prevented our getting exactly the $3: 1 \mathrm{H}_{2}: \mathrm{N}_{2}$ ratio in the product gas. The important numbers are residual $\mathrm{CO}$ and gas yields as temperatures change and/or gasification catalyst is added. Observations from these tests are:

- The gasification catalyst $\left(10 \mathrm{wt} \%\right.$ dry mix $\mathrm{K}_{2} \mathrm{CO}_{3}$ ) markedly shifts the $\mathrm{CO}$ to $\mathrm{H}_{2}$ at both $650^{\circ} \mathrm{C}$ and $750^{\circ} \mathrm{C}$.

- Addition of the gasification catalyst increased gas yields noticeably.

Although it is not shown in Table 27, the water content of the exit gases is of interest. In all cases it exceeded 70 mole\% of the product stream. This suggests a huge excess of steam was present and supports our earlier contention that more work is needed at lower steam flow rates. The effect of the decreased steam flow on $\mathrm{CO}$ concentration will be of prime interest.

PDU Results With the Fluid-Bed Gasifier

The PDU with the fluid-bed gasifier was operated for a series of tests in the temperature range of $500^{\circ} \mathrm{C}$ to $750^{\circ} \mathrm{C}$ with several secondary catalysts and without secondary catalyst for various steam rates. Most tests included at least $4 \mathrm{~h}$ of operation at steady state.

The initial test series used a Harshaw Ni-3266 catalyst in the form of a 1/16-in. $(1.6-\mathrm{mm})$ extrudate. These tests were all at a temperature of about $500^{\circ} \mathrm{C}$ for generation of a methane-rich gas. Because of the catalyst size, substantial amounts of recycle gas had to be used to fluidize the catalyst bed. The high gas velocity and the low temperature in the bed were probably responsible for the low carbon conversion compared to subsequent tests at lower linear velocities and higher temperatures. Figure 41 shows the effect of varying the steam-to-wood ratio on the product gas composition for these tests. Table 28 summarizes the data from these test with the Harshaw Ni-3266 catalyst.

Several of the tests used forest residue of the composition shown in Table 26. The forest residue had a high ash content compared to the typical headrig sawdust that was used for most tests. No discernable difference in the performance of the PDU with the forest residue feedstock was noted. 


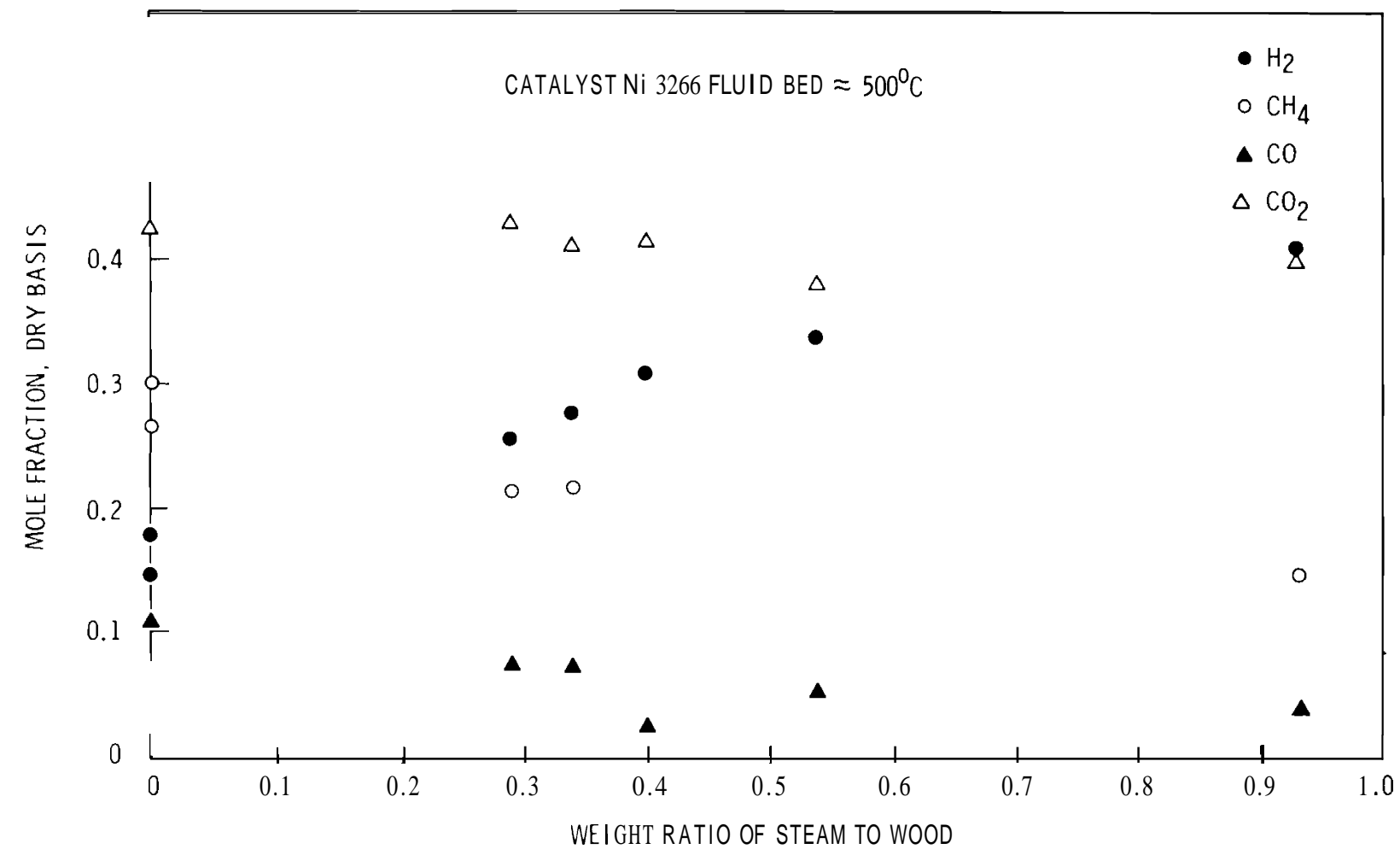

FIGURE 41. Effect of Steam-to-Wood Ratio on Gas Composition from the Fluid-Bed Gasifier

Attrition problems with the extrudate catalyst prompted the purchase of spherical material for use in the fluid bed. The material was sized to allow fluid bed operation at a lower velocity than required for the extrudate. Inert spheres of nonporous alumina (U.S. Screen $-20+40$ mesh) and catalyst spheres (U.S. Screen $-16+30$ mesh) of nickel on a ceramic substrate were obtained for testing to compare results with and without a catalyst. Tests with the inert spheres were completed at $550^{\circ}, 600^{\circ}$, and $750^{\circ} \mathrm{C}$. Results of these tests are shown in Table 29.

Operation with spherical particles and heaters submerged in the bed improved the gasifier performance in several ways. Heat transfer was greatly improved allowing operation at $750^{\circ} \mathrm{C}$. Temperature control was markedly improved. The bed became isothermal with five thermocouples in the bed differing less than $5^{\circ} \mathrm{C}$. With the agitated bed and with the fluid bed of larger catalyst size, the temperatures in the bed varied as much as $100^{\circ} \mathrm{C}$. Figure 42 
TABLE 28. Results of PDU Tests With Nickel Extrudate Catalyst

\begin{tabular}{llccccccc}
\multicolumn{1}{c}{ Test No. } & $\mathbf{1}$ & 2 & 3 & 4 & 5 & 6 & \multicolumn{1}{c}{7} \\
\hline Temperature, & ${ }^{\circ} \mathrm{C}$ & 550 & 470 & 495 & 495 & 450 & 505 & 510 \\
Feedstock & & Headrig & Headrig & Headrig & Headrig & Forest & Forest & Headrig \\
& & Sawdust & Sawdust & Sawdust & Sawdust & Residue & Residue & Sawdust
\end{tabular}

Weight Ratio

Steam-to-Wood

.93

.29

.34

.54

$.40 \quad-0-$

$-0-$

Gas Composition, vo $1 \%$

$\begin{array}{lccccccc}\mathrm{H}_{2} & 41 & 26 & 28 & 34 & 31 & 18 & 15 \\ \mathrm{CH}_{4} & 15 & 22 & 22 & 22 & 23 & 27 & 30 \\ \mathrm{CO} & 4 & 8 & 8 & 6 & 33 & 7 & 11 \\ \mathrm{CO}_{2} & 40 & 43 & 41 & 38 & 42 & 48 & \mathbf{4 3} \\ \mathrm{C}_{2} & 0.0 & 0.2 & 0.2 & 0.0 & 0.0 & 0.0 & 0.2 \\ \mathrm{C}_{3} & 0.0 & 0.3 & 0.2 & 0.2 & 0.2 & 0.0 & 0.1\end{array}$

Cold Gas

Efficiency, \%

62

36

42

66

43

48

43

Carbon Conversion, \%

$\begin{array}{lrrrrrrr}\text { gas } & 67 & 44 & 47 & 64 & 49 & 52 & 48 \\ \text { liquid } & -- & 1 & 1 & 1 & 1 & 1 & 2 \\ \text { solid } & 4 & 44 & 51 & 33 & 23 & 30 & 17\end{array}$

Potential $\mathrm{CH}_{4}$

scf/ton

$\left(\mathrm{nm}^{3} / \mathrm{t}\right)$

950

(300)

5400

$6400 \quad 9000$

6700

$5900 \quad 6000$

(170) (200) (280) (210) (180)

shows a comparison of the bed temperature profiles for a case with 1) the extruded catalyst without submerged heaters and 2) the spherical catalyst with submerged heaters. 
TABLE 29. Results of PDU Tests with Nonporous Alumina Spheres

\begin{tabular}{|c|c|c|c|}
\hline $\begin{array}{c}\text { Test No. } \\
\end{array}$ & 1 & 2 & 3 \\
\hline Temperature, ${ }^{\circ} \mathrm{C}$ & 550 & 600 & 750 \\
\hline \multicolumn{4}{|l|}{ Gas Composition, vo $1 \%$} \\
\hline & 21.4 & 24.7 & 31.6 \\
\hline $\mathrm{CH}_{4}$ & 14.8 & 14.9 & 13.6 \\
\hline CO & 23.6 & 27.2 & 29.0 \\
\hline $\mathrm{CO}_{2}$ & 38.1 & 30.8 & 23.1 \\
\hline$c_{2}, c_{3}, c_{4}$ & 1.9 & 2.3 & 2.6 \\
\hline Weight Ratio Steam:Wood & .75 & .75 & .76 \\
\hline $\begin{array}{l}\text { scf product/lb wood } \\
\left(\mathrm{nm}^{3} / \mathrm{kg}\right)\end{array}$ & $\begin{array}{c}6.8 \\
(0.42)\end{array}$ & $\begin{array}{l}6.8 \\
(0.42)\end{array}$ & $\begin{array}{l}15.4 \\
(0.96)\end{array}$ \\
\hline \multicolumn{4}{|l|}{ Carbon Conversion, \% } \\
\hline gas & 37 & 36 & 75 \\
\hline Tiquid & 6 & 3 & 4 \\
\hline char & 28 & 29 & 20 \\
\hline $\begin{array}{l}\text { Cold Gas Efficiency, \% } \\
\text { Potential } \mathrm{CH}_{4}\end{array}$ & 28 & 30 & 72 \\
\hline $\begin{array}{l}\text { scf/ton } \\
\left(\mathrm{nm}^{3} / \mathrm{t}\right)\end{array}$ & $\begin{array}{l}3550 \\
(110)\end{array}$ & $\begin{array}{l}3880 \\
(120)\end{array}$ & $\begin{array}{l}8850 \\
(280)\end{array}$ \\
\hline
\end{tabular}

Using spherical media in the bed allowed operation without recycling product gas. Steam was the only reactant gas. As a result of the consequent low velocities in the gasifier, the char residence time increased. Gas yields increased dramatically. The char decreased in size and a fine char dust was blown from the gasifier to the gas cleanup system. The system was incapable of adequately cleaning this gas at low velocities and the downstream piping plugged frequently. 

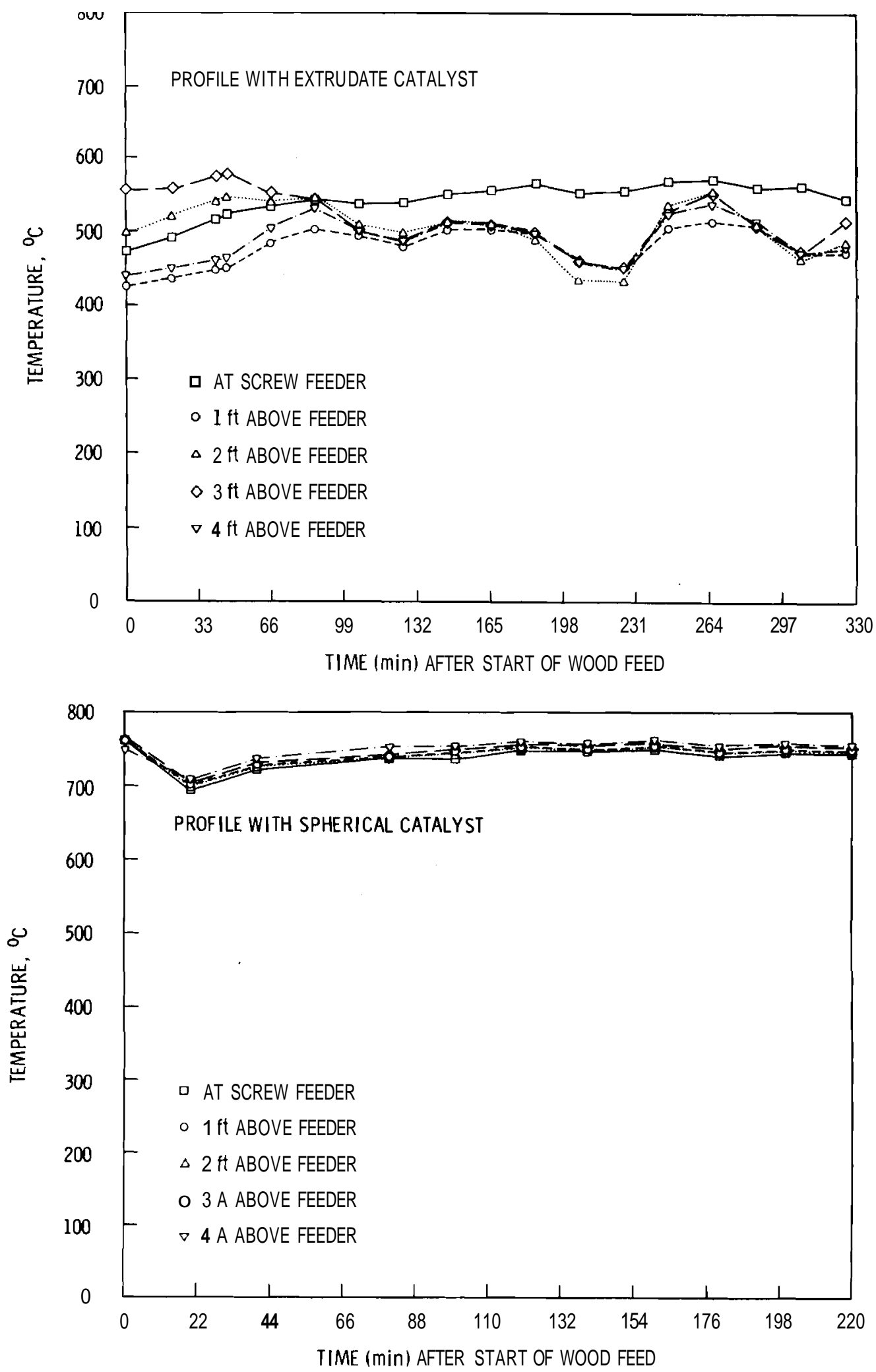

FIGURE 42. Temperature Profiles in Fluid-Bed Gasifier 
A spherical catalyst was obtained from W. R. Grace \& Co., The Davison Chemical Division of Baltimore, Maryland. The catalyst composition is proprietary but has the following general properties:

- main constituents - alumina, nickel

- U.S. Screen Size - $-16+30$ mesh

- particle density - $92 \mathrm{lb} / \mathrm{ft}^{3}\left(1480 \mathrm{~kg} / \mathrm{m}^{3}\right)$

- bulk density - $55 \mathrm{lb} / \mathrm{ft}^{3}\left(880 \mathrm{~kg} / \mathrm{m}^{3}\right)$

Results of tests with the spherical catalyst before and after regeneration are presented in Table 30 .

The catalyst was regenerated with steam at $750^{\circ} \mathrm{C}$ followed by hydrogen reduction at $450^{\circ} \mathrm{C}$ after Tést 4 . Regeneration was effective as can be determined from the data in Table 30 (Test 5). However, the catalyst appears to deactivate rapidly after regeneration (Tests 6 and 7).

Graphical comparisons of catalyzed versus uncatalyzed results are shown in Figure 43 for methane production and Figure 44 for synthesis gas production. The advantages of catalyzed gasification are obvious. Calculation of Equilibrium Gas Compositions

A computer program that calculates chemical equilibrium between solid carbon and gases was developed in 1980. The program was needed to determine the deviations from equilibrium in both the laboratory-scale gasifier and the PDU gasifier. The program was useful for estimating gasifier performance at 10 atm pressure for the economic evaluation of methane and methanol production. Finally, the program was used to determine the effects of varying the steamto-wood ratio at $7 \mathrm{~atm}$ to help provide design data for future pressurized operation.

The equilibrium program describes a batch system. Wood and steam are put into the system and equilibrium compositions at a specified temperature and pressure are calculated. It can be easily modified for other feedstocks and other reacting gases. 
TABLE 30. Results of Fluid Bed PDU Tests with Nickel Catalyst

\begin{tabular}{|c|c|c|c|c|c|c|c|}
\hline Test No. & 1 & 2 & 3 & 4 & 5 & 6 & 7 \\
\hline Temperature, ${ }^{{ }^{\circ} \mathrm{C}}$ & 550 & 600 & 650 & 700 & 700 & 710 & 750 \\
\hline \multicolumn{8}{|c|}{ Gas Composition, vol\% } \\
\hline $\mathrm{H}_{2}$ & 47.6 & 43.5 & 53.5 & 42.4 & 55.0 & 46.8 & 34.0 \\
\hline $\mathrm{CH}_{4}^{2}$ & 11.7 & 14.3 & 4.3 & 7.9 & 2.0 & 5.2 & 12.3 \\
\hline $\mathrm{CO}$ & 7.4 & 11.5 & 18.4 & 25.2 & 21.2 & 24.0 & 27.9 \\
\hline $\mathrm{CO}_{2}$ & 33.0 & 30.3 & 23.3 & 22.7 & 20.5 & 21.3 & 22.1 \\
\hline $\mathrm{C}_{2}$ & 0.0 & 0.0 & 0.0 & 1.2 & 0.0 & 0.8 & 1.9 \\
\hline$c_{3}$ & 0.2 & 0.2 & 0.3 & 0.4 & 0.0 & 0.2 & 0.4 \\
\hline
\end{tabular}

$\begin{array}{llllllll}\text { Weight Ratio Steam:Wood } & 1.0 & 0.60 & 0.63 & 0.76 & 0.75 & 0.6 & 0.7\end{array}$

Product Gas Yield

$\begin{array}{lccccccc}\mathrm{scf} / \mathrm{lb} \text { wood } & 21.7 & 19.4 & 21.9 & 18.6 & 27.2 & 18.5 & 16.1 \\ \left(\mathrm{~nm}^{3} / \mathrm{kg}\right) & (1.35) & (1.21) & (1.37) & (1.16) & (1.70) & (1.15) & (1.01)\end{array}$

Carbon Conversion, \% gas

liquid

solid

$\begin{array}{rrrrrrr}78 & 74 & 70 & 73 & 82 & 66 & 72 \\ 1 & 1 & 1 & 3 & 1 & 1 & 2 \\ 26 & 15 & 18 & 23 & 22 & 21 & 23\end{array}$

Potential Methane Yield

$\begin{array}{llllllll}\mathrm{scf} / \mathrm{ton} & 11,000 & 10,900 & 9,800 & 9,200 & 11,500 & 8,500 & 8,900 \\ \left(\mathrm{~nm}^{3} / \mathrm{t}\right) & (340) & (340) & (310) & (290) & (360) & (260) & (280)\end{array}$

Potential Methanol Yield without reforming,

wt/wt dry wood

$\begin{array}{lllllll}0.34 & 0.29 & 0.44 & 0.35 & 0.58 & 0.37 & 0.28\end{array}$

Cold Gas Efficiency

79

$77 \quad 75 \quad 71$

71

88

65

67 


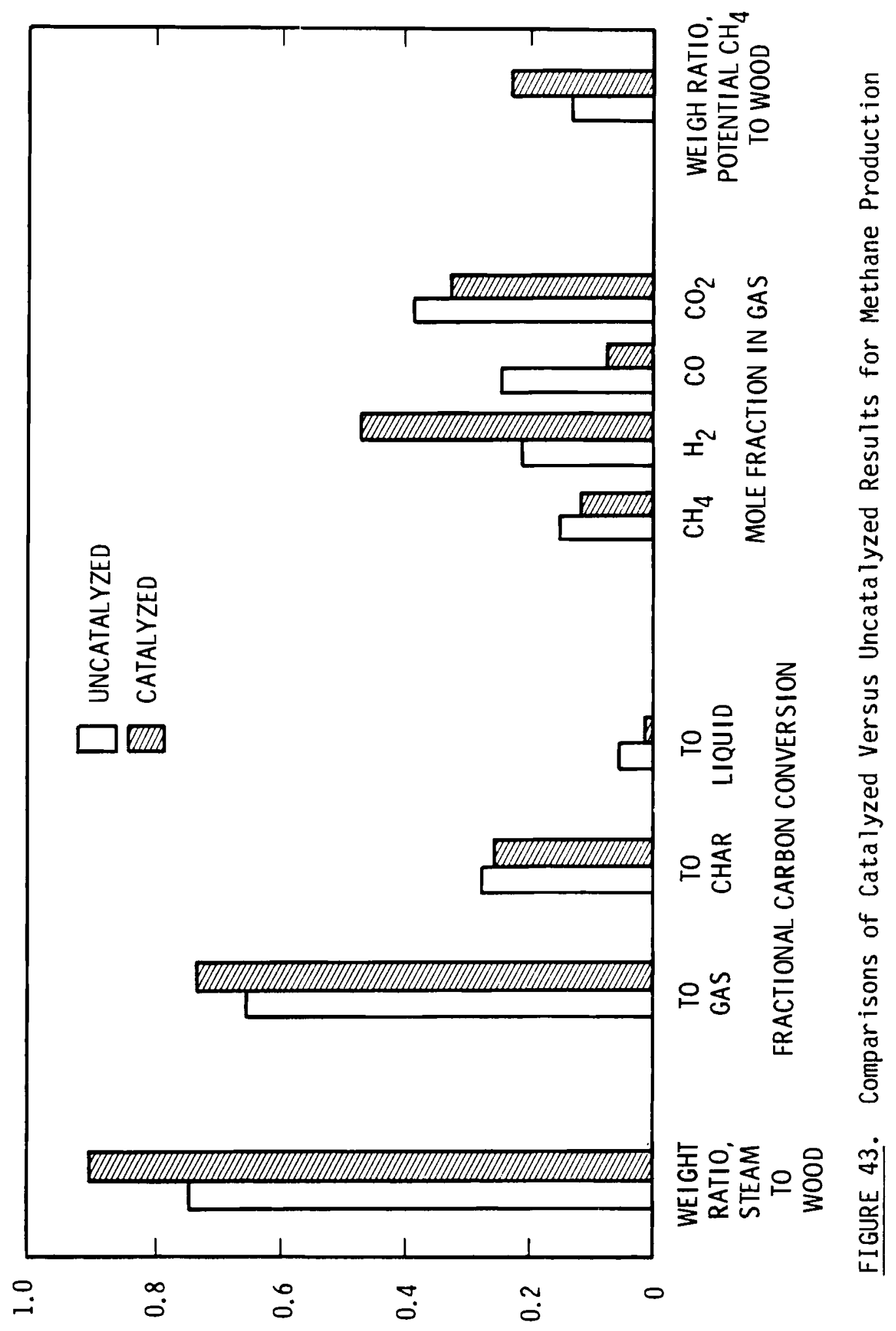




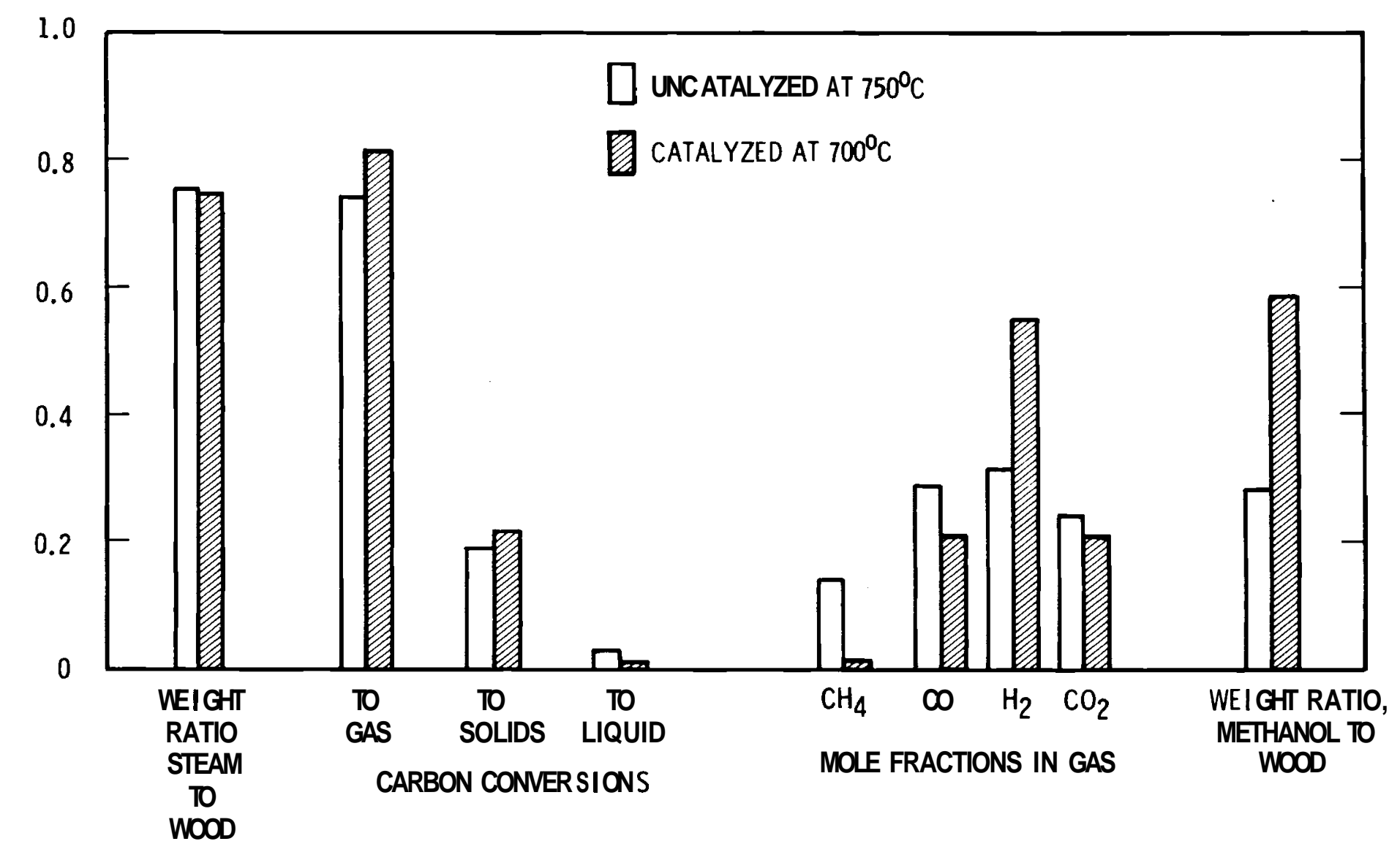

FIGURE 44. Comparisons of Catalyzed versus Uncatalyzed Results for Synthesis Gas Production 
The assumptions used in the program are:

- no liquid phase present

- the only gas species considered are $\mathrm{H}_{2}, \mathrm{H}_{2} \mathrm{O}, \mathrm{CH}_{4}, \mathrm{CO}$, and $\mathrm{CO}_{2}$

- any solid is $100 \%$ carbon and has an activity of 1

- all hydrogen and oxygen in the wood are converted to gas.

The method of solution is an iterative Newton-Raphson solution of seven equations and seven unknowns. The equations include an element balance for carbon, hydrogen, and oxygen, (three equations), three equilibrium equations, and one equation expressing Dalton's law of partial pressures. The equilibrium equations are for the following heterogeneous reactions:

$$
\begin{aligned}
& \mathrm{C}+\mathrm{CO}_{2}+2 \mathrm{CO} \\
& \mathrm{C}+\mathrm{H}_{2} \mathrm{O}+\mathrm{CO}+\mathrm{H}_{2} \\
& \mathrm{C}+2 \mathrm{H}_{2}+\mathrm{CH}_{4}
\end{aligned}
$$

Equilibrium constants for these reactions were obtained for a temperature range of $700^{\circ} \mathrm{K}$ to $1200^{\circ} \mathrm{K}$ from Gumz (1950) and fitted to equations of the form $K=\exp \left(A+B / T+C / T^{2}\right)$, where $K$ is the equilibrium constant, $T$ is absolute temperature, and $\mathrm{A}, \mathrm{B}$, and $\mathrm{C}$ are constants.

Figures 45 and 46 show the effects of temperatures on the dry gas equilibrium composition at atmospheric pressure for steam-to-wood ratios of 0.33 and 1 , respectively. These ratios were suggested from early laboratory experiments for methane production and synthesis gas production, respectively. Note the increase in the carbon conversion to gas with increasing temperature. Results from one PDU test and laboratory-scale reactor tests are plotted with the $1 \mathrm{~atm}$ equilibrium calculations for comparison. Potential methane and methanol yields are plotted in Figure 47. The effect of temperature on equilibrium standard heats of reaction is shown in Figure 48. Figure 49 shows the effect of pressure on the standard heats of reaction.

For the economic scale-up of biomass gasification for methane or synthesis gas production, it may be desirable to operate at elevated pressures to reduce the downstream compression costs. The equilibrium program has been used to estimate the effects of operating at 10 atm for use in the economic feasiblity studies. 


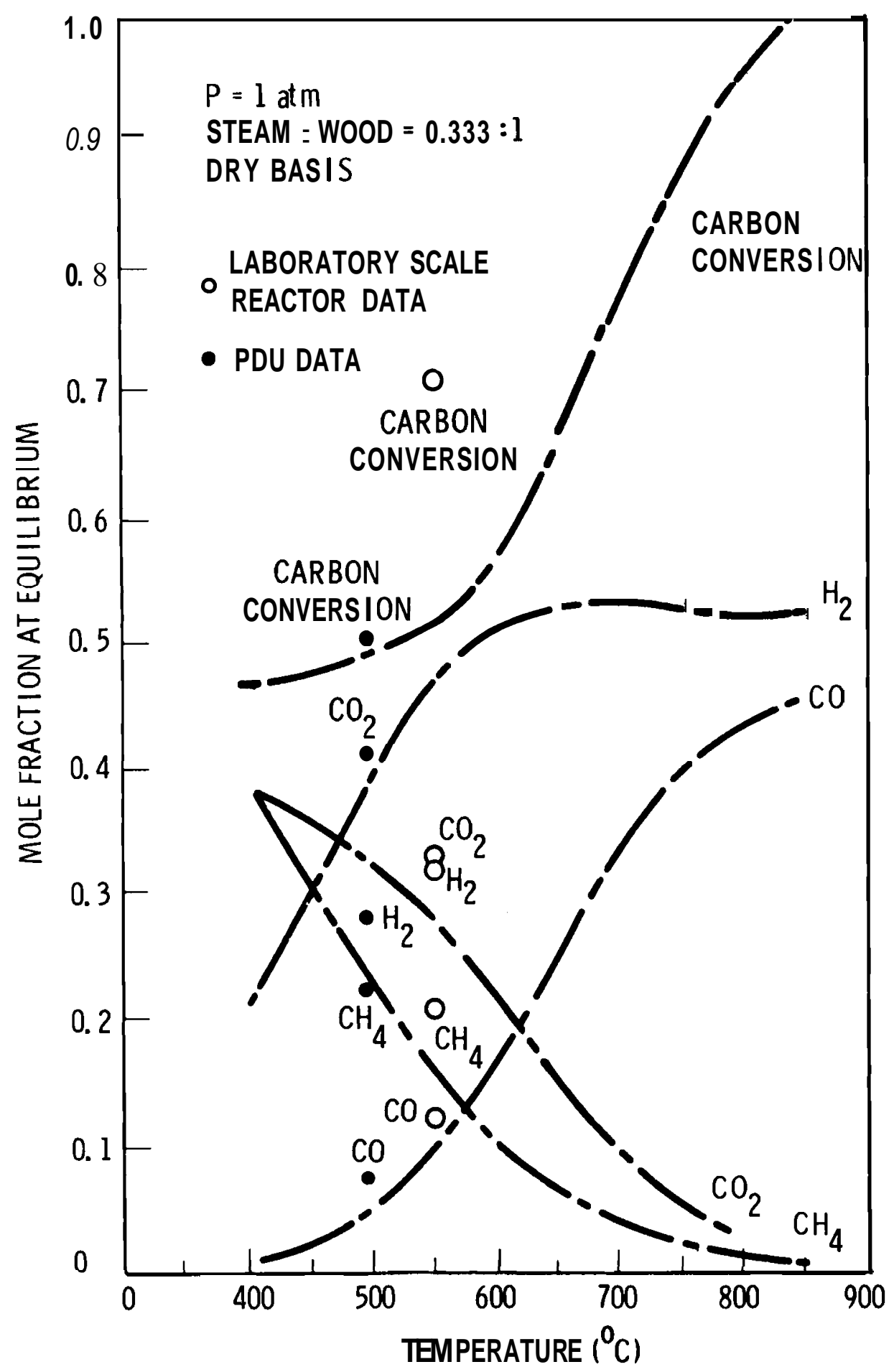

FIGURE 45. Effects of Temperature on the Dry Gas Equilibrium Composition at Atmospheric Pressure for Steam-to-Wood Ratio of 0.33 


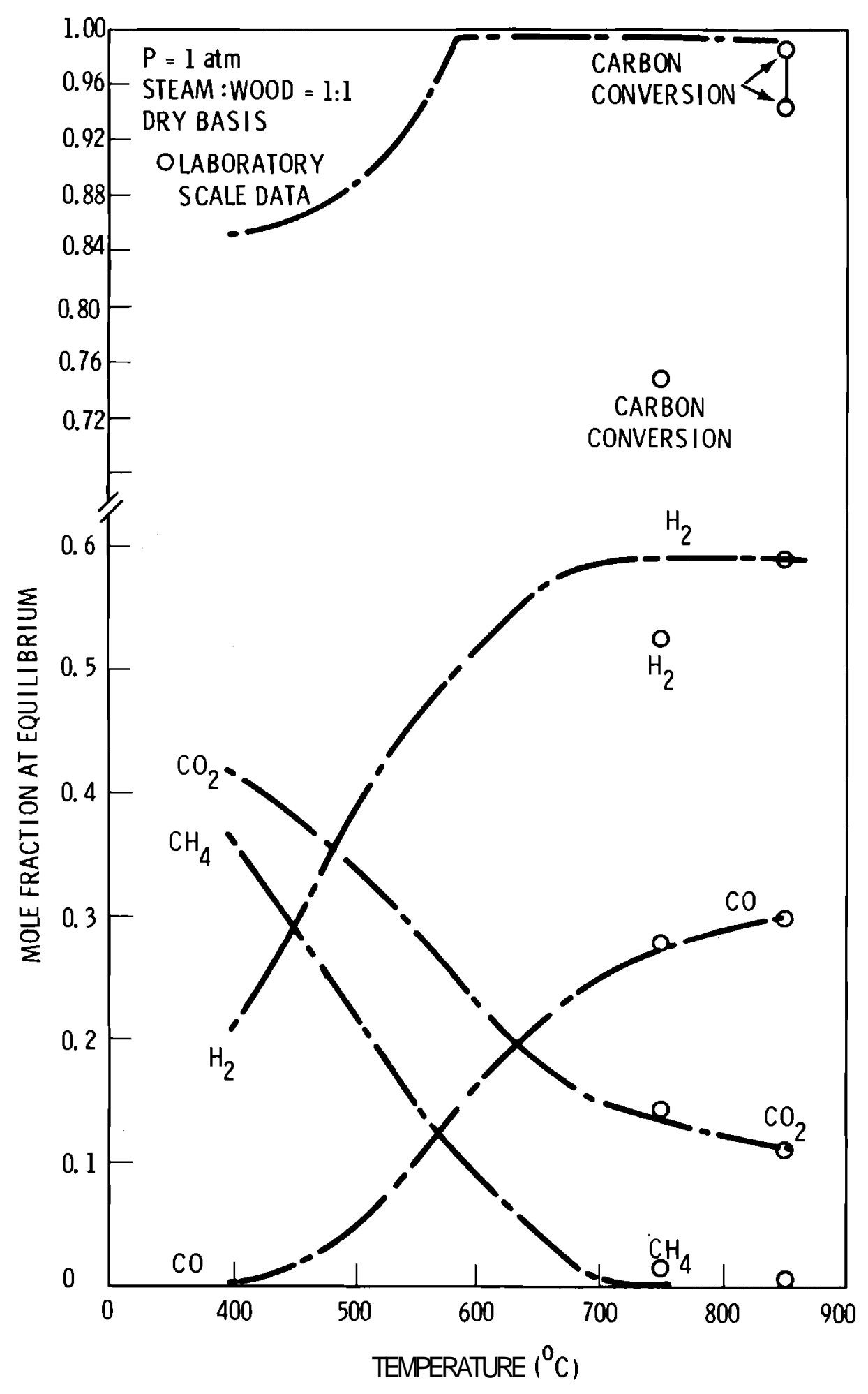

FIGURE 46. Effects of Temperature on the Dry Gas Equilibrium Composition at Atmospheric Pressure for Steam-to-Wood Ratio of 1 


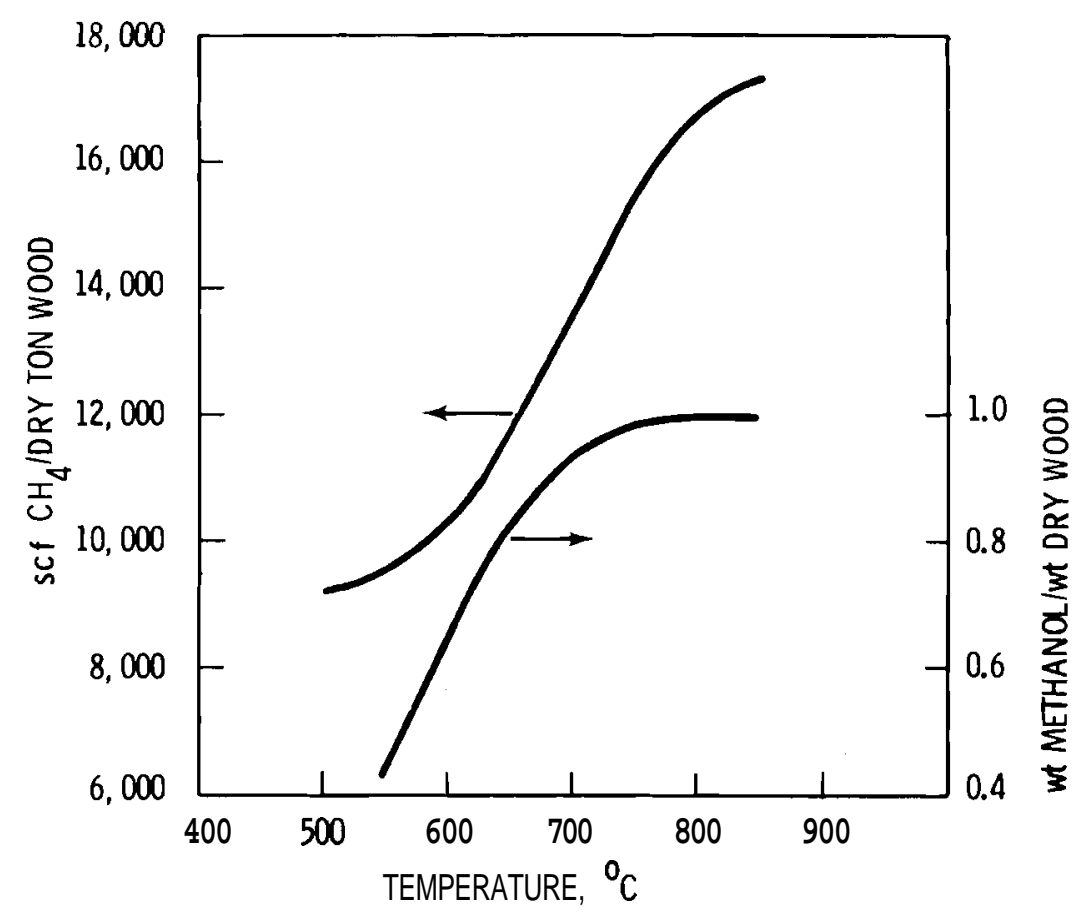

FIGURE 47. Potential Methane and Methanol Yields at Atmospheric Pressure

Figure 50 shows the equilibrium dry gas composition of a simulated SNG production case. Methane production is greatly favored by increased pressure. Carbon conversion to gas is slightly affected.

Figure 51 shows the pressure effect of a simulated synthesis gas case. By equilibrium calculations, carbon conversion is $100 \%$ at $750^{\circ} \mathrm{C}$. Again, methane production increases with pressure. Methane is not desirable above certain levels of methanol synthesis. The final decision of the desired gasification pressure will have to weigh the increased methane content of the gas against the reduced compression costs.

One other advantage of pressure operation is that the overall reaction becomes less endothermic and in some cases becomes exothermic. This fact can greatly reduce the complexity of the gasifier. Less heat transfer area will be needed at higher pressures. 


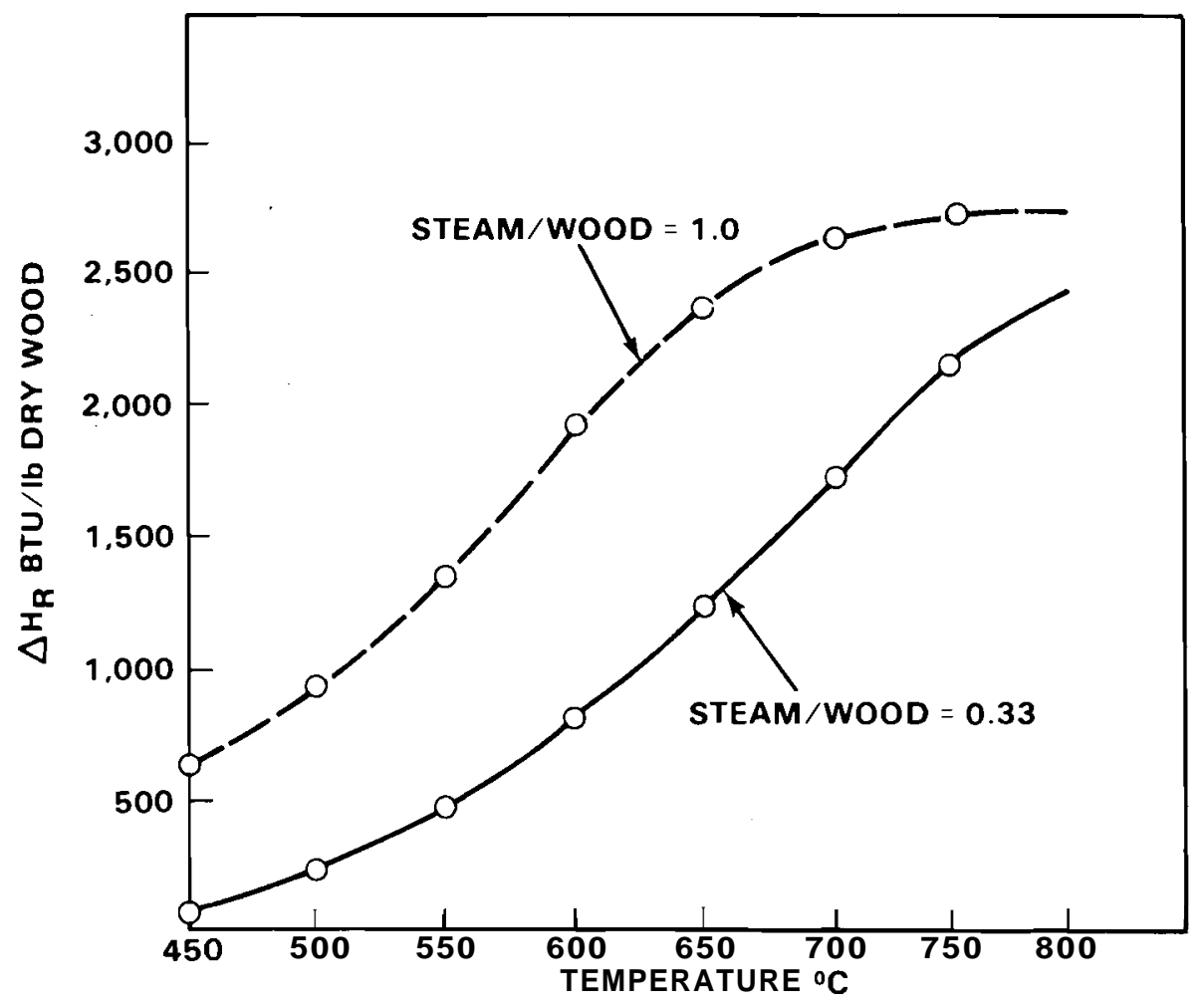

FIGURE 48. Effect of Temperature on Equilibrium Standard Heats of Reaction 


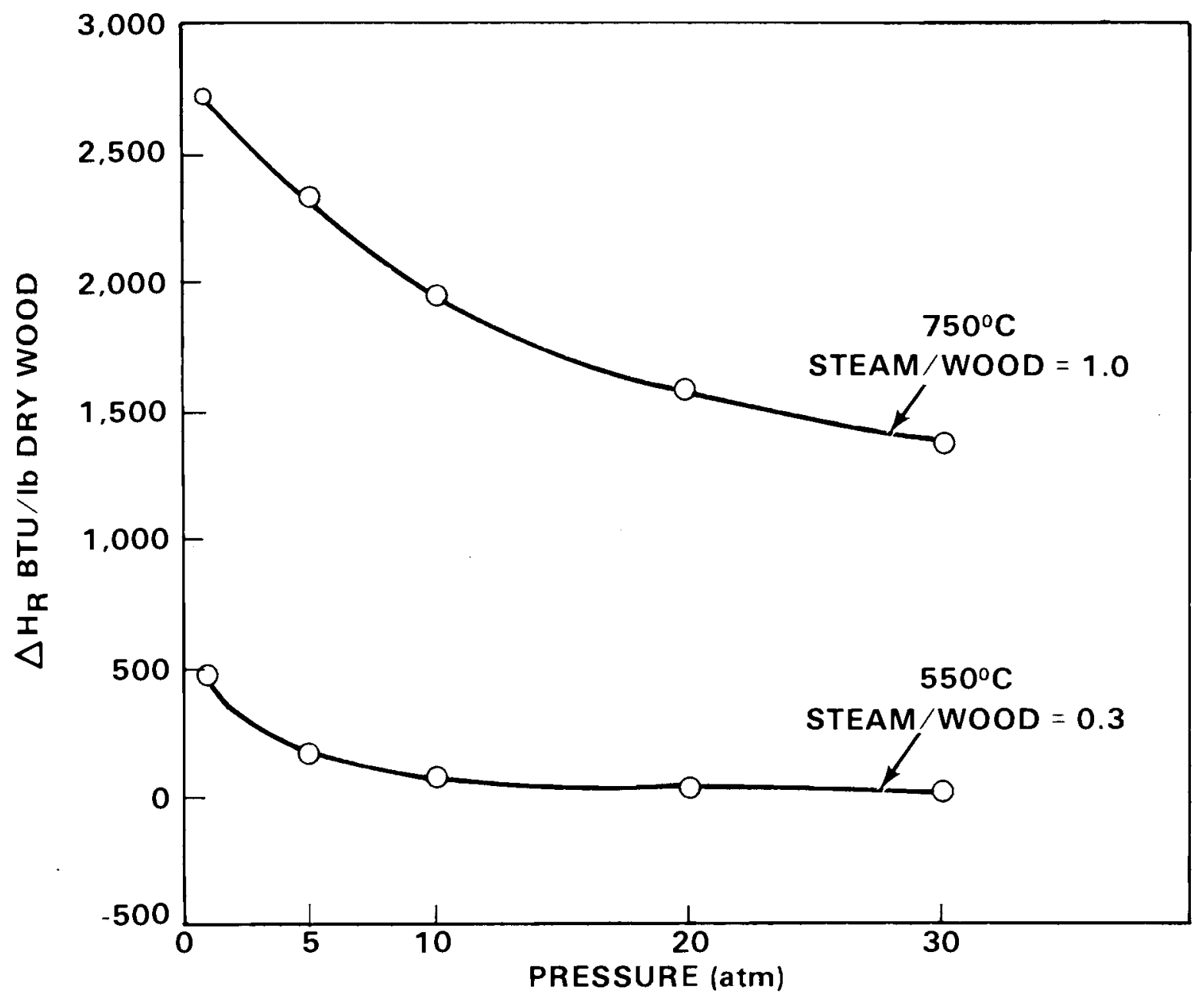

FIGURE 49. Effect of Pressure on Equilibrium Standard Heats of Reaction 


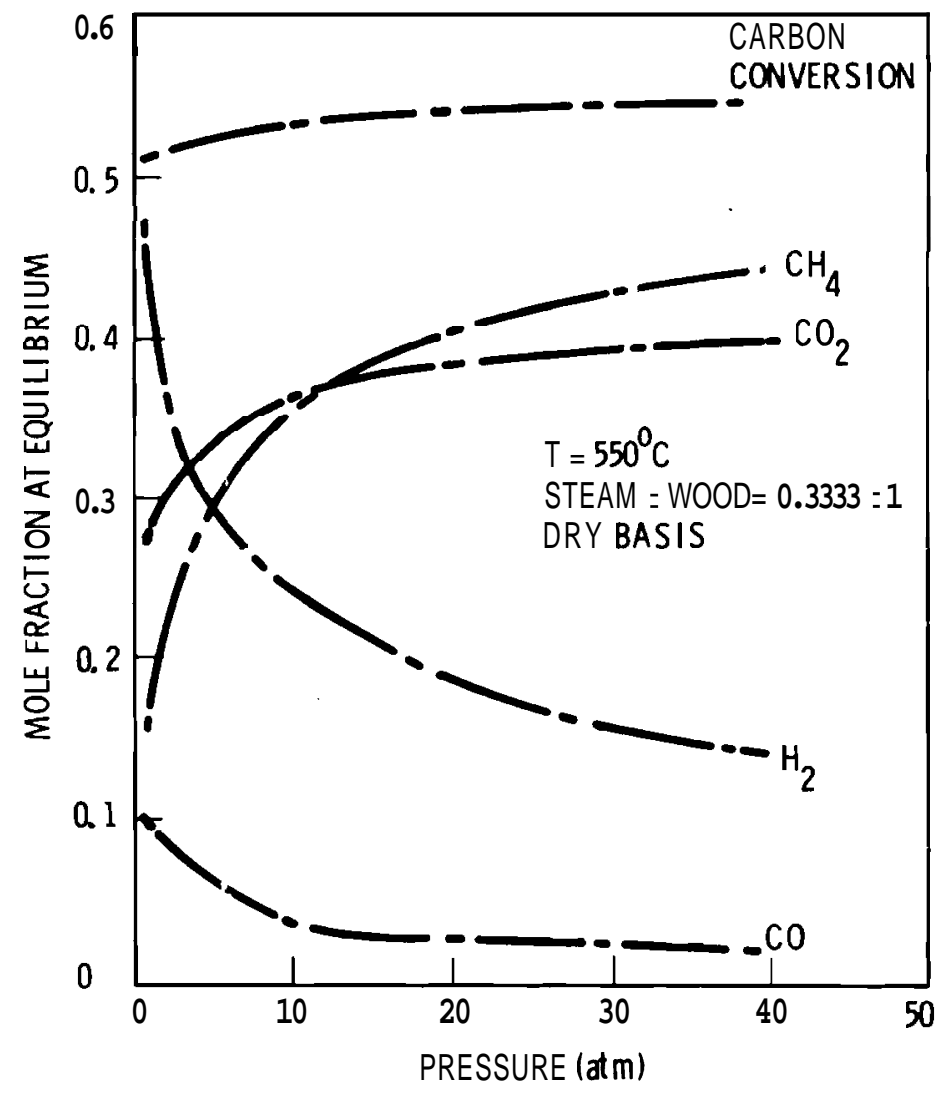

FIGURE 50. Effect of Pressure on Production of a Methane-Rich Gas 


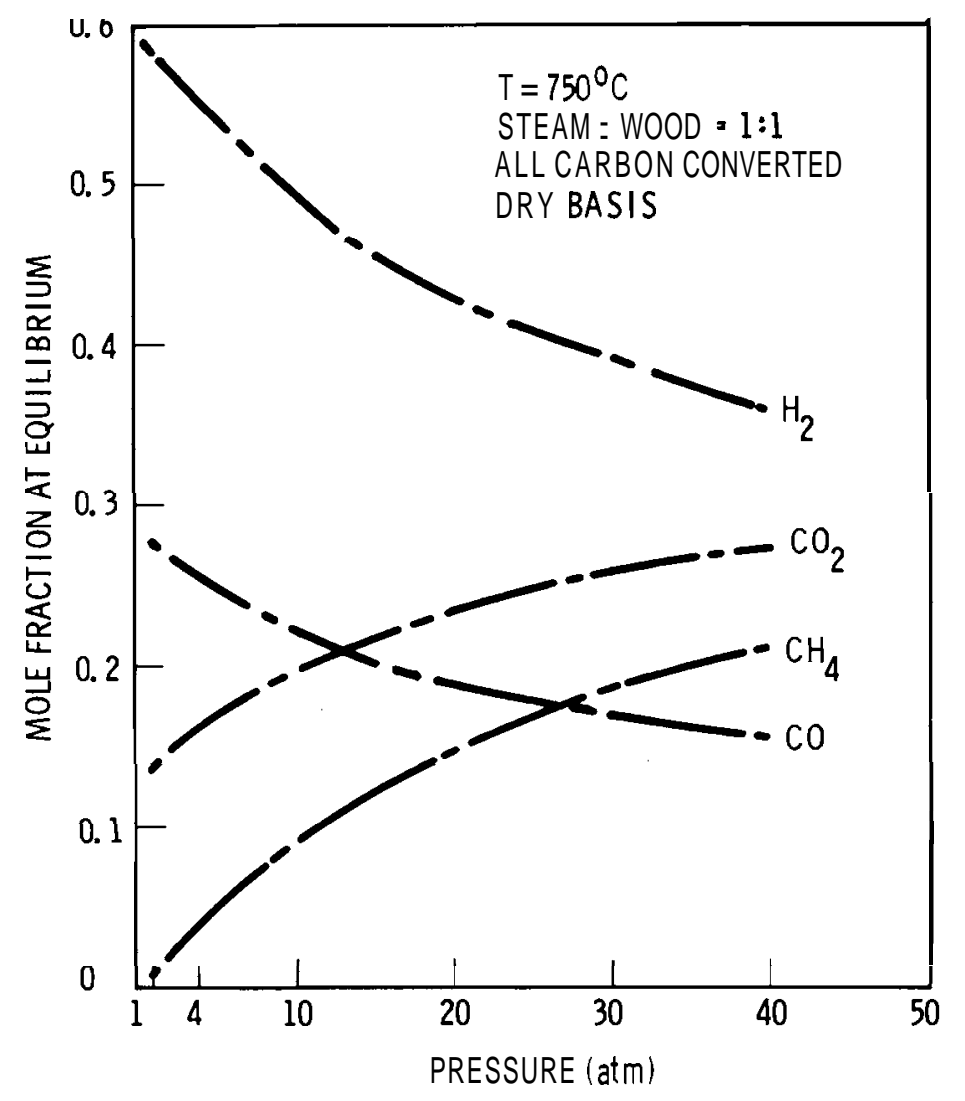

FIGURE 51. Effect of Pressure on Production of a Methanol Synthesis Gas 


\section{FEASIBILITY STUDIES}

Information on process economics is needed to determine which options offer significant cost advantages and should, therefore, be further investigated. For this study, Davy McKee of Cleveland, Ohio evaluated the economics of using catalytic steam gasification of wood in two commercial operations. Two process plants were designed for the study: 1) for the conversion of wood to methane and 2) for the conversion of wood to methanol. Results of the study are summarized in the following discussion and detailed in Appendices A through D of this report.

Since the catalytic processes are still in the development stage, process conditions and outputs are constantly changing. Already, yields from catalytic gasification are improved over those transmitted to Davy McKee for use in their evaluations. Because these changes can significantly affect process economics, a computer code is being developed to evaluate the effect of process modifications on overall economic feasibility.

\section{ECONOMICS OF CATALYTIC GASIFICATION}

Two different plants and plant capacities were considered for application of catalytic gasificaton of wood: a wood-to-methane plant and a wood-tomethanol plant, each at 2000 and 200 tons (1800 and 180 t) per day dry wood. Design bases and descriptions of these plants are presented in the following discussion. Capital and operating costs estimated by Davy McKee are summarized for the plants. Product selling prices are presented for utility and private investor financing. Details are presented in Appendices A through D of this report.

Wood-to-Methane Plant

The design basis for the wood-to-methane plant was developed in the laboratory and PDU studies and adjusted to operation at 10 atm pressure. The main adjustment was an increase in the methane concentration in the gases from the gasifier. Overall gas yield from the gasifier used in the design is less than more recent PDU yields as presented in earlier discussion. 
The design basis for the plant is summarized in Table 31. A block diagram for the wood-to-methane plant is shown in Figure 52. Wood to the plant is considered to be $60 \%$ forest residue, $20 \%$ fir , and $20 \%$ alder with the composition shown in Table 32. The design basis for the small plant is simply scaled to the capacity of 200 tons/day dry wood (180 t/day).

Char and catalyst (nickel on silica-alumina) are collected from the gas by the gas cleaning system and combined with the overflow from the gasifier. The ratio of char to catalyst by weight is 50:1. Half the catalyst material is recovered in the raw gas from the gasifier and half comes with the overflow from the gasifier. The entrained particulate has the following size distribution:

\begin{tabular}{|c|c|}
\hline Size, $\mu$ & Weight o \\
\hline $\begin{array}{c}+149 \\
-149+105 \\
-105+74 \\
-74+53 \\
-53+10 \\
-10\end{array}$ & $\begin{array}{r}10 \\
5 \\
5 \\
5 \\
55 \\
20\end{array}$ \\
\hline
\end{tabular}

Fines in the char-catalyst mixture are primarily char. Very little catalyst is in the fines that are removed by screening. The char and catalyst in the coarse fraction can then be separated by a magnetic roll separator. Catalyst recovery is $95 \%$ for the wood-to-methane plant.

The catalyst is regenerated by passing steam at $650^{\circ} \mathrm{C}$ over the catalyst for $20 \mathrm{~h}$. The total steam requirement is 20 times the weight of catalyst. The catalyst is reduced by product gas from the gasifier. The consumption of hydrogen to reduce the catalyst is $6.4 \times 10^{-4} \mathrm{lb} \cdot \mathrm{mole} / \mathrm{lb}(\mathrm{g} \cdot \mathrm{mole} / \mathrm{g})$ of catalyst. All other operations in the schematics shown in Figure 51 are based on commercially available technology. A brief description of the plants is presented in the following discussion.

The wood-to-methane plants were designed to process 2000 ton/day (1800 t/day) of dry wood and $10 \%$ of this capacity. Production for the large 
TABLE 31. Wood-to-Methane Plant Design Basis--2000 ton/day Dry Wood Wood-to-Methane

Capacity, Dry Tons Wood/day ( $t /$ day) Location

Product Specifications
2000 (1800)

Pacific Northwest

SNG:

$\mathrm{H} \mathrm{N}-960 \mathrm{Btu} / \mathrm{scf}$

- $\left(36 \mathrm{~mJ} / \mathrm{nm}^{3}\right)$

0.1 vol\% co

3 vol\% $\mathrm{CO}_{2}$

$\mathrm{H}_{2} \mathrm{~S}-0.25 \mathrm{~g} / 100 \mathrm{scf}$

- $\left(0.57 \mathrm{~g} / 100 \mathrm{~nm}^{3}\right)$

Water - $7 \mathrm{1b} / 10^{6} \mathrm{scf}$

- $\left(110 \mathrm{~kg} / 10^{6} \mathrm{~m}^{3}\right)$

Gasifier Conditions

Temperature, ${ }^{\circ} \mathrm{C}$

550

Pressure, atm

10

Steam Rate, wt/wt Dry Wood

0.33

Char production, wt/wt MAF (a) Wood 0.24

Char Heating Value, Btu/lb $(\mathrm{kJ} / \mathrm{kg}) \quad 13,500$

$(31,400)$

Gas Production, wt/wt MAF wood

1.09

Cold Gas Efficiency, \%

65

Gas Composition, vo 1\%

38.0

11.2

$\mathrm{CH}_{4}$

23.6

$\mathrm{CO}_{2}$

19.5

$\mathrm{CO}$

7.7

(a) MAF is moisture ash free. 


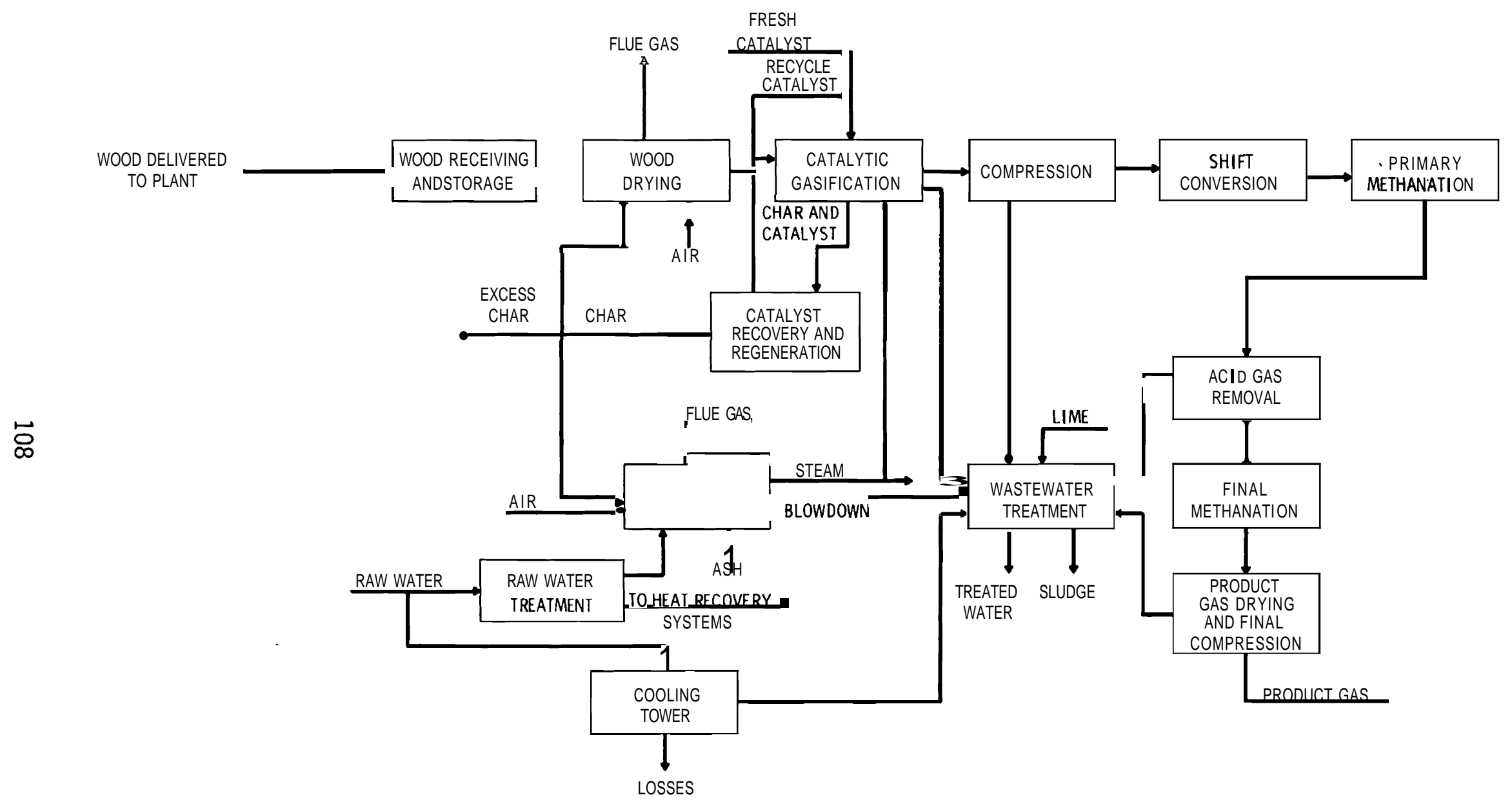

\section{FIGURE 52. Wood-To-Methane Process Areas}


TABLE 32. Ultimate Analysis of Feedstock

$\begin{array}{crrrrr} & \text { Residue } & \text { Alder } & & \text { Fir } & \text { Weighted } \\ \text { Wt\% Dry } & & & & \\ \text { Carbon } & 46.39 & 45.34 & 47.98 & 46.50 \\ \text { Hydrogen } & 5.84 & 5.90 & 5.96 & 5.87 \\ \text { Nitrogen } & 0.00 & 0.00 & 0.00 & 0.00 \\ \text { Oxygen } & 39.09 & 47.78 & 44.88 & 41.99 \\ \text { Ash } & 8.68 & 0.98 & 1.18 & 5.64 \\ \text { Wt\% Moisture (as received) } & 53.90 & 50.81 & 35.00 & 49.50 \\ \text { Btu/dry lb } & 8,720 & 8,610 & 8,780 & 8,710\end{array}$

plant is 21.6 million scfd $\left(610,000 \mathrm{~nm}^{3} /\right.$ day $)$ of SNG with a HHV of $956 \mathrm{Btu} / \mathrm{scf}$ $\left(35,600 \mathrm{~kJ} / \mathrm{nm}^{3}\right)$. Al1 process and support facilities necessary to convert wood to SNG are included in the cost estimates.

The thermal efficiency of the plants, as defined by Equation (8), is $58.3 \%$. When the heating value of the excess char is included in the output, the thermal efficiency is $62.6 \%$.

$$
\text { Efficiency, } \%=100 \times \frac{\text { SNG } H N}{\text { Wood, HN + Electricity + Diesel Fuel }}
$$

Wood storage, handling, and drying are major capital cost outlays for the plants. A brief description of the systems for the large plant follows.

The bulk of the feedstock is received already chipped. The chips are delivered by truck-trailer rigs that are weighed on one of the two truck scales when entering and leaving the unloading area. Six unloading stations are installed to permit a maximum unloading rate of $1200 \mathrm{ton} / \mathrm{h}(1090 \mathrm{t} / \mathrm{h})$, which represents 48 trucks $/ h$. The capacity to handle this number of trucks ensures continuous unloading particularly when trucks are making deliveries from several logging sites and may arrive in groups. Each truck-unloading station consists of a hydraulic truck dumper, a truck dump hopper, and a chain feeder. 
Each chain feeder transports the chips onto a tripper/stacker belt conveyor or onto a reclaiming belt conveyor. The tripper/stacker conveyor delivers the chips to one of the two primary storage piles via a double wing stacker. Each primary pile is limited to approximately $40 \mathrm{ft}(12 \mathrm{~m}) \mathrm{high}$, as some bark and fines are supplied along with the chips. The stacker builds a 25-day capacity storage; any enlargement of the storage is done by two bulldozers spreading the piles. Each of the two primary storage piles is $2800 \mathbf{f t}$ $(850 \mathrm{~m})$ long and $80 \mathrm{ft}(24 \mathrm{~m})$ wide for the 25 -day capacity, with possible enlargement to $240 \mathrm{ft}(73 \mathrm{~m})$ width for a 125-day capacity.

The reclaiming of chips from the primary storage is done with 14 chain reclaimers ( $8 \mathrm{ft}(2.4 \mathrm{~m})$ wide), seven for each pile. Each reclaimer has a capacity of $700 \mathrm{ton} / \mathrm{h}(630 \mathrm{t} / \mathrm{h})$ which represents the total required reclaiming rate based on $8 \mathrm{~h} /$ day, 5 days/week. The bulldozers are used to push chips towards reclaimers when needed. Two reclaiming belt conveyors, one for each pile, collect chips from the respective chain reclaimers and deliver them to the primary screening station. The primary screening station consists of equipment for rock and tramp iron removal and for rechipping of oversize chips.

Screened chips are transported by a tripper/stacker conveyor to the secondary storage pile. Stacking and reclaiming of the chips are identical to the method used for primary storage. Two piles, each $1800 \mathrm{ft}(550 \mathrm{~m})$ long and $80 \mathrm{ft}(24 \mathrm{~m})$ wide form a 14-day storage. Also a provision is made to bypass secondary storage by using one of the two reclaiming belt conveyors.

The chips from secondary storage are screened to remove any incidental oversize trash and conveyed by chain conveyors to the surge bins for the dryers. Two conveying strands and two secondary screens are used to ensure uninterrupted chip supply.

Six rotary drum dryers complete with a burner, ash removal cyclone, exhaust dust cyclone, ducting, and all necessary appurtenances are installed to reduce the moisture content of green chips from $50 \mathrm{wt} \%$ of total feed to $10 \mathrm{wt} \%$. The by-product char from the gasifier is used to fuel the burners for the dryers. Five dryers normally operate while the sixth dryer is on standby. 
Dried chips are conveyed from the dryers to a surge bin of one hour capacity. The chip inventory of this bin allows a startup of the standby dryer. The chips from this bin are conveyed to three gasifier lock hopper systems equally spaced at $120^{\circ}$. The chips are then screw fed continuously to the base of the gasifier at an adjustable rate from each lock hopper.

Three gasifiers are provided for the large plant. Each gasifier in the large plant is cylindrical with dimensions of $15 \mathrm{ft}(4.3 \mathrm{~m})$ ID by $45 \mathrm{ft}$ $(13.7 \mathrm{~m})$ total height. Each is provided with $440 \mathrm{ft}^{2}\left(41 \mathrm{~m}^{2}\right)$ of 2 -in. $(5-\mathrm{cm})$ tubing (RA-533 or Incoloy $800 \mathrm{H}$ ) for heat addition to the fluid bed of wood char and catalyst. The operating depth of the fluid bed is $10 \mathrm{ft}(3 \mathrm{~m})$. A single scaled-down version of this gasifier is provided for the 200-ton/day plant.

The wood chips are gasified in the presence of catalyst with steam to produce a gas containing methane, carbon dioxide, hydrogen, carbon monoxide, and water. Gasification is not complete and there is a char residue by-product. The gasifier operates at conditions of 10 atm $(150 \mathrm{psia})$ and $550^{\circ} \mathrm{C}\left(1000^{\circ} \mathrm{F}\right)$. The steam-carbon reaction is highly endothermic, while the methanation reaction is exothermic. The net gasification reactions are slightly exothermic; however, a heat input is needed to assist heatup of reactants. The heat is supplied by hot combustion gases (up to $1000^{\circ} \mathrm{C}$ ) flowing through a bank of tubes immersed in the reaction bed. Char residue by-product is the fuel for the gasifier heater. After leaving the gasifier, the combustion gases pass through a series of heat exchangers to recover heat. The gases are used to superheat steam to the gasifier operating temperature, to generate $600 \mathrm{psig}$ steam, and to preheat the combustion air to the char burner.

The remainder of the gasification area is devoted to heat recovery, catalyst recovery, regeneration and recycle, and char recovery. The raw gas from the gasifier passes through a series of exchangers that recover heat by generating superheated steam. These exchangers are a series of coils in a refractory-lined shell through which the raw gas flows. These exchangers are, in the order that the raw gas sees them, the steam superheater, the boiler, and the boiler feedwater preheater. The gas is cooled to $175^{\circ} \mathrm{C}\left(350^{\circ} \mathrm{F}\right)$ in these exchangers. The gas contains particulates in the form of entrained char and 
catalyst. The gas is then cleaned by a cyclone followed by a bag filter containing a high temperature glass fabric. The gas then flows to the next processing area. The catalyst recovery area consists of screens and a magnetic separator and is completely enclosed to prevent air contact with the catalyst.

Commercially available systems comprise the remainder of the plant. Acid gas removal is by the Benfield process.

All liquid wastewater streams for the plant are treated in a neutralizing basin and a subsequent three-stage biological treatment system before being allowed to overflow to drainage.

The capital cost estimate for the 2000-ton/day plant as determined by Davy McKee, Inc., is sumnarized in Table 33. The capital cost estimates (September 1980 basis) for the 2000 -ton $(1800-t) /$ day dry wood plant is $\$ 95,115,000$. Estimate accuracy is reported to be $\pm 25 \%$.

Breakdown of the total direct costs by plant area is given in Table 34 for the 2000-ton dry wood/day plant. The major cost areas are wood storage and

TABLE 33. Wood-To-Methane Capital Cost Summary--2000 ton/day Dry Wood

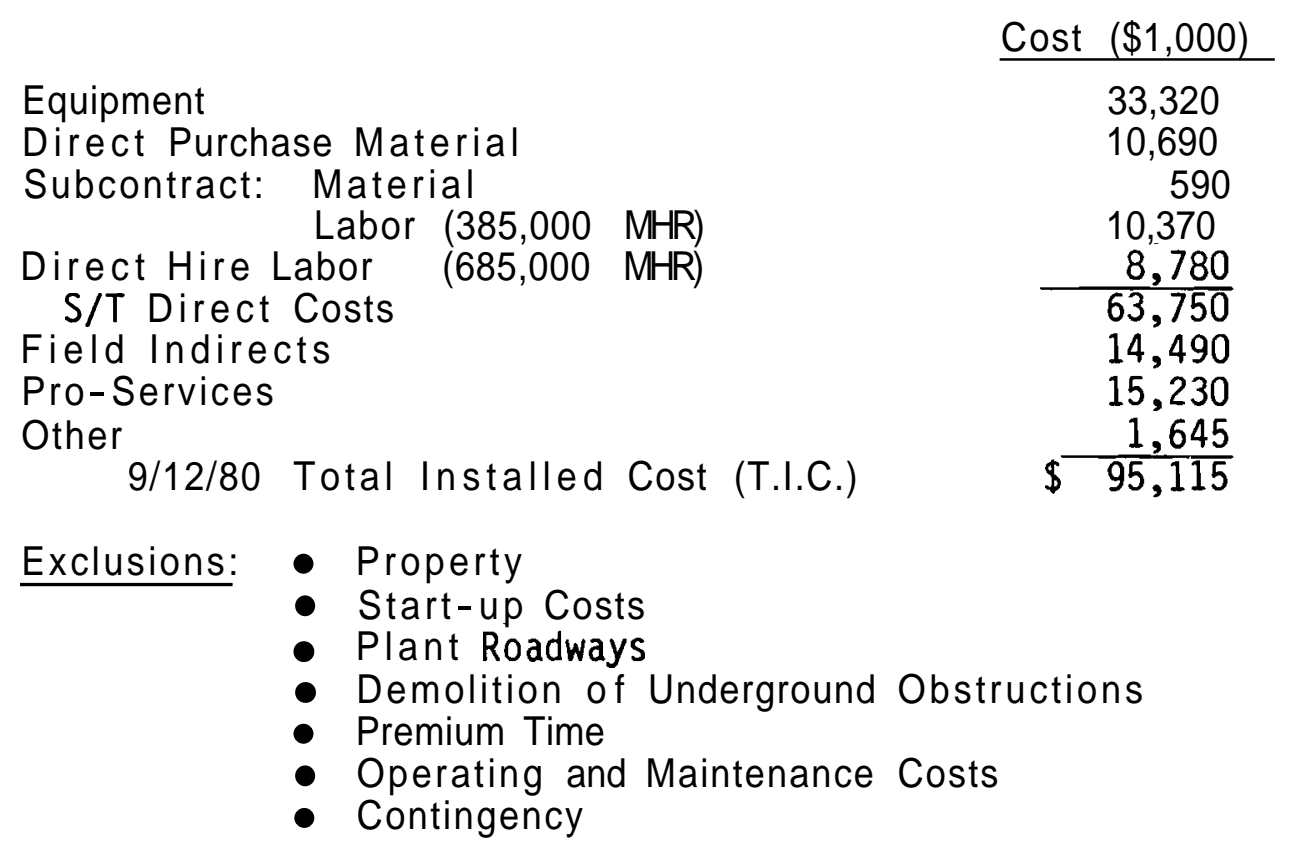


TABLE 34. Direct Cost Summary for Wood-to-Methane Plant-2000 ton/day Dry Wood

\begin{tabular}{lr} 
& Cost $(\$ 1,000)$ \\
\cline { 2 - 2 } Wood Storage and Handling & 17,704 \\
Wood Drying & 6,821 \\
Gasification Area & 11,986 \\
Compression & 1,926 \\
Shift Conversion & 2,998 \\
Primary Methanation & 2,192 \\
Acid Gas Removal & 2,143 \\
Final Methanation and Product Gas Drying & 2,964 \\
Catalyst Regeneration & 1,512 \\
Waste Water Treatment & 1,801 \\
Raw Water and Cooling Water Treatment & 2,483 \\
Boilers and EX Systems & 7,290 \\
Miscellaneous Utility Systems $\quad$ TOTAL & 1,928 \\
\cline { 2 - 2 } & 63,748
\end{tabular}

handling, gasification and wood drying. The gasification area includes the gasifiers, heat recovery equipment, char and catalyst recovery equipment, and wood and catalyst feed hoppers.

The production cost of inethane from wood is calculated based upon the capital costs and operating costs. The methods of calculating these costs are those presented in "Coal Gasification Commercial Concepts Gas Costs Guidelines," a paper prepared for the U.S. Energy Research and Development Administration and the American Gas Association by C. F. Braun \& Co. (NTIS 8463). There are two potential methods of financing a plant of this type, 1) utility financing, and 2) private investor financing. Production costs are calculated using both procedures.

The total plant investment is estimated to be $\$ 95,115,000$ (September 1980 basis). The total capital requirement for the plant is obtained by addition of an allowance for funds during construction, start-up costs, and working 
capital. These costs and the basis for their calculation are shown in Table 35. The total capital requirement for this plant is $\$ 115,191,000$.

The annual direct operating costs for wood conversion to methane are shown in Table 36. These costs include raw materials, utilities, catalysts and chemicals, labor, administration and general overhead, supplies, and taxes and insurance, with a credit for by-product char. Total maintenance costs are calculated as a percentage of plant investment as suggested by the guidelines. The annual costs are $\$ 29,990,000$. The most significant costs are wood, gasifier catalysts, labor, and taxes and insurance. Labor costs are not very easy to reduce significantly, while taxes depend upon local conditions and incentives. The major variable costs are wood and catalyst usage in the gasifier. Studies to improve catalyst life are in progress. At $\$ 20 /$ dry ton for wood, which is the value used for the base case shown in Table 36, wood costs are almost 45\% of the total direct costs and almost one-third of the total production costs with utility financing. Thus, either lowering the wood cost or improving yields from the wood have more impact on costs than any other single variable. The production costs have also been calculated for wood costs of $\$ 5, \$ 10$, and $\$ 40$ per dry ton delivered to the plant, and the impact is illustrated in Figure 53.

TABLE 35. Total Capital Cost Requirement For Wood-to-Methane Plant-2000 ton/day Dry Wood

Total Plant Investment $\frac{\text { Cost }(\$ 1,000)}{95,115}$

Allowance for Funds During Construction (Total Plant Investment x 1.25 yr x 0.09)

10,698

Start-up Costs (20\% of Total Annual Gross Operating Costs)

6,084

Working Capital [Sum of (1) raw material inventory of 14 days at full rate, (2) materials and supplies at $0.9 \%$ of total plant investment, and (3) net receivables at $1 / 24$ annual gas and by-product revenue at calculated sales price] 3,294

Total Capital Requirement $\$ 115,191$ 
TABLE 36. Annual Direct Operating Costs For Wood-to-Methane Plants--2000 ton/day Dry Wood

Operating Factor: 330 days/yr

Cost Component

Annual Use

\$/Unit

Cost

Cost Component
Raw Material
Wood
Utilities
Water
Electricity
Diesel Fuel
Catalysts and Chemicals
Chemicals
Shift Catalyst
Methanation Catalyst
Gasifier Catalyst
Labor
Process Operating
Maintenance
Supervision
Total Gross Operating Cost Per Year
Chares and Insurance
Administration and General Overhead
Supplies

660,000 dry tons

$20 /$ dry ton

$\$ 1000 / \mathrm{yr}$

332,640 Mgal

$3.25 \times 10^{7} \mathrm{kWh}$

$108,900 \mathrm{gal}$

$0.50 / \mathrm{Mgal}$

$0.03 / \mathrm{kWh}$

$1.00 / \mathrm{gal}$

166

974

109

$1500 / \mathrm{ft}^{3}$

380,160 1b

$107 / \mathrm{ft}^{3}$

$435 / \mathrm{ft}^{3}$

510

$8.51 / 1 \mathrm{~b}$

160

444

51 men $2080 \mathrm{~h}$

(a $60 \%$ of total

$10.70 / \mathrm{h}$

3,235

maintenance

( 20\% of process

operating and

maintenance labor

(3) $60 \%$ of total labor

2,636

9 $30 \%$ of process

operating labor

a $40 \%$ of total

maintenance cost

1,135

2,527

732

2.7\% of total plant investment

$\underline{2,568}$

30,421

28,050 tons

$15.35 /$ ton

(431)

Total Net Operating Cost Per Year 


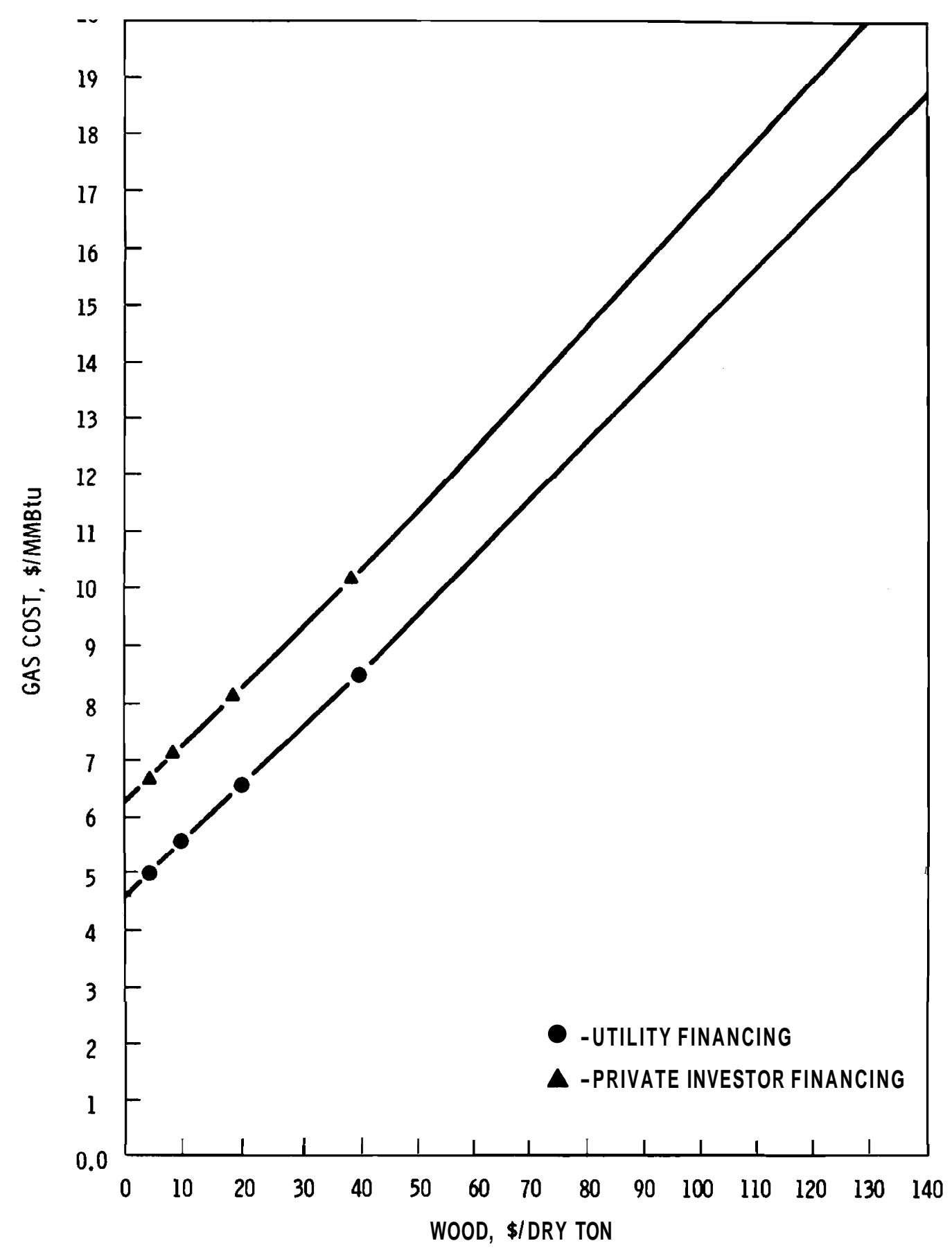

FIGURE 53. Effect of Wood Prices on Gas Cost for 2000 ton/day Dry Wood 
Tables 37 and 38 give the methods for calculating production costs based on utility financing and private investor financing, respectively. The calculations for the base case of a wood cost of $\$ 20 / d r y$ ton are shown. For utility financing, the SNG production costs are \$5.09, \$5.56, \$6.50, and \$8.34 per million Btu for wood prices of $\$ 5, \$ 10, \$ 20$, and $\$ 40$ per dry ton. For private investor financing, the SNG production costs are $\$ 6.62, \$ 7.11, \$ 8.10$ and $\$ 10.06$ per million Btu for the corresponding wood costs.

The same design basis was used to determine operating costs for a 200-dryton wood/day (180 t/day) plant for production of SNG. All yields are $10 \%$ of the yields from the larger plant. The only difference in the system was on-site chipping of the wood residue. Details are presented in Appendix $C$ and summarized below.

The total investment for the 200-dry-tonlday (180-tiday) plant was estimated to be $\$ 26,680.000$ (September 1980 basis). To obtain the total capital requirement for the plant, additional costs must be added to the estimated plant investment. These costs are an allowance for funds during construction, start-up costs, and working capital. These costs and the basis for their calculation are shown in Table 39. The total capital requirement for this plant is $\$ 31,805,000$.

The annual direct operating costs for the small plant were calculated and are shown in Table 40. These costs include raw materials, utilities, catalysts and chemicals, labor, administration and general overhead, supplies, and taxes and insurance, with a credit for by-product char. Total maintenance costs were calculated as percentage of plant investment as suggested by the guidelines. These annual costs are $\$ 6,833,600$. The most significant costs are wood, gasifier catalyst, labor, and taxes and insurance. Labor costs would not be very easy to reduce significantly, while taxes will depend upon local conditions and incentives. The major variable costs are wood and catalyst usage in the gasifier. At $\$ 20 / d r y$ ton for wood, which is the value used for the base case shown in Table 40 , wood costs are almost $20 \%$ of the total direct costs and almost $15 \%$ of the total production costs using utility financing. Thus, either 
TABLE 37. Methane Cost-Utility Financing Method--2000 ton/day Dry Wood Bases:

20-yr project life

5\% year straight line depreciation on total capital requirement excluding work capital

48\% federal income tax rate

$75 / 25$ debt/equity ratio

$10 \%$ interest on debt

$15 \%$ return on equity

Definition of Terms:

$$
\begin{aligned}
& C=\text { Total capital requirement, } 106 \$ \\
& W=\text { Working capital, } 10^{6} \$ \\
& N=\text { Total net operating cost }, 10^{6} \$ / y r \\
& G=\text { Annual gas production, } 10^{12} \mathrm{Btu} / \mathrm{yr} \\
& \mathrm{d}=\text { Fraction debt } \\
& \mathrm{i}=\text { Interest on debt, } \% / \mathrm{yr} \\
& \mathrm{r}=\text { Return on equity, } \% / \mathrm{yr} \\
& \mathrm{p}=\text { Return on rate base } \% / \mathrm{yr}
\end{aligned}
$$

Equation for Return on 2ate Base:

$$
p=(d) i+(1-d) r
$$

General Gas Cost Equation:

$$
\begin{aligned}
& \text { Average gas cost, \$/milion Btu }= \\
& \frac{\mathbf{N}+0.05(\mathrm{C}-\mathrm{W})+0.005(\mathrm{p}+48 / 52(1-\mathrm{d}) \mathrm{r})(\mathrm{C}+\mathrm{W})}{\mathrm{G}}
\end{aligned}
$$

Calculation:

$$
p=(0.75)(10)+(1-0.75)(15)=11.25
$$

Average gas cost, $\$ / \mathrm{mi}$ llion Btu =

$\frac{29.990+(0.05)(115.171-3.294)+0.005[11.25+(48 / 52)(1-0.75) 15](115.171+3.294)}{6.811}$ $=\$ 6.50$ 
TABLE 38. Methane Cost - Equity Financing Method--2000 ton/day Dry Wood Bases:

20-yr project life

16-yr sum-of-the-years' - digits depreciation on total plant investment

$100 \%$ equity capital

$12 \%$ DCF return rate

$48 \%$ federal income tax rate

Definition of Terms:

$\mathbf{I}=$ Total plant investment, $10^{6} \$$

$\mathrm{S}=$ Start-up cost, $10^{6} \$$

$W=$ Working capital, $106 \$$

$N=$ Total net operating cost, $10^{6} \$ / y r$

$G=$ Annual gas production, $10^{12} \mathrm{Btu} / \mathrm{yr}$

Gas Cost Equation at 12\% DCF Return

Gas Cost, $\$ / 10^{6}$ Btu $=$

$$
\frac{N+0.247 I+0.1337 S+0.2305 W}{G}
$$

Calculation:

Gas cost, $\$ / 10^{6} \mathrm{Btu}=$

$$
\frac{29.990+(0.247)(95.095)+(0.1337)(6.084)+(0.2305)(3.748)}{6.811}
$$

$=\$ 8.10$ 
TABLE 39. Total Capital Requirement for 200-ton/day Wood-to-Methane Plant

Total Plant Investment

Allowance for funds During Construction

(Total Plant Investment x 1.25 years $\times 0.09$ )

$\frac{\text { Cost }(\$ 1,000)}{26,680}$

3,002

Start-up Costs (20\% of Total Annual Gross

operating Costs)

1,375

Working Capital (Sum of (1) raw material

inventory of 14 days at full rate, (2) materials

and supplies at $0.9 \%$ of total plant investment

and (3) net receivables at 1/24 annual gas and

by-products revenue at calculated sales price)

Total Capital Requirement

\begin{tabular}{rr}
56 & $(1)$ \\
240 & $(2)$ \\
452 & $(3)$ \\
\hline
\end{tabular}

$\$ 31,805$

lowering the wood cost or improving yields from the wood would have more impact on costs than any other single variable. The production costs have also been calculated for wood costs of $\$ 5, \$ 10$, and $\$ 40$ per dry ton delivered to the plant.

In Tables 41 and 42 the methods for calculating production costs are given based upon utility financing and private investor financing, respectively. The calculations for the base case of a wood cost of $\$ 20 /$ dry ton are shown. For utility financing, the SNG production costs are $\$ 14.34, \$ 14.83, \$ 15.86$, and $\$ 17.84$ per million Btu for wood prices of $\$ 5, \$ 10, \$ 20$, and $\$ 40$ per dry ton. For private investor financing, the SNG production costs are $\$ 18.76, \$ 19.26$, $\$ 20.28$, and $\$ 22.31$ per million Btu for the corresponding wood costs.

Wood-to-Methanol Plant

The design basis for the wood-to-methanol plant was developed in the laboratory and PDU studies and adjusted to operation at 10 atm pressure. The main adjustment was an increase in the methane concentration in the gases from the gasifier. Overall gas yield used in the design basis is less than recent operating results from the PDU as presented above.

The design basis for the 2000-ton (1800-t) dry wood/day plant is shown in Table 43. A schematic flow diagram showing process areas is given in 
TABLE 40. Annual Direct Operating Costs for 200-ton/day Wood-to-Methane Plant Operating Factor: 330 days/yr

\section{Cost Component}

Raw Material

Wood

Utilities

Water

Electricity

Diesel Fuel

Catalysts and Chemicals

Chemicals

Shift Catalyst

Methanation Catalyst

Gasifier Catalyst

Labor

Process Operating

Mai ntenance

Supervision

Administration and General Overhead

Supplies

Operating

Maintenance

Taxes and Insurance

Total Gross Operating Cost per Year

By-Product Credits

Char

Total Net Operating Cost per Year
Annual Use

$\$ /$ Unit $\$ 1000 / y r$

66,000 dry tons

$20 /$ dry ton $1,320.0$

33,264 Mgal

$7.76 \times 10^{6} \mathrm{kWh}$

10,890 gal

$0.50 / \mathrm{Mgal}$

$0.03 / \mathrm{kWh}$

$1.00 / \mathrm{gal}$

16.6

232.8

10.9

$150 \mathrm{ft}^{3}$

$100 \mathrm{ft}^{3}$

$38,016 \mathrm{lb}$

$107 / \mathrm{ft}^{3}$

$435 / \mathrm{ft}^{3}$

$8.51 / 1 b$

51.0

16.0

43.5

323.5

44 men of $2080 \mathrm{~h}$

(d) $60 \%$ of total

maintenance

(b) $20 \%$ of process

operating and

maintenance labor

$10.70 / \mathrm{h}$

979.3

760.8

348.0

1252.9

(d) $60 \%$ of total labor

293.8

operating labor

(a) $40 \%$ of total

maintenance

507.2

(3) $2.7 \%$ of total

investment

720.4

6876.7

2805 tons

$15.35 /$ ton

(43.1)

$\$ 6833.6$ 
TABLE 41. Gas Cost - Utility Financing Method--200 ton/day Dry Wood Bases:

20 -yr project life

$5 \%$ year straight line deprecitation on total capital requirement excluding working capital

$48 \%$ federal income tax rate

$75 / 25$ debt/equity ratio

$10 \%$ interest on debt

$15 \%$ return on equity

Definition of Terms:

$C=$ Total Capital Requirement, $10^{6} \$$

$W=$ Working Capital, $10^{6} \$$

$N=$ Total Net Operating Cost, $10^{6} \$ / y r$

$G=$ Annual Gas Production, $1012 \mathrm{Btu} / \mathrm{yr}$

$\mathrm{d}=$ Fraction debt

$\mathbf{i}=$ Interest on debt, $\% / y r$

$r=$ Return on equity, $\% / y r$

$p=$ Return on rate basis, $\% / y r$

Equation for Return on Rate Base:

$p=(d) \mathbf{i}+(1-d) r$

General Gas Cost Equation:

Average Gas Cost, $\$ /$ mil lion Btu $=$

$\frac{N+0.05(C-W)+0.005(p+48 / 52(1-d) r)(C+W)}{G}$

$C=31.805 \times 10^{6} \$ / y r$

$W=.748 \times 10^{6} \$ / y r$

$\mathrm{N}=6.834 \times 10^{6} \$ / \mathrm{yr}$

$G=.681 \times 10^{12} \mathrm{Btu} / \mathrm{yr}$

Calculation:

$p=(0.75)(10)+(1-0.75)(15)=11.25$

Average gas cost, $\$ /$ million Btu $=$

$\frac{6.834+(.05)(31.805-.748)+(.005)(14.70)(31.805+.748)}{.681}$

$=\$ 15.86$ 
TABLE 42. Gas Cost - Equity Financing Method--200 ton/day Dry Hoad Bases:

20-yr project file

16-yr sum-of-the-years' - digits depreciation on total plant investment

$100 \%$ equity capital

$12 \%$ DCF return rate

$48 \%$ federal income tax rate

Definition of Terms:

$\mathbf{I}=$ Total plant investment, $10^{6} \$$

$S=$ Start-up costs, $10^{6} \$$

$W=$ Working Capital, $10^{6} \$$

$N=$ Total net operating cost, $10^{6} \$ / y r$

$G=$ Annual gas production, $1012 \mathrm{Btu} / \mathrm{yr}$

Gas Cost Equation at 12\% DOF Return:

Gas cost, $\$ / 10^{6}$ Btu $=$

$\frac{N+0.247 I+0.1337 S+0.2305 W}{G}$

$I=26.680 \times 10^{6} \$$

$S=1.375 \times 10^{6} \$$

$W=.873 \times 10^{6} \$$

$\mathrm{N}=6.834 \times 10^{6} \$ / \mathrm{yr}$.

$G=.681 \times 10^{12} \mathrm{Btu} / \mathrm{yr}$

Calculation:

Gas cost, $\$ / 10^{6}$ Btu $=$

$=6.834+(0.247)(26.680)+(0.1337)(1.375)+(0.2395) \times(0.873)$ .681

$=\$ 20.28$ 
TABLE 43. Wood-to-Methanol Plant Design Basis--2000 ton/day Dry Wood

$\begin{array}{ll}\text { Capacity, Dry Tons Wood/day (t/day) } & \text { Wood-to-Methanol } \\ \text { Location } & \text { Pacific Northwest } \\ \text { Product Specifications } & \text { Methanol: } 99.3 \% \text { purity }\end{array}$

Gasifier Conditions

Temperature, ${ }^{\circ} \mathrm{C}$

Pressure, atm 10

Steam Rate, wt/wt Dry Wood $\quad 0.75$

Char Production, wt/wt MAF Wood $\quad 0.15$

Char Heating Value, Btu/lb $(\mathrm{kJ} / \mathrm{kg}) \quad 14,000 \quad(33,000)$

Gas Production, wt/wt MAF wood $\quad 1.60$

Cold Gas Efficiency, \% 88

Gas Composition, vol\%

28.7

36.6

$\begin{array}{lr}\mathrm{CH}_{4} & 4.0 \\ \mathrm{CO}_{2} & 12.4 \\ \mathrm{CO}^{2} & 18.3\end{array}$

Figure 54. The design basis for the small plant is simply scaled to a capacity of 200 ton/day dry wood (180 tlday). Wood feedstock is the same as presented in Table 32.

The wood-to-methanol plants are designed to process 2000 tons $(1800 \mathbf{t})$ per day of dry wood and $10 \%$ of this capacity. Production for the large plant 


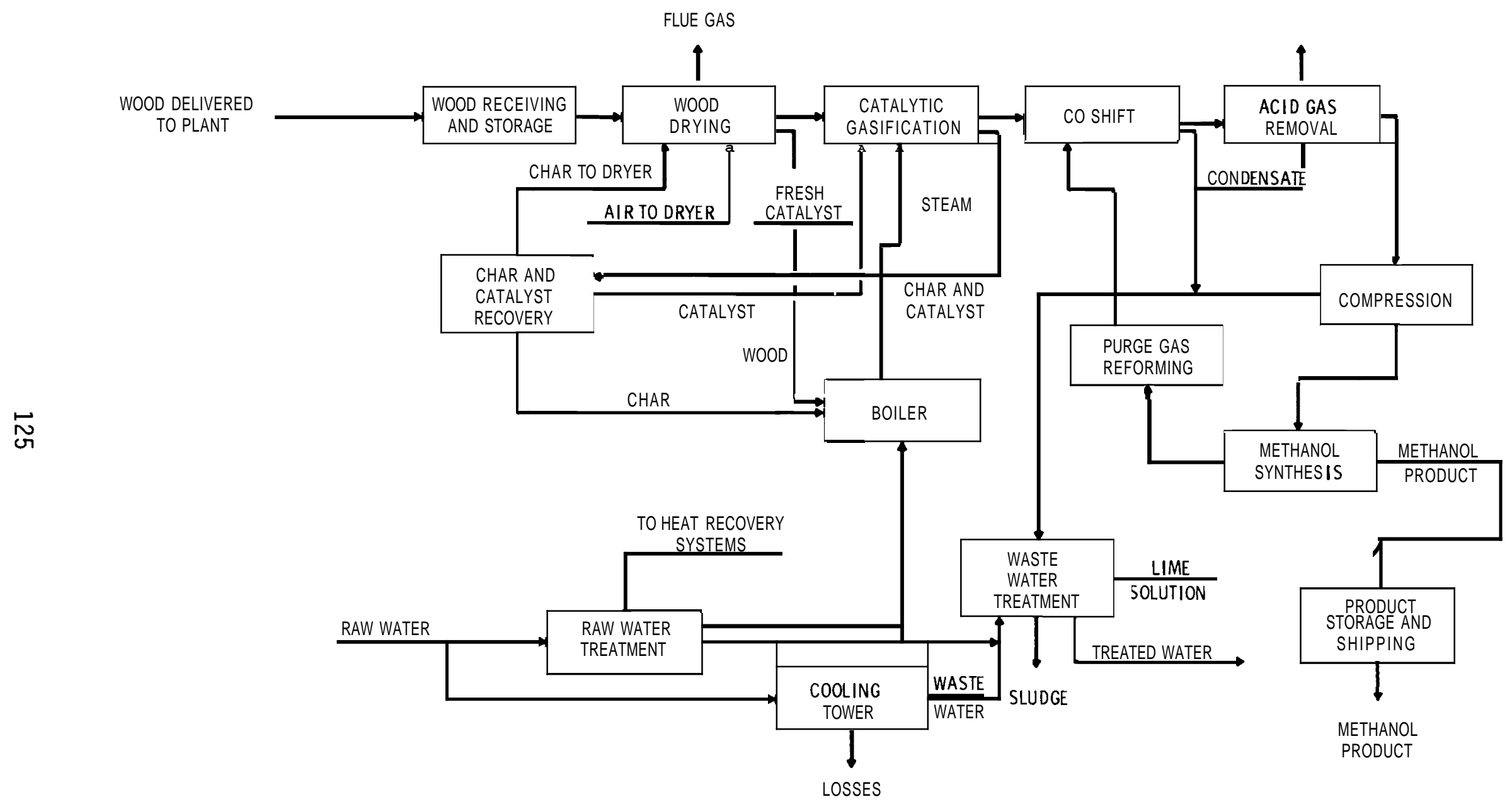

FIGURE 54. Wood-To-Methanol Process Area 
is 997 tons $(900 \mathrm{t})$ per day of methanol with a HN of 9784 Btu per pound $(22,700 \mathrm{~kJ} / \mathrm{kg})$. All process and support facilities necessary to convert wood to methanol are included in the estimate.

The thermal efficiency of the plant is defined as

$$
\text { Efficiency, } \%=100 \times \frac{\text { Methanol, } H \mathrm{H}}{\text { Wood, } H \mathrm{HN}+\text { Electricity }+ \text { Diesel Fuel }}
$$

The thermal efficiency is $53 \%$.

Wood storage, handling, and drying are identical to the systems described previously for the wood-to-methane plant, The small plant includes on-site chipping of the residue.

Three gasifiers are provided for the 2000 ton $(1800 \mathrm{t}) /$ day plant. Each gasifier is cylindrical with dimensions of $15 \mathrm{ft}(4.3 \mathrm{~m})$ I D by $50 \mathrm{ft}(15 \mathrm{~m})$ total height. Each is provided with $3900 \mathrm{ft}^{2}\left(360 \mathrm{~m}^{2}\right)$ of 2 -in. $(5-\mathrm{cm})$ tubing (RA-533 or Incoloy $800 \mathrm{H}$ ) for heat addition to the fluid bed of wood char and catalyst. The operating depth of the fluid bed is $10 \mathrm{ft}(3 \mathrm{~m})$. A single, scaled-down version of their design is provided for the 200 ton/day plant.

Fines in the char-catalyst mixture are primarily char. Very little catalyst is in the fines which are removed by screening. The char and catalyst in the coarse fraction can then be separated by a magnetic roll separator. Catalyst recovery is $90 \%$ for the wood-to-methanol plant. No regeneration of catalyst is considered.

All other operations in the schematics shown in Figure 54 are based on commercially available technology. A brief description of the plants is presented in the following discussion.

Wood chips from the gasifier feed bins are continuously fed by screw conveyors to the fluidized-bed gasifier. High pressure steam is fed into each bed to gasify the wood as well as fluidize the solids. Contained within the bed is the catalyst required for the reaction, a 318-in. (9.5- $\mathrm{mm})$ diameter spherical ball of nickel catalyst on a silica-alumina structure. The gasifiers in the 
wood-to-methanol plants operate at a temperature of $750^{\circ} \mathrm{C}\left(1380^{\circ} \mathrm{F}\right)$ and a pressure of $10 \mathrm{~atm}$ (150 psia). At these conditions most hydrocarbons are cracked to give a crude synthesis gas consisting primarily of hydrogen and carbon oxides with only a small amount of methane.

About 285 tons per day (dry basis) (259 t/day) (or 10\% of this for the small plant) of the wood supplied to the gasification area are burned to supply the necessary heat input to the gasifier. This is accomplished by first allowing the hot combustion gases--approximately $980^{\circ} \mathrm{C}\left(1800^{\circ} \mathrm{F}\right)$--to circulate through tube bundles located in each gasifier bed. These gases upon exiting the tube bundles are then used to preheat the gasifier fluidizing steam and combustion air for the wood burners.

The remainder of the gasification area in the plant is devoted to heat recovery, catalyst recovery and recycle, and char recovery. The raw gas from the gasifier passes through a series of exchangers that recover heat by generating superheated steam. These exchangers are a series of coils in a refractory lined shell through which the raw gas flows. These exchangers are, in the order that the raw gas sees them, the steam superheater, the CO shift preheater, the boiler, and the boiler feedwater preheater. The gas is cooled to $175^{\circ} \mathrm{C}\left(350^{\circ} \mathrm{F}\right)$ in these exchangers. The gas contains particulate in the form of entrained char and catalyst. The gas is then cleaned by a cyclone followed by a bag filter containing a high temperature glass fabric. The gas then flows to the next processing area. The catalyst recovery area consists of screens and a magnetic separator and is completely enclosed to prevent air contact with the catalyst.

Commercially available systems comprise the remainder of the plant. Acid gas removal is by the Benfield process. The ICI low pressure methanol process is used for the methanol synthesis. All liquid wastewater streams for the plant are treated in a neutralizing basin and a subsequent three stage biological treatment system before being allowed to overflow to drainage.

The capital cost estimate as determined by Davy McKee, Inc., is summarized in Table 44 for the 2000-ton dry wood/day plant. The capital cost estimate (September 1980 basis) for the 2000-ton dry wood (1800-t)/day plant is $\$ 120,830.000$. Estimate accuracy is reported to be $\pm 25 \%$. 
TABLE 44. Wood-to-Methanol Capital Cost Summary--2000 ton/day Dry Wood

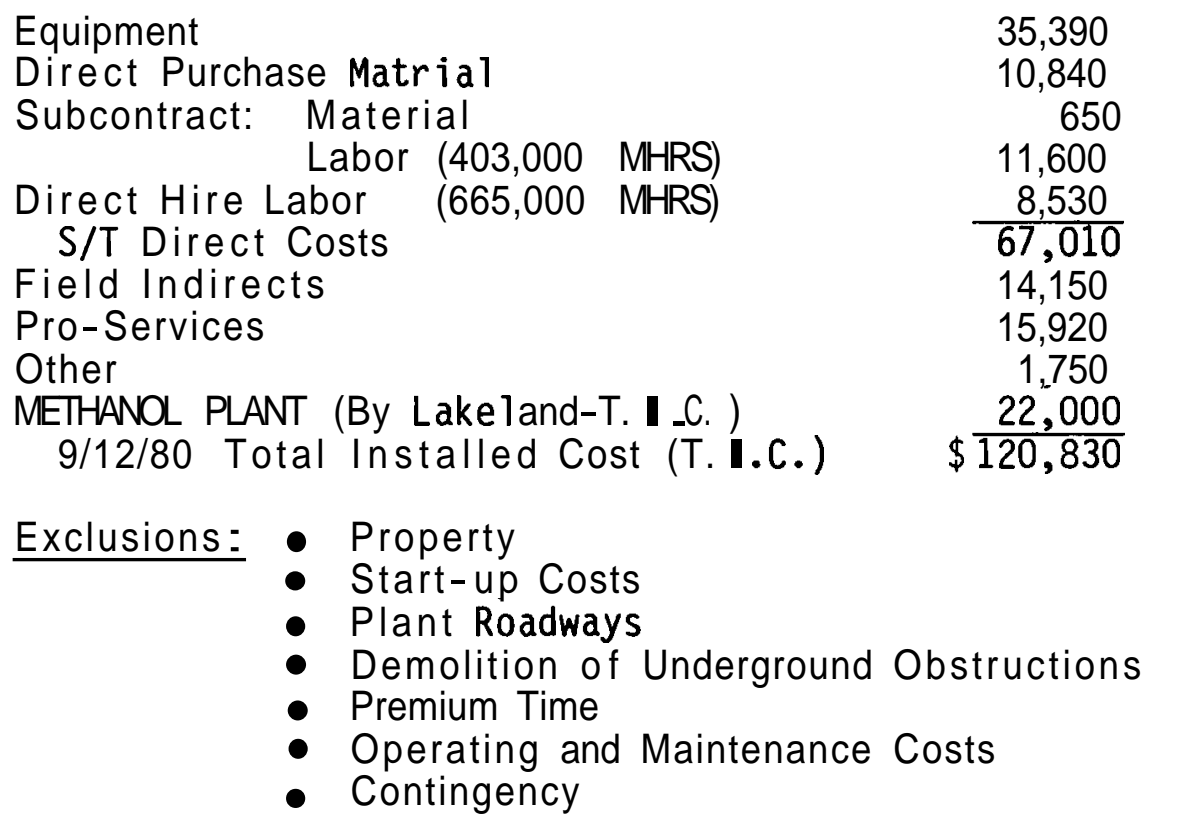

Breakdown of the total direct costs by plant area is given in Table 45 for the 2000-ton (1800-t) dry wood/day plant. The major cost areas are wood storage and handling, gasification and wood drying. The gasification area includes the gasifiers heat recovery equipment, char and catalyst recovery equipment, and wood and catalyst feed hoppers.

The production cost of fuel-grade methanol from wood is calculated based upon the capital costs and operating costs. The methods of calculating these costs are those presented in "Coal Gasification Commercial Concepts Gas Cost Guidelines", a paper prepared for the United States Energy Research and Development Administration and the American Gas Association by C. F. Braun \& Co. (NTIS 8463). Production costs are calculated using two potential methods of financing a plant of this type, (1) utility financing, and (2) private investor financing.

The total investment for the 2000-ton (1800-t)/day dry wood plant is estimated to be $\$ 120,830,000$ (September 1980 basis). The total capital requirement 
TABLE 45. Direct Cost Sumary For Wood-to-Methanol Plant-2000 ton/day Dry Wood

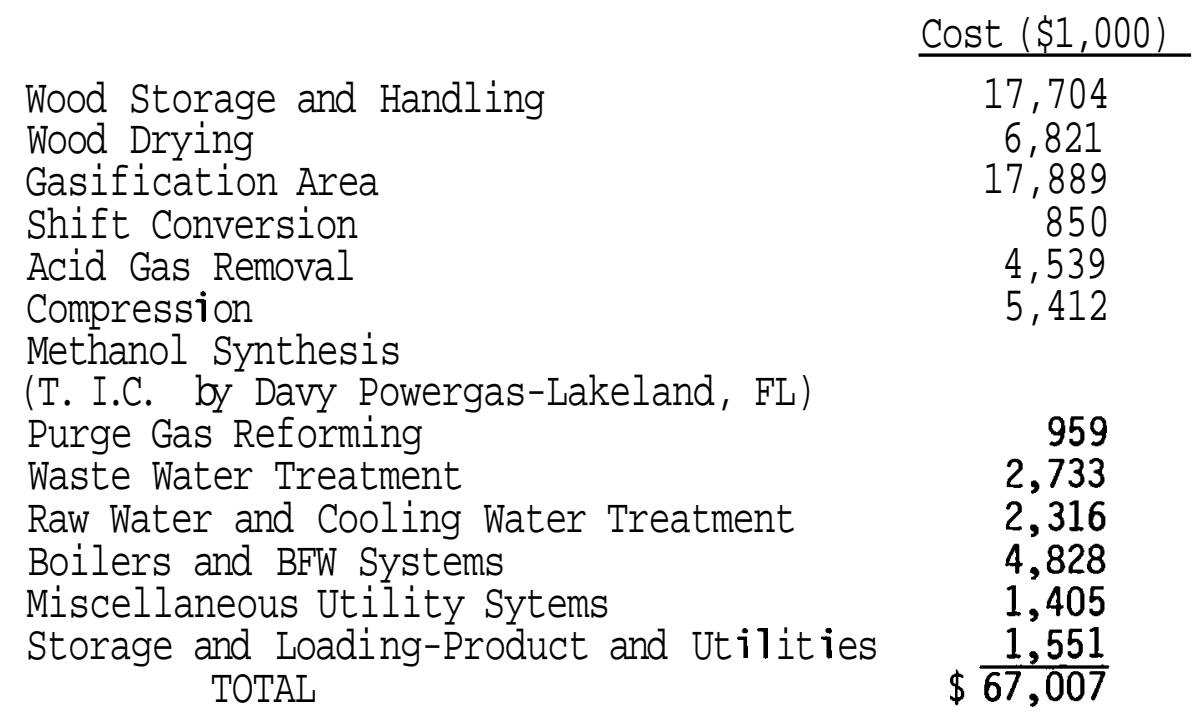

for the plant is obtained by addition of an allowance for funds during construction, start-up costs, and working capital. These costs and the basis for their calculation are shown in Table 46. The total capital requirement for this plant is $\$ 145,571,000$.

The annual direct operating costs for the 2000-ton/day dry wood plant have been calculated and are shown in Table 47. These costs include raw materials, utilities, catalyst and chemicals, labor, administration and general overhead, supplies, and taxes and insurance. Maintenance costs are calculated as a percentage of capital investment, as suggested by the cited guidelines and are $\$ 36,464,000$. The most significant costs are wood, gasifier catalyst, labor, and taxes and insurance. Labor costs are not very easy to reduce significantly, while taxes will depend upon local conditions and incentives. The major variable costs are wood and catalyst usage in the gasifier. Studies on improvement of catalyst life are in progress. At $\$ 20 /$ dry ton for wood, which is the value used for the base case shown in Table 47, wood costs are about one-third of the total direct costs and one-fourth of the total production costs. Thus, either lowering the wood cost or improving yields from the wood have more impact on costs than any other single variable. The production costs 
TABLE 46. Total Capital Required For Wood-to-Methanol Plant-2000 ton/day Dry Wood

Total Plant Investment

Allowance for Funds During Construction

(Total Plant Investment x 1.25 y $r$ x 0.09)

Start-up Costs $(20 \%$ of Total Annual Gross

Operating Costs)

Working Capital (Sum of (1) raw material inventory of 14 days at full rate,

(2) materials and supplies at $0.9 \%$ of total plant investment, and (3) net receivables at $1 / 24$ annual methanol revenue at calculated sales price)

Total Capital Requirement
Cost $(\$ 1,000)$

120,830

13,588

7,293

$560(1)$

$1,087(2)$

$2,223(3)$

have also been calculated for wood costs of $\$ 5, \$ 10$, and $\$ 40$ per dry ton, and the impact is illustrated in Figure 55. These prices for wood include delivery to the plant.

In Tables 48 and 49 methods are given for calculating production costs based upon utility financing and private investor financing, respectively. The calculations for the base case of a wood cost of $\$ 20 /$ dry ton are shown. For utility financing, the methanol production costs are $\$ 0.45, \$ 0.48, \$ 0.55$, and $\$ 0.69$ per gallon for wood prices of $\$ 5, \$ 10, \$ 20$, and $\$ 40$ per dry ton. For private investor financing, the methanol production costs are \$0.59, \$0.62, $\$ 0.69$, and $\$ 0.83$ per gallon for the corresponding wood costs.

The same design basis was used to determine operating costs for a 200-ton dry wood $(180-t)$ per day plant for production of fuel grade methanol. All yields are $10 \%$ of the yields from the larger plant. Details are presented in Appendix 0 and summarized below.

The total plant investment was estimated to be $\$ 34,830,000$ September 1980 basis. To obtain the total capital requirement for the plant, additional costs must be added to the estimated plant investment. These costs are an allowance 
TABLE 47. Annual Direct Operating Costs For Wood-to-Methanol Plant-2000 ton dry wood/day

Operating factor: 330 days/yr

Cost Component $\quad$ Annual Use $\quad \frac{2 \text { Cost }}{\text { \$/Unit } \$ 1000 / y r}$

$\frac{\text { Raw Material }}{\text { Wood }}$

660,000 dry tons $20 /$ dry ton 13,200

Utilities

Water

Electricity

Diesel Fuel

526,522 Mga 1

$1.76 \times 10^{8} \mathrm{KWh}$

108,900 gal

$0.50 / \mathrm{Mga} 1$

$0.03 / \mathrm{kWh}$

$1.00 / g a 1$

263

5,280

Catalysts and Chemicals

Gasifier Catalyst

Shift Catalyst

Chloride Guard Catalyst

Sulfur Guard Catalyst

Methanol Catalyst

Reformer Catalyst

330,66016

$150 \mathrm{ft} 3$

$3,300 \mathrm{ft3}$

$2,500 \mathrm{ft} 3$

Confidential

$140 \mathrm{ft} 3$

$\begin{array}{lr}8.51 / 1 \mathrm{~b} & 2,814 \\ 107 / \mathrm{ft}^{3} & 16 \\ 151 / \mathrm{ft}^{3} & 498 \\ 75 / \mathrm{ft}^{3} & 188 \\ 23 \overline{5} / \mathrm{ft}^{3} & 360 \\ & 33\end{array}$

Labor

Process Operating

Maintenance

55 men a $2080 \mathrm{~h}$

(d) $60 \%$ of total

$10.70 / \mathrm{h} \quad 1,224$

maintenance

Supervision

(a) $20 \%$ of process

operating and

maintenance labor

877

Administration and General Overhead $60 \%$ of total labor

Supplies

Operating

(a) $30 \%$ of process

operating labor

Maintenance

o $40 \%$ of total

maintenance cost

367

(a) $2.77 \%$ of total

plant investment

2,106

$\underline{\text { Taxes and Insurance }}$

Total Operating Cost Per Year

$\underline{3,261}$

$\$ 36,912$ 


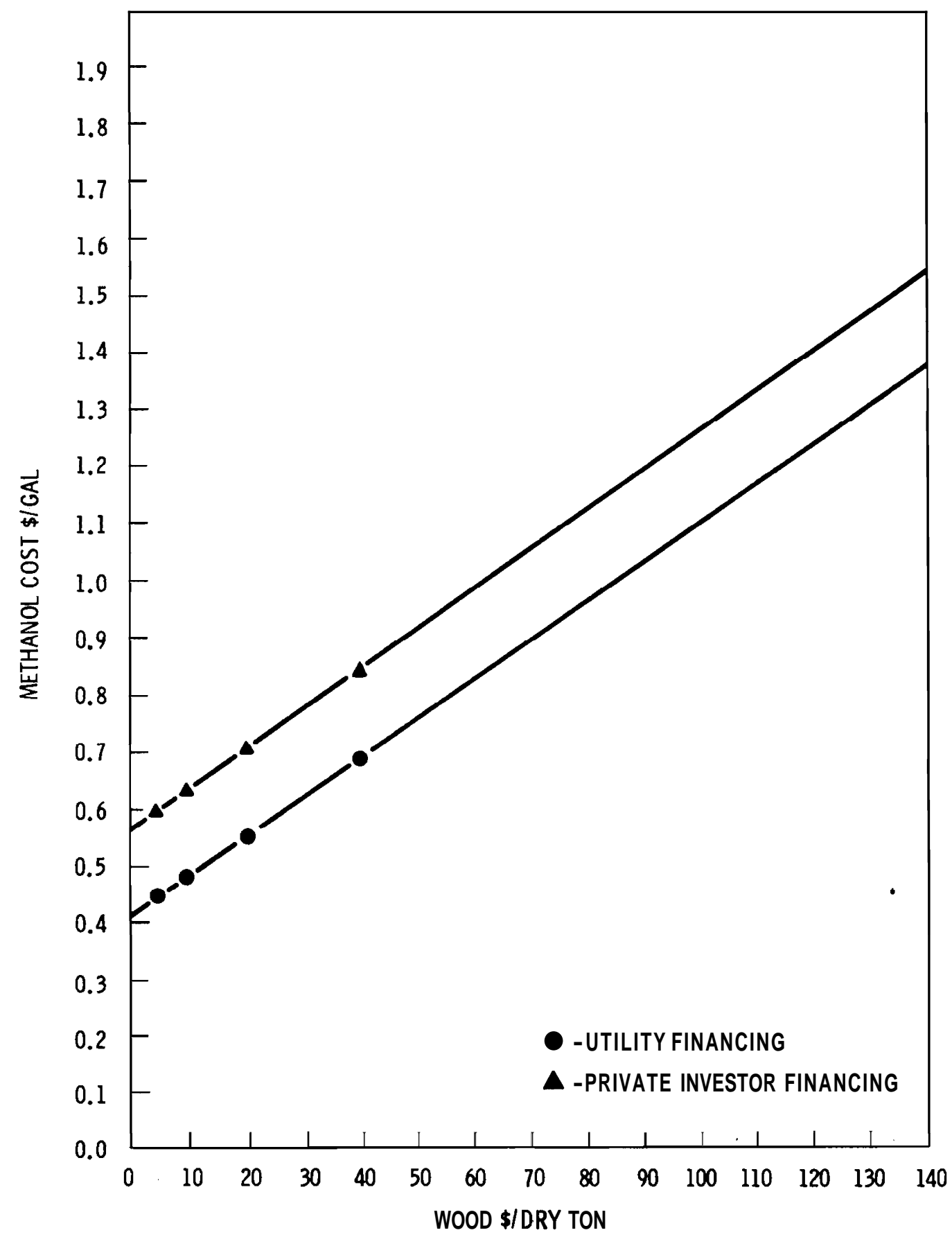

FIGURE 55. Effect of Wood Prices on Methanol Cost for 2000 ton/day Dry Wood 
TABLE 48. Methanol Cost-Utility Financing Method--2000 ton/day Dry Wood Bases:

20 -yr project life

$5 \% / y r$ straight line depreciation on total capital requirement excluding working capital

$48 \%$ federal income tax rate

$75 / 25$ debt/equity ratio

$10 \%$ interest on debt

$15 \%$ return on equity

Definition of Terms:

$C=$ Total capital requirement, $10^{6} \$$

$W=$ Working capital, $10^{6} \$$

$\mathrm{N}=$ Total net operating cost, $10^{6} \$ / \mathrm{yr}$

$G=$ Annual fuel production, $10^{6} \mathrm{gal} / \mathrm{yr}$

$\mathrm{d}=$ Fraction debt

$\mathbf{i}=$ Interest on debt, $\% / y r$

$r=$ Return on equity, $\% / y r$

$p=$ Return on rate base, $\% / y r$

Equation for Return on Rate Base

$p=(d) \mathbf{i}+(1-d) r$

Average methanol cost, $\$ / g a l=$

$\frac{\mathrm{N}+0.05(\mathrm{C}-\mathrm{W})+0.005(\mathrm{p}+48 / 52(1-\mathrm{d}) \mathrm{r})(\mathrm{C}+\mathrm{W})}{\mathrm{G}}$

Calculation:

$$
\begin{aligned}
& p=(0.75)(10)+(1-0.75)(15)=11.25 \\
& G=98.8110^{6} \mathrm{ga} 1 / \mathrm{yr} \\
& C=145.58 \quad 10^{6} \$ / \mathrm{yr} \\
& W=3.8710^{6} \$ / \mathrm{yr} \\
& N=36.9110^{6} \$ / y r
\end{aligned}
$$

Average methanol cost $=$

$$
\frac{36.91+(.05)(141.71)+(.005)(14.70)(149.45)}{98.81}
$$

$=\$ 0.55 / \mathrm{ga} 1$ 
TABLE 49. Methanol Cost-Equity Financing Method--2000 ton/day Dry Wood Bases:

20-yr project life 16-yr sum-of-the years' - digits depreciation on total plant investment $100 \%$ equity capital $12 \%$ DOF return rate $48 \%$ federal income tax rate

Definition of Terms:

$I=$ Total plant investment, $10^{6} \$$

$S=$ Start-up costs, $10^{6} \$$

$W=$ Working capital, $10^{6} \$$

$N=$ Total net operating cost, $10^{6} \$ / \mathrm{yr}$

$G=$ Annual methanol production, $10^{6} \mathrm{ga} 1 / \mathrm{yr}$

Methanol Cost Equation at 12\% DCF Return

Methanol cost, $\$ /$ gal =

$\frac{N+0.247 I+0.1337 S+0.2305 W}{G}$

$N=36.91 \$ 10^{6} / \mathrm{yr}$

$G=98.8110^{6} \mathrm{gal} / \mathrm{yr}$

$I=120.78106 \$ / y r$

$S=7.2910^{6} \$ / y r$

$W=3.87 \quad 10^{6} \$ / y r$

Calculation:

Average methanol cost $=$

$\frac{36.91+(.247)(120.78)+(.1337)(7.29)+(.2305)(3.87)}{98.81}$
$=\$ 0.69 / \mathrm{gal}$


for funds during construction, start-up costs, and working capital. These costs and the basis for their calculation are shown in Table 50. The total capital requirement for this plant is $\$ 41,221,000$.

TABLE 50. Total Capital Requirement for 200-ton Dry Wood/Day Methanol Plant

Total Plant Investment

Allowance for Funds During Construction

(Total Plant Investment x 1.25 yr x 0.09)

Start-up Costs (20\% of Total Annual Gross

Operating Costs)

Working Capital (Sum of (1) Raw Material Inventory of 14 days at full rate,

(2) Materials and Supplies at $0.9 \%$ of

Total Plant Investment, and (3) Net

Receivables at $1 / 24$ annual methanol

revenue at calculated sales price)

Total Capital Requirement

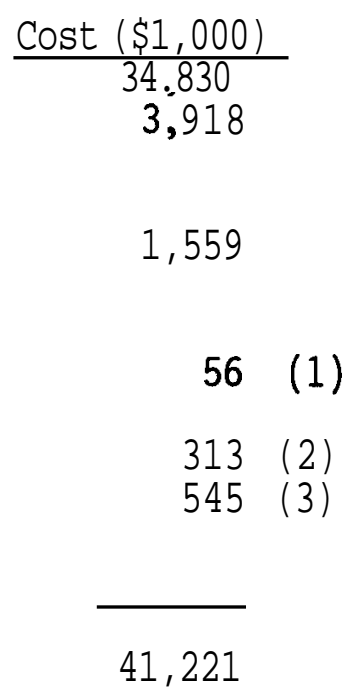

The annual direct operating costs were calculated and are shown in Table 51. These costs include raw materials, utilities, catalyst and chemicals, labor, administration and general overhead, supplies, and taxes and insurance. Maintenance costs are calculated as a percentage of capital investment, as suggested by the cited guidelines. These annual costs are $\$ 7,794,800$. The most significant costs are wood, gasifier catalyst. labor, and taxes and insurance. Labor costs would not be very easy to reduce significantly, while taxes will depend upon local conditions and incentives. The major variable costs are wood and catalyst usage in the gasifier. At $\$ 20 /$ dry ton for wood, which is the value used for the base case shown in Table 51, wood costs are about $17 \%$ of the total direct costs and are $10 \%$ of the total production costs. Thus, either lowering the wood cost or improving yields from the wood have more impact on costs than any other single variable. The production costs have also been calculated for wood costs of $\$ 5, \$ 10$, and $\$ 40$ per dry ton. These prices for wood include delivery to the plant. 
TABLE 51. Annual Direct Operating Costs for 200-ton Dry Wood/Day Methanol Plant Operating Factor: 330 days/yr

Cost Component

Raw Material

Wood

Utilities

Water

Electricity

Diesel Fuel

Catalysts and Chemicals

Gasifier Catalyst

Shift Catalyst

Chloride Guard Catalyst

Sulfur Guard Catalyst

Methanol Catalyst

Reformer Catalyst

Labor

Process Operating

Maintenance

Supervision

Administrative and General Overhead

Supplies

Operating

Maintenance

$\underline{\text { Taxes and Insurance }}$

Total Gross Operating Costs Per Year(a)
Annual Use $\quad \frac{\text { Cost }}{$\cline { 2 - 3 }$\$ 1000 / \mathrm{yr}}$

66,000 Dry Ton 20/Dry Ton $\quad 1,320.0$

52,652 Mgal

$2.43 \times 107 \mathrm{kWh}$

$10,890 \mathrm{gal}$

$0.50 / \mathrm{Mga} 1$

$0.03 / \mathrm{kwh}$

$1.00 / \mathrm{gal}$

26.3

729.6

10.9

33,066 1b

$15 \mathrm{ft} 3$

$8.51 / 1 \mathrm{~b}$

$107 / \mathrm{ft}^{3}$

$151 / \mathrm{ft}^{3}$

$75 / \mathrm{ft}^{3}$

$250 \mathrm{ft} 3$

Confidential

$235 / \mathrm{ft}^{3}$

281.4

1.6

50.0

18.8

36.0

$15 \mathrm{ft} 3$

3.5

48 Men e $2080 \mathrm{~h}$

(a $60 \%$ of Total

$10.70 / \mathrm{h}$

$1,068.3$

873.6

Maintenance

D $20 \%$ of process

213.7

operating and

maintenance labor

(a $60 \%$ of Total Labor

$1,293.4$

(a $30 \%$ of Process

320.5

Operating Labor

a $40 \%$ of Total

Maintenance Cost

582.4

a $2.77 \%$ of Total

Plant Investment
964.8

$7,794.8$

(a) No credits were taken for any by-product so that Total Net Operating Costs are the same as the Total Gross. 
Tables 52 and 53 give the methods for calculating production costs based upon utility financing and private investor financing, respectively. The calculations for the base case of a wood cost of $\$ 20 /$ dry ton are shown. For utility financing, the methanol production costs are $\$ 1.20, \$ 1.23, \$ 1.30$ and $\$ 1.44$ per gallon for wood prices of $\$ 5, \$ 10, \$ 20$, and $\$ 40$ per dry ton. For private investor financing, the methanol production costs are $\$ 1.60, \$ 1.63$, $\$ 1.70$ and $\$ 1.84$ per gallon for the corresponding wood costs.

\section{COMPUIER MODEயING STUDIES}

Computer modelling work is underway to develop a program that will describe commercial plants for producing methane and methanol by catalytic gasification of biomass. The model will do heat and material balance calculations and then economic evaluations. The effects on overall economics of changing process parameters should be easily determined.

The heart of the modelling effort is the ASPEN computer code being developed at Massachusetts Institute of Technology. ASPEN is an acronym for Advanced Simulation for Process Engineering analysis. One of the primary objectives of the ASPEN project is to develop a prototype simulator and demonstrate the ability to simulate specific fossil fuel conversion processes of interest to DOE

This simulator is flexible and will model a variety of unit operations. It performs heat and material balance calculations, does crude equipment sizing calculations and computes several economic parameters. It is considered a state-of-the-art simulation code and is still being revised and tested. It is the only known publicly available code that will handle streams with solids or model solids handling equipment.

Several chemical reactor models are available in ASPEN, but all are ideal descriptions such as an equilibrium model, a plug flow model and a backmix model. None of these adequately describes the batch reactor used in our laboratory studies or the fluid-bed reactor in the PDU. Fortunately the ASPEN code is designed to allow the user to supply his own models when necessary. 
TABLE 52. Methanol Cost - Utility Financing Method--200 ton Dry Wood/Day Bases:

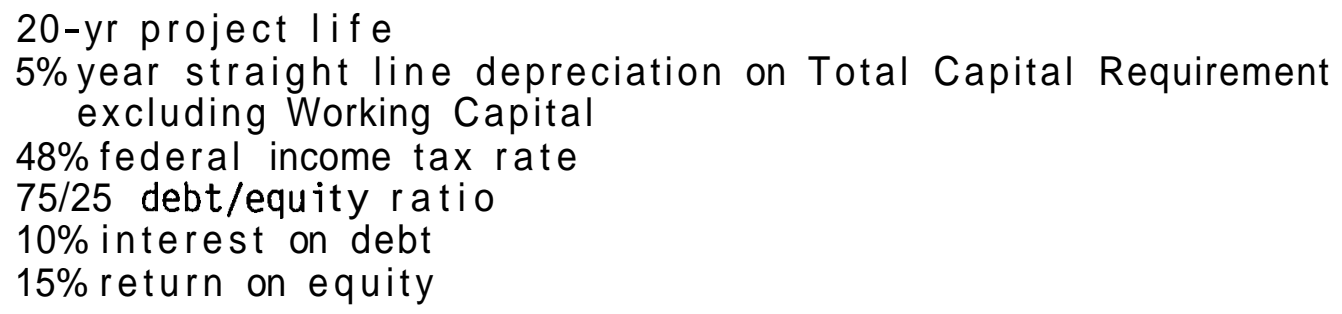

Definition of Terms:

$$
\begin{aligned}
& C=\text { Total Capital Requirement, } 10^{6} \$ \\
& W=\text { Working Capital, } 10^{6} \$ \\
& N=\text { Total Net Operating Cost, } 10^{6} \$ / y r \\
& G=\text { Annual Fuel Production, } 10^{6} \mathrm{gal} / \mathrm{yr} \\
& \mathrm{d}=\text { Fraction Debt } \\
& \dot{i}=\text { Interest on Debt, } \% / \mathrm{yr} \\
& r=\text { Return on equity, } \% / y r \\
& p=\text { Return on Rate Base, } \% / y r
\end{aligned}
$$

Equation for Return on Rate Base:

$p=(d) i+(1-d) r$

Average Methanol Cost, $\$ / g a 1=$

$$
\frac{N+.05(C-W)+.005(p+48 / 52(1-d) r)(C+W)}{G}
$$

Calculation:

$$
\begin{aligned}
& p=(0.75)(10)+(1-0.75)(15)=11.25 \\
& G=9.911 \times 10^{6} \mathrm{ga} / \mathrm{yr} \\
& C=41.221 \times 10^{6} \$ / \mathrm{yr} \\
& W=.914 \times 10^{6} \$ / \mathrm{yr} \\
& N=7.795 \times 10^{6} \$ / y r \\
& \text { Average Methanol Cost }= \\
& \frac{7.795+(.05)(40.307)+(.005)(14.70)(42.135)}{9.911} \\
& =\$ 1.30 / \mathrm{gal}
\end{aligned}
$$


TABLE 53. Methanol Cost - Equity Financing Method--200 ton Dry Wood/Day

Bases:

20-yr project life

16-yr sum-of-the-years' digits depreciation on Total Plant Investment

$100 \%$ equity capital

$12 \%$ DCF return rate

$48 \%$ federal income tax rate

Definition of Terms:

$I$ = Total Plant Investment, $10^{6} \$$

$\mathrm{S}=$ Start-up Costs, $10^{6}$

W = Working Capital, $106 \$$

$N=$ Total Net Operating Cost, $106 \$ / y r$

$\mathrm{G}=$ Annual Methanol Production, $106 \mathrm{ga} / \mathrm{yr}$

Methanol Cost Equation at 12\% DCF Return

Methanol Cost, $\$ /$ gal $=$

$\underline{N+0.247 I+0.1337 S+0.2305 W}$

G

$N=7.795 \$ 10^{6} / \mathrm{yr}$

$G=9.91110^{6} \mathrm{gal} / \mathrm{yr}$

$I=34.83010^{6} \$ / \mathrm{yr}$

$S=1.55910^{6} \$ / y r$

$W=1.071 \quad 10^{6} \$ / \mathrm{yr}$

Calculation:

Average methanol cost $=$

$7.795+(.247)(34.830)+(.1337)(1.559)+(.2305)(1.071)$

9.911

$=\$ 1.70 / \mathrm{gal}$ 
The reactor models existing in the ASPEN program are not accurate descriptions of our experimental units primarily because mass and heat transfer effects are ignored. Thus, much time has been spent analyzing our data to quantify any diffusional limitations.

Some of the laboratory work showed an increase in reaction rate as the steam flow rate increased. This suggests at least the possibility of diffusional limitations in the system. Furthermore, some of the high temperature $\left(850^{\circ} \mathrm{C}\right)$ data did not fit with the rest on a standard activation energy plot. The apparent activation energy decreased at the higher temperatures. Once again this suggests diffusional limitations. These observations were justification for trying to quantify relative kinetic and diffusional rates.

The analysis started simple by assuming steam was the primary reacting species. Furthermore, it was assumed that a global kinetic expression could describe the actual gasification reaction. For a single particle we then get the following by equating the rate of steam transfer to the surface to the rate of steam consumption by chemical reaction:

$$
-r=k m A_{p}\left(C_{B}-S\right)=k_{R} C_{S}
$$

where $\quad r=$ Rate of steam reaction

$\mathrm{k}_{\mathrm{m}}=$ Mass transfer coefficient

$A_{P}=$ Surface area of particle

$C_{B}=$ Bulk steam concentration

$C_{S}=$ Particle surface steam concentration

$\mathrm{k}_{\mathrm{R}}=$ First order kinetic rate constant

The mass transfer coefficient is a function of the Schmidt and Reynolds numbers. It was evaluated using the $j$ factor.

$$
j=\left(\frac{k_{m}}{\rho \star \bar{u}}\right)\left(\frac{\mu}{\bar{u}_{\rho} D}\right)^{2 / 3}
$$


where: $j=\frac{0.357}{(R E)^{0.359}}$. For fixed bed with $\operatorname{Re}=\frac{d_{\rho} u_{\rho}}{\mu} \quad$ between 3 and 2000

$$
\begin{aligned}
\rho & =\text { Mass density } \\
\rho^{\star} & =\text { Molar density } \\
\mathrm{u} & =\text { Gas velocity } \\
\mu & =\text { Gas viscosity } \\
D & =\text { Diffusion coefficient } \\
d_{P} & =\text { Particle diameter }
\end{aligned}
$$

A diffusion coeffiecient for steam in the other gases was evaluated using techniques in Reid, Prausnitz, and Sherwood (1977).

By rearranging the rate equations we get a form for the rate expression that includes mass transfer effects.

$$
r=\frac{k_{m} k_{R} A_{p} C_{B}}{k_{R}+k_{m} A_{p}}=\frac{k_{R} C_{B}}{1+\frac{k_{R}}{k_{m} A_{p}}}
$$

The limiting cases are worth noting

If $k_{m} A_{p} \gg k_{R}$ then $r=k_{R} C_{B}$

If $k_{R} \gg k_{m} A_{p}$ then $r=k_{m} A_{p} C_{B}$

If $k_{R}=k_{m} A_{p}$ then $r=1 / 2 k_{R} C_{B}$
Kinetics limit overall rate Mass transfer limits rate Both mass transfer and kinetics influence rate

A problem arises in determining $k_{R}$ from the batch reactor data. Experimental data were collected for the expression.

$$
-\frac{d W_{c}}{d t}=k_{c} w_{c}
$$

where $W_{C}=$ Weight of carbon. In terms of carbon conversion to gases $\left(X_{C}\right)$ this becomes 


$$
\begin{aligned}
-\frac{d W_{c_{0}}\left(1-x_{c}\right)}{d t} & =k_{c} w_{c_{0}}\left(1-x_{c}\right) \\
+\frac{d x_{c}}{d t} & =k_{c}\left(1-x_{c}\right)
\end{aligned}
$$

Where $W_{c_{0}}=$ initial weight of carbon present.

No simple relationship exists between $k_{C}$ and $k_{R}$ because the stoichiometry for steam reacting with wood is not well defined for varying steamlwood ratios and temperatures. Furthermore, the concentration of steam in the reactor at any time was not measured. From material balance considerations a steam concentration was calculated and a "pseudo stoichiometry" proposed at each temperature. This allowed calculation of $k_{R}$ values from the measured $k_{c}$ rate constants. Then one can compute a ratio of $k_{R} / k_{m} A_{p}$.

Some preliminary results are

\begin{tabular}{cc} 
Temperature, ${ }^{\circ} \mathrm{C}$ & $\frac{{ }_{\mathrm{R}} / \mathrm{k}_{\mathrm{m}} \mathrm{A}_{\mathrm{p}}}{1.3}$ \\
\hline 550 & 1.8 \\
750 & 3.2 \\
850 & 12.1
\end{tabular}

Although there are many uncertainties in the calculated values for $k_{R}$, the trend shown is interesting. These results suggest surface diffusion cannot be ignored and it tends to limit rates at high temperatures in the batch reactor. The primary reason for this is believed to be the low gas velocities $(<2 \mathrm{~cm} / \mathrm{s})$. A similar analysis of the PDU data showed the mass transfer rate was high enough at $500^{\circ} \mathrm{C}$ so kinetics are probably limiting there. Gas velocities at $500^{\circ} \mathrm{C}$ were, $100 \mathrm{~cm} / \mathrm{s}$. No good PDU data at $850^{\circ} \mathrm{C}$ are available to check the model at high temperatures.

Butt and Weekman (1974) have tabulated a series of test criteria to determine whether heat and/or mass transfer effects are important for catalytic reactions. The criteria check for surface diffusion as well as pore diffusion resistances. The formulations can apply equally well to wood particles if the 
pore characteristics are known. Information on pore structure in wood was taken from Boyd et al. (1979). Results from applying the criteria of Butt and Weekman supported the following conclusions:

1) Mass transfer does affect overall reaction rates in the batch reactor.

2) Heat transfer rates in the batch reactor rate are low enough that particle temperatures (at steady state) are $20-40^{\circ} \mathrm{C}$ (at $550^{\circ} \mathrm{C}$ and $850^{\circ} \mathrm{C}$, respectively) lower than the gas temperatures. (Radiation effects are ignored in Weekman's analysis).

3) Neither heat nor mass transfer limitations occur in the PDU (at least not at $500^{\circ} \mathrm{C}$ ).

4) Pore diffusion limitations do not exist in either the batch reactor or the PDU.

An important qualifier here is that several of Weekman's criteria require the same $k_{R}$ value mentioned earlier. Uncertainities in getting that number have already been mentioned.

Efforts to derive a purely kinetic model are based on describing the PDU since mass and heat transfer limitations do not appear to be important. A fair amount of information in the literature exists for describing the pyrolysis of coals and cellulose and then gasification of a wide variety of chars (Lowry 1963). Unfortunately nearly all the rate expressions are intended to predict only carbon conversions. Few go on to give methods for predicting gas yields. No one has successfully modelled gasification of coal or wood by predicting both conversions and gas compositions. Our plan is to:

1) Assume pyrolysis occurs rapidly and is not affected by steam. We allow the pyrolysis reaction to give equilibrium yields of carbon and produce known amounts of gases. Pure carbon is the assumed solid product. Tar formation is ignored. 
2) Take the pyrolysis products as the starting mixture for the following set of reactions
a) $\mathrm{C}+\mathrm{H}_{2} \mathrm{O} \rightarrow \mathrm{CO}+\mathrm{H}_{2}$
b) $\mathrm{C}+\mathrm{CO}_{2} \rightarrow 2 \mathrm{CO}$
c) $\mathrm{C}+2 \mathrm{H}_{2} \rightarrow \mathrm{CH}_{4}$
d) $\mathrm{CO}+3 \mathrm{H}_{2} \rightarrow \mathrm{CH}_{4}+\mathrm{H}_{2} \mathrm{O}$
e) $\mathrm{CO}+\mathrm{H}_{2} \mathrm{O} \rightarrow \mathrm{CO}_{2}+\mathrm{H}_{2}$

Not all of these reactions are mutually independent. Reaction a) - b) will give e) on a purely stoichiometric basis. However, reaction e) is catalyzed by some of the catalysts used in our tests. Hence, including it was the easiest way to account for this catalytic effect.

The equilibrium predictions appear reasonable. Rate data for the solid reactions $(a, b, c)$ come from Lowry but are for coconut shell charcoal and are based on unit mass of carbon in the system. Coconut shell charcoal was the closest thing to wood for which data were available. Reaction rate constants for the gas phase reactions have also been found based on unit catalyst weight. When all rates are adjusted to a common moles/time basis, the gas phase reaction rates are about 3 orders of magnitude higher than the slowest carbon reaction rate $\left(\right.$ at $550^{\circ} \mathrm{C}$ ). This means no more carbon disappears after pyrolysis so gas phase compositions are changed only by reactions $d$ and e. The resulting carbon conversions are lower than experimentally observed and gas compositions do not agree either. Efforts now are directed toward finding better rate data and checking for any errors in converting all information to a consistent set of units.

\section{FUTURE MODELLING EFFORTS}

After a consistent set of kinetic data is determined that will agree with the PDU data, the gasifier model will be coded to fit into the ASPEN computer program. The ASPEN program can then generate heat and material balance information for selected changes in operating conditions. A visual inspection of these results will show which equipment needs to be resized (based on a comparison with Davy McKee base-1ine studies). Theoretically the ASPEN code can automatically go from heat and material balance calculations to equipment 
sizing to equipment costing and then to economic evaluations. The manual inspection is desirable if only one or two pieces of equipment will change size. The savings in computer run time will be significant.

Once equipment costs are defined ASPEN generates a report on the economics of the process. The calculations and format of the report follow ESCOE guidelines. 


\section{ACKNOWFDGNENTS}

The authors are especially grateful to T. J. Kendron, 0. A Kuby, M. McClintock, and J. H. Rooker of Davy McKee, Inc., who completed the economic evaluations. Special appreciation is also extended to J. E. Leonard, W. F. Riemath, G. L. Roberts, E. D. Smith, and W. A. Wilcox, of PNL, whose efforts have been vital to the success of the experimental program. 
REFERENCES

Andrew, P., G. Martin and A. Noher. 1971. "The Cracking of Butyl-Benzenes Over Silica-Alumina Catalysts." Journal of Catalysis 21:255-262.

Araki, M., and V. Ponec. 1976. "Methanation of Carbon Monoxide on Nickel and Nickel-Copper Alloys." Journal of Catalysis 44:439-448.

Boyd, M., et al. 1979. "Pyrolysis and Gasification of Hybrid Poplar SPP." In Proceedings of the 1979 Annual AIChE Meeting, paper 78C, San Francisco, California.

Butt, J. B., and V. W. Weekman, Jr. 1974. "Characterization of the Activity Selectivity and Aging Properties of Heterogeneous Catalysts." AIChE Symposium Series 70(143):27-41.

Gardner, N., E. Samuels and K. Wilks. 1979. Advan. Chem. Ser. 131:217.

Gumz, W. 1950. Gas Producers and Blast Furnaces. Wiley and Sons, New York.

Johnson, J. L. 1974. Advan. Chem. Ser. 131:145.

Lefrancois, P. A., K. M. Barclay and G. T. Skaperdas. 1967. Advan. Chem. Ser. $69: 68$.

Lowry, H. H., ed. 1963. Chemistry of Coal Utilization, Supplementary Vol. Chapter 20, John Wiley and Sons, New York.

Mitchell, D. H., et al. 1980. "Methane/Methanol by Catalytic Gasification of Biomass." CEP 76(9):53-57.

Mudse, L. K., L. J. Sealock, Jr., and S. L. Weber. 1979. "Catalyzed Steam Gásification of Biomass." Journal of Analytical and Applied Pyrolysis $1: 165-175$.

Mudge, L. K., et al. 1979a. "Catalytic Gasification of Wood Residues for Methanol Generation." In Proceedings of Mid-American Wood Combustion Conference, MASEC-CF-80-005, Traverse City, Michigan.

Mudge, L. K., et al. 1979b. "Catalytic Gasification of Biomass," p. 351-357. In Proceedings of the 3rd Annual Biomass Energy Systems conference, SER I/TP-33285, Golden, Colorado.

Mudge, L. K., et al. 1979c. "Investigation of Gasification of Biomass in the Presence of Catalysts," PNL-SA-7939. Presented at the 8th Thermochemical Conversion Contractor's Meeting, Seattle, Washington.

Mudge, L. K., et al. 1979d. "Investigation of Gasification of Biomass in the Presence of Catalysts," PNL-SA-7939. Rev. 1. Presented at the 9th Thermochemical Conversion Contractor's Meeting, Rolla, Missouri. 
Mudge, L. K, et al. 1980. "Investigation of Gasification of Biomass in the Presence of Catalysts," PNL-SA-7939, Rev. 2. Presented at the 10th Thermochemical Conversion Contractor's Meeting, Berkeley, California.

Reid, R. C., J. M. Prausnitz and T. K. Sherwood. 1977. "The Properties of Gases and Liquids." 3rd ed,. McGraw Hill, New York.

Robertus, R. J., et al. 1979. "Investigation of the Gasification of Wood in the Presence of Mixed Catalysts." Presented at the Annual AIChE Meeting, San Fransisco, California.

Sea lock, Jr., J., S. L. Weber and L. K. Mudge. 1980. "Kinetics and Mechanisms of Steam Gasification of Biomass in the Presence of Alkali Carbonates." Biosources Digest 2(1):12-26.

Shafizadeh, F. 1975. "Industrial Pyrolysis of Cellulosic Materials." Applied Pyrolysis Symposium No. 28, pp. 153-174. Wiley and Sons, New York.

Shafizadeh, F., P. S. Chin and W. DeGroot. 1975. J. Fire and Flammability/ Fire Retardant Chem. 2:195.

Walkup, P.C., et al. 1978. "Investigation of Gasification of Biomass in the presence of Multiple Catalysts." In Proceedings of the Second Annual Symposium on Fuels from Biomass. CoNF-7805107-P1, W. W. Shuster, ed., Rensselaer Polytechnic Institute, Troy, New York.

Weber, S. L., et al. 1980. Gasification of Biomass in the Presence of Multiple Catalysts for the Direct Production of Specific Products.

PNL-SA-7763, Pacific Northwest Laboratory, Richland, Washington. 


\section{$\underline{\text { DISTRIBUTION }}$}

No. of

i Copies

OFFSITE

A A. Churm

DOE Patent Division

9800 South Cass Avenue

Argonne, IL 60439

\section{B. J. Berger}

DOE

Biomass Energy Systems Division 600 E. St. N.W.

Washington, DC 20545

Simon Friedrich (2)

DOE

Biomass Energy Systems Division 600 E. St. N. W.

Washington, $\mathbb{C} 20545$

27 DOE Technical Information Center
No. of

Copies

ONSITE

DOE Richland Operations Office

H. E. Ransom

D. R. Segna

26 Pacific Northwest Laboratory

C. M. Devary

D. H. Mitche 11

L. K. Mudge (10)

R. E. Nightingale

R. J. Robertus

G. F. Schiefelbein (2)

L. J. Sealock, Jr.

P. C. Walkup

S. L. Weber

Publishing Coordination (2)

Technical Information (5) 